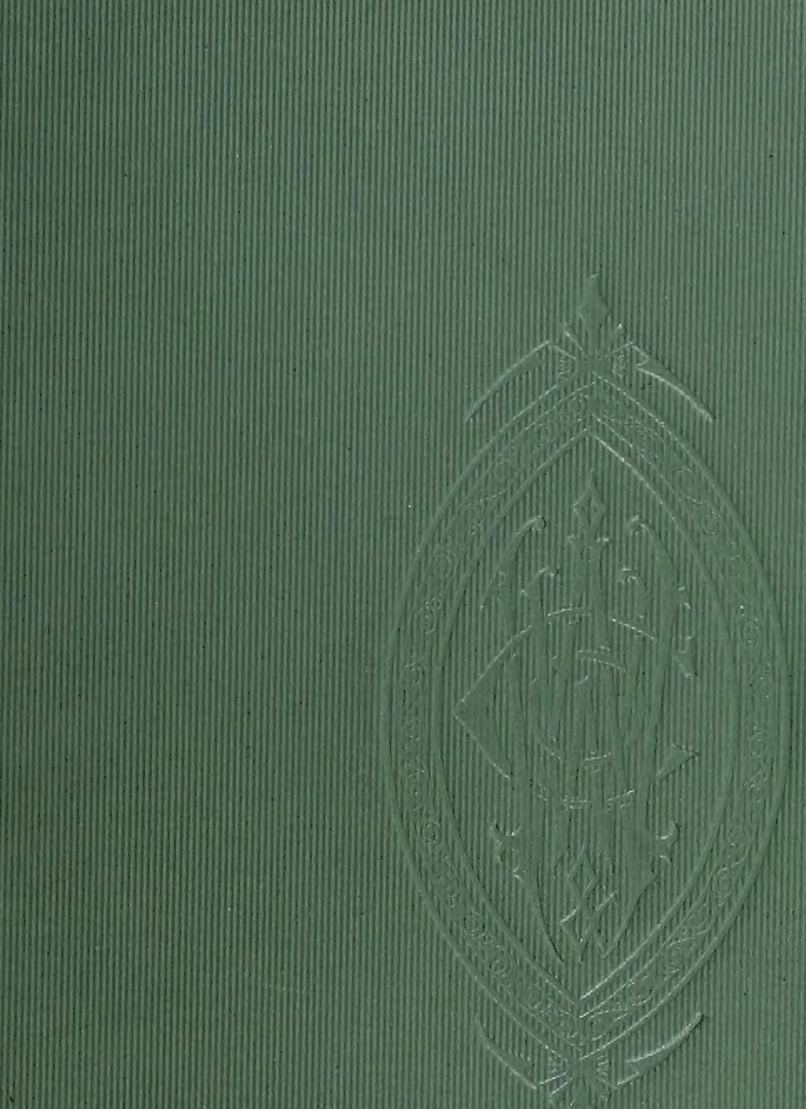




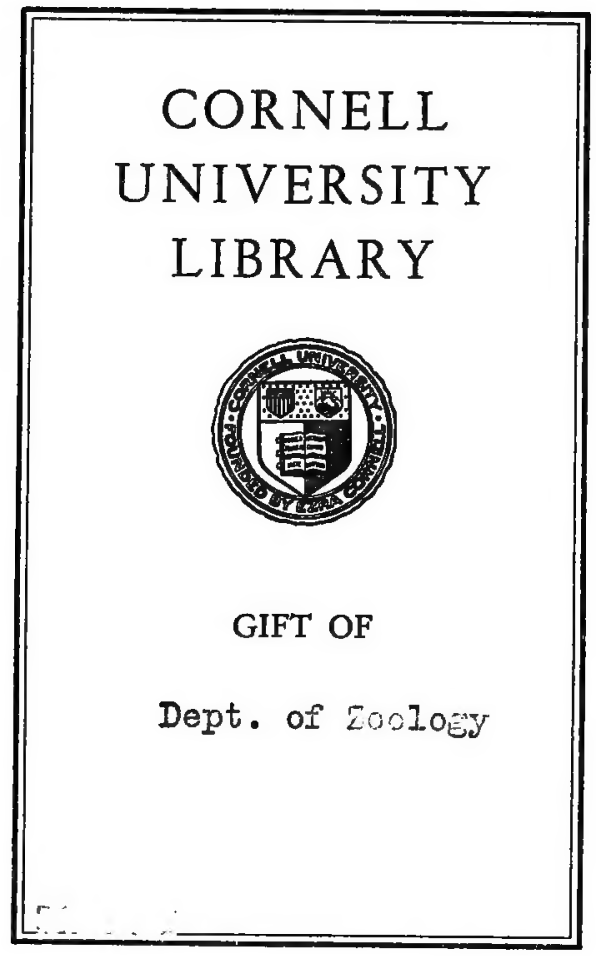




\section{QL 53.G46 Cornell University Library}

Practical zoology for medical \& junior $s$

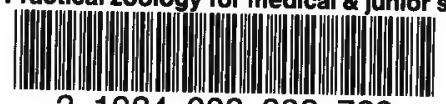

31924003393729 


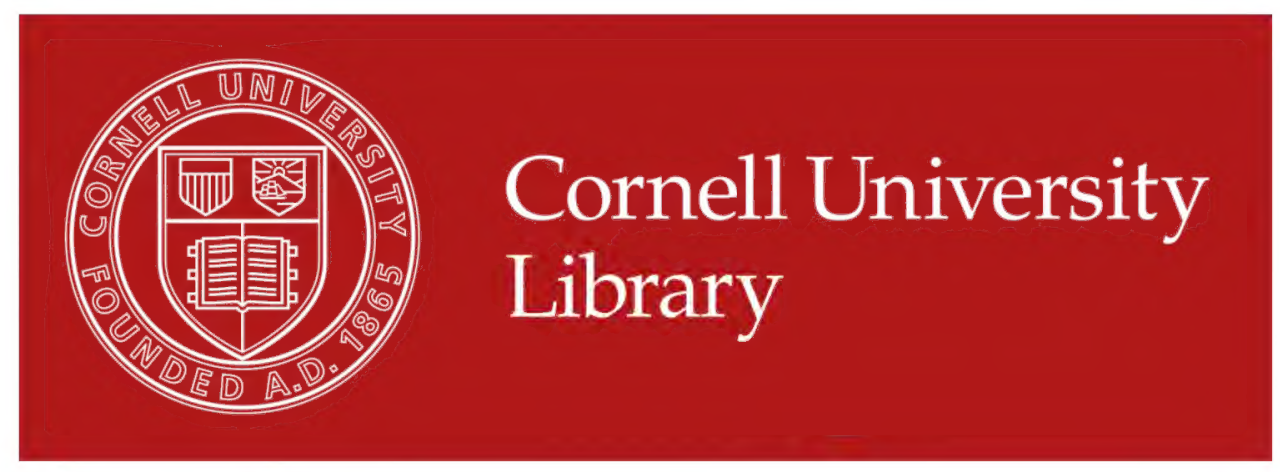

The original of this book is in the Cornell University Library.

There are no known copyright restrictions in the United States on the use of the text. 


\section{PRACTICAL ZOOLOGY}





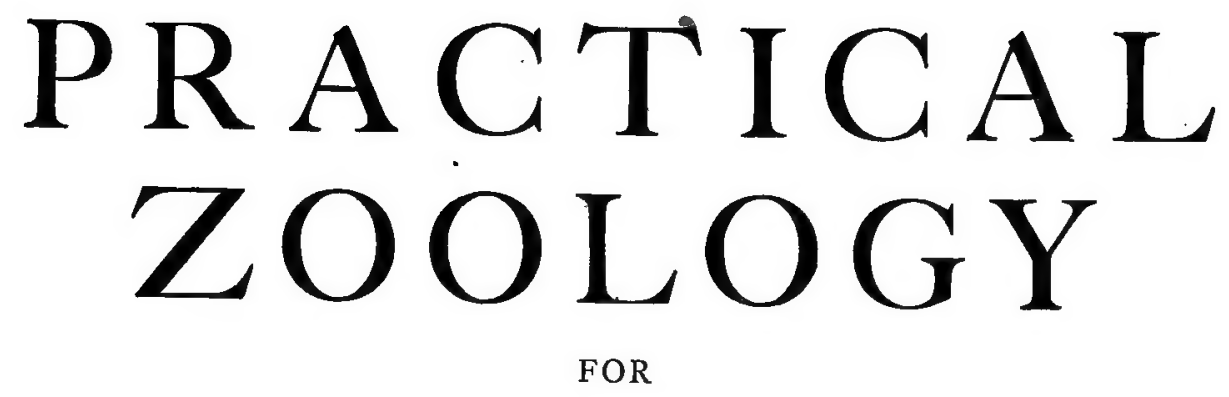

\title{
MEDICAL $\oint^{\circ}$ JUNIOR STUDENTS
}

\author{
By \\ f. D. F. GILCHRIST, M.A., D.Sc., Ph.D. \\ Professor of Zoology in the University of Cape Tozen \\ AND \\ C. von BONDE, M.A. \\ Lecturer in Zoology in the University of Cape Toren
}

NEW YORK
WILLIAM WOOD \& CO., 5 I FifTh Avenue
EDINBURGH

E. \&ٔ S. Livingstone, 16 and I 7 Teviot Place I 922 
PRINTED IN GREAT BRITAIN BY THE RIVHRSIDE PRESS LIMITED EDINBURGH 


\section{PR E F A CE}

TIIIS book is intended for Students of Elementary Zoology. The part dealing with the Frog and the Platana or Clawed Toad has been in use for some time at Cape Town University, and has proved so valuable an aid to the work in the practical classes that other types have now been added in this new and enlarged edition.

Being specially adapted for the requirements of students in South Africa, the book contains descriptions of certain South African types which are not dealt with in other practical manuals; and, at the suggestion of the publishers, in order to make the work useful for other students, the principal European types, which are sometimes used in South Africa, have also been described.

It is recommended that the Frog be studied first, as it is particularly suitable for an introduction to the subject. The other types may be taken in any order convenient.

The instructions given throughout the text will be clearly understood by reference to the numerous figures. The figures are not to be copied by the student. A drawing of the actual dissection is to be made on the blank page provided; and the student should be prepared to point out the various parts to the teacher.

The instructions can be followed without preliminary lectures, and are designed for the use of medical students and others whose course in General Zoology may be unduly restricted by the inclusion of anatomical details. A short lecture course is often overburdened with these details which, we think, can much better be given in the form of a practical handbook.

With a few exceptions, the figures are original and have been drawn from actual dissections.

The publishers are particularly desirous of expressing their thanks to Mr Robert A. Staig (formerly Demonstrator of Zoology, School of Medicine of the Royal Colleges, Edinburgh, and University of Glasgow) for the continual assistance of his advice in the preparation of this publication for the Press, and for the excellence of his work in reading the proofs and compiling the index.

J. D. F. G.

C. v. B.

ZOOLOGICAL LABORATORY,

UNIVERSITY OF CAPE TOWN, I5th May, 1922. 



\section{CONTENTS}

UThe Proteus Animalcule (Amaba)

The Slipper Animalcule (Paramecium)

MoNOCYSTIS

$\checkmark$ SPonges (Porifera)

$\checkmark$ The Fresh-Water Polyp (Hydra)

14

oThe Sea-Anemone (Actinia)

26

$\checkmark$ The Liver-Fluke (Fasciola or Distoma)

34

$\checkmark$ The TAPE-Worm (Taenia)

$\checkmark$ The Earth-Worm (Lumbricus)

40

46

The Medicinal Leech (Hirudo)

The Cockroach (Periplaneta) . . . . . . . . 74

The Fresh-Water Crayfish (Astacus) and the Cape Crawfish (Jasus) , 88

The SNall (Helix) . . . . . . . . II4

ᄂ. The Fresh-Water Mussel (Anodonta) and the Common Marine Mussel (Mytilus) . $\quad . \quad$. $\quad . \quad$. . . . . . .

The Lancelet (Amphioxus, syn. Branchiostoma) . . ' . I42

The Spiny Dogrish (Acanthias, syn. Squalus), OR the Spotted Dogfish (Scyllium), and THE Skate (Raia) . . . . . . I52

The Frog (Rana) and the Platana or Clawed Toad (Xenopus) .

The Pigeon (Columba) . . . . . . . . 236

The Rabit (Lepus) . . . . . . . . . . 266

a Classification of the above Types . . . 3i6

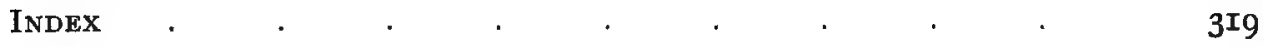





\section{L L USTRATIONS}

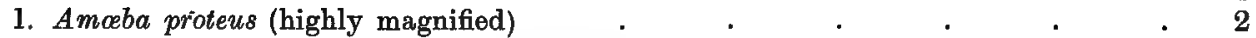

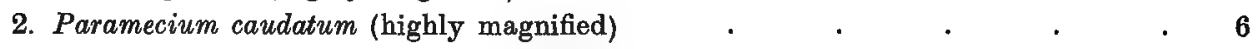

3. Life-history Stages of Monocystis agilis (highly magnified) . . . $\quad 10$

4. Transverse Section through a part of the wall of Sycon gelatinosum . $\quad$. 14

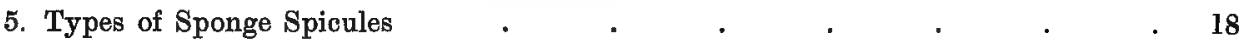

6. Transverse Section of an Ascon Sponge (diagrammatic) . . . . 20

7. Transverse Section of a Sycon Sponge . $\quad . \quad$. $\quad . \quad$. $\quad . \quad 2 \quad 22$

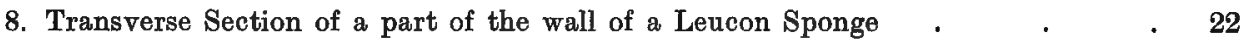

9. Transverse Section of a Rhagon Sponge . . . . . . . . $\quad . \quad 24$

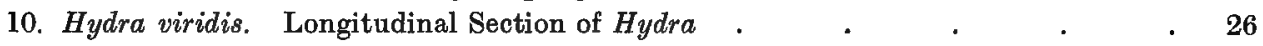

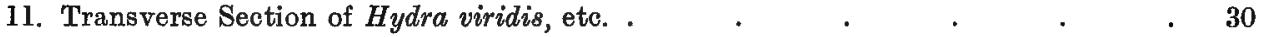

12. Transverse Section of a Sea-anemone . $\quad . \quad$. $\quad . \quad$. $\quad . \quad 34$

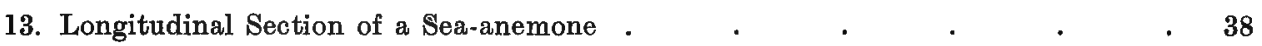

14. Dorsal and Ventral View of the Liver-fluke (Fasciola) . $\quad . \quad$. $\quad$ - 42

15. Transverse Section through the body of a Liver-fluke . $\quad . \quad$. $\quad . \quad 4 \quad 44$

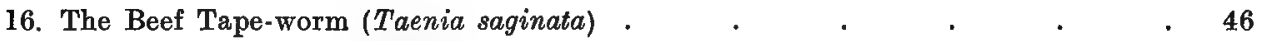

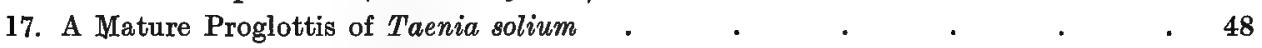

18. Transverse Section through a proglottis of Taenia solium $\quad . \quad$. $\quad$ - $\quad 50$

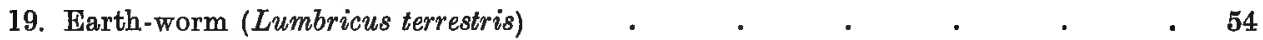

20. Alimentary, Vascular, Nervous and Reproductive Systems of the Earth-worm . $\quad 58$

21. Transverse Section (diagrammatic) through the middle of the body of the Earth-

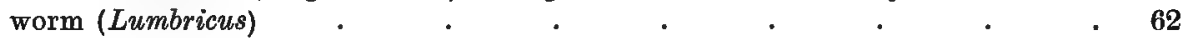

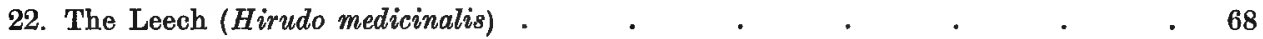

23. Transverse Section (diagrammatic) through the middle of the body of the Leech

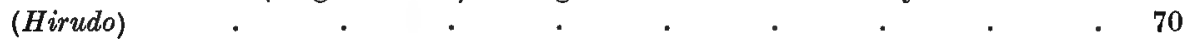

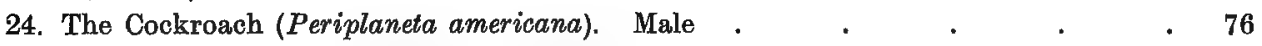

25. The Cockroach. Front, side and dorsal views of the head . . . 78

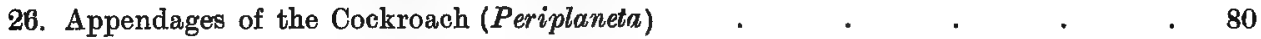

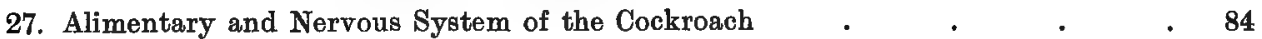

28. The European Fresh-water Crayfish (Astacus) . $\quad . \quad$. $\quad . \quad$. $\quad .90$

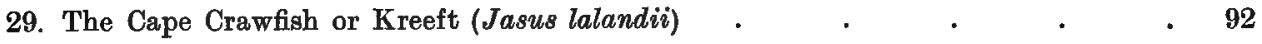

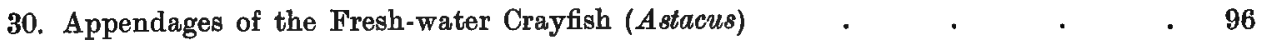

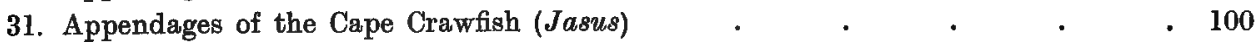

32. The Fresh-water Crayfish (Astacus). General Structure and Nervous System , 108

33. The Cape Crawfish (Jasus). General Structure and Nervous System . 110

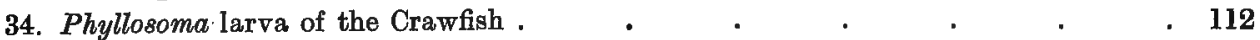

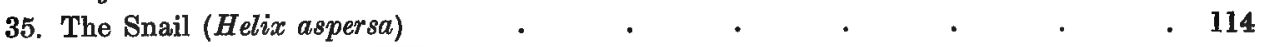

36. The Snail (Helix). Dorsal view after removal of shell . $\quad$. $\quad$. $\quad 116$

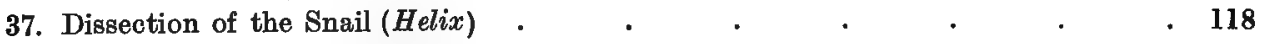

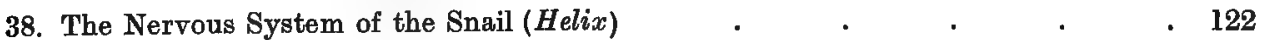

39. Inner view of the left half of the head region (odontophore, etc.) of the Snail $\quad 124$

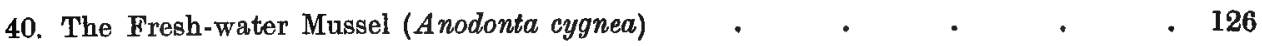


FIG.

41. The Common Marine Mussel (Mytilus edulis)

42. Inner side of the Shell (right valve) of the Fresh-water Mussel (Anodonta)

43. Inner side of the Shell (right valve) of the Marine Mussel (Mytilus)

44. Transverse Section of Gill of Fresh-water Mussel (Anodonta)

45. The Fresh-water Mussel. Shell removed

46. The Fresh-water Mussel dissected from the left side to show the general structure

47. The Marine Mussel dissected from the left side to show the general structure

48. The Lancelet (Amphioxus lanceolatus) viewed from the left side.

49. Amphioxus dissected from the right side

50. Transverse Sections of Amphioxus

51. The Spiny Dogfish (Acanthias, syn. Squalus)

52. The Dogfish (Acanthias, syn. Squalus). Dissection

53. The Skate (Raia). Dissection

54. Urino-genital System of the Dogfish

55. Dorsal View of the Pectoral Girdle and Fin Skeleton of the Skate

56. Afferent Branchial or Ventral Arterial System of the Dogfish

57. The Afferent Branchial or Ventral Arterial System of the Skate .

58. The Dogfish (Acanthias, syn. Squalus). Efferent Branchial or Dorsal Arterial System .

59. The Efferent Branchial or Dorsal Arterial System of the Skate and of the Dogfish (Scyllium)

60. Skull and Visceral Arches of the Dogfish (Scyllium) as seen from the left side

61. The Brain, Cranial Nerves and Eye Muscles of the Dogfish

62. Ventral View of the Brain of the Dogfish

63. The Brain, Cranial Nerves, and Eye Muscles of the Skate

64. The Frog (Rana). The Platana or Clawed Toad (Xenopus)

65. Buccal or Mouth Cavity of Rana and of Xenopus

66. Muscular System and Vascular System (part) of Rana and of Xenopus

67. Dissection of Rana and of Xenopus, showing the Alimentary System.

68. Muscles of the Left Hind-limb of Rana and of Xenopus, from the Ventral Surface

69. Muscles of the Left Hind-limb of Rana and of Xenopus, from the Dorsal Surface .

70. Venous System (part) of Rana and of Xenopus, from the Ventral Aspect

71. Dissection of the Leg of Rana and of Xenopus, from the Dorsal Surface.

72. Arterial System of Rana and of Xenopus .

73. The Alimentary Canal of Rana and of Xenopus . . . . . . . 212

74. The Urino-genital System (male) of Rana and of Xenopus . . . . 214

75. The Urino-genital System (female) of Rana and of Xenopus . . . 216

76. Pectoral Girdle of Rana and of Xenopus .

77. Pelvic Girdle of Rana and of Xenopus, side view .

78. The Hind-limb and the Fore-limb of Xenopus . . . . . . . 220

79. The Vertebral Column and Pelvic Girdle of Rana and of Xenopus $\quad$ - . 222

80. Dorsal View of the Skull of Rana and of Xenopus

81. Ventral View of the Skull of Rana and of Xenopus

82. Side View of the Skull of Rana and of Xenopus .

83. Spinal Nerves and Sympathetic Nervous System (left side only) of Rana and of Xenopus 


\section{IILUUSTRATIOṄS}

FIG.

86. The Pigeon. Dissection showing the Alimentary Canal, etc.

87. The Pigeon. The Vascular, Renal and Reproductive Systems .

88. The Pectoral Girdle, Sternum and Ribs; and the Pelvic Girdle of the Pigeon . 252

89. The Fore-limb of the Pigeon . . . . . . . . . . . 254

90. The Hind-limb of the Pigeon . $\quad$ - $\quad . \quad+\quad . \quad 258$

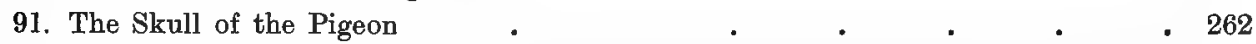

92. The Rabbit (Lepus cuniculus). Dissection showing the Alimentary System, etc. 276

93. The Rabbit. Dissection of the Neck and Thorax showing the lungs, etc. - 280

94. The Solar Plexus, and neighbouring structures, of the Rabbit . • . 282

95. The Rabbit. The veins and arteries of the Abdominal Region, and the Urino-

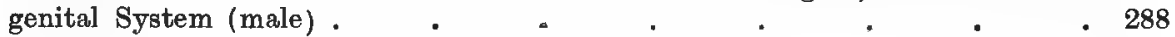

96. The Skull of the Rabbit. Dorsal and Ventral View . . . . 294

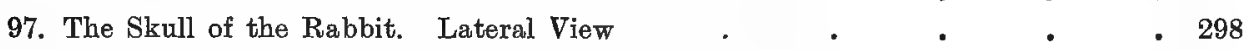

98. Dorsal and Anterior view of the Atlas Vertebra of the Rabbit . . 298

99. Left-side and Anterior view of the Axis Vertebra of the Rabbit . . 300

100. Left-side and Anterior view of the Sixth Cervical Vertebra of the Rabbit . 300

101. Right-side and Anterior view of the Fifth Thoracic Vertebra of the Rabbit $\quad 302$

102. Right-side and Anterior view of the Second Lumbar Vertebra of the Rabbit . 302

103. The Rubbit. Left Scapula, left Humerus, and Skeleton of Fore-arm . $\quad 306$

104. The Rabbit. The Sacrum, and the Pelvic girdle . . . . . 308

105. The Rabbit. Left Femur, left Tibia-fibula, and Skeleton of Foot $\quad$. $\quad 312$ 




\section{THE PROTEUS ANIMALGULE (Amoba proteus)}

AMCEBE are found amongst debris deposits or on mud in fresh-water pools and slow-flowing streams. They are mostly invisible to the naked eye, rarely exceeding one quarter of a millimetre in diameter.

Place a drop of water containing Amobæ on a slide, cover it with a coverslip, and examine with the low power of the microscope.

\section{Form and General Structure.}

Note that the general form of Amoeba is irregular and continually changing, the protoplasm flowing out into blunt processes called lobopods or pseudopodia, by means of which it moves and secures its food.

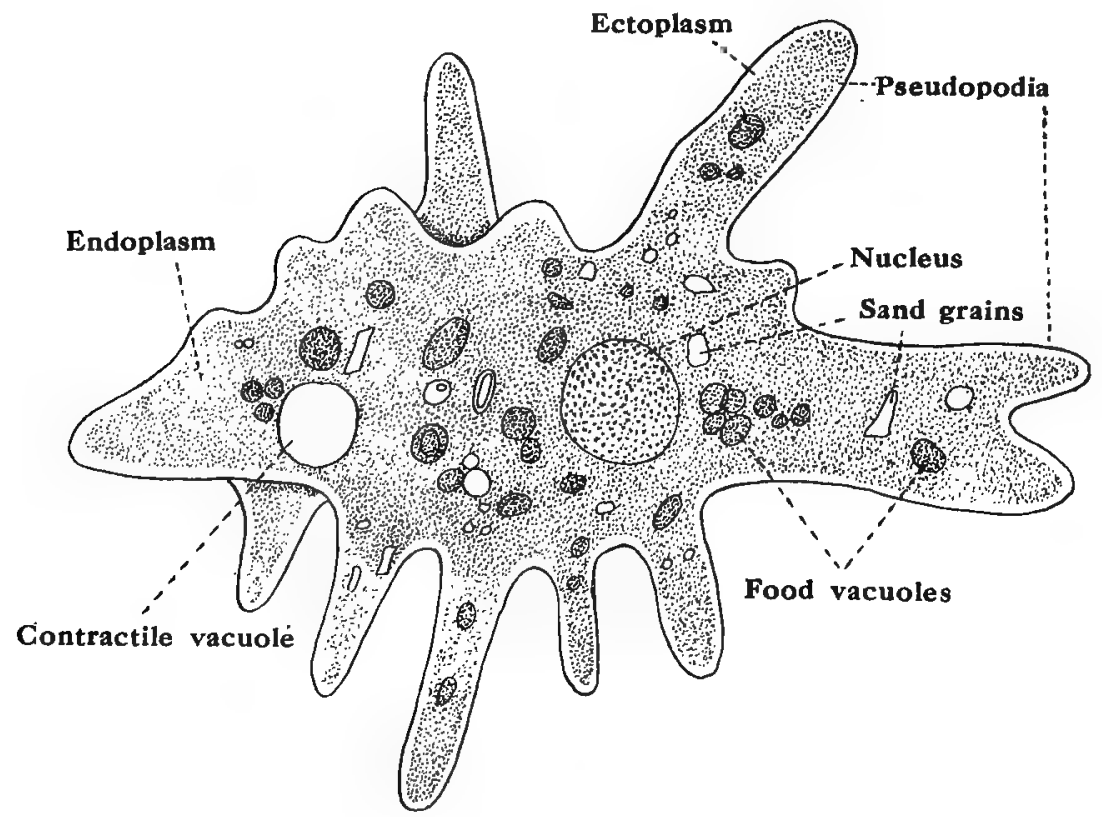

Frs. 1.-Amoba proteus (highly magnified). After Gruber.

Examine the specimen under the high power and note the structure. The body is a naked mass of protoplasm, not uniform throughout, but showing two distinct portions :

(a) The ectoplasm or ectosarc, a thin film, forming the clear outer portion of the body.

(b) The endoplasm or endosarc, forming the inner portion. It is granular, and the granules render the flowing movements of the protoplasm visible. Within it are seen the following structures :-

(i) The nucleus, a spherical body, denser than the rest of the endoplasm. 

(ii) The food vacuoles, spaces containing digestive fluid and ingested food material, e.g., diatoms, algæ, etc. Grains of sand, fat globules, green vegetable organisms and other foreign bodies are also frequently present in the endoplasm.

(iii) The contractile vacuole, a space filled with. a watery fluid. Evidently it functions as a drain for the finer wastes of the protoplasm. As it swells it is moved to the surface, and there contracts and discharges. The vacuole is formed anew, usually about the same position, when the effete liquid again gathers into a droplet.

Make drawings of $A m a b a$ at regular intervals, noting the direction of the flow of the granules. The nucleus may be rendered more distinct by the addition of a drop of acetic acid. 



\section{THE SLIPPER ANIMALCULE (Paramecium)}

Paramecium, one of the ciliate Infusoria, is a minute animal found in water in which decaying organic matter is present. It may be seen with the naked eye. A culture of Paramecia can be obtained by steeping hay in water and allowing it to decay, and by adding to this infusion some weeds from a freshwater pond which contains Paramecia.

Put a drop of water containing Paramecia on a slide, and place a cover-slip over it. Use a square cover-slip, and put a dot of soft wax on two corners at one side, so as to raise the slip slightly. Examine the slide under the low power.

\section{Form and General Structure.}

Note that the general form of Paramecium is definite; it is roughly oval in outline, being somewhat rounded anteriorly and bluntly pointed posteriorly.

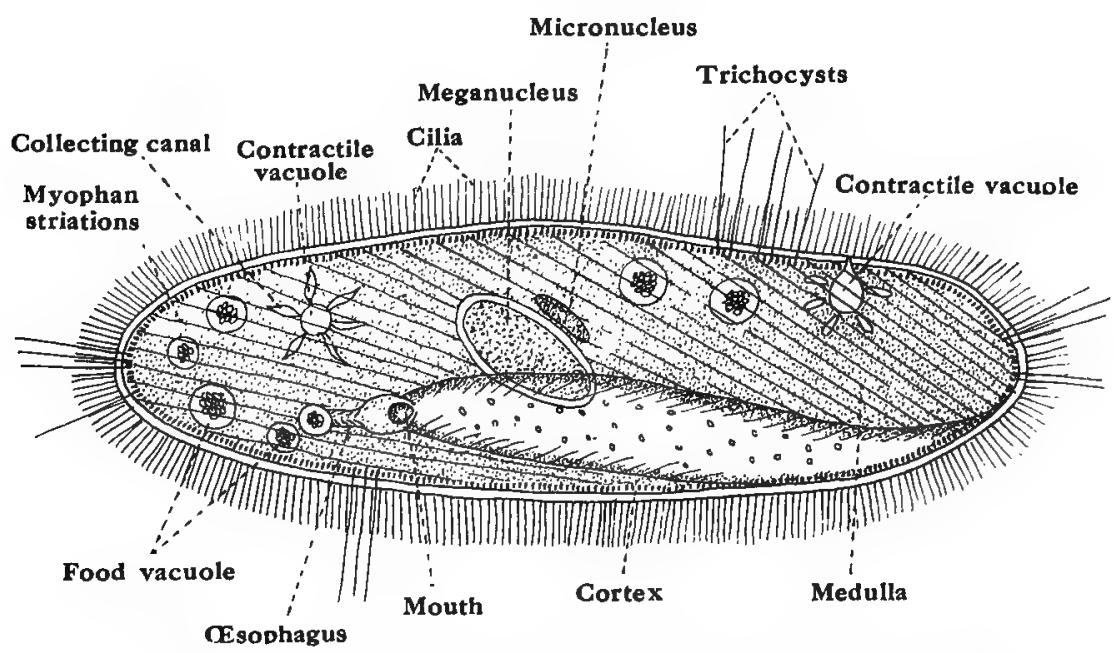

Fra. 2. -Paramecium caudatum (highly magnified). After Butschli.

Examine a Paramecium under the high power and note the following structures:-

(a) The ectoplasm, ectosare or cortex, which consists of four layers :

(i) The pellicle, the outermost tough investing layer, which gives definite form to the creature.

(ii) The contractile layer of myoneme threads or myophan striations.

(iii) The trichocyst layer. The trichocysts, minute spindle-shaped bodies, arranged side by side. When the animal is irritated, by adding a drop of very dilute acetic acid, each trichocyst discharges a very fine thread, very much longer than the cilia; and the creature is then clothed in a matted coating of fine hairs. The function of these trichocysts is protective. 



\section{THE SLIPPER ANIMALCULE}

(iv) The spongy layer, the innermost portion of the ectoplasm, in which fluid from the endoplasm collects. This fluid gathers particularly in two sets of radiating channels or collecting canals, and these drain off to form two large central drops, the contractile vacuoles. The formation or expansion (diastole) of each vacuole goes on until it comes into contact with the pellicle, then sudden contraction (systole) occurs, and the large spherical vacuole disappears. This process is repeated at brief intervals. The two vacuoles always re-form about the same position, between the centre and each end of the body.

The other structures connected with the ectoplasm are :

(v) The cilia, numerous delicate vibratile filaments arranged in longitudinal rows over the whole outer surface. In the gullet specially large cilia adhere together and there form an undulating membrane.

(vi) The oral groove or peristome, which begins near the anterior end of the Paramecium and leads to the mouth, which opens into the gullet. The food particles, carried in by the action of the peristome cilia, pass through the mouth into the gullet, and are there driven onward by the undulating membrane. The food vacuoles are formed at the bottom of the gullet and carried into the endoplasm. To see the formation of food vacuoles, put a drop of Indian ink at the edge of the coverslip and watch the ingestion of the ink particles.

(vii) The potential anus, a spot in the cortex, situated about midway between the mouth and the posterior end of the animal, and only visible when the waste products are extruded.

(b) The endoplasm, endosarc or medulla, which is granular and fluid, and which forms the central portion of the body. In the endosarc the following structures may be seen :-

(i) The food vacuoles, spaces containing the particles of food.

(ii) The macronucleus or meganucleus, a large ovoid body situated near the middle of the cell. This nucleus is concerned with the ordinary life of the body.

(iii) The micronucleus, a very much smaller body lying at the side of the macronucleus. It is specialised for reproduction. Some species, e.g., Paramecium aurelia, have two micronuclei.

Make a sketch of Paramecium to show the above features. 



\section{MONOCYSTIS}

Monocystis, one of the Sporozoa, is a common internal parasite in the reproductive organs of the earthworm (Lumbricus).

Cut open an earthworm (dorsal side) under salt solution. Open into the median seminal vesicles so as to expose the internal funnel openings of the vasa deferentia. Frequently Monocystis magna (one or several) is seen attached to the funnel by one end; it looks like a tiny whitish thread.

\section{Form and Structure of Monocystis magna.}

Carefully remove a specimen, along with the portion of funnel to which it is attached, and place it in a drop of salt solution on a slide. Put on a cover-slip, and examine under low power.

It is worm-like, and about a quarter of an inch long. Notice the clear thin
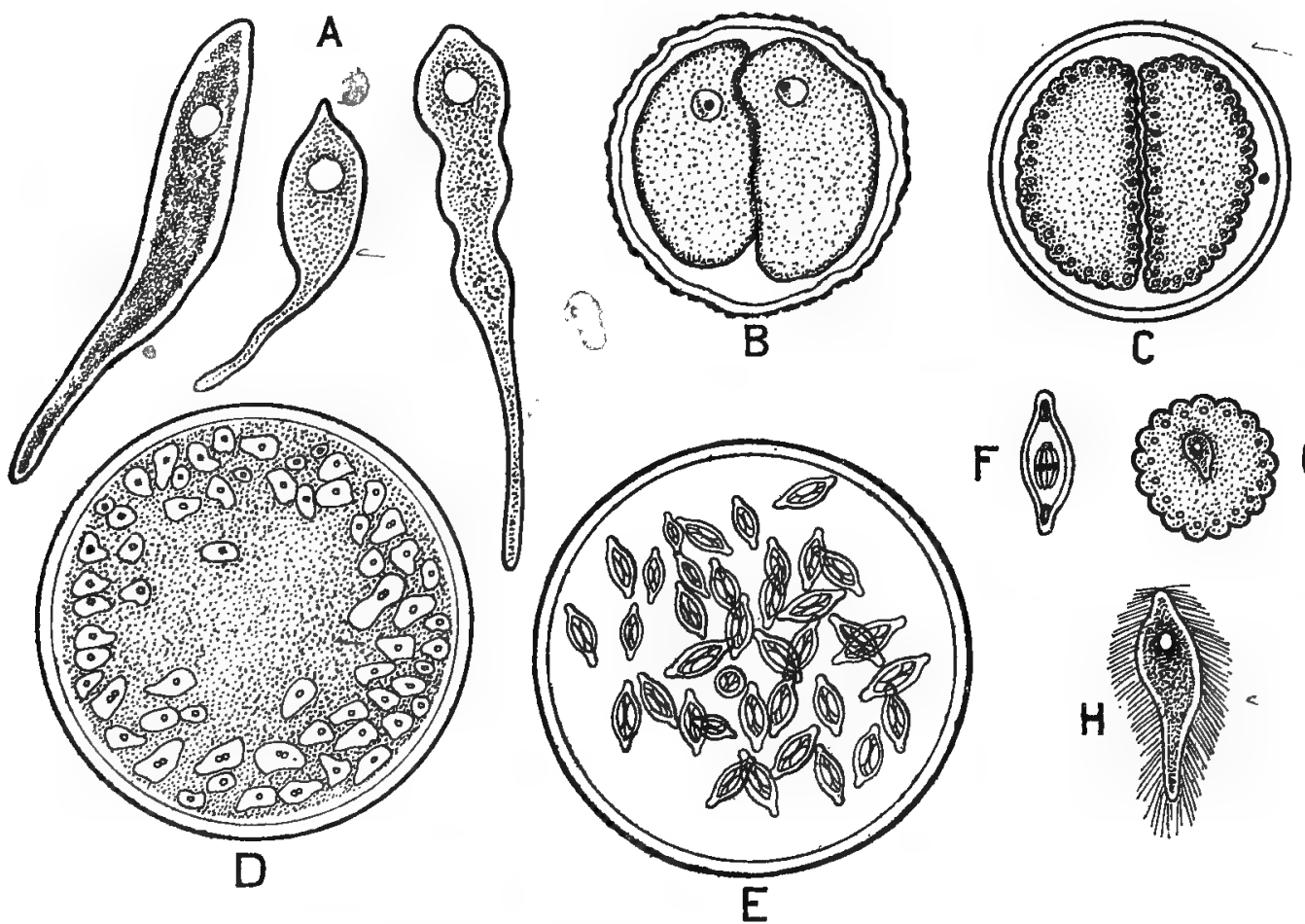

FIG. 3. - Life-history Stages of Monocystis agilis (highly magnified). With permission from Parker and Haswell's Text-book of Zoology.

A. Three trophozoites; B. Cyst containing two gametocytes; C. Stage prior to formation of gametes. Note the numerouls small nuclei. D. Gametocytes broken up and gametes formed. Some of the gametes are conjugating in pairs, some pairs have fused to form zygotes; E. Cyst containing ripe spores or psendonaricellae; F. A single spore or pseudo. navicella containing falciform sporozoites; G. A sporozoite inside a sperm-morula; H. A young trophozoite coated with tails of destroyed sperms.

outer cortex of contractile ectoplasm, the outermost layer of which forms a stiff pellicle. The inner mass of endoplasm, the medulla. is finely granular and 

laden with reserve food substance; and within it there is a rounded, clearlooking fluid nucleus. This is the vegetative or trophic stage of the parasite, the trophozoite. Notice the characteristic "euglenoid" movement of Monocystis, which causes some variation in its long oval shape.

Structure and Life-history Stages of Monocystis agilis.

Monocystis magna may also be found free in the cavity of the seminal vesicles. In that situation, in well-infested worms, most of the life-history stages of a small species, Monocystis agilis, are generally present.

With a pipette remove some of the fluid contents of a seminal vesicle and put a drop of it, diluted with salt solution, on a clean slide. Cover with a coverslip, and examine the slide under the microscope. The fluid chiefly consists of countless hair-like spermatozoa and numerous sperm-morulæ-i.e. mulberrylike clusters of developing spermatozoa - and these form the normal contents of the seminal vesicles. Amidst the sperms and morulæ the following Monocystis stages may be seen :-

(a) Free adult trophozoites (Fig: $3, A$ ), in form and structure similar to those of $M$. magna, as noted above.

(b) Trophozoites which, having attained the limit of growth and being ripe for reproduction, have rounded themselves off and become gametocytes. These may be seen in closely associated pairs, or at the more advanced stage of

(c) Paired gametocytes within a cyst (Fig. 3, B) which they have secreted.

(d) Cyst containing two gametocytes about to form gametes. Note the numerous small nuclei which have been formed and moved towards the surface of the body (Fig. 3, C).

(e) Cyst showing the gametocytes broken up into small portions, each containing a nucleus; these are the gametes (Fig. $3, D$ ), some of which are seen in conjugation, and some pairs are already fused and therefore zygotes. Notice that there is in the cyst a certain amount of residual protoplasm, which serves for the nourishment of the gametes.

(f) Clear bluish cysts containing numerous small boat-shaped spores or pseudonavicellæ (Fig. 3,E). The zygotes become ovoid and secrete tough chitinous coats, and by division each segments into a cluster of eight sausage-shaped sporozoites surrounding a small amount of residual protoplasm. In that way the zygote is transformed into a spore (Fig. 3, $\boldsymbol{E}$ and $\boldsymbol{F}$ ). These spores must be transmitted to another host before they/can develop further. Probably the earthworm is eaten by a bird, and the spores passed out undigested along with the excreta. The spore may then be swallowed by another worm; and the spore-coat being dissolved by the digestive juices, the sporozoites will therefore be set free. From the food-canal they find their way into the seminal vesicles, and they enter the sperm-morulæ.

(g) A sporozoite inside a sperm-morula (Fig. 3, G). It derives nourishment from the surrounding protoplasm and develops into a young trophozoite.

(h) Young trophozoites coated with sperms (Fig. 3, H). 



\section{SPONGES (Porifera)}

As different speçies of Sponges can usually be obtained in the fresh condition for examination, no particular type has been selected for description; but a general account of sponge structure is given as a guide to the practical examination of the type available.

\section{Form and General Structure.}

Sponges are sedentary (except in the larval state), and live attached to the surfaces of rocks, weeds, etc. They are aquatic and mostly marine, and they have a plant-like appearance. Some are solitary, many are colonies of " individuals" closely grouped or compacted together. These colonies are formed by vegetative budding from a creeping stolon, and become more or less complex by branching. The great differences in size, form and appearance among sponges are largely due to the nature of the budding. The

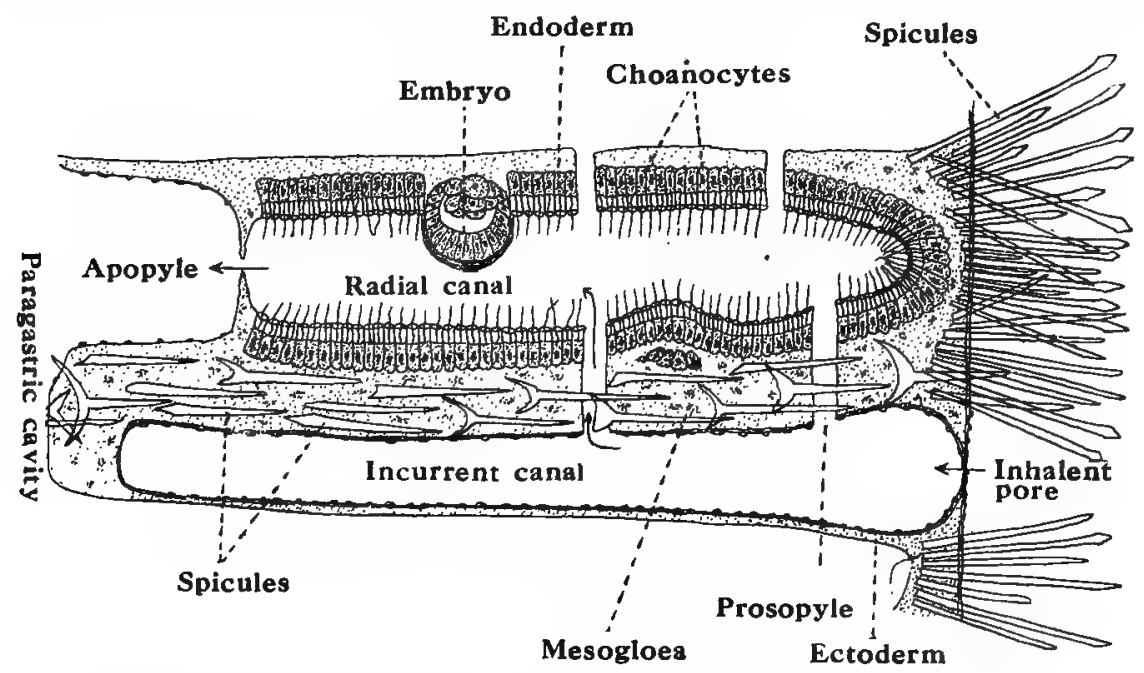

Fig. 4. - Transverse Section through a part of the wall of Sycon gelatinosum. After Parker and Haswell.

simplest types are tubular in form (e.g., Leucosolenia, a simple Ascon sponge), or sac-shaped (e.g., Grantia, a Sycon sponge).

The body of a sponge is a system of canals or waterways; the water passes in through numerous minute inhalent pores in the body-wall, and, after circulating throughout the internal cavity or cavities, it passes out at one or several large exhalent openings or oscula. The chief internal differences in sponges are seen in this canal system, of which there are distinct types. Otherwise the structure of the body is similar in all the sponges. 

Sponges are two-layered (diploblastic) Metazoa. The two layers are the outer dermal layer (" ectoderm "), which consists of flattened epithelial cells and pore-forming porocytes, and the inner gastral layer ("endoderm "), which is composed of flagellate collar-cells or choanocytes. Between the layers is a middle jelly (mesoglœa) containing wandering amœbocytes, some of which form the characteristic limy or siliceous spicules of the supporting skeleton.

(a) The Dermal Layer or "Ectoderm."

This covers the outer surface of the sponge, and is composed of flattened epithelial cells, with porocytes here and there. The porocytes are cells which become hollowed out and thus form the temporary inhalent pores. The epithelial cells (dermal epithelium) take the form of thin scales, so closely cemented together by their edges that their boundaries are not readily distinguishable-i.e. they form a syncytium. In sponges which have more or less complex canal systems, formed by outgrowths and foldings of the body-wall, portions of the dermal layer are internal and line the inhalent or incurrent canals. Groups of spicules project through the dermal layer.

(b) The Gastral Layer or "Endoderm."

This layer lines the gastral or paragastric cavity (in the simplest sponges) and the radiating chambers or radial canals (in the higher types). The cells of the gastral cavity (in the higher types) are thin epithelial cells ; those of the radiating chambers are collar-cells or choanocytes. The collar-cells are flask-shaped; each has a nucleus, a long whip-like flagellum projecting from the free end, also a delicate collar which surrounds the lower portion of the flagellum. The collar is retractile, and the flagellum also can be withdrawn.

(c) The Middle Jelly or "Mesogloa."

This gelatinous matrix, situated between the two layers, contains wandering amoboid cells or amœbocytes. The amœbocytes probably serve as carriers of food and removers of waste; but some of them develop into genital cells, and others become scleroblasts or spicule-forming cells. The spicules are embedded in the jelly matrix, and in certain sponges are felted together into a supporting skeletal framework. There are various kinds of spicules, viz. :-

(i) Monaxon spicules, having a needle-like form with a single axis.

(ii) Triaxon spicules, consisting of four radii of a sphere, meeting each other at equal angles at the centre and thus producing a four-rayed form.

(iii) Polyaxon spicules, which have numerous axes typically radiating out from a common centre.

Further variations occur in some sponges, giving rise to the following sorts :-

(i) Triradiate spicules, consisting of three rays branching from a common centre in the form of a tripod. 

(ii) Anchor spicules, having the form of an anchor.

(iii) Amphidisc spicules, consisting of a rod bearing at the distal

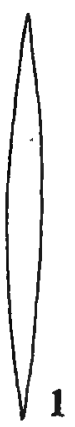

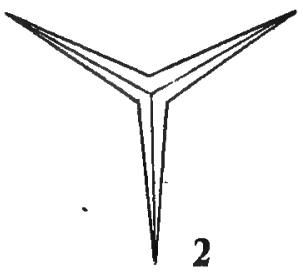

1

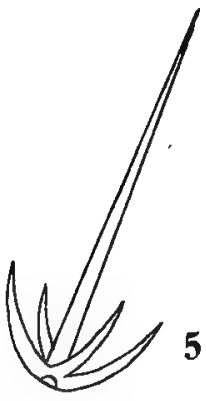

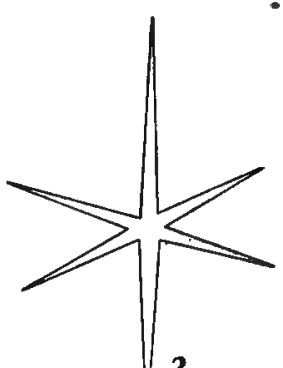

3
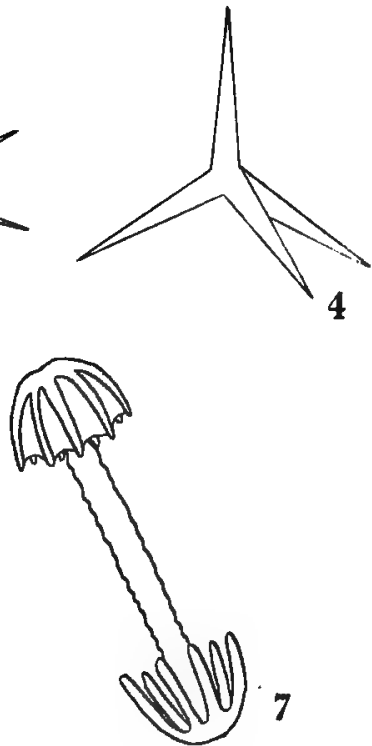

FIG. 5. - Types of Sponge Spicules. After J. Arthur Thomson. 1, Monaxon; 2, triradiate; 3 , triaxon ; 4 , tetraxon ; 5 , anchor; 6 , polyaxon ; 7 , an amphidise.

extremities disc-like expansions curved towards the centre and prolonged into several tooth-like protuberances.

\section{The Main Types of Canal-system.}

All the cavities of the body traversed by the currents of water which nourish the sponge are termed collectively the canal-system. This system attains a high degree of complexity, and four different types may be distinguished according to the situation of the choanocytes :

1. The Ascon Type.

The canal-system is simple. The water enters through the numerous temporary inhalent pores in the body-wall into the central gastral cavity of the tube. at the top of which is the exhalent osculum, through which the water passes out. The choanocytes line the gastral cavity. Examples: Leucosolenia, Clathrina (Class, Calcarea; Order, Homoccla). (See Fig. 6.)

2. The Sycon Type.

This type arises from the Ascon type by a process of outgrowth and folding of the body-wall, resulting in the formation of a number of blind diverticula of the gastral cavity and the restriction of the choanocytes to the interior of these diverticula, which are therefore called the flagellated or radiating chambers (radial canals). The gastral cavity is lined by flattened epithelium derived from the dermal layer. Between the radiating chambers canals are enclosed, from which the water flows into the chambers. These are called the incurrent or inhalent canals, and are lined by the flat epithelium of the 

dermal layer. The inhalent canals open to the exterior by the ostia, and also communicate with the radiating chambers by means of small apertures, the prosopyles. The radiating chambers open into the gastral cavity through the apopyles. Thus the water enters the ostia or inhalent pores into the

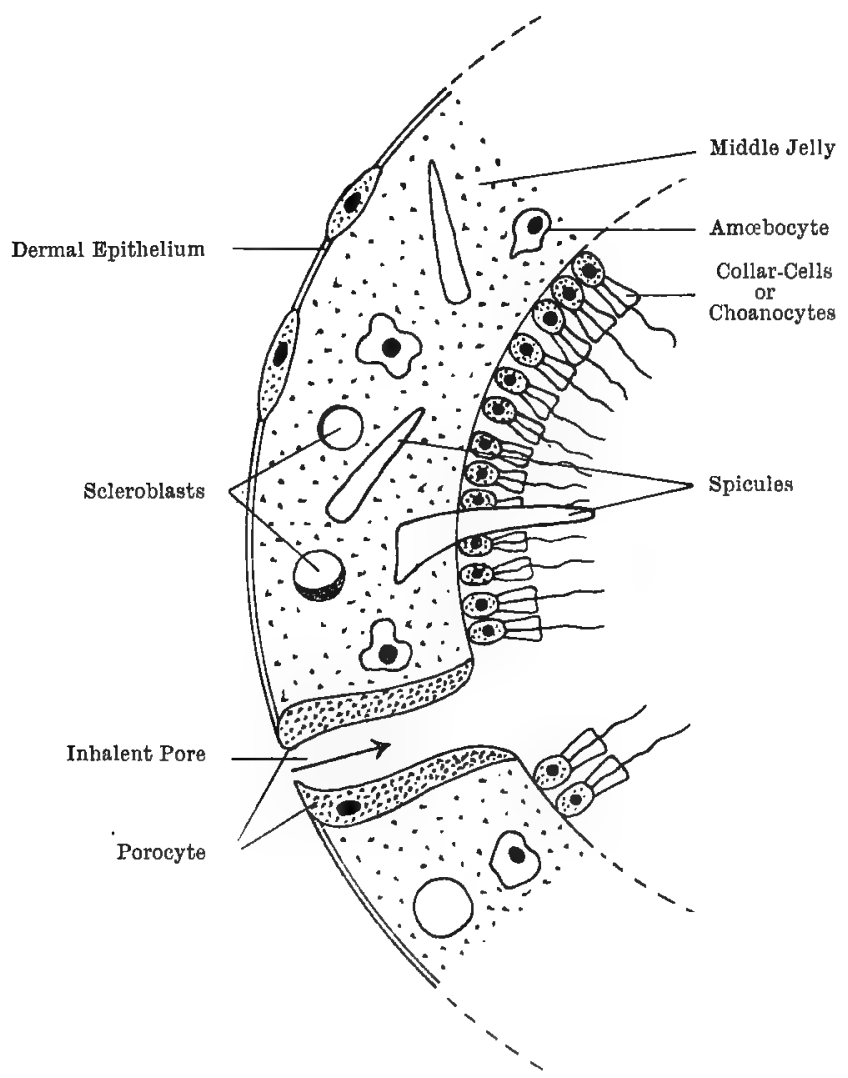

FI', 6. -Transverse Section of an Ascon Sponge (diagrammatic). After J. Graham Kerr.

incurrent or inhalent canals; thence it passes through the prosopyles into the radiating chambers or radial canals, and from these it goes through the apopyles into the gastral or paragastric cavity and out by the exhalent osculum. Example: Sycon (Class, Calcarea; Order, Heterocoela). (See Figs. 4 and \%.)

3. The Leucon Type.

By a further process of folding this type is derived from the Sycon type, the result being that diverticula of the gastral cavity arise and into each diverticulum several radial canals open. Thus the primary incurrent canal communicates' by means of secondary inhalent canals, from which the prosopyles arise, with a secondary radial canal lined by choanocytes, which opens by an apopyle into the primary radial canal or radiating chamber. All the primary radial canals open into the gastral cavity. Therefore the water enters through the ostia into the primary incurrent canals; thence it 

goes into the secondary incurrent canals and through the prosopyles into the secondary radial canals ; from these it passes by the apopyles into the primary

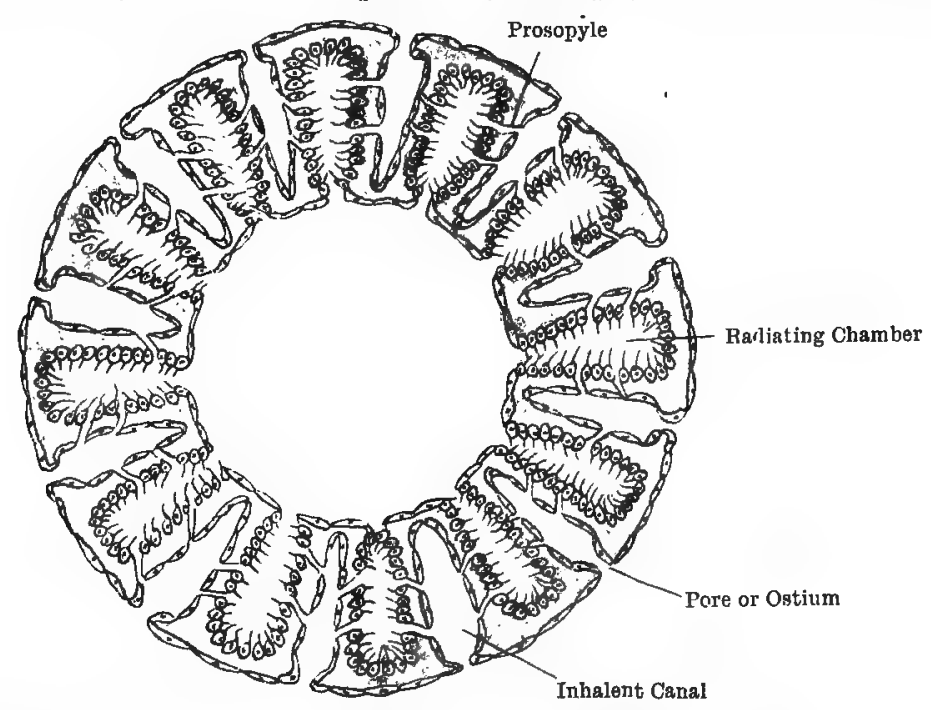

FIG. 7. -Transverse Section of a Sycon Sponge. The central space is the gastral carity. From Masterman's Text-book of Zoology.

radial canals, and so into the gastral or paragastric cavity. Example: Leucilla (Class, Calcarea; Order, Heterocœla).

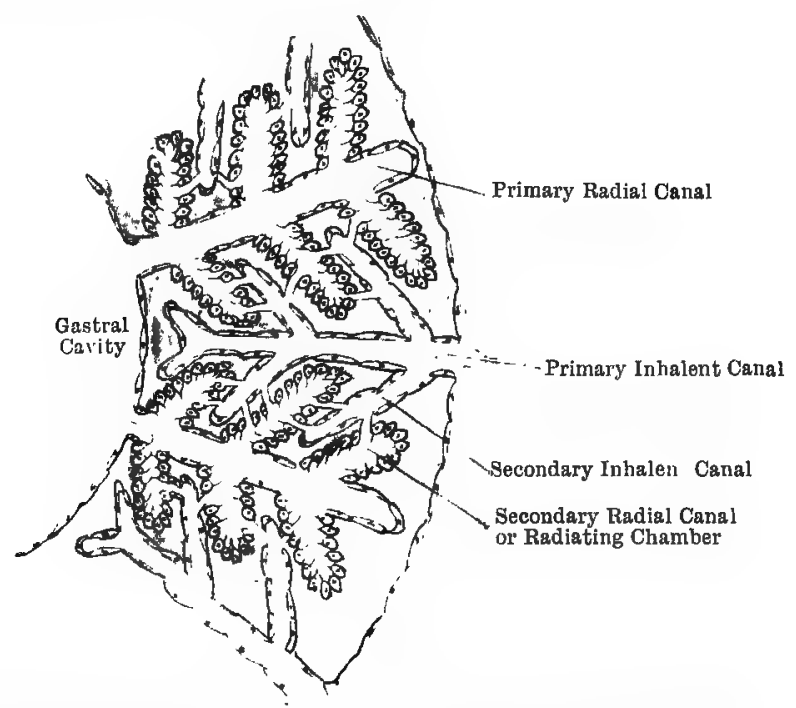

FIr. 8. - Transverse Section of a part of the wall of a Leucon Sponge. From Masterman's T'ext-book of Zoology.

4. The Rhagon Type.

This type resembles the last one and can be derived from it. Here the primary incurrent canal communicates by the prosopyle with the secondary radial canals, which take on a rounded shape and are lined by choanocytes. 

From these the apopyles open into the primary radial canal, which is in communication with the gastral cavity. Thus water enters through the ostia;

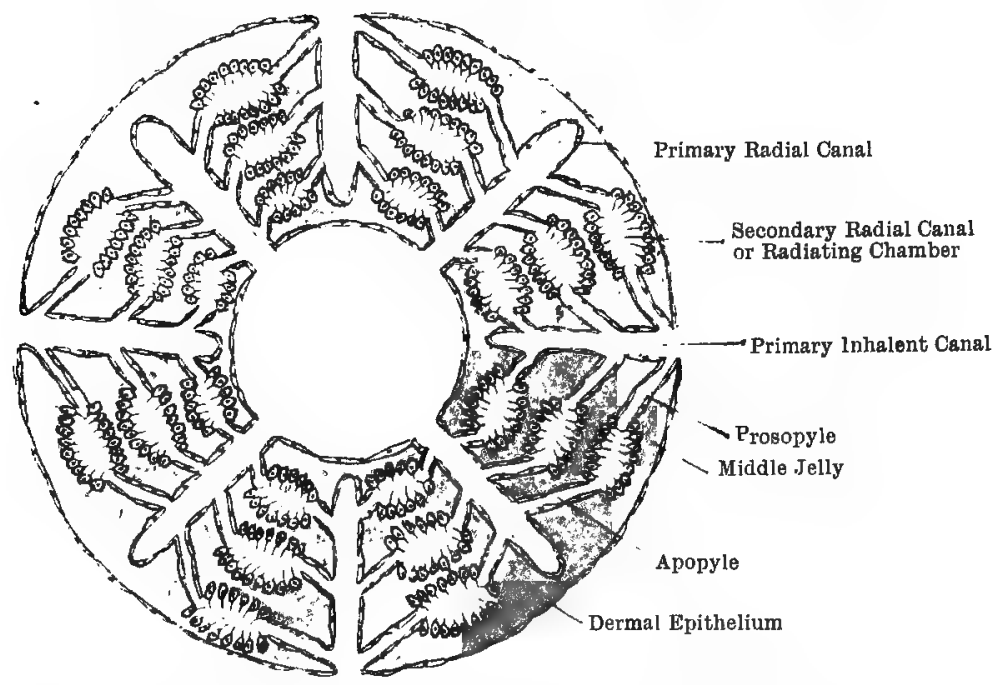

FIri. 9.--'Transverse Section of a Rlıagon Sponge. From Masterman's I'ext-book of Zoology.

thence by the prosopyles into the secondary radial canals ; and from these by the apopyles into the primary radial canals, and so into the gastral cavity. Example: Oscarella (Class, Demospongiæ; Order, Myxospongida). 



\section{THE FRESH-WATER POLYP (Hydra viridis)}

Hydra is a small fresh-water animal, occurring in lochs, ponds, ditches, etc. If a glass jar is filled with some water and weeds collected from a pond and allowed to stand for a while undisturbed, then there may be seen little whitish or green bodies, from 2 to $6 \mathrm{~mm}$. in length, adhering to the weeds
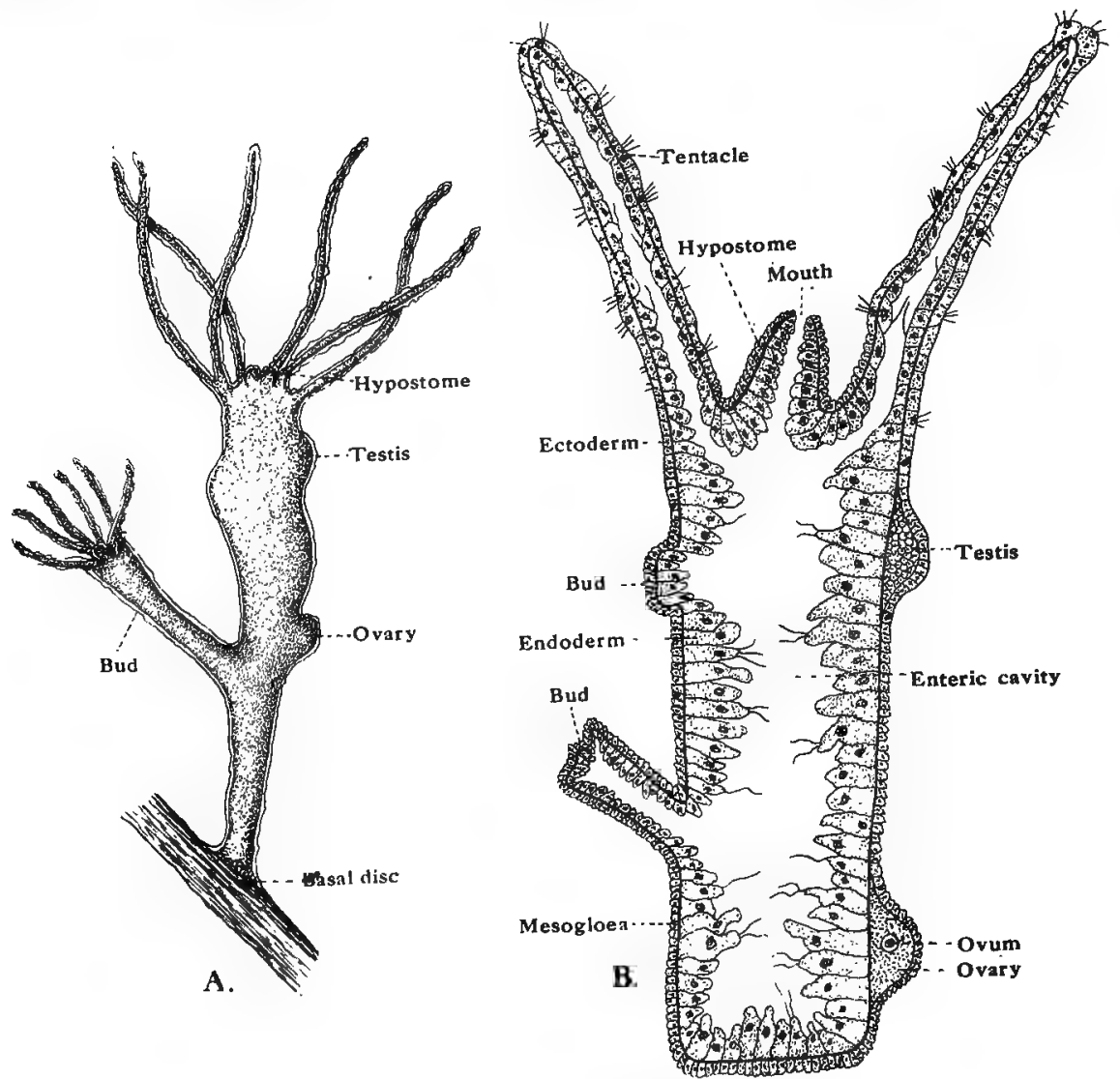

FIG. 10.-A. Hydra viridis $\times 10$; B. Longitudinal Section of Hydra viridis. After Parker and Haswell.

or to the sides of the jar. Cut off a piece of weed to which a Hydra is adhering, or remove one with a pipette or a dipping tube, and place it on a slide in a drop of water. Cover with a supported cover-slip, and examine under the low power of the microscope.

\section{A. General Form and External Features.}

Hydra, when fully extended, has a long and slender thread-like appearance. Its tubular body is attached at one end by a flattened basal disc. 

The free end bears a circlet of six or more tentacles, which are hollow prolongations of the body. At the top of the tube, and surrounded by the tentacles, is a low conical projection, the oral cone or hypostome, in the centre of which is the circular mouth aperture. At the sides of the body projections or bulgings may be seen; these may be daughter buds at various stages of development, or they may be the developed reproductive organs. The animal is hermaphrodite; the testis is situated near the mouth end, while the ovary is usually near the "foot" or base of the body tube.

Notice the clumps or batteries of stinging cells (nematocysts) studding the tentacles.

Make a drawing of Hydra to show the above features.

\section{B. Microscopic Structure.}

Examine a longitudinal and a transverse section of Hydra under the low power, and note that the body-wall has the following layers :-

(a) The ectoderm, a thin layer of many cells packed tightly together, forming a protective covering for the body.

(b) The endoderm, a thick layer of larger columnar cells lining the colenteron or enteric cavity.

(c) The mesoglœa or supporting lamella, apparently structureless, between the ectoderm and the endoderm.

Note the colenteron, enteric or digestive cavity occupying the centre of the body. The mouth leads into the cœlenteron, which extends into the tentacles, these being hollow processes, and also into the buds.

Make a drawing of a longitudinal section and a transverse section of the body.

Examine the layers of the body-wall under the high power and note the component cells :

(a) The ectoderm.

This layer is made up of large ectoderm cells, somewhat conical in shape, arranged side by side and with their broader ends outwards. Each of these cells has a nucleus and a very large vacuole (not shown in Fig. $11, B$ and $C$ ); and the tapering end of the cell is drawn out into crosspiece processes which contain contractile fibrils. These muscular processes lie alongside the mesogloea and (in trvanserse sections) are just visible as minute dots. The ectoderm cells are therefore myo-epithelial cells. The spaces between the inner and narrower ends of the ectoderm cells are filled up with small and round interstitial cells. Some of the interstitial cells become specialised for reproduction and give rise to the testis (one or more) by a proliferation forming a small conical heap projecting externally and covered by the ectodermal cells. The ovary is similarly formed; at first it contains several ova, but ultimately only one large ovum remains. Embedded in and between some of the large ectoderm cells there are clear oval sacs with well-defined walls. These are the stinging cells, thread cells, or nematocysts ; and each consists of a tough sac, the neck of which is turned outside in as a hollow pouch. The free end of the pouch is continued into a 

hollow and coiled filament, and from its inner surface project the barbs. The nematocyst, which contains a fluid, lies in a special interstitial cell known as the cnidoblast. The cnidoblast contains a hollow sac, and in this sac the nematocyst lies. The free end of the cnidoblast is produced into a delicate pointed process, the cnidocil or "trigger-hair." The slightest touch of the cnidocil causes sudden contraction of the cnidoblast, and the pressure (possibly

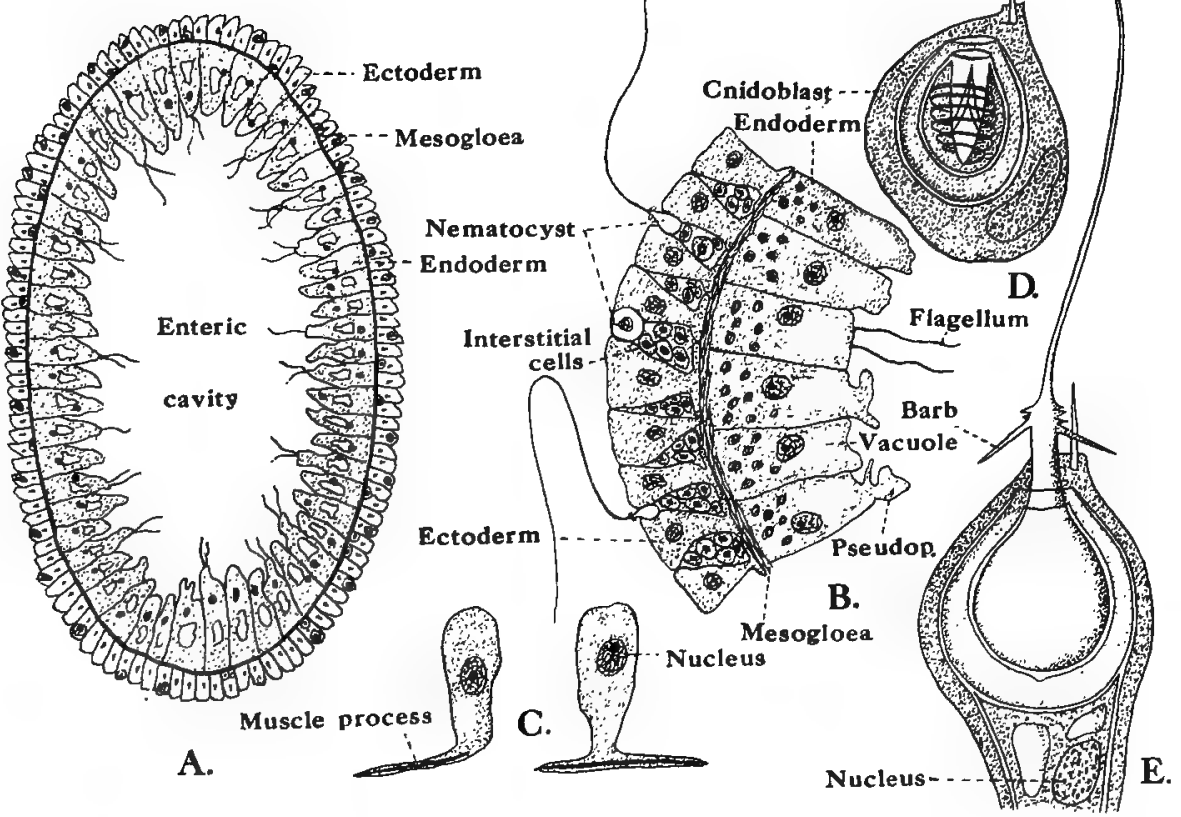

Fil . 11.-A. Transverse Section of Hydra viridis (greatly enlarged); B. Small part of the bodywall highly magnified; C. Two isolated ectoderm cells; D. Cnidoblast, before the extrusion of the nematocyst thread; E. Cnidoblast, after the extrusion of the nematocyst thread. C.-E. after Parker and Haswell.

through contact with the water) causes the instant eversion and extrusion of the nematocyst neck and thread. There are small nerve cells connected with the cnidoblasts.

(b) The endoderm.

This layer is made up of large endoderm cells lining the cœlenteron; these are similar in shape to the ectoderm cells, and each has a nucleus, a large vacuole, and also either pseudopodia or two flagella which project into the coelenteron. The endoderm cells also have crosspiece muscular processes, and are therefore myo-epithelial cells. The muscular processes run circularly, and can be properly seen only in longitudinal sections. Some of the endodern cells near the mouth are specialised as gland cells, which secrete a digestive ferment. There are also gland cells on the "foot" or base of Hydra, and their sticky secretion probably enables it to attach itself firmly to surfaces. The green 

colour of Hydra viridis is due to numerous green symbiotic Flagellates which are present in the endoderm cells.

(c) The mesoglœa.

This is a thin, structureless lamella, forming a sort of strengthening sheath. On the outer surface a distinct longitudinal striation is formed by the muscle processes of the ectoderm cells. On the inner surface transverse fibres occur, which appear to be connected with the muscle processes of the endoderm cells.

Make a drawing of a small part of the body-wall to show the layers and the component cells.

Put a drop or two of acetic acid and methylene blue at the edge of the coverslip, and observe the extrusion of the nematocysts. Notice that some of them (small ones) are without barbs. Then gently tap the cover-slip, so as to break up the dead $H y d r a$; and examine and draw the isolated cells.

Two Ciliate Infusorians are often seen moving about on the skin of Hydra, namely, Kerona, a commensal, and Trichodina, an ectoparasite. 



\section{THE SEA-ANEMONE (Actinia)}

\section{External Features.}

The Sea-anemone has the form of a cylinder, the height of which slightly exceeds the diameter. The cylinder or column is fixed by its broad base. At the free end the column passes into a horizontal plate, the disc or peristome. In the middle of the disc is the slightly elevated slit-like mouth. Arising from the disc, and encircling the mouth, are numerous short tentacles regularly arranged in circles. There is a pore at the tip of each tentacle through which water may be passed.

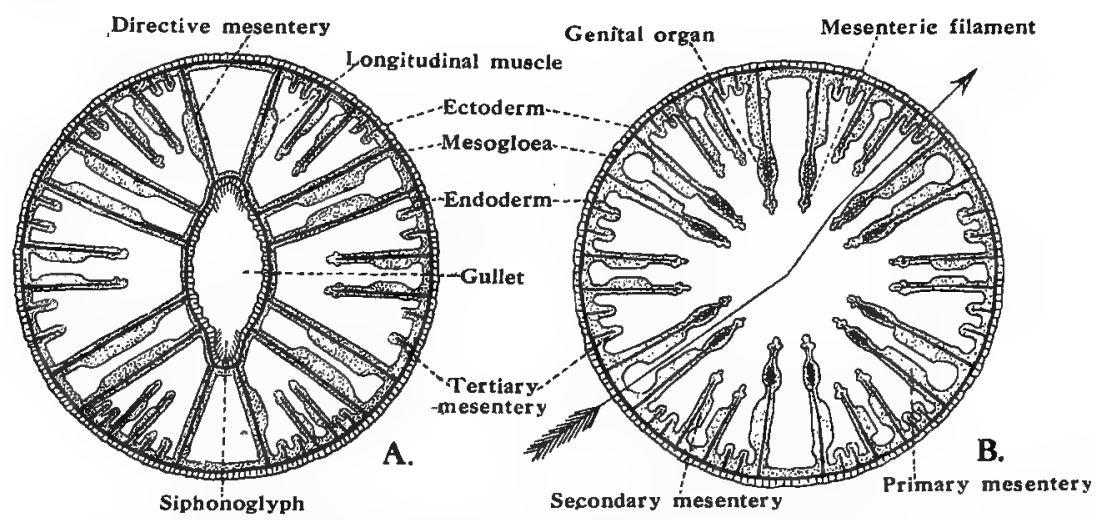

Frg. 12.-A. Transverse Section through the gullet region (stomodæum) of a Seaanemone; B. Transverse Section below the gullet, about the position indicated by the arrow in Fig. 13, A.

\section{General Structure (Transverse Section).}

If a transverse section is made across the column a short way below the tentacles the following structures will be seen :-

(a) The body-wall, composed of ectoderm, mesogloa and endoderm.

(i) The ectoderm consists chiefly of ciliated, sensory, stinging and gland cells, and also of numerous muscle cells.

(ii) The mesogloea is a tough and fairly thick supporting tissue between the ectoderm and endoderm, and it forms the basis for their cells. It contains amoboid cells which have wandered into it from the ectoderm chiefly; it is therefore mesenchyme tissue or incipient mesoderm.

(iii) The endoderm consists mainly of flagellate cells, with muscular fibres at their roots. 

(b) The gullet or stomodæum. This has the form of a flattened cylinder hanging down into the interior of the body. It is marked with longitudinal grooves, two of which, termed the ciliated grooves or siphonoglyphs, occur at the ends of the long diameter of the gullet, and correspond to the corners of the mouth. They are broad and deep and sometimes bear cilia. The gullet is composed of ectoderm, mesoglœa and endoderm.

(c) The mesenteries. These consist of supporting mesogloea, covered on both sides with endoderm. Muscles occur on the mesenteries which are divisible into the following groups :-

(i) Primary mesenteries, usually twelve in number, all reaching to the gullet. They are arranged in six pairs. The cavity enclosed by each pair is known as the intraseptal cavity; the cavity between adjacent pairs is the interseptal cavity. The two pairs attached to the siphonoglyphs of the gullet divide the animal into bilaterally symmetrical halves and are called the directive mesenteries. The retractor or longitudinal muscles on these directives are turned away from each other, and are within the interseptal spaces; while on all the other mesenteries the muscles are facing, and within the intraseptal spaces.

(ii) Secondary and tertiary mesenteries arise later in the interseptal chambers and are short, not reaching to the gullet. In all these the longitudinal muscles of each pair face each other.

The gonads or reproductive organs are developed in the substance of the mesenteries, and are derived from the endoderm.

Longitudinal Section.

In a longitudinal section the following features may be seen :-

(a) The body-wall, consisting of ectoderm, mesoglœa, and endoderm.

(b) The basal disc, similar to the body-wall, by which the animal fixes itself.

(c) The gullet, with the longitudinal ridges. This hangs down into the body and terminates in a free edge produced at each end of the long diameter into a descending lobe or lappet.

(d) A primary mesentery. Its upper half is attached to the gullet, its lower half is free. It is attached to the basal disc and to the body-wall. In development it arises as a growth from the body-wall to the gullet. An aperture, the ostium, occurs in the mesentery and places the adjacent compartments of the enteron in communication.

(e) A secondary and a tertiary mesentery. These do not reach the gullet. their edges are free in the enteric cavity.

(f) The mesenterial filaments on the free edges of the mesenteries. Gland cells, which secrete a digestive ferment, are present in the epithelium of these filaments. 

(g) The acontia, long delicate threads springing from the edges of the mesenteries; they bear nematocysts, and can be protruded through minute apertures in the body-wall known as cinclides.

(h) The genital organs or gonads on the primary mesenteries.

(i) The muscles of the mesenteries. These are:

(i) The longitudinal or retractor muscle, a narrow band stretching from the base to the disc on one side of each mesentery.

(ii) The parietal muscle, passing obliquely across the lower angle of the mesentery.

(j) There is a circular sphincter muscle around the oral margin.

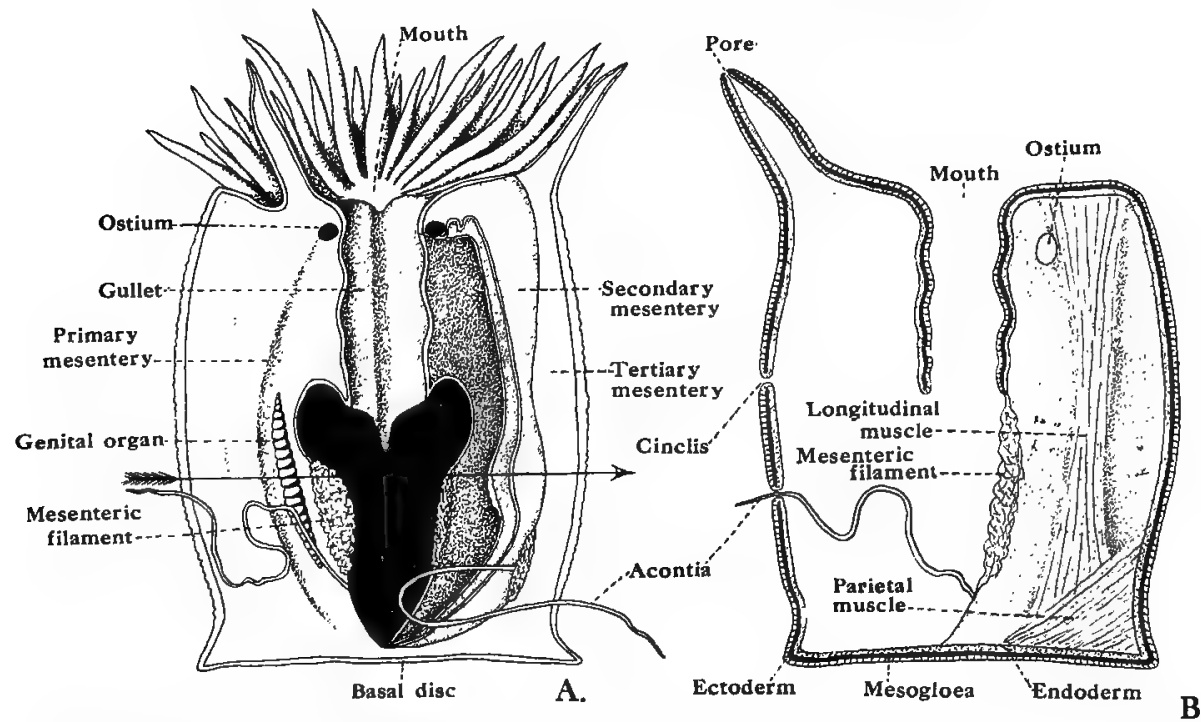

Fra. 13.-A. Longitudinal Section of a Sea-anemone (at the position indicated by the arrow in Fig. 12, B.); B. Longitudinal Section (diagramnatic) of a Sea-anemone. 



\section{THE LIVER-FLUKE (Fasciola or Distoma hepatica)}

THE adult Liver-fluke is commonly found in the bile-ducts of the sheep. It causes the disease known as "liver rot."

\section{External Features.}

It is an unsegmented and flattened worm, leaf-like in form and about an inch long. At its broader end it has a triangular projection, the head-lobe or cephalic cone. The surface of the body is devoid of cilia, but is covered by minute spines pointing backwards. At the tip of the head-lobe is the small cup-shaped anterior sucker with the mouth in its centre. On the ventral surface is the ventral sucker, situated just behind the head-lobe. The genital aperture is situated between the anterior and the ventral suckers, but nearer the latter. The excretory pore lies in the middle of the posterior end of the body, slightly on the dorsal surface.

\section{Alimentary System,}

In order to make out this system clearly, the fluke may be injected through the mouth with a solution of Prussian blue. It should then be placed between two slides, tied together, so as to flatten it. Put the slides with the fluke into 90 per cent. alcohol for about twelve hours, and then dehydrate, clear, and mount in balsam. The mouth leads into a small ovoid muscular pharynx. From this a short osophagus leads to the intestine, which immediately divides into two parts, each giving off a number of blind pouches or cæca. The intestine ends blindly posteriorly, there being no anus.

\section{Excretory System.}

This may be seen by an injection (similar to that in the case of the alimentary system) made in the middle line of the body near the excretory pore. It consists of a longitudinal main trunk opening at the posterior end by the excretory pore. The trunk is formed from the union of two anterior ducts on each side. The posterior two are dorsal, the anterior two are ventral. These ducts are formed from smaller ducts, and these in turn from numerous capillary tubules, each of which begins with a flame-cell or excretory cell.

\section{Reproductive System.}

This system is complicated. The animal is hermaphrodite.

\section{Female.}

The ovary is a branched and unpaired organ lying in the anterior part of the body on the right side. A short and narrow oviduct leads from the ovary towards the middle line to join the median yolk-duct or vitellarian duct, which is formed by the union of two transverse ducts leading from the junction of the two long lateral ducts on each side. These are formed from the numerous 

ductules of the diffuse system of yolk-glands along each side of the body. The oviduct and the median vitellarian duct are surrounded at their junction by the shell-gland; and these united ducts form the wide convoluted uterus which opens (beside the penis) into the common genital outlet.

A short tube, known as Iaurer's canal, runs from the junction of the oviduct and the median vitellarian duct and opens by a pore on the mid-dorsal surface.

2. Male.

This system consists of a pair of much-branched testes lying in the middle of the posterior half of the body. The branches of each testis open into a vas

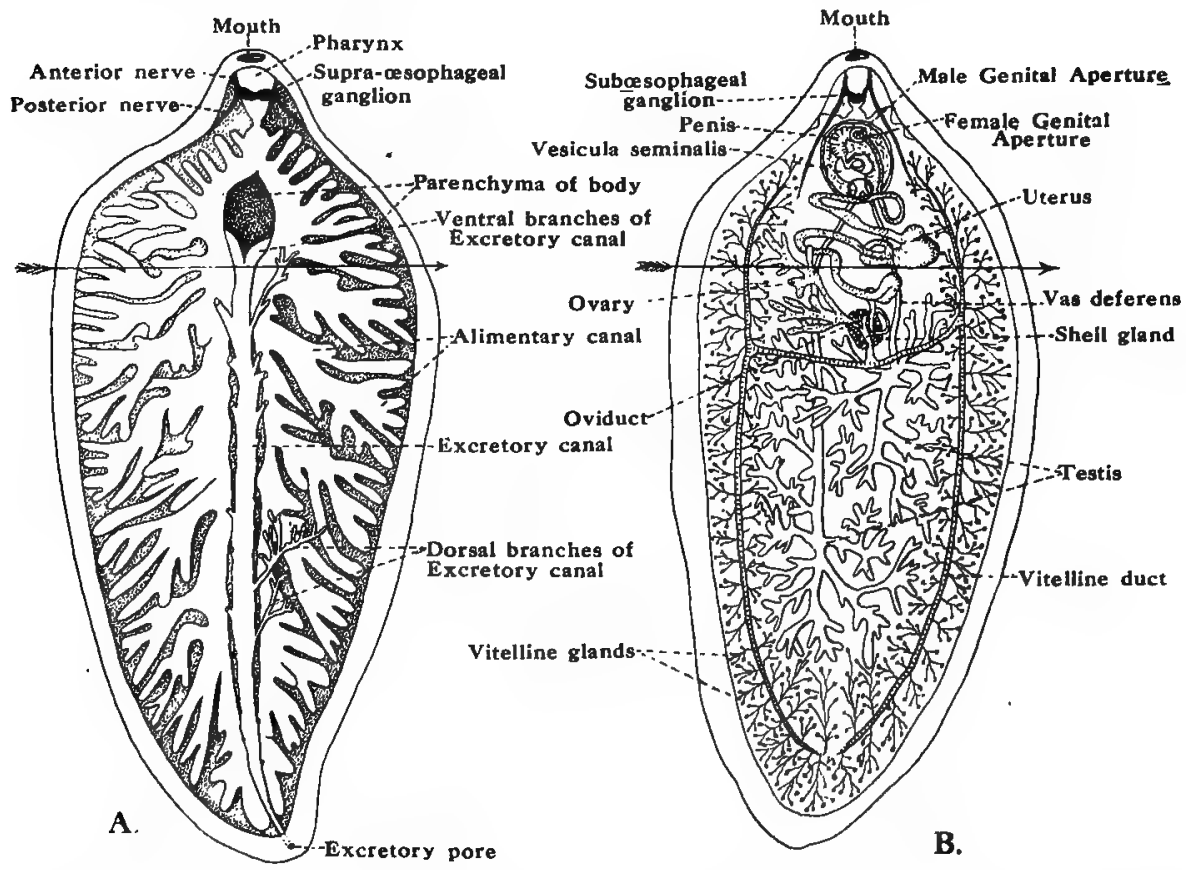

FIc. 14.-A. Dorsal View of the Liver-fluke (Fasciola hepatica), showing the alimentary canal and the excretory system; B. Ventral View, showing the reproductive system ( $x 4)$.

deferens, the two vasa deferentia running forward to the cirrus-sac (a depression between the ventral sucker and the genital aperture or outlet) and there uniting to form an elongated sac, the vesicula seminalis. From this a fine duct, the ductus ejaculatorius, runs forward into a muscular organ called the penis or cirrus. This opens by the small male genital pore in the common genital aperture or outlet. The penis is evaginated, when the sperms are expelled, and the ejaculatory duct is then telescoped inside it.

\section{Nervous System.}

This consists of a ring round the œsophagus with two lateral ganglia and a single ventral ganglion on it. Nerves are given off from the ganglia to the anterior region of the body, and from each lateral ganglion a lateral nerve runs backwards under the cæca of the alimentary canal to the posterior end of the body. 



\section{Transverse Section of Body.}

In a transverse section through the body (as indicated by the arrows in Fig. 14, $A$ and $B$ ) the following structures will be seen :-

(a) The cuticle, a homogeneous layer with spinules developed in it.

(b) A layer of circular muscles.

(c) A layer of longitudinal muscles.

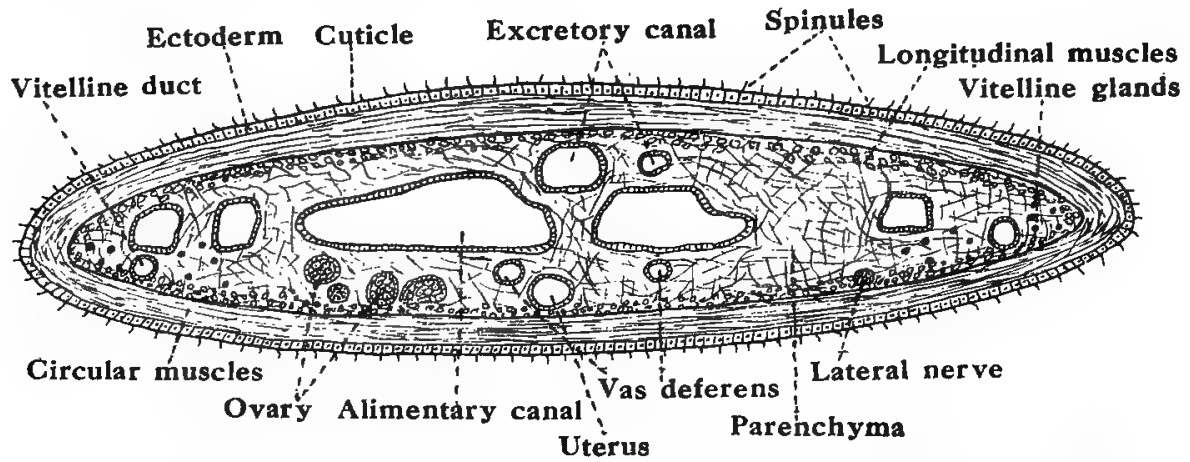

Fig. 15.-Transverse Section through the body of a Liver-fluke (at the position indicated by the arrows in Fig. 14, A and B).

(d) The spaces between the various organs, filled by a peculiar form of connective tissue, the parenchyma.

(e) The intestine with the lateral cæca.

(f) Vitellarian ducts and yolk-glands.

(g) The uterus.

(h) The ovary.

(i) The vasa deferentia.

$(j)$ The excretory ducts.

(k) The lateral nerves. 



\section{THE TAPE-WORM (Taenia)}

VARIous species of tape-worms are parasites in the alimentary canal of Vertebrates. Two of the commonest species are Taenia serrata, which is found in the dog, and Taenia or Dipylidium caninum, which is found in the dog and

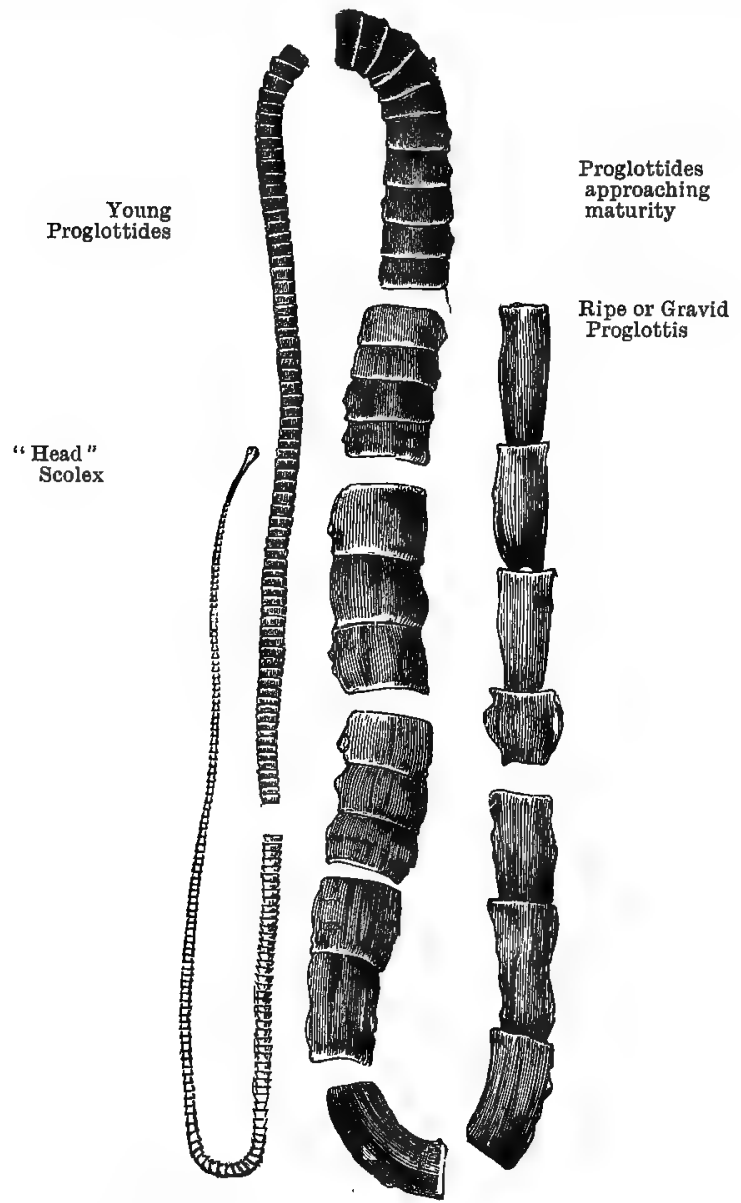

Frt. 16. - The Beef Tape-worm (Taenia saginata). Selected portions of a single specimen. After Leuckart.

also in the cat. Portions of these tape-worms are generally discharged with the fres of the host, and thus may easily be obtained. Complete specimens may be procured by cutting open the intestine of dogs or cats which have been destroyed.

Form and General Structure.

The Tape-worm has the form of a long segmented ribbon. Towards the anterior end the ribbon becomes much narrower, and at this end the extremely 

small "head" and scolex are situated. The rest of the animal is called the body or strobila.

The top of the scolex is the somewhat conical rostellum, the base of which expands into the rounded "head." The rostellum has a circlet of minute recurved hooks, and the head bears four rounded suckers. By means of these hooks and suckers the tape-worm attaches itself to the lining of its host's intestine.

The body or strobila is made up of a series of segments or proglottides. These are narrower behind the head region and gradually increase in size towards the posterior end. Each proglottis, when mature, contains a set of hermaphrodite reproductive organs. At first the male organs alone are developed, then the female organs appear; and later the whole segment, on the ripening of the female organs, is filled with developing eggs or embryos, and only remnants of the male and female organs, except the uterus, remain.

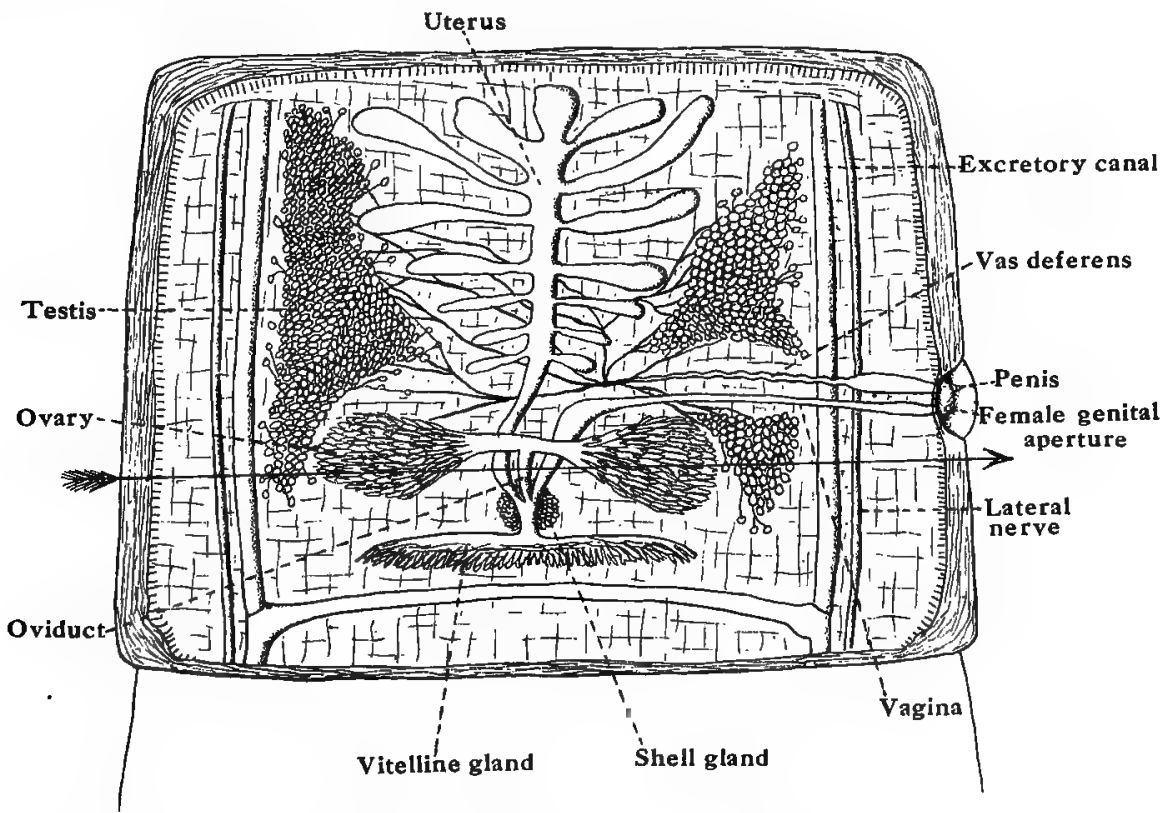

FIG. 17.-A Mature Proglottis of Taenia 8olium $(\times 6)$.

\section{A Typical Mature Proglottis.}

Examine a mature proglottis, which has been stained and mounted, and note the following parts :-

\section{The Reproductive System:}

(a) Female organs.

The ovary is paired and occupies the lateral posterior part of the proglottis. Each ovary consists of a series of tubes in which the ova develop; and these tubes converge into a central tube leading from each ovary, the two tubes joining to form the median oviduct. Occupying the middle of the anterior half of the proglottis is the uterus, a branched tube containing the fertilised eggs. 

Posteriorly the uterus joins the yolk-duct from the yolk or vitelline gland. From the junction of the oviduct and uterus with the yolk-duct the vagina originates. At the junction of these ducts lies the shell-gland. The vagina passes forwards and then to the side, to open by the female genital aperture within the genital atrium, which is situated at the genital papilla on one side of the proglottis.

(b) Male organs.

The testes consist of numerous rounded lobes occupying the greater part of the sides of the proglottis. A fine efferent duct leads from each lobe ; and these ducts (vasa efferentia) eventually unite into a vas deferens, which passes along parallel to the vagina and opens by the male genital aperture within the genital atrium: The vas deferens is slightly swollen near its end into the vesicula seminalis.

\section{Nervous System.}

This system is represented in the proglottis by two lateral nerve cords passing backwards through all the proglottides, and on the outer side of the main excretory canals.

\section{Excretory System.}

This is shown by a pair of longitudinal lateral excretory canals which pass backwards along the whole length of the animal. These are connected by a transverse canal in the posterior part of each proglottis. The excretory system is of the same type as that of the Liver-fluke.

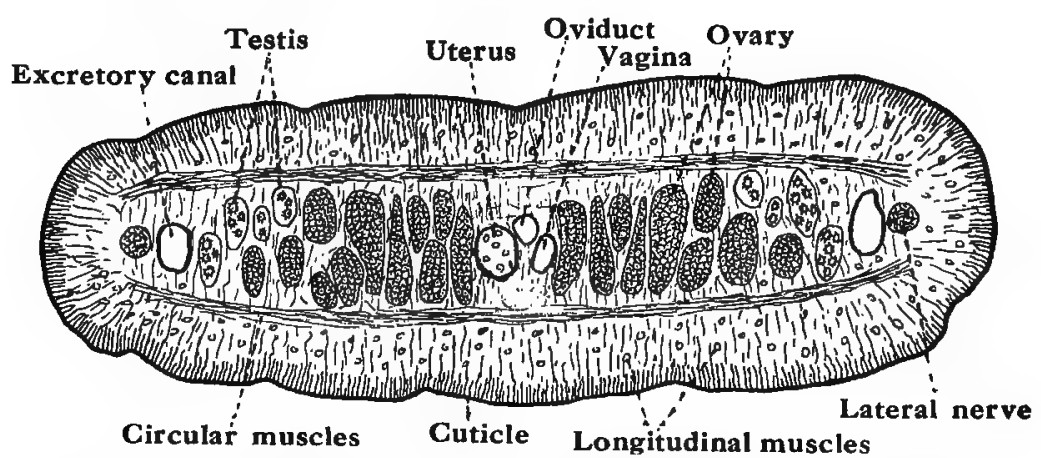

FIG. 18. - Transverse Section through a proglottis of Taenia solium (about the position indicated by the arrow in Fig. 17).

\section{Transverse Section of a Proglottis.}

In a transverse section through a proglottis (as indicated by the arrow in Fig. 17) the following structures will be seen :-

(a) The cuticle, the smooth thick covering layer.

(b) The cells of the ectoderm, extending inwards from the surface.

(c) The longitudinal muscles.

(d) The circular muscles. 

(e) The parenchyma, a packing tissue, scattered throughout which are numerous small calcareous bodies.

(f) The longitudinal excretory canals.

(g) The longitudinal lateral nerve cords.

(h) The uterus.

(i) The oviduct.

(j) The vagina.

(k) The ovary.

(l) The testes.

\section{A Ripe or Gravid Proglottis.}

Examine a ripe proglottis, one which has been stained and mounted; and notice that only traces of the reproductive organs remain, excepting the uterus, which has become extensively branched and is full of developing eggs or embryos.

Open a proglottis, force out some of the eggs and examine these with a high power. Notice that the rounded embryos within their tough double envelopes have each six chitinous hooks (hexacanth embryo). 



\section{THE EARTH-WORM (Lumbricus terrestris)}

\section{External Features.}

1. Make a drawing of the dorsal surface, of the first forty segments, showing :

(a) The body, divided by a series of circular furrows into a number of annuli corresponding to the segments or somites, the internal divisions of the body.

(b) The prestomium, a small conical projection at the anterior end of the body. Its base intersects the first annulus.

(c) The clitellum, a thickened band of glandular tissue, extending over segments 32 to 37 .

(d) The dorsal blood-vessel (if visible), beneath the skin along the median line.

(e) The dorsal pores, situated mid-dorsally in the furrows between the segments, the first one between segments 10 and.11.

2. Make a drawing of the ventral surface, of the first seventeen segments, showing :

(a) The mouth, on the 1st segment and overarched by the prestomium.

(b) The eight chætæ or setæ, in each segment except the first and the last. These setæ are arranged in four pairs, a lateral pair and a ventral pair on each side of the median line.

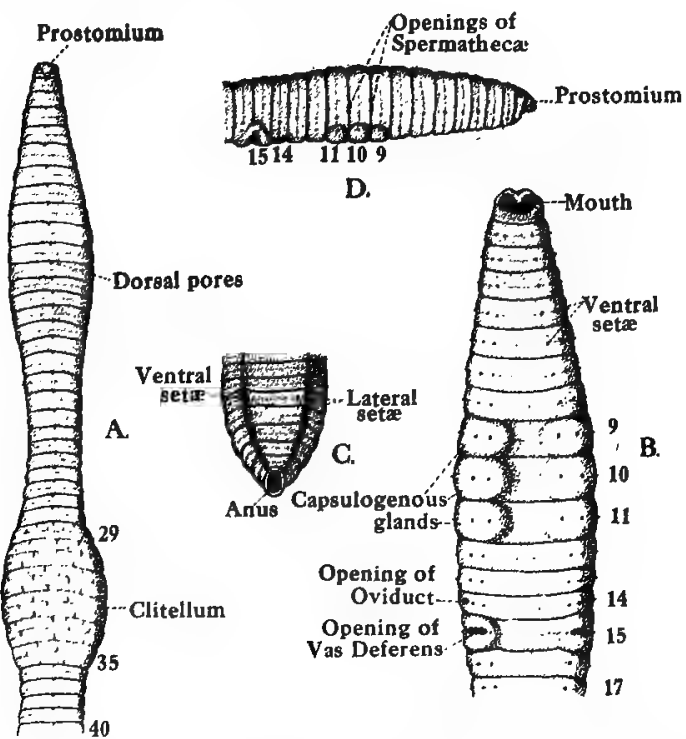

Fic. 19. - Earth-worm (Lumbricus terrestris). A. Dorsal View of the first 40 segments; B. Ventral View of the first 17 segments ; C. Ventral View of the last 6 segments; D. Lateral View of the first 16 segments. 

(c) The capsulogenous or spermaducal glands, situated on the ventral surface of the 9th, 10th, and 11th segments.

(d) The openings of the oviducts, on either side of the median line, in the 14th segment.

(e) The openings of the vasa deferentia, slit-like apertures with tumid lips, on either side of the median line, in the 15th segment.

3. Make a drawing of the side showing :

(a) The lateral setæ.

(b) The openings of the spermathecæ, situated in the grooves between the 9th and 10th, and the 10th and 11th segments.

\section{General Structure.}

Pin the worm down, under water or in salt solution, by inserting a pin through the prestomium and one through the last segment so that the dorsal surface is uppermost. Cut along the mid-dorsal line from the 25th to the 1st segment and reflect the body-wall, placing pins obliquely through it on each side. Put a pin through each side of the 13th segment.

Note the mesenteries or transverse septa dividing the colome into a series of compartments. In each segment, except the first three and the last, there is a pair of nephridia, one on either side of the alimentary canal, opening to the exterior by the nephridiopores, which are situated near the ventral chætæ.

$A$. The Alimentary System.

The mouth leads into a short buccal cavity. Following this is a stout muscular pharynx, which extends from about the 3rd to the 6th segment. The pharynx is attached to the body-wall by radiating muscular strands. Succeeding the pharynx is the cesophagus, a straight and narrow tube extending to the 14th segment. There are three pairs of osophageal pouches or calciferous glands, one pair in the 11th and two pairs in the 12th segment. The œsophagus expands into a thin-walled crop in the 15th and 16th segments. The crop is succeeded by the gizzard, with thick muscular walls, which extends to about the 19th segment. Following the gizzard is the long straight intestine, which leads back to the anus, the terminal opening at the posterior end of the body. The intestine is surrounded by a layer of "yellow-cells" (coelomic epithelium).

$B$. The Vascular System (Principal Blood-vessels).

The dorsal blood-vessel lies above the alimentary canal and extends along the greater part of its length. Anteriorly it gives rise to smaller blood-vessels, which extend over the dorsal surface of the pharynx. In each of the segments, 7 to 11 inclusive, the dorsal vessel gives rise on each side to a smaller vessel, which curves round the oesophagus and leads into the sub-intestinal or ventral vessel. These six half-hoop-like vessels are spoken of as "hearts." The ventral vessel lies between the alimentary canal and the nerve cord, and extends along the course of the nerve cord. It may readily be seen by pushing the alimentary canal to one side.

Make a drawing to show the alimentary and the vascular systems. 

C. The Nervous System.

Cut through the anterior end of the œesophagus and carefully remove the whole alimentary canal posterior to this. Push the pharynx over to one side so as to expose the nervous system.

The "brain" is situated on the anterior part of the pharynx in the second segment of the body, and consists of a pair of supra-pharyngeal ganglia. Each ganglion gives off nerves to the prestomium. These ganglia are connected (by

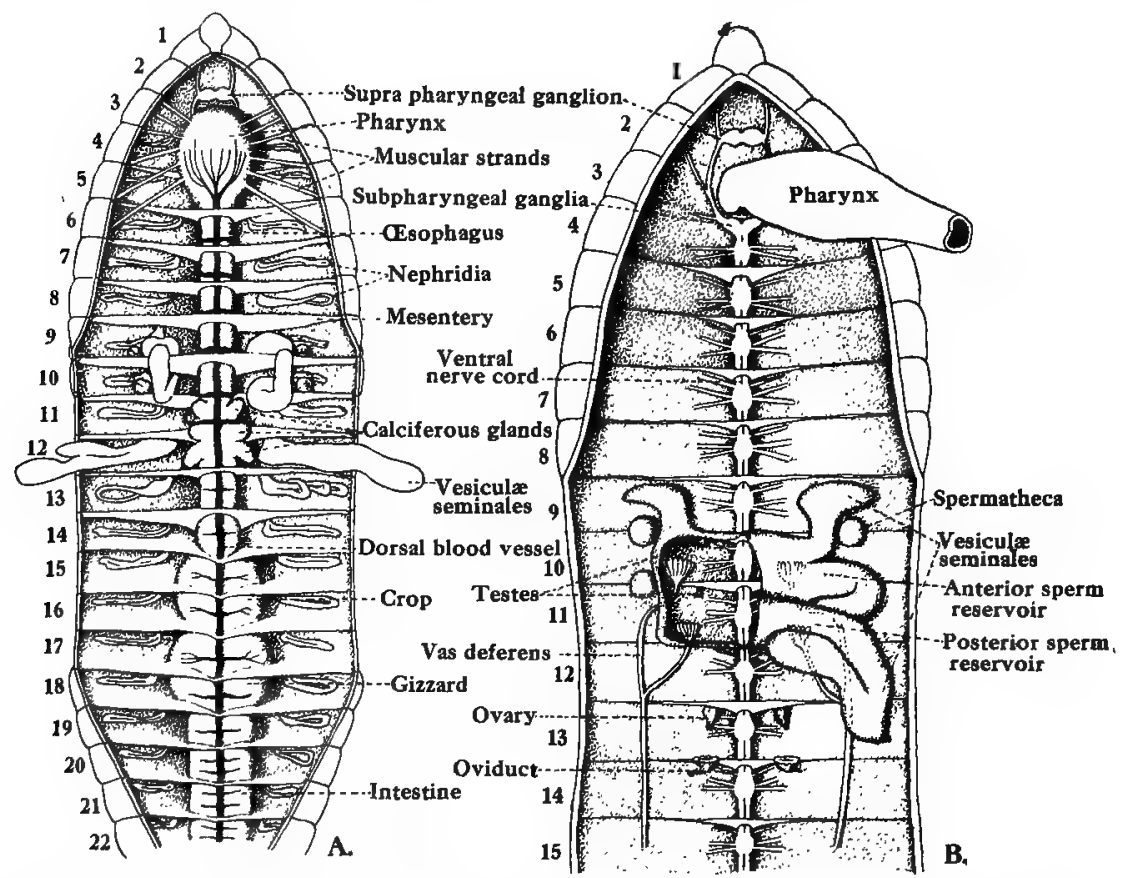

FIG. 20.-A. Alimentary and Vascular Systems of Earth-worm (Lumbricus) ; B. Nervous and Reproductive Systems.

a pair of circum-pharyngeal commissures passing round each side of the pharynx) with a pair of sub-pharyngeal ganglia lying in the 4th segment. From them the ventral nerve cord is continued straight back in the middle line to the posterior end of the body. The ventral nerve cord is double, but the cords are more or less fused together. In each segmient the cord swells to form a ganglion, which gives off three pairs of nerves, one pair near the anterior septum and two pairs near the posterior septum.

$D$. The Reproductive System.

The Earth-worm is hermaphrodite. The reproductive organs and ducts are situated in segments 9 to 15.

The ovaries are a pair of small pear-shaped bodies lying in the 13th segment, one on either side of the nerve cord. Each is attached to the posterior face of the septum between the 12th and 13th segments. Facing the ovaries, in the same segment but on the septum behind, there are two wide ciliated funnels; these are the internal cœlomic openings of the oviducts. Each oviduct passes through the septum between the 13th and 

14th segments, and opens to the exterior by the female genital aperture on the 14th segment.

The vesiculæ seminales or sperm-sacs lie above the nerve cord in segments 9 to 12, and completely cover in the testes and the internal openings of the vasa deferentia. Each seminal vesicle consists of two parts, a spacious median unpaired sac or sperm-reservoir, and paired lateral expansions of these, the seminal vesicles proper. These expansions are seen on opening the worm, appearing as three pairs of sacs at the sides of the alimentary canal. The anterior median seminal vesicle lies in the mid-ventral part of the 10th segment; and its four corners are produced into pouches, the pair of anterior lateral seminal vesicles,. which extend from the 10th segment and occupy the cavity of the 9th, and the first pair of posterior lateral seminal vesicles, which push backwards and occupy the cavity of the 11th segment. The posterior median seminal vesicle lies in the mid-ventral part of the 11th segment, and it has only one pair of pouches -namely, the second pair of posterior lateral seminal vesicles, which extend so far back as to occupy the 12th and 13th segments. Carefully remove the vesicles of one side so as to expose the testes and the internal funnels of the vasa deferentia.

The testes are two pairs of small bodies attached, on either side of the nerve cord, to the posterior faces of the septa separating the 9th and 10th and the 10th and 11th segments. Immediately behind each testis lies a large ciliated funnel, the internal opening of a seminal duct. On eash side the seminal duct of the anterior testis passes backwards through the septum separating the 11th and 12th segments, and is joined in segment 12 by the seminal duct of the posterior testis. The two ducts form the vas deferens, which passes through the successive septa to segment 15 and there opens to the outside by the male genital aperture.

In the 9th and 10th segments there is a pair of small white spherical sacs, the spermathecæ or receptacula seminis, opening by pores between segments 9 and 10 , and 10 and 11.

Make a complete sketch showing as much as possible of the reproductive and nervous systems.

\section{Transverse Section of Body.}

In a transverse section of the body of the Earth-worm the following structures will be seen :-

(a) The thin cuticle.

(b) The epidermis, consisting of a single layer of cells.

(c) The dermis, a very thin layer of connective tissue.

(d) The circular muscles.

(e) The longitudinal muscles, arranged into seven bundles.

(f) The setæ or chætæ. situated in special setigerous sacs formed from the epidermis.

(g) The colome or body-cavity, the space between the body-wall and the alimentary canal.

(h) The intestine, which is coated externally with the "yellow-cells" or coelomic epithelium. It has a deep dorsal fold, the typhlosole, projecting downwards into the cavity of the intestine. This fold is filled 

with "yellow-cells." The wall of the intestine is composed of a muscular layer, and is lined with ciliated epithelium.

(i) The dorsal blood-vessel, lying in the "yellow-cells" above the intestine.

(j) The ventral or sub-intestinal blood-vessel, lying beneath the intestine.

(k) The ventral nerve cord, lying beneath the ventral blood-vessel. Just beneath the nerve cord is the sub-neural vessel.

(l) Portions of the septa, and portions of nephridia.

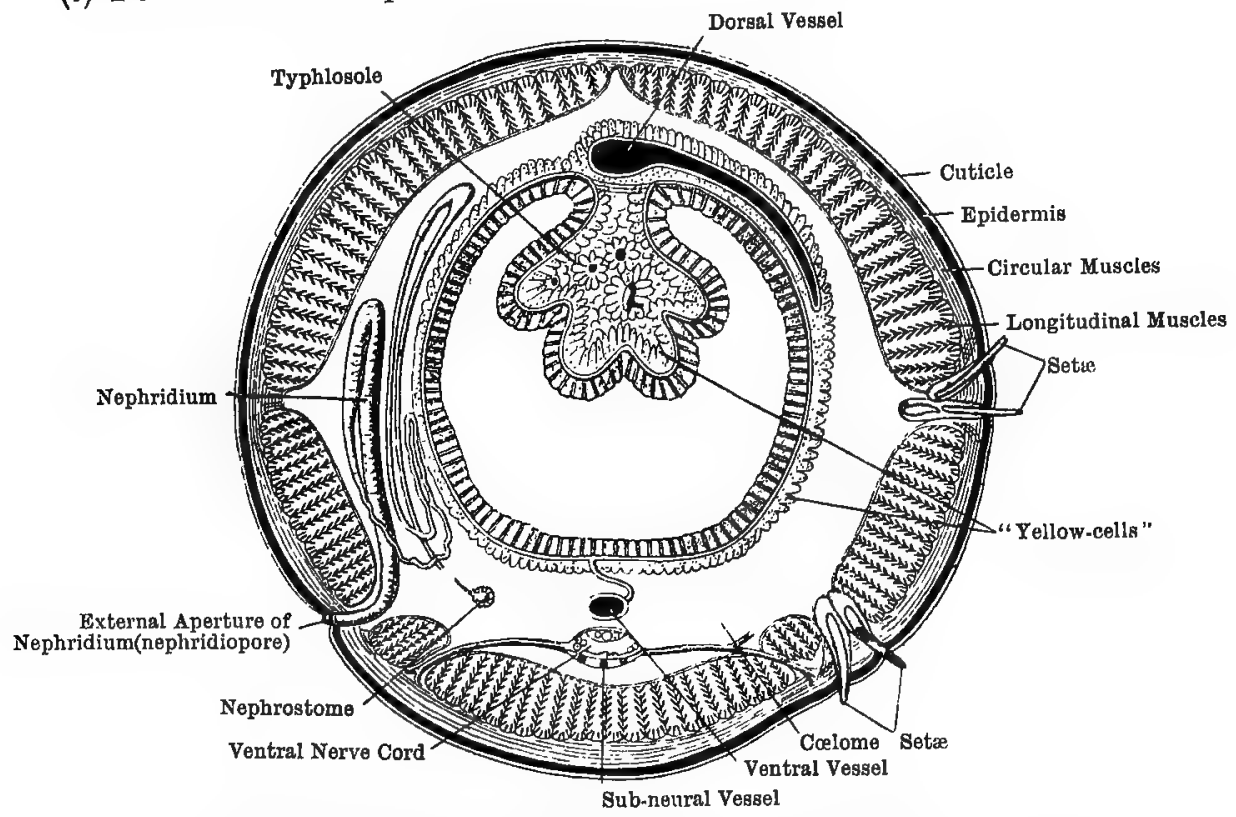

FIc. 21.-Transverse Section (diagrammatic) through the middle of the body of the Earth-worm (Lumbricus). A nephridium is shown (entire) on the left side of the figure, and setæon the right side. After Marshall and Hurst. With permission from Parker and Haswell's Text-book of Zoology.

Carefully remove one of the ovaries, along with the portion of the septum to which it is attached and with the attached nephridium. Mount on a slide in salt solution, and examine with a low power. Notice the ripe ova in the thin distal end of the pear-shaped ovary. The nephridium is tubular and consists of a very small ciliated funnel, a looped main portion which is glandular and solid (the duct passes through the cells), and a much wider and non-glandular bladder which opens to the exterior. The bladder has muscular walls, and within it may be seen parasitic Nematode worms. The ciliated funnel opens into the coelome or body-cavity, and this internal opening is the nephrostome. Notice the blood capillaries on the walls of the nephridium.

The contents of the seminal vesicles and the spermathecæ should be examined under high power. The first contain developing spermatozoa, and the second have ripe spermatozoa received from another worm.

Note.-The South African Earth-worm (Chilota) is very suitable for dissection, especially with reference to the reproductive system, and should therefore be studied by senior students if possible. 



\section{THE MEDICINAL LEEGH (Hirudo medicinalis)}

\section{External Features.}

1. Make a drawing of the ventral surface of the Leech showing :-

(a) The body divided by a series of transverse furrows into a definite number of annuli (about ninety-five). The annuli are more numerous than the true segments of the body; and, except at the two extremities, each segment contains five annuli. The anterior annulus of each segment bears six sensory papillæ, both dorsally and ventrally. A pair of nephridiopores occurs on the posterior annulus of each segment, from the 6 th to the 22nd inclusive. Thus the sensory papillæ determine the anterior border of each segment of the body, while the nephridiopores determine the posterior border of segments 6 to 22 . There are five segments in front of the one bearing the first pair of nephridiopores, and four behind the one bearing the last pair, giving a total of 26 true segments, of which each of the first six and the last four has less than five annuli.

(b) The anterior sucker, oval in shape, at the anterior end of the body. It has a cup-like hollow, in the middle of which is a small aperture, the mouth, with the three jaws surrounding it.

(c) The blind posterior sucker, at the posterior end of the body, circular in shape and larger than the anterior one.

(d) The male genital aperture, situated in the middle of the second annulus of the 10th segment.

(e) The female genital aperture, situated in the middle of the second annulus of the 11th segment.

2. Make a drawing of the dorsal surface of the first seven segments to show :

(a) The five pairs of small eyes on the dorsal surface of the anterior sucker.

(b) The sensory papilla, six in the anterior annulus of each segment, except in those annuli containing the eyes. Here there are only four, the eyes taking the place of the other two in annuli $1,2,3,5$ and 8 . There are five pairs of eyes.

3. Make a drawing of the dorsal surface of the last four segments to show :

(a) The anus, situated in the middle of the last annulus of the body, just in front of the junction between the posterior sucker and the end of the body.

(b) The sensory papillæ, occupying the same positions as in the other segments.

\section{General Structure.}

Pin the animal down under water, with the dorsal surface uppermost, by inserting pins through the sides of the suckers. Cut along the mid-dorsal line, 

taking care not to injure the alimentary canal, which lies close to the skin. Carefully remove the integument from the alimentary canal and pin out the flaps on each side. Note the dorsal blood-vessel lying over the alimentary canal in the mid-dorsal line.

Note the nephridia, a pair occurring in each segment from the 6th to the 22nd. Each nephridium has a closed but porous funnel, the "testis-lobe," contained in a cavity of the coelom above the testis, a much-coiled glandular main portion with fine ciliated ducts and blood capillaries in its walls, and a muscular ciliated bladder opening to the exterior by a nephridiopore. The inner end of the "testis-lobe" probably corresponds to the nephrostome of the Earth-worm.

\section{$A$. The Alimentary System.}

The mouth is situated in the anterior sucker and is surrounded by the jaws. These are arranged radially, one being median and dorsal, the other two ventrolateral. Each is a compressed muscular cushion with a chitinous surface produced into numerous teeth. The mouth leads into a muscular pharynx situated in the 4 th to 7 th segments. It is connected by strong radiating muscles to the body-wall. There are numerous unicellular glands in the wall of the pharynx, and the secretion of these glands prevents the coagulation of the blood. The œesophagus, following the pharynx, is a very short tube leading into the extensive crop. This consists of eleven pouches on each side, the first ten pairs of these storing pockets being directed outwards and each corresponding to a segment. The eleventh pair passes backwards parallel to the intestine and reaches to the 24th segment. After giving off the eleventh pair the crop is succeeded by the stomach, a small spherical dilatation, opening behind into the intestine, a narrow straight tube passing into the somewhat dilated rectum, which turns slightly upwards and opens at the anus in the last annulus of the last segment.

B. The Vascular System.

This system is complex. It consists of a spongework of sinuses (i.e., irregular channels with non-muscular walls) filled with a fluid which is not really blood, but which apparently functions as such, namely, coelomic fluid containing the red blood-pigment, hæmoglobin. The spongework completely fills the original open space, the body-cavity or cœlome, which is consequently represented by the complicated system of coelomic sinuses, and these seemingly replace the true blood-vessels of a proper blood system. The principal sinuses are :

(a) The dorsal sinus, along the mid-dorsal line above the alimentary canal, and connected behind with the ventral sinus by fine channels which pass between the intestine and the last pair of storing pockets.

(b) The ventral sinus, under the alimentary canal. It surrounds and encloses the ventral nerve cord.

(c) The lateral "blood-vessels," a pair of tubular channels along the sides of the body. These are probably sinuses with muscular walls. They are connected by cross channels, which pass beneath the ventral sinus.

Make a drawing showing as much as possible of the alimentary system and the vascular system. 

C. The Nervous System.

Cut through the anterior end of the pharynx and remove the alimentary canal from the body. On the anterior part of the pharynx are the two suprapharyngeal ganglia. They are connected by the circum-pharyngeal commissures to the ventral nerve-chain, which lies inside the ventral sinus and which consists of twenty-three pairs of ganglia connected by two very closely

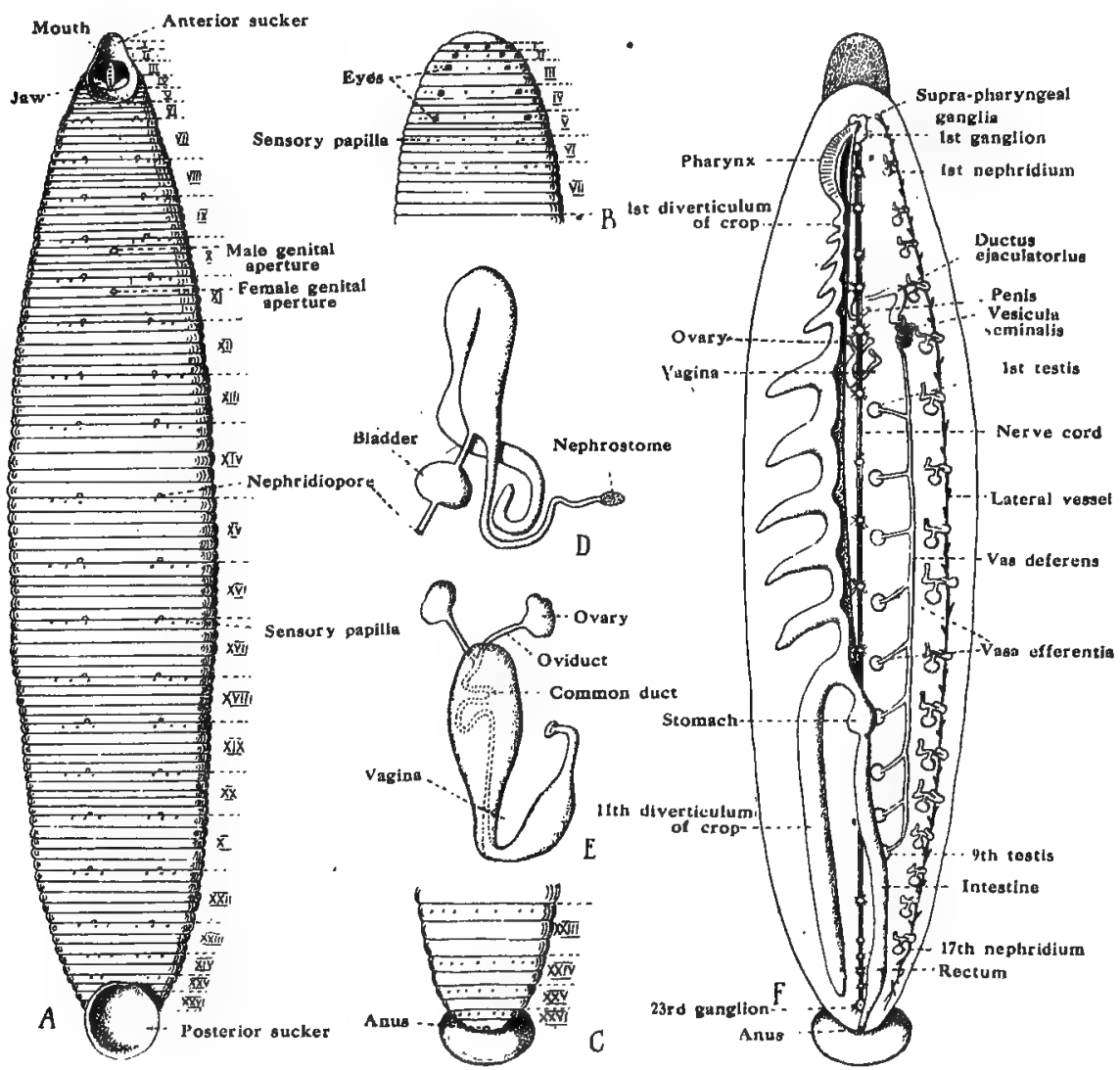

F1t. 22. -A. The Leech (Hirudo medicinalis), ventral view; B. Dorsal view of anterior segments; C. Dorsal view of posterior segments; D. Nephridium; E. Female genital organs (spread out); F. Dissection (made from dorsal surface) to show the internal structure. The alimentary canal has been cut open and the right half removed (as far as the end of the crop), so as to expose the underlying organs. A.-E., after Borradaile; F., after Parker and Haswell.

apposed connectives. The first or sub-pharyngeal ganglia are larger than the others and represent the fusion of the first five pairs of ganglia. The last ganglia represent six or seven pairs fused together. Each ganglion or conjoint pair of ganglia gives off nerves to supply the corresponding segment.

$D$. Reproductive System.

The ovaries are a pair of very small. coiled bodies enclosed in small rounded sacs, lying close to the mid-ventral line in the 11th segment. From each sac a short oviduct passes inwards and backwards; the right one passes under 

the nerve cord and unites with the left one to form a common median duct. This common duct is surrounded by the albumen gland, and it opens into a curved muscular tube, the vagina, which opens in the middle line on the ventral surface of the second annulus of the 11th segment.

The testes are nine pairs of spherical sacs lying along each side of the ventral sinus in segments 12-20. Each gives off from its outer surface a narrow efferent duct, which joins the larger vas deferens running parallel to the alimentary canal. In the 10th segment each vas deferens increases in width and forms a complex coil, the epididymis or vesicula seminalis, giving rise anteriorly to a widened muscular tube, the ductus ejaculatorius. From each ductus ejaculatorius a narrow duct passes to the penis, which is a curved muscular organ protrusible through the male genital aperture in the middle line on the ventral surface of the second annulus of the 10th segment.

Make a drawing to show the Nervous System and the Reproductive System.

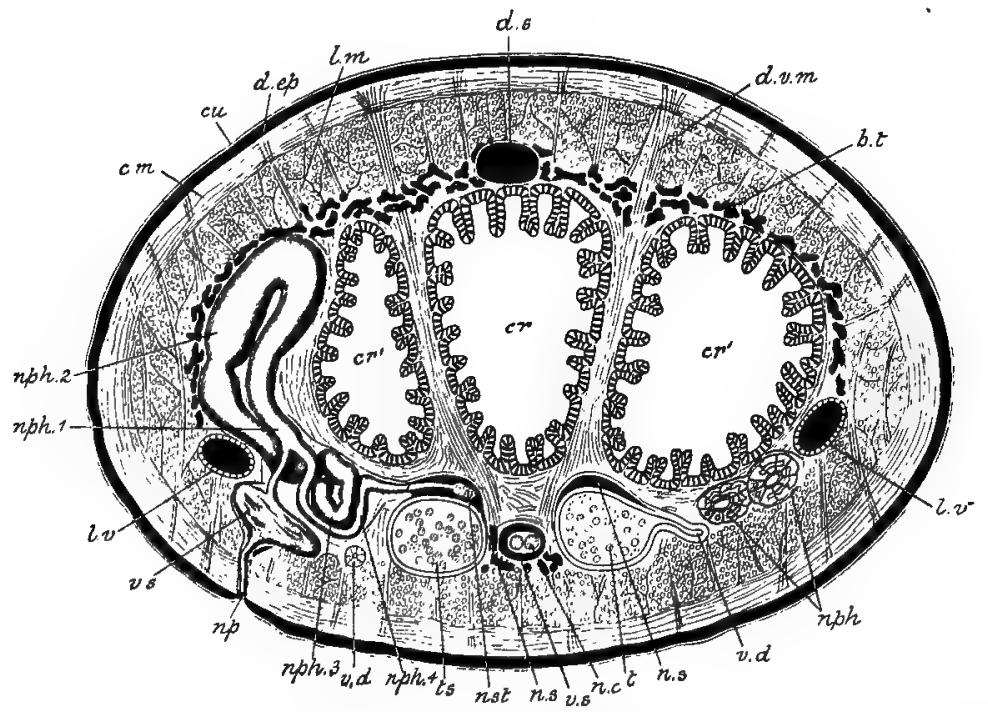

Fig. 23. - Transverse Section (diagrammatic) through the middle of the body of the Leech (Hirudo). A nephridium is shown (entire) on the left side of the figure. After Marshall and Hurst. With permission from Parker and Haswell's Text-book of Zoology.

$c u$. cuticle; $d_{n} e_{2}$. epidermis ; c.m. circular and oblique muscles; $l_{n} m$. longitudinal muscles; $d_{n} v$. m. dorsoventral muscles; b.t. botryoidal tissue ; er. crop ; or'. diverticula of crop (storing pockets); $u_{.8}$. dorsal sinus; l.v. lateral sinus or "blood-vessel"; $v_{*}$. ventral sinus; n.e. nerve cord ; n.s. nephrostomial sinus; $t s$. testis ; $v . d$. vas deferens; $n p h$ section of nephridinm; nph. 1 . anterior limb of main lobe of nephridium; uph. 3 . posterior limb of main lobe of nephridium; nph. 3. apical lobe of nephridium; $n p \hbar .4$. testis-lobe of nephridium ; nat. "cauliflower lobe" or inner end of the testis-lobe (nephrostome); v\&. vesicle or bladder of nephridium; np. external aperture of nephridium or nephridiopore.

\section{Transverse Section of Body.}

In a transverse section of the body of a Leech the following structures may be seen :-

(a) The thin cuticle.

(b) The epidermis. 

(c) The dermis, containing a plexus of "blood" capillaries.

(d) The circular and oblique muscles.

(e) The longitudinal muscles.

(f) The dorso-ventral muscles, passing from the dermis through the circular muscles and between the longitudinal muscles.

(g) The botryoidal tissue around the crop and occupying most of the body cavity or cœilome.

(h) The crop, with its lateral pouches or storing pockets.

(i) The lateral "blood-vessels" or sinuses on the outer side of the crop.

(j) The dorsal sinus above the crop.

(k) The ventral sinus surrounding and enclosing the nerve cord.

(l) The peri-nephrostomial sinuses above the testis and enclosing the "testis-lobe" of the nephridium.

$(m)$ The vas deferens between the lateral sinus and the ventral sinus.

(n) Portions of the nephridia. 



\section{THE COCKROACH (Periplaneta americana)}

\section{External Features.}

1. Make a drawing of :

(i) A dorsal view of the Cockroach with the wings of the right side extended showing :

(a) The head, bearing the eyes and the antennæ.

(b) The prothorax, to the underside of which the first pair of walking legs is attached. The dorsal shield of the prothorax, the pronotum, is large and projects forwards, so that it conceals the short and thin neck; and the head may also be drawn under it.

(c) The mesothorax, to the under side of which the second pair of walking legs is attached. The anterior wings are dark coloured; they protect the posterior wings, and are known as the wing-covers or elytra or tegmina. They are attached to the dorsal surface. Note that the wing-covers extend beyond the posterior end of the body. The dorsal shield of the mesothorax, the mesonotum, is thin and semi-transparent, being covered by the wing-covers.

(d) The metathorax, bearing the third pair of walking legs on its ventral surface and the posterior pair of wings on the dorsal surface. The metanotum or dorsal shield of the metathorax is smaller than, but similar to, the mesonotum.

(e) The abdomen. In both sexes there are ten abdominal segments, but in the female some of the segments are modified. A typical abdominal segment has a broad dorsal chitinous plate, the tergum, and an equally broad ventral plate, the sternum. The tergum and sternum meet at an acute angle at the sides of the body, and are united by a soft colourless cuticle. In the abdomen of the female cockroach only eight terga are externally visible. These are the first seven and the 10th. Two more (8th and 9th) are usually concealed beneath the 7 th tergum, but they may be seen by extending the abdomen. The 10th tergum is a flat plate notched in the middle of its posterior margin. Beneath it are two triangular chitinous sclerites, the podical plates, between which the anus opens in the middle line. The abdomen of the female is broader and flatter than that of the male.

In the male the abdomen is narrower and the terga more convex than in the female. The first tergum is somewhat small and the sternum is only an oval chitinous plate. Both the terga and sterna of the next six segments are broad chitinous plates ; 

but the 8th and 9th terga are reduced to narrow bands of chitin, overlapped and concealed by the posterior margin of the 7 th tergum as in the female. The 10th tergum is a flat rounded plate, projecting beyond the posterior margin of the

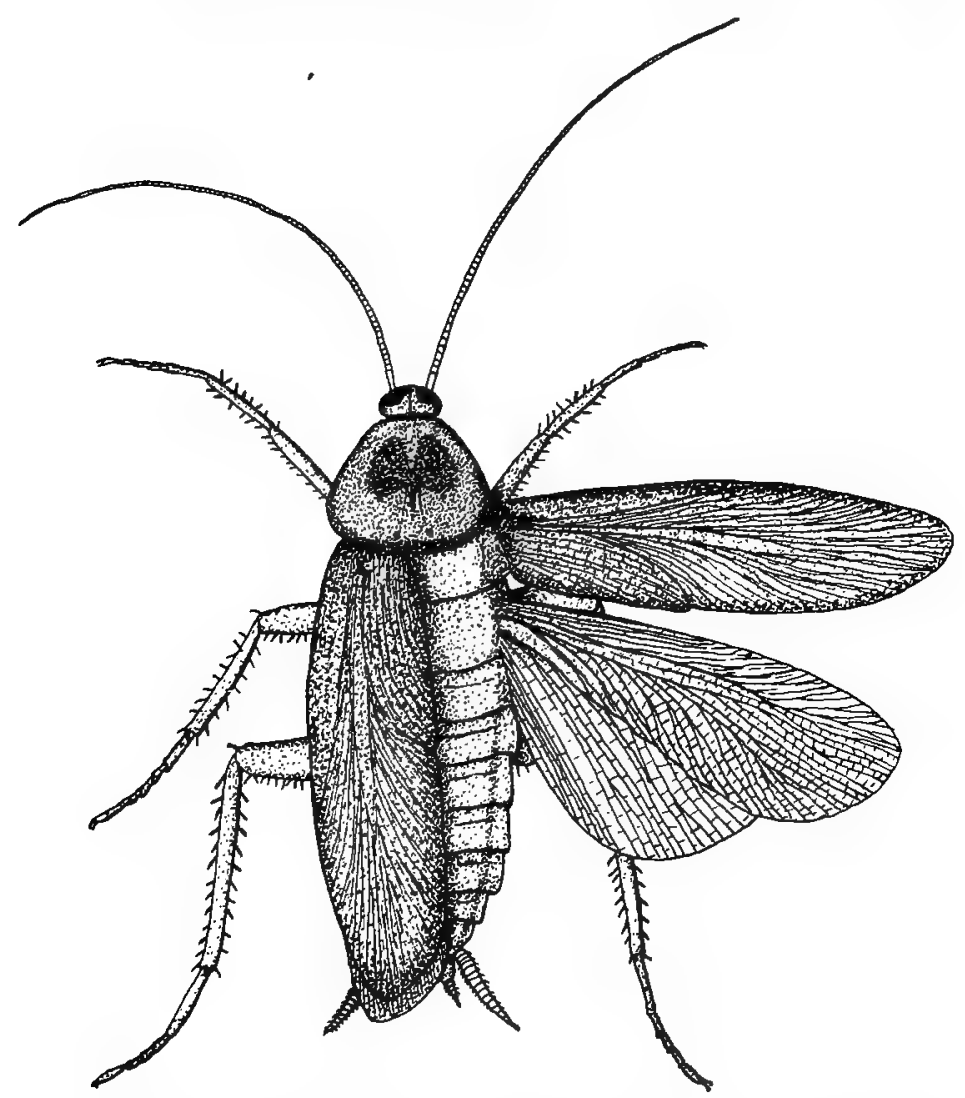

FiG. 24.-The Cockroach (Periplaneta americana). Male $\left(\times 1 \frac{1}{2}\right)$.

body, with a notch in its posterior margin. Under it lie the podical plates and the anus as in the female.

The anal cerci, occurring in both sexes, are a pair of spindleshaped, many-jointed appendages projecting beneath the edge of the 10th tergum. The anal styles, occurring in the male only, are attached to the sternum of the 9th segment. (See Fig. 2\%, A.)

(ii) A ventral view showing the position of the head with its appendages, and also the attachments of the legs as described above, the anal cerci (and styles in the male) and the opening of the anus.

Notice the stigmata or respiratory openings (twenty pairs) on the sides of the body, between the thoracic segments and on the first eight abdominal segments (between the tergum and sternum, and at the front end of each segment). 

The Head.

The head, as seen from the front, is pear-shaped, having a semicircular outline above and narrowing downwards. A side view shows that it is compressed from front to back, with top and sides regularly rounded. The mouth, surrounded by the jaws, opens below. The clypeus occupies the large central part of the front, and extends almost completely across the widest part of the face. It is divided above by a sharply bent suture from the two epicranial plates, which form the top of the head as well as a great part of its back and sides. The labrum or upper lip hangs like a flap from its lower edge. A little

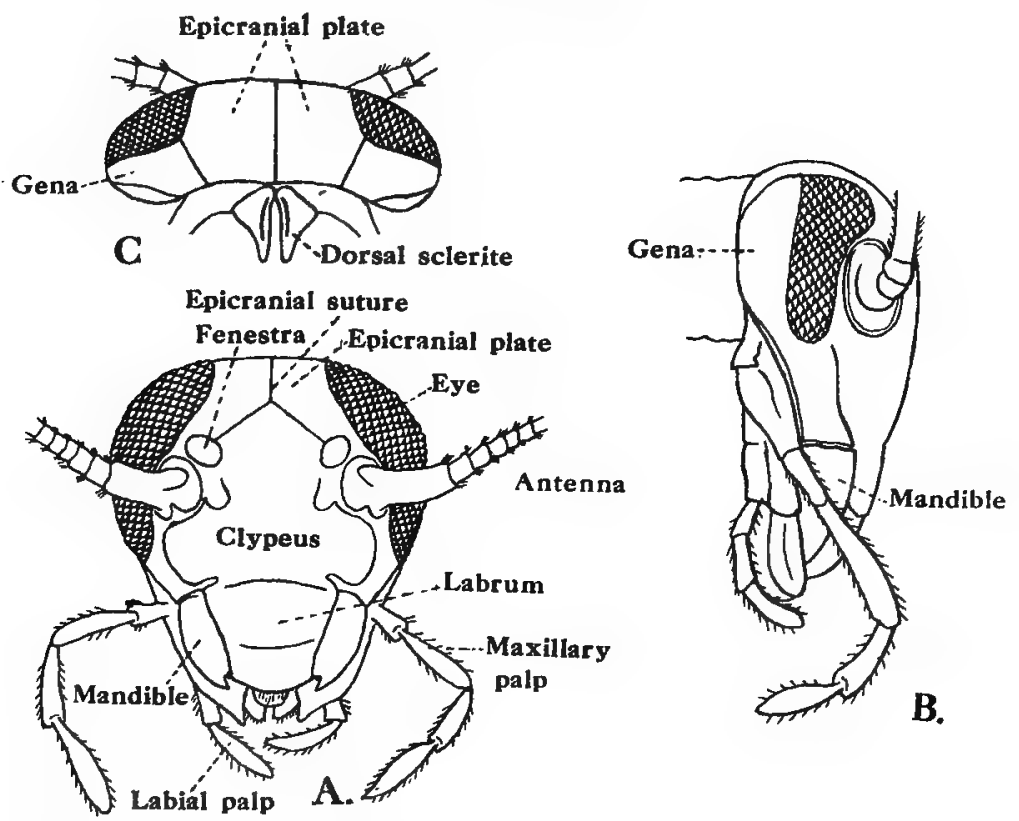

FI(*. 25.-The Cockroach (Periplaneta americana). A. Front view ; B. Side view ; C. Dorsal view of the head.

above the articulation of the labrum the width of the clypeus is reduced. In the angle so formed the anterior articulation of the mandible is situated. The labrum is narrower than the clypeus and of a square shape, the lower angles being rounded. It hangs down and forms the front wall of the mouth. The top and back of the head are covered by two epicranial plates, which meet in the middle line. The sides of the head are completed by the eyes and the genæ or "cheeks." The large compound eye is bounded above by the epicranium, and in front, by a narrow band which connects the epicranium with the clypeus, and behind, by the gena. The gena passes downwards between the eye and the epicranial plate, then curves beneath the eye, and just appears upon the front of the face, being loosely connected at this point with the clypeus.

A shield-shaped aperture on the posterior surface of the head, called the occipital foramen, marks the place where the neck joins the back of the head. The neck itself is slender and soft, and is covered with a soft white cuticle, except 

where the eight hard chitinous plates or sclerites occur, there being two dorsal, two ventral, and two lateral pairs of these plates.

The antennæ are attached to the front of the head immediately below the eyes. Each antenna consists of a stout basal joint, movably articulated, by a ring of soft cuticle, in a cavity of the clypeus. On the inner and upper side of each antenna is a small circular white area, situated at the end of the suture dividing the epicranium from the clypeus. These areas are called the fenestræ.

Make three drawings of the head to show (i) the front, (ii) the side, and (iii) the dorsal aspect.
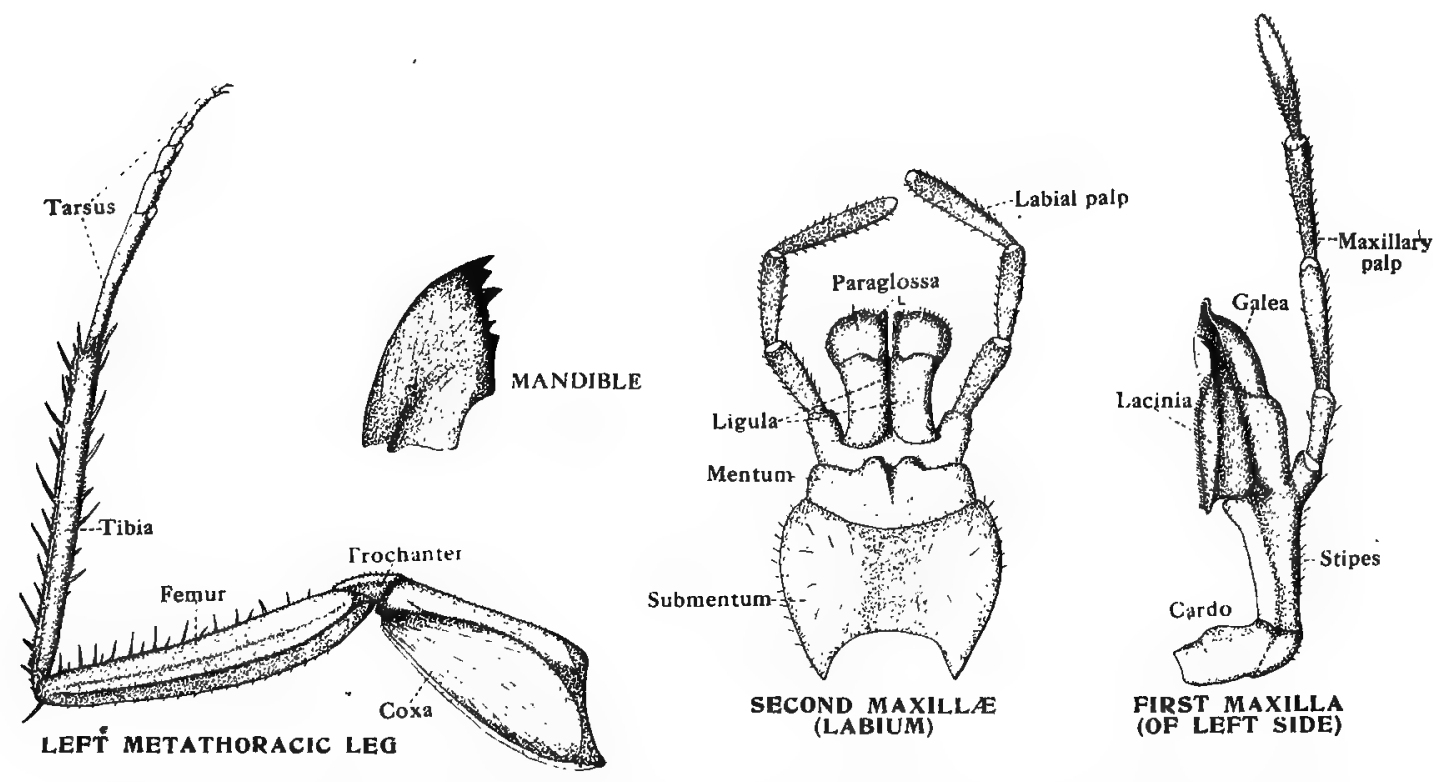

FIG. 26. - Appendages of the Cockroach (Periplaneta americana). The part of the second maxilla marked $L$ is the glossa, which corresponds to the lacinia of the first maxilla.

\section{The Mouth Parts.}

Remove the labrum so as to expose the mandibles. Each mandible is attached by a convex condyle to the lower end of the epicranial plate, and also by a concave anterior articulation to the clypeus. Remove and draw a mandible, noting the strong tooth-like process of chitin.

Situated just behind the mandible of either side is the 1st maxilla. Remove and draw the 1st maxilla, noting its parts :-A basal two-jointed portion consisting of the cardo and the stipes. The cardo is a transverse plate bent upon itself and bearing the stipes. To the side and lower end of the stipes is attached the five-jointed maxillary palp, while the lacinia and galea are articulated to its extremity. The lacinia is internal and posterior to the galea. Its base is broad and it narrows to a bifid tooth of hard chitin. Its inner surface is beset with a cluster of strong setæ.

On the posterior surface of the head, below the occipital foramen, the lower lip or labium is situated. It is formed by the fusion of the basal portions of the 

second maxillæ. It is continuous with the chitinous integument of the neck. Remove and draw the labium, noting its parts :- The broad shield-like base divided by a transverse suture into a large submentum (the fused cardines), and a distal smaller mentum (the fused stipites). To the mentum are attached the free portions of the second maxillx, each consisting of the paraglossa corresponding to the galea, the glossa corresponding to the lacinia, and the three-jointed labial palp. The paraglossæ and glossæ together constitute the ligula.

\section{A Walking Leg.}

Remove and draw the metathoracic leg of the left side, noting its parts :-

(a) The coxa, the broad and flattened basal portion.

(b) The trochanter, a small piece obliquely and almost immovably attached to the proximal end of the femur, on its inner side.

(c) The femur, nearly straight and narrowed at both ends, and with a shallow longitudinal groove, fringed by stiff bristles, 'along its inner border.

(d) The tibia, longer than the femur, and armed with numerous stiff spines directed towards the free end of the limb.

(e) The five-jointed tarsus, the proximal joint being the longest, while the distal joint, the pulvillus, bears a pair of equal and strongly curved claws.

\section{Internal Structure.}

$A$. The Alimentary System, and associated organs.

Cut through the junction of the terga and sterna of the abdomen and the thorax, and completely remove the terga, taking care not to injure the underlying structures. Notice the tubular and chambered heart along the middle line of the body, the diffuse white fatty body, and the silvery air-tubes or tracheæ. Carefully free the alimentary canal from the fatty body and the tracheæ which envelop it, and examine and draw the following parts :-

The mouth opens into the buccal cavity, on the floor of which is a raised fold, the lingua or tongue or hypopharynx. The ducts from a pair of salivary glands with reservoirs open into the buccal cavity, which is continued into the oesophagus. The œsophagus is a very narrow tube, laterally compressed in the neck, but in the thorax it gradually expands into the very long and thin-walled crop, which extends back into the abdomen. The crop is followed by a short conical gizzard or proventriculus, with thick muscular walls, and containing six teeth and six pads with setæ. These aforenamed parts are lined with cuticle and represent the fore-gut or stomodæum. The narrow end of the gizzard leads into the stomach (the mid-gut or mesenteron). The stomach is a simple tube, provided, at its anterior end, with eight hepatic cæca which secrete a digestive fluid; and, at its posterior end, there are six bundles of very fine and long Malpighian tubules, which are the excretory organs. Each bundle comprises ten or more thread-like tubules, so that as many as sixty to seventy tubules may be present. The stomach then leads into the small intestine or ileum, which is followed by the large intestine, represented by the colon and the short rectum, 

which has six long rectal bands on its surface. The ileum, colon and rectum represent the hind-gut or proctodæum. The anus opens beneath the 10th tergum and between the podical plates.

\section{$B$. The Nervous System.}

Remove the epicranial plates of the head so as to expose the brain, which

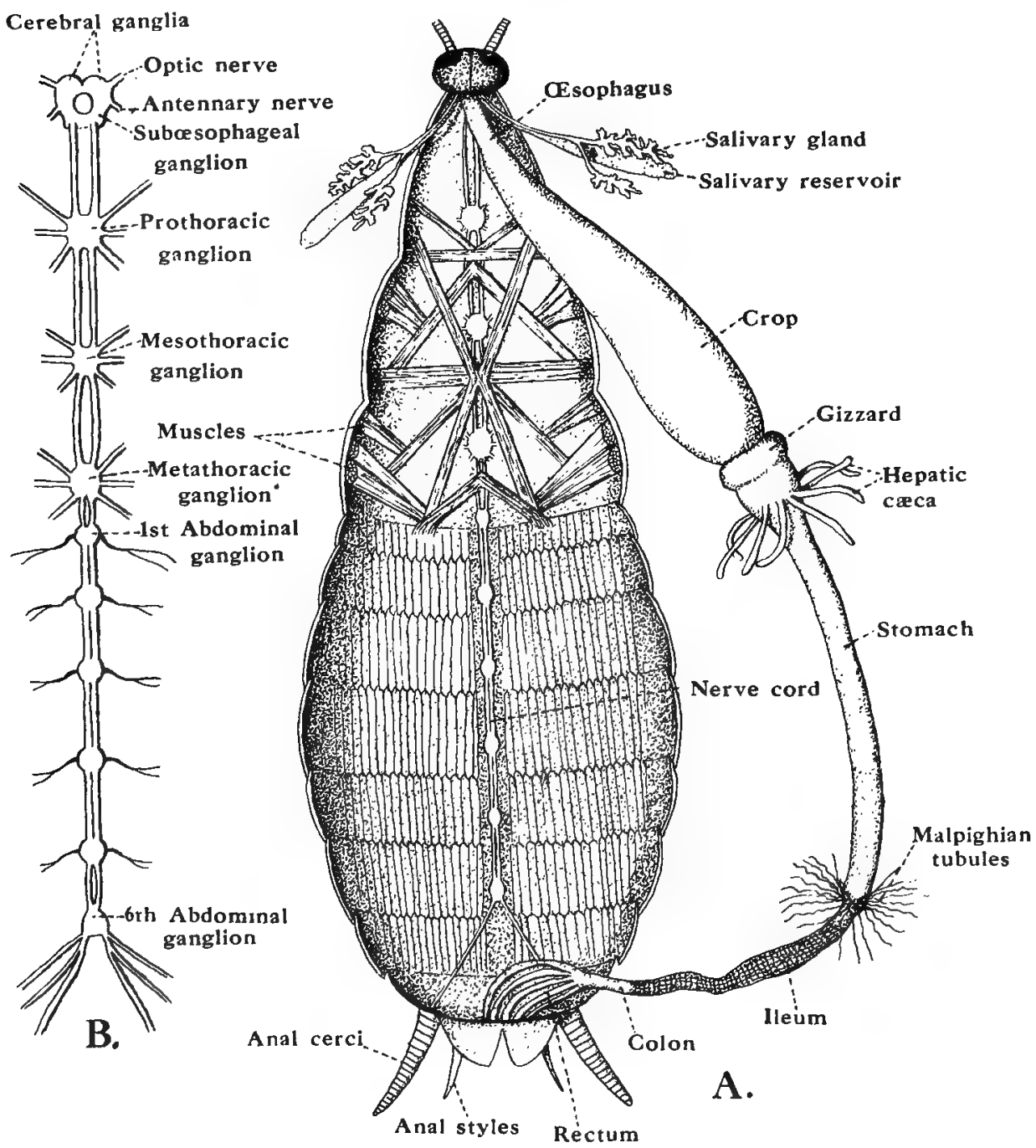

FiG. 27. The Cockroach (Periplaneta americana). A. Dissection of male showing the alimentary system, etc. ; B. Nervous system.

consists of two supra-œsophageal or cerebral ganglia incompletely divided by a deep and narrow median fissure. The optic and antennary nerves are given off to the eyes and the antennæ respectively. The cerebral ganglia are connected by the circum-œsophageal commissures to the sub-œsophageal ganglia lying in the head immediately in front of the submentum. The sub-œsophageal ganglia supply nerves to the mandibles, maxillæ, and labium, and are joined by a long and 

slender pair of connectives (arising from the top of the ganglia) with the first pair of thoracic ganglia lying in the pro-thorax. There is a pair of ganglia in each of the thoracic segments and in each of the first six abdominal segments. A double ventral nerve-chain connects the ganglia; each pair supplies its own segment with nerves, while the sixth abdominal ganglion supplies its own segment and also the posterior segments of the body.

Make a drawing of the nervous system. 



\title{
THE FRESH-WATER CRAYFISH (Astacus) THE CAPE CRAWFISH (Jasus lalandii)
}

\author{
First Day
}

\section{External Features.}

1. Make a drawing of the animal viewed from the dorsal surface to show :

(a) The large carapace or cephalo-thoracic shield covering the whole of the head region and thorax. The carapace is marked off hy grooves into definite areas, which may be named after the organs in the body over which they lie. There is a short transverse groove in the middle of the carapace called the cervical or neck groove, which marks off the head region from the thorax. The part of the carapace, in front of this groove covers the stomach, and may therefore be called (i) the cephalo-gastric region. The part just behind this covers the heart, and may be called (ii) the cardiac or thoracic region. On each side of the body there is a part of the carapace which protects the gills; these gill-covers are called the branchiostegites, and form (iii) the branchial region of "the carapace. The grooves which mark them off from the cardiac region are called the branchio-cardiac grooves. If these grooves are traced forwards it will be seen that each divides into two branches, one passing forward towards the base of the antenna and the other and more distinct one passing to the underside of the body. These two branches enclose a small area of the carapace covering the liver and which is therefore called (iv) the hepatic region.

On the cephalo-gastric region a prominent projection of the carapace in the middle line is seen; this is the rostrum. It has a broad base and ends in front in a sharp spine. It has a smaller spine on each side. [In Jasus the rostrum is small.]

(b) The six abdominal segments, at the end of which is the telson which may represent the 7th abdominal segment. Each has a ring-like form, presenting a broad dorsal region or tergum, a narrow ventral region or sternum, and downwardly directed lateral processes, the pleura.

(c) The stalked eyes, situated at the anterior end of the cephalo-thorax, one on either side of the rostrum.

(d) The following appendages as seen from above :--

(i) The pair of biramous antennules, each with an otocyst, the auditory and balancing organ, on their basal joints. [In Jasus the antennules have each a pair of small terminal flagella. ]

(ii) The pair of antennæ.

(iii) The five pairs of walking legs. The anterior three walking legs of each side end in a pincer-like claw. The first walking leg (the cheliped) is much stouter than any of the others, its claw 

being very large. [In Jasus this clave is absent, but in the female the posterior walking leg of each side bears a small claw or chela.] (iv) The large fan-shaped appendages or uropods of the 6th abdominal segment which, together with the telson, form the tail.

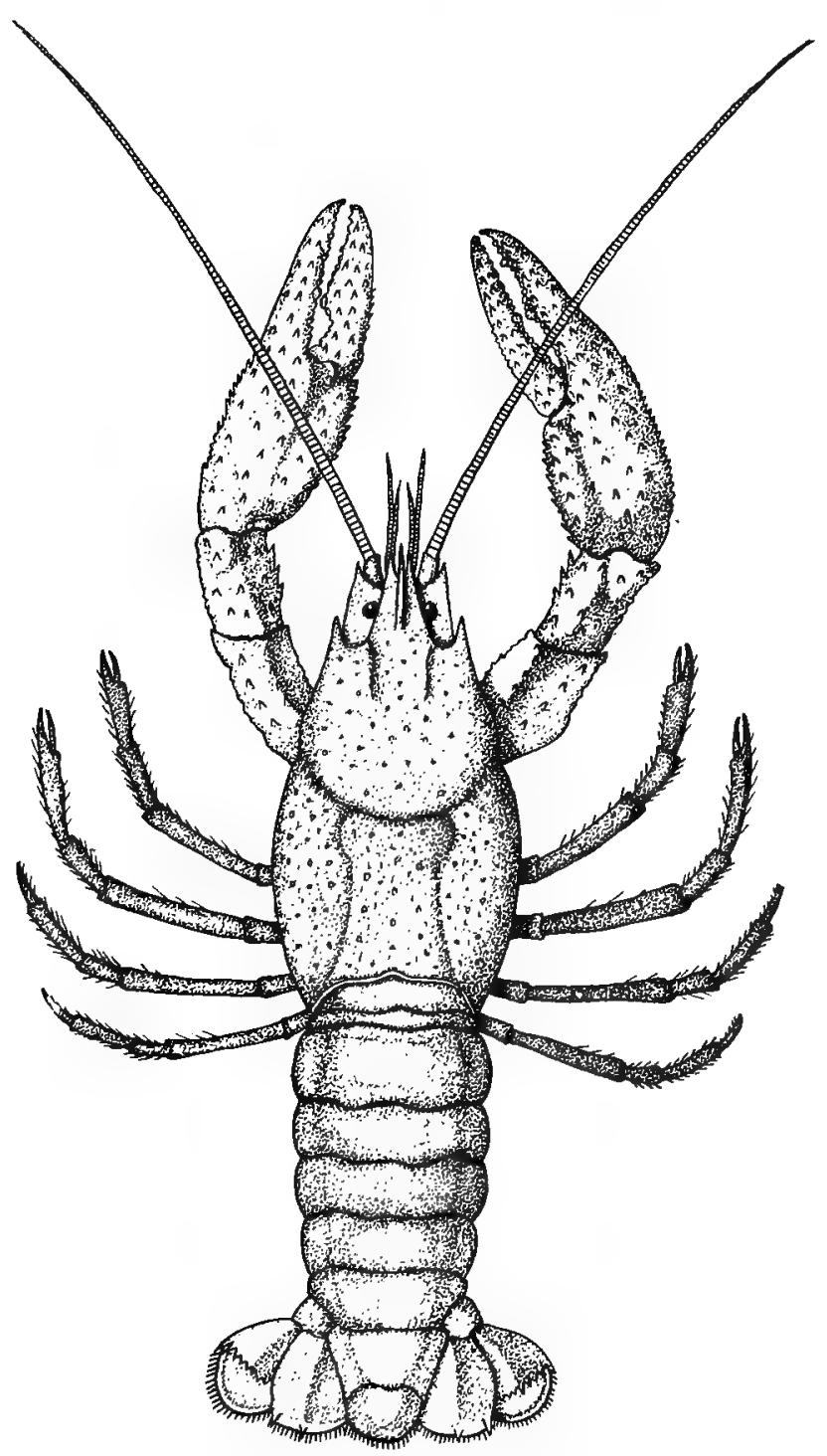

FIe. 28. -The European Fresh-water Craytish (Astacus).

2. Examine the specimen from the ventral surface and note :-

(a) The opening of the "green gland" or nephridium at the base of each antenna.

(b) The appendages of the head and the first three pairs of thoracic appendages crowded together. 



\section{THE FRESH-WATER CRAYFISH-THE CAPE CRAWFISH}

(c) The five pairs of walking legs. In the male there is a genital aperture at the base of the fifth leg of each side. In the female the genital apertures occur at the bases of the third legs.

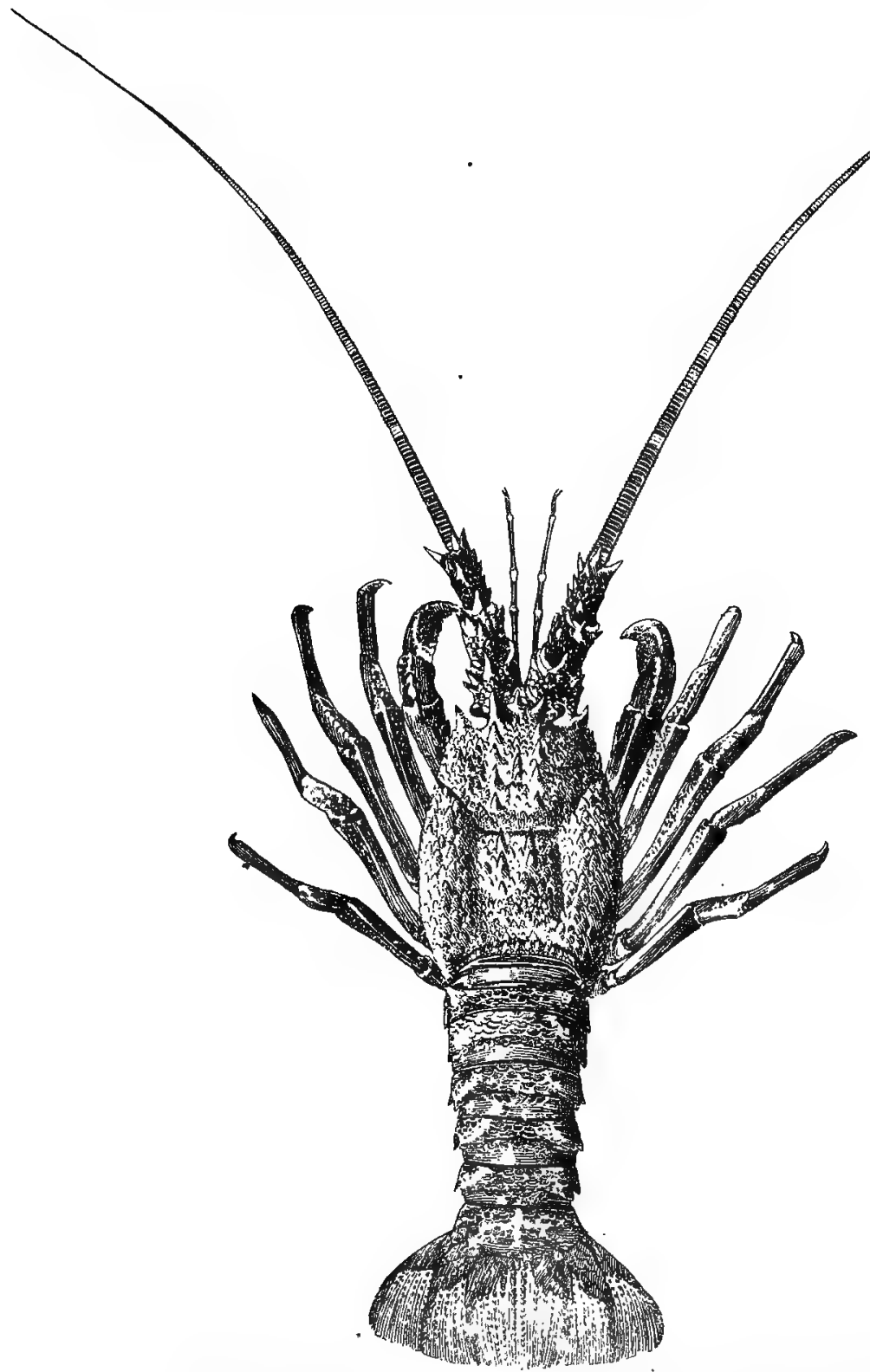

Fri. 29. - The Cape Crawfish or Kreeft (Jasus lalandii). Greatly reduced.

(d) The appendages of the abdomen. These are attached to the hinder side of the sternum near its outer ends, and the part of the sternum between each appendage and the adjoining pleuron is called an epimeron. 



\section{THE FRESH-WATER CRAYFISH-THE CAPE CRAWFISH}

(e) The telson.

(f) The anus, situated on the ventral surface of the telson.

\section{The Respiratory System.}

Cut along the branchio-cardiac groove of the left side with a pair of scissors, and remove the branchiostegite so as to expose the branchial chamber with the gills. The gills are soft and feathery vascular outgrowths. The stem of each gill contains two longitudinal vessels (afferent and efferent), with which the numerous hollow thin-walled filaments are connected. The gills receive differ ent names according to their positions, and are thus divided into three sets :

(a) The podobranchs, attached with the epipodites to the basal segment of each thoracic appendage except the first maxillipedes and the fifth walking legs. The epipodites are thin leaf-like plates directed upwards and lying in the gill cavity between the thoracic wall and the branchiostegite.

(b) The arthrobranchs, attached to the membrane connecting the thoracic appendages with the trunk. They are usually in pairs, and are separated from the podobranchs by the epipodites.

(c) The pleurobranchs, attached to the inner wall of the branchial chamber above the attachments of the appendages.

The number and arrangement of the gills in Astacus is as follows :-

\begin{tabular}{|c|c|c|c|c|}
\hline \multicolumn{2}{|c|}{ Appendage } & Podobranch & Arthrobranch & Pleurobranch \\
\hline $\begin{array}{l}\text { Second maxilla } \\
\text { First maxilliped } \\
\text { Second maxilliped } \\
\text { Third maxilliped } \\
\text { First walking leg or } \\
\text { Second walking leg } \\
\text { Third walking leg } \\
\text { Fourth walking leg } \\
\text { Fifth walking leg }\end{array}$ & $\begin{array}{c}: \\
: \\
\text { cheliped } \\
: \quad: \\
: \\
:\end{array}$ & $\begin{array}{r}0 \\
\text { ep } \\
1+\mathrm{ep} \\
1+\mathrm{ep} \\
1+\mathrm{ep} \\
1+\mathrm{ep} \\
1+\mathrm{ep} \\
1+\mathrm{ep} \\
0\end{array}$ & $\begin{array}{l}0 \\
0 \\
1 \\
2 \\
2 \\
2 \\
2 \\
2 \\
0\end{array}$ & $\begin{array}{l}0 \\
0 \\
0 \\
0 \\
0 \\
0(1) \\
\mathrm{r}(1) \\
\mathrm{r}(1) \\
1\end{array}$ \\
\hline & Tote & 6 & 11 & $1+2 \mathbf{r}(4)$ \\
\hline
\end{tabular}

ep, signifies an epipodite. $r$, signifies a rudimentary gill.

The figures in brackets show the differences in the gill formula between Astacus and Jasus, which has four pleurobranchs.

N.B.--The Norway lobster (Nephrops) has five podobranchs and a rudiment (on second maxilliped), eleven arthrobranchs, and four pleurobranchs.

\section{The Appendages.}

Remove the appendages from the left side of the animal, commencing with the uropods and working forwards to the head. Lay them out in the order in which they were removed:-

A. The Five Abdominal Appendages of the Left Side.

There are appendages on all the abdominal segments except the telson. [In. Jasus there are no appendages on the first and the last segments.] 

(a) The uropod is attached to the side of the 6th abdominal segment. A - uropod consists of a basal segment or protopodite, which is very broad
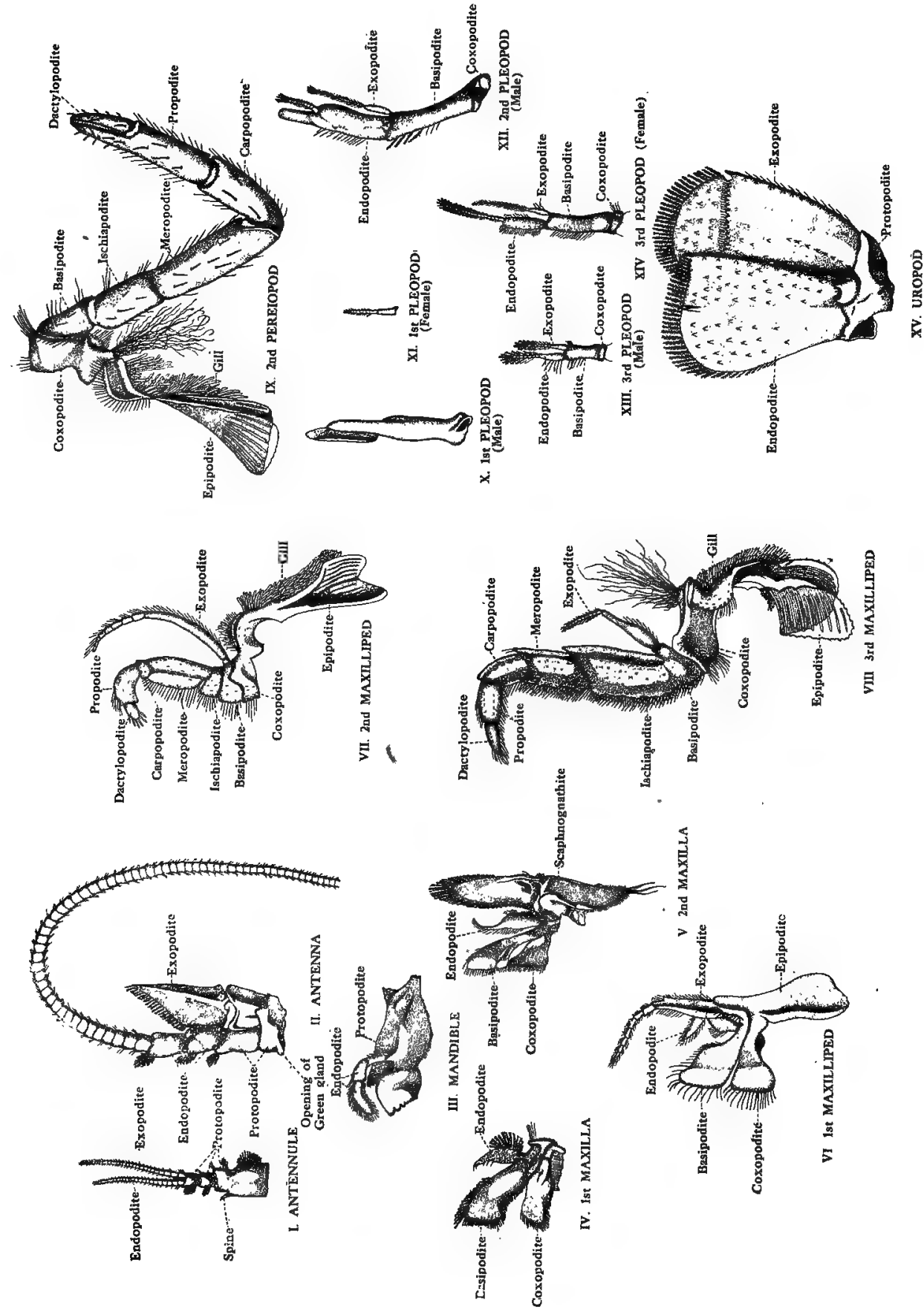

尊

and thick and not divided into two joints, and which bears a broad flattened outer branch or exopodite, and a similarly shaped inner 



\section{THE FRESH-WATER CRAYFISH-THE CAPE CRAWFISH}

branch or endopodite. The two uropods, together with the median telson, form the five-lobed tail, the swimming paddle.

(b) The pleopods are attached on each side of the 1st to 5th segments.

In the female the first pleopod is more or less vestigial. In the male the first and second pleopods form incomplete tubes and act as copulatory organs. The coxopodite is present, but there is no exopodite and the basipodite appears fused with the endopodite. A typical pleopod--e.g., the second-consists of a basal segment or protopodite, composed of coxopodite and basipodite, bearing an endopodite whose proximal joint is enlarged and an exopodite in the form of a jointed rod.

[In Jasus the pleopods are attached to the second, third, fourth, and fifth segments. In the female the first pleopod is composed of a single basal protopodite bearing an endopodite and an exopodite which are equally developed. The second, third, and fourth have the endopodite in the form of a rod. In the male the endopodite is absent, all the pleopods being similar.]

Draw a uropod, and the first and third pleopods.

$B$. The Eight Thoracic Appendages of the Left Side.

These are divided into the five walking legs and the three maxillipeds.

(a) The walking legs or pereiopods are attached to the side of the thoracic region.

Each leg is composed of a basal two-jointed protopodite (the coxopodite and the basipodite) and a five-jointed endopodite (the ischiopodite, meropodite, carpopodite, propodite, and dactylopodite). There is no exopodite. A podobranch and an epipodite are attached to the coxopodite of the first four walking legs of each side. The first pereiopod of each side ends in a large pincer-like claw or chela, formed by the dactylopodite working against a prolongation of the propodite, and is therefore called the cheliped.

In the second and third pereiopods of each side there is also a claw present, but it is much smaller than that of the first walking leg. Note the genital apertures.

[In Jasus the chela is usually present on the last pair of pereiopods in the female.]

(b) The Maxillipeds.

(i) The third maxilliped is attached just anterior to the first walking leg. It is composed of a basal two-jointed protopodite (the coxopodite and the basipodite) bearing a five-jointed endopodite (the ischiopodite, meropodite, carpopodite, propodite, and dactylopodite) and a smaller exopodite ending in a feeler-like flagellum. A podobranch and an epipodite are attached to the coxopodite.

(ii) The second maxilliped resembles the third, but is smaller. [In Jasus the endopodite is only four-jointed, the ischiopodite and meropodite having fused together.]

(iii) The first maxilliped differs from the other two. The coxopodite and basipodite are broad thin plates, while the endopodite is short and only two-jointed. The unjointed portion of the exopodite is long. An epipodite is present, but it has no gill. [In Jasus the endopodite is only single-jointed.] 

Draw the third and first walking legs, and the third, second, and first maxillipeds.
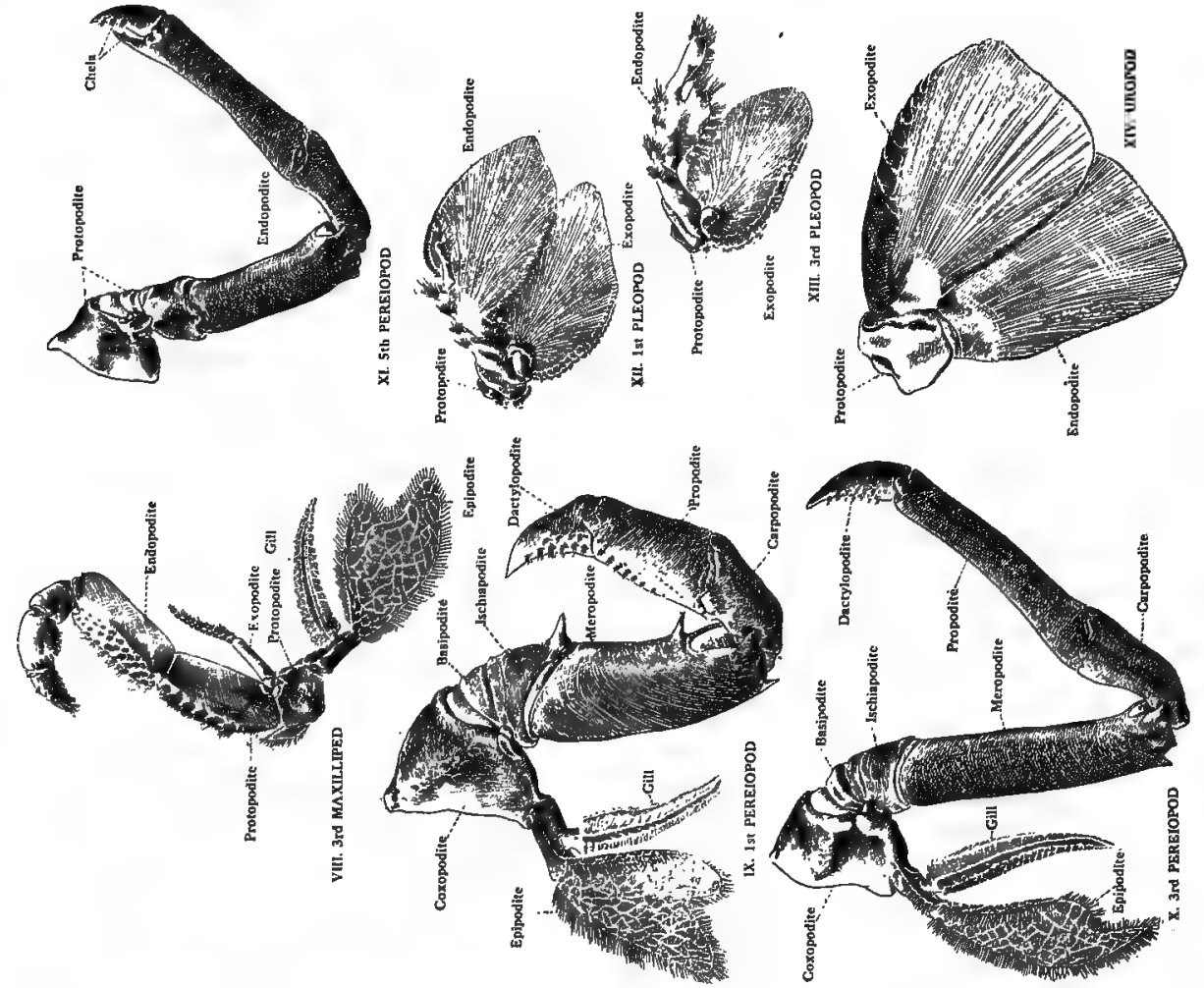

ه્ّ

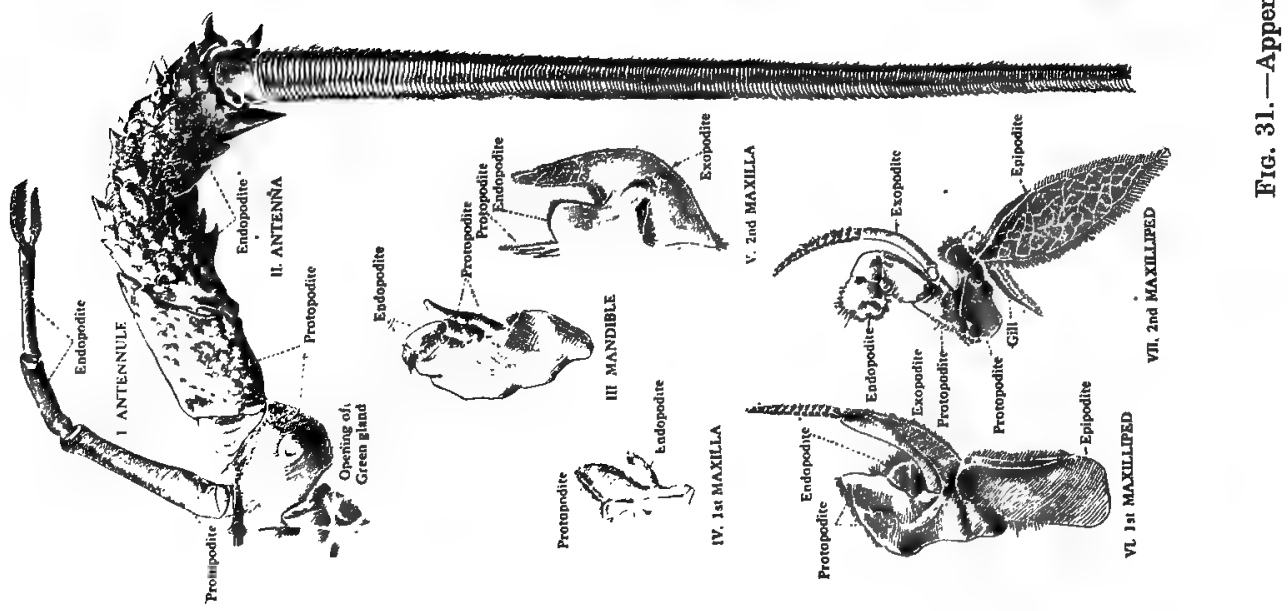

C. The Five Head Appendages of the Left Side.

These are modified chiefly into sensory and oral organs.

(a) The second maxilla is situated in front of the first maxilliped but towards the side of the body. The protopodite consists of two thin lamellar plates (coxopodite and basipodite) subdivided by deep fissures. The 

endopodite is very small, and the exopodite is fused with the epipodite to form the scaphognathite or baler. The function of the baler is respiratory; it causes a constant forward current of water in the gill chamber. [In Jasus the protopodite has three pointed prolongations and is very small.]

(b) The first maxilla consists of three leaf-like parts, the basal two being the protopodite, while the single distal one is the endopodite. The exopodite is absent.

(c) The mandible consists of a strong and transversely elongated protopodite, bearing a three-jointed palp, which is the endopodite. [In Jasus the basal joint of the palp is regarded as the protopodite, and the remaining joints as the endopodite.]

(d) The antenna has a two-jointed protopodite. The basal joint is small, and on its ventral face is the opening of the "green gland." The upper joint is larger and externally it bears a broad flat exopodite or squame, while internally the feeler, the elongated endopodite, is attached to it by two stout basal joints. [In Jasus there is no exopodite, and the basal joint of the protopodite is fused to the body.]

(e) The antennule has a three-jointed base (the protopodite) and two terminal flagella representing the exopodite and the endopodite. [In Jasus the protopodite is two-jointed, the endopodite is a single two-jointed rod terminating in two small flagella, and the exopodite is absent.]

Draw the above appendages.

\section{Second Day}

\section{Internal Structure.}

Cut along the branchio-cardiac groove of each side with a pair of scissors from behind forwards and remove the branchiostegites of each side. Carefully raise the central part of the carapace from behind, separate it from the underlying integument, and then remove it completely by severing it just behind the rostrum. Cut through the tergal or dorsal portions of the abdominal segments on both sides and remove them. Remove the brightly pigmented tissue which lines the inside of the carapace, so as to expose the internal organs.

Note the following structures:---

(a) The dorsal extensor muscles, paired longitudinal bands along the dorsal region of the abdomen and inserted into the front of each segment.

(b) The large abdominal flexor muscles, occupying the ventral region of the abdomen, and arising from the endophragmal skeleton.

(c) The dorsal extensor muscles, arising from the sides of the thorax.

(d) The "stomach" or gizzard, situated in the anterior region of the cephalo-thorax. Notice the two pairs of muscles, arising from the body-wall, which work the gizzard.

(e) The adductor muscles, working the mandibles, situated on either side of the posterior end of the gizzard. 

$(f)$ The digestive glands or "liver," a yellowish bilobed mass of coiled tubes, lying in the thorax on each side of the alimentary canal.

(g) The long and straight intestine, along the mid-dorsal line of the body, and between the extensor and flexor muscles in the abdomen.

(h) The gonad (testis in male or ovary in the female), portions of it on each side of the intestine. Note the long and coiled vasa deferentia (or short oviducts in the female).

(i) The heart lying within the pericardium in the dorsal region of the thorax.

(j) The median ophthalmic, antennary, hepatic, and superior abdominal arteries.

$A$. The Vascular System (part).

Examine the heart and note that it has three pairs of apertures or ostiaa pair on the dorsal surface, a pair on the ventral surface, and a pair placed laterally. [In Jasus there are troo pairs of ostia placed dorsally.] The heart is attached to the walls of the pericardial sinus or pericardium by strands of connective tissue. From the anterior end of the heart the following vessels arise :-

(a) The single median ophthalmic artery, which passes over the gizzard and then branches into two ophthalmic arteries, one to each eye.

(b) The pair of antennary arteries, one passing over the "liver" on each side and supplying the antennæ.

(c) The pair of hepatic arteries arising one on either side of the heart between the ophthalmic and antennary artery, and passing down into the substance of the "liverr."

From the posterior end of the heart there arises the superior abdominal artery, which passes backwards on the dorsal surface of the intestine to the tail region. It supplies each segment of the abdomen by a pair of smaller arteries. Just posterior to the heart the superior abdominal artery gives rise to a sternal artery, which passes vertically downwards to the ventral region of the cephalothorax. Sever this artery at its origin, and lay it aside for further examination.

$\boldsymbol{B}$. The Alimentary System.

The mouth is an elongated opening below the head. It is bounded in front by a wide upper lip or labrum, on the sides by the mandibles, and behind by the paragnatha, which resembles the first maxilla. A short wide gullet leads upwards and forwards from the mouth to the large stomach or gizzard, which is divided into two portions, the anterior cardiac chamber or gastric mill and the smaller posterior pyloric chamber. From this the short mid-gut or mesenteron, which has a dorsal pouch or cæcum, leads into the long intestine, which ends at the anus situated beneath the telson. The gullet and gizzard represent the fore-gut or stomodæum ; and the intestine is the hind-gut or proctodæum.

Note the large "liver," which consists of two digestive glands, a big yellowish mass of tubules, lying on each side of the pyloric stomach. Ducts from the tubules unite into an hepatic duct opening into the mesenteron on each side.

Cut through the gullet or oesophagus and the intestine (near the anus), and carefully remove the alimentary canal with the attached "liver." Remove the "liver" on the left side, and make a side-view sketch of the alimentary canal.

Remove the stomach or gizzard and open it along the ventral wall. Note 



\section{THE FRESH-WATER CRAYFISH-THE CAPE CRAWFISH}

the internal structure. The gastric mill contains ossicles and teeth, and in the pyloric portion there is a sieve of fine hairs.

C. The Reproductive System.

In the Female note :-

(a) The ovary (when ripe) is a $\mathrm{Y}$-shaped organ, consisting of two anterior lobes and a posterior lobe. [In Jasus the ovaries are a pair of long reddish organs, lying on either side of the alimentary canal, and united by a median transverse bridge.]

(b) The oviducts, a pair of short straight tubes, one leading from each lobe to open at the genital aperture on the third walking leg.

In the Male note :-

(a) The testis, which is three-lobed. like the ovary, and similarly situated. [In Jasus the testes are a pair of elongate rohite organs, connected together like the ovaries, and in a similar position.]

(b) The vasa deferentia, a pair of thick, coiled, white tubes, each given off at the junction of the three lobes, and opening to the exterior at the genital aperture on the last walking leg.

Make a complete drawing showing the vascular, alimentary, reproductive and muscular systems. Remove, and draw, the gonad (male or female) with its ducts.

D. The Skeletal System.

Remove all the muscles from the cephalo-thorax and the abdomen so as to expose the internal skeleton, taking care not to break the sternal artery. The ventral and lateral regions of the thoracic exoskeleton are produced into the interior of the body in the form of a segmental series of calcified plates, so arranged as to form a row of lateral chambers in which lie the muscles of the limbs, and a median tunnel-like passage or sternal canal, containing the thoracic portion of the nervous system. This entire endophragmal system, as the series of plates is called, constitutes a kind of internal skeleton.

$\boldsymbol{E}$. The Nervous System.

Expose the nerve cord in the abdominal region and trace it forwards. In this region note the six abdominal ganglia on the nerve cord. The sixth ganglion is the largest and represents the ganglion of the 6th abdominal segment and that of the telson fused together. The pairs of ganglia are fused, and the double nerve cord is fused in the abdominal region. In the cephalothorax the paired nerve cord lies in the sternal canal of the endophragmal skeleton. In order to expose it, cut through the sternal canal on each side and remove the roof. Note the sub-œsophageal ganglion, a fused mass consisting of the three posterior cephalic and the three anterior thoracic ganglia. Leading from the subosophageal ganglion, on each side of the œsophagus, is the circum-œsophageal commissure connecting it with the supra-oesophageal ganglion situated at the base of the antennules. This ganglion sends nerves to the eyes, antennules and antennæ. The sub-œsophageal ganglion supplies the mandibles, maxillæ, and the first and second maxillipeds. In each remaining segment of the cephalothorax is an indistinctly-double ganglion sending nerves to the third maxillipeds 



\section{THE FRESH-WATER CRAYFISH-THE CAPE CRAWFISH}

and the walking legs. The ganglia are connected by a double nerve cord. There are six pairs of free thoracic ganglia, each pair being incompletely fused. Between the fourth and fifth thoracic ganglia the double nerve cord is separated to form a loop through which the sternal artery passes.

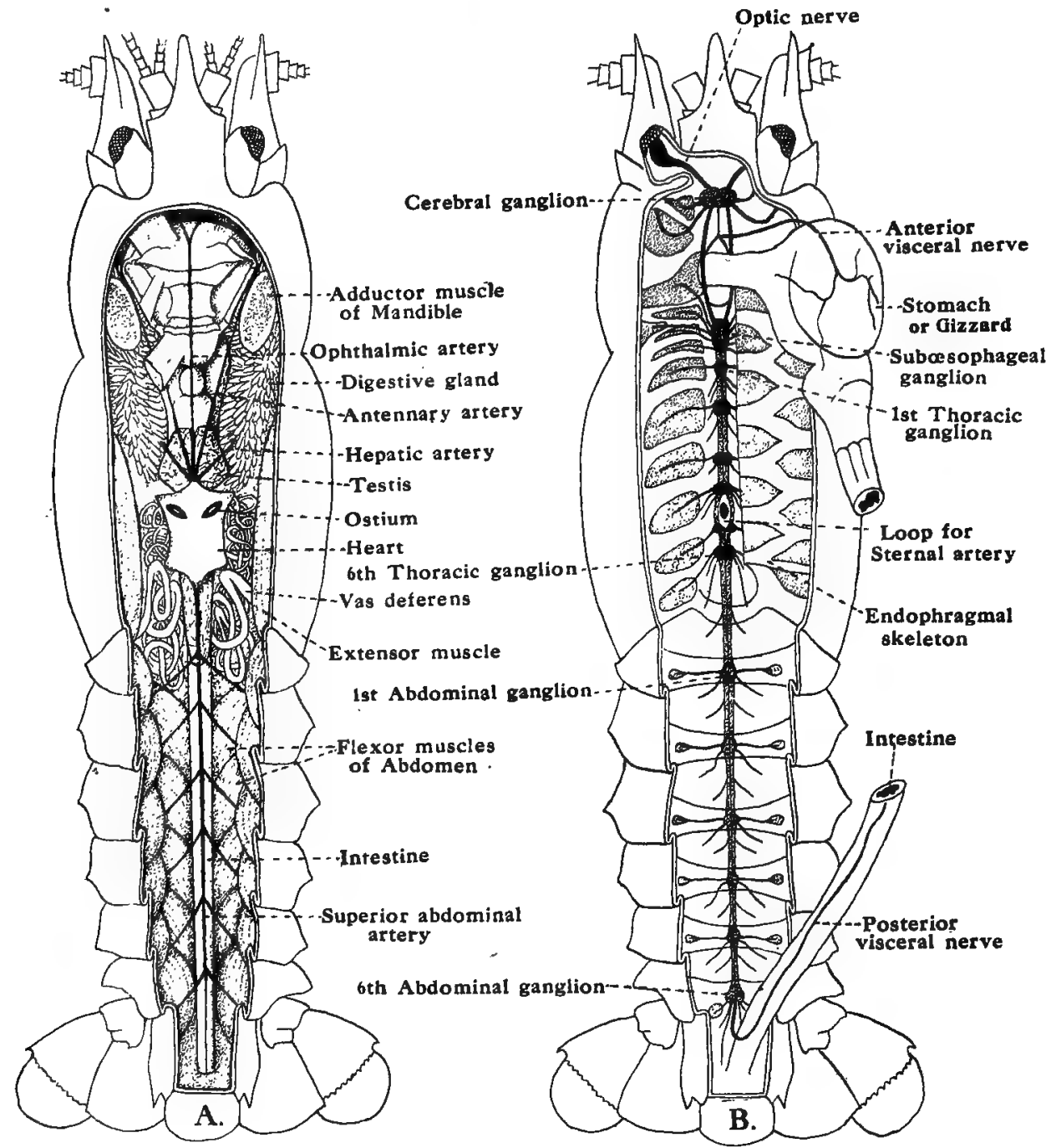

FIG. 32. -The Fresh-water Crayfish (Astacus). A. Dissection of a male showing the general structure ; $B$. the nervous system.

Note the transverse post-osophageal commissure immediately behind the osophagus and joining the two circum-œsophageal commissures. From the supra-œesophageal ganglion a visceral nerve passes backwards to supply the stomach, while from the last abdominal ganglion there arises a posterior visceral nerve supplying the intestine.

[In Jasus there are five pairs of free thoracic ganglia, and the loop for the sternal artery occurs between the third and fourth pairs.] 



\section{THE FRESH-WATER CRAYFISH-THE CAPE CRAWFISH}

$\boldsymbol{F}$. The Vascular System (continued).

Trace the sternal artery through the aperture in the nerve cord; and note that it divides ventrally into the ventral thoracic artery and the inferior

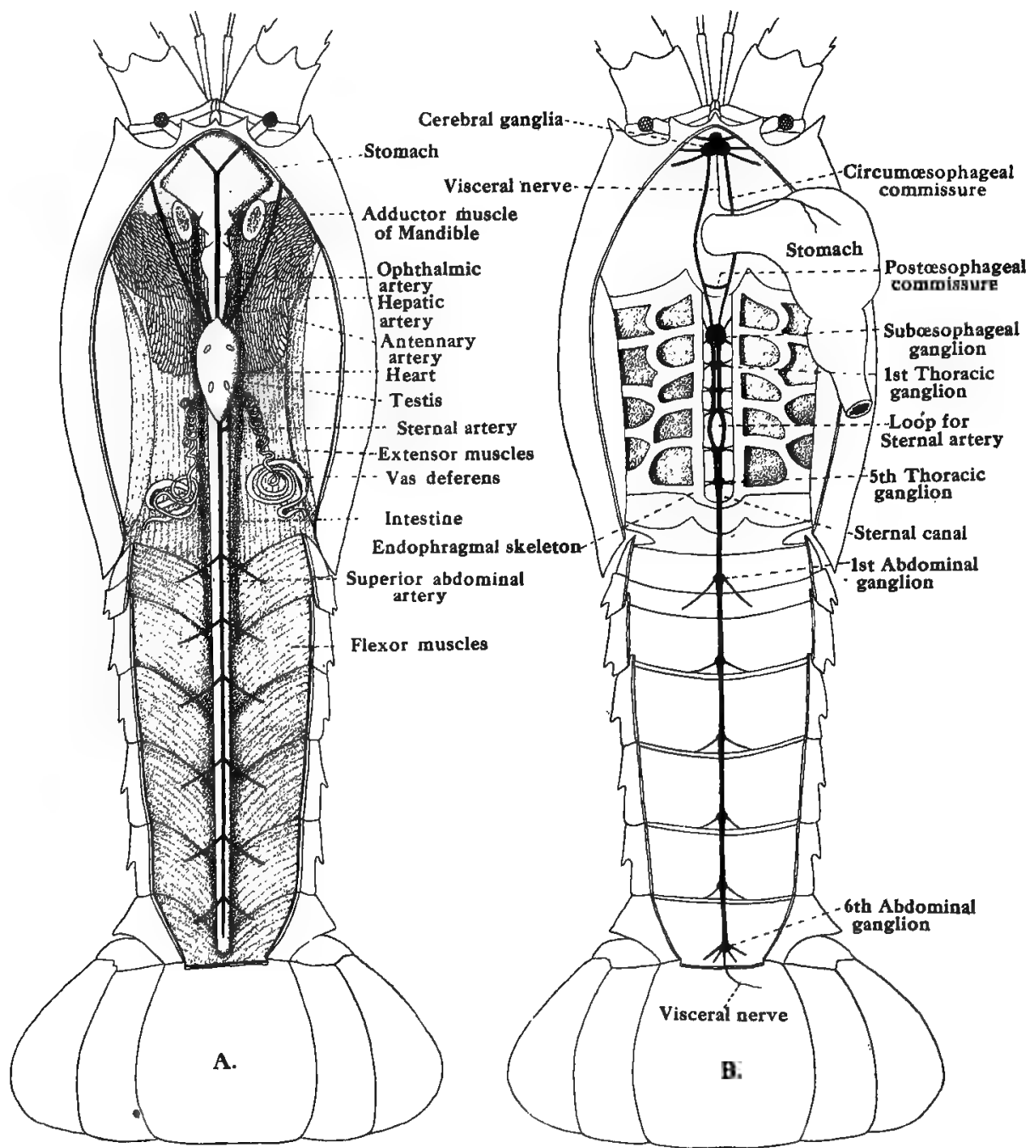

FIG. 33. - The Cape Crawfish (Jasus). A. Dissection of a male showing the general structure; B. the nervous system.

abdominal artery-vessels which run in close connection with the nerve cord and which supply the limbs and other organs of the body.

\section{Examination of a Larval Form (Phyllosoma).}

Examine under the microscope, or with a lens, a larval form (Phyllosoma) of the Crawfish. Note and draw :--

(a) The large head region, distinct from the thoracic region, and the very small abdominal region. 



\section{THE FRESH-WATER CRAYFISH-THE CAPE CRAWFISH}

(b) The two well-developed eyes, and a median eye spot.

(c) The antennules.

(d) The antennæ, with an exopodite and an endopodite branch.

(e) The third maxilliped.

(f) The first and second walking legs, with well-developed feather-like exopodites.

(g) The long third pair of walking legs, with the rudiment of the exopodite on the first segment of the limb. The fourth and fifth walking legs and the appendages of the abdomen have not yet appeared.

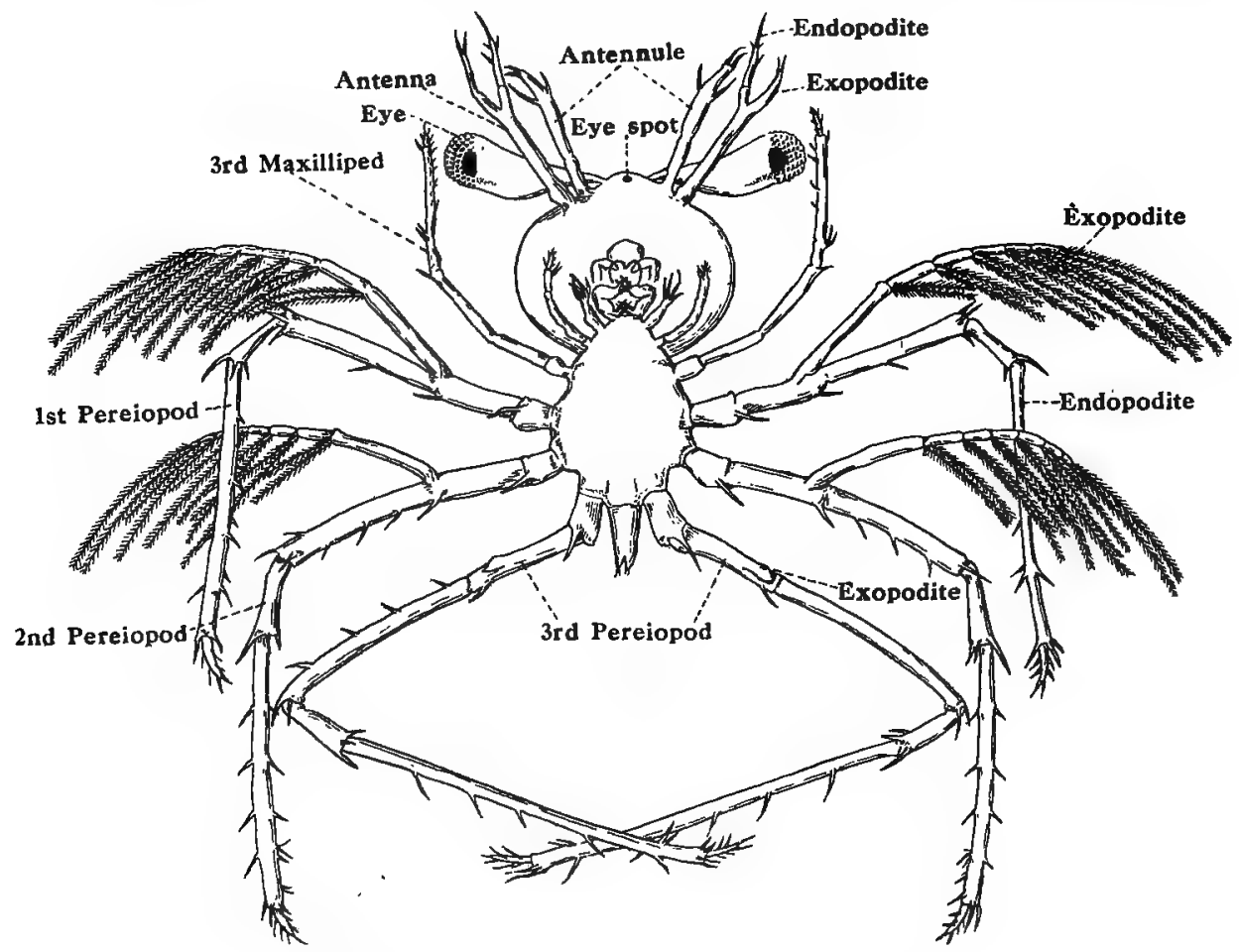

Frr. 34.-Phyllosoma larva of the Crawfish. Enlarged. 



\section{THE SNAIL (Helix aspersa)}

\section{External Features.}

1. Make a drawing of the Snail, viewed from the right side, to show :

(a) The univalve spirally coiled shell (a right-handed conical spiral) within which is the twisted visceral hump containing the chief internal organs. Round the mouth of the shell is the collar, the thickened edge of the mantle.

(b) The head, with two pairs of tentacles and the mouth. The mouth is situated ventrally at the anterior end of the head. The tentacles are retractile; the upper and larger pair have eyes at their tips, the lower and smaller pair arise in front of the larger ones.

(c) The large muscular foot, constituting the organ of locomotion, on which the animal glides. It is the flattened ventral part of the body-wall.

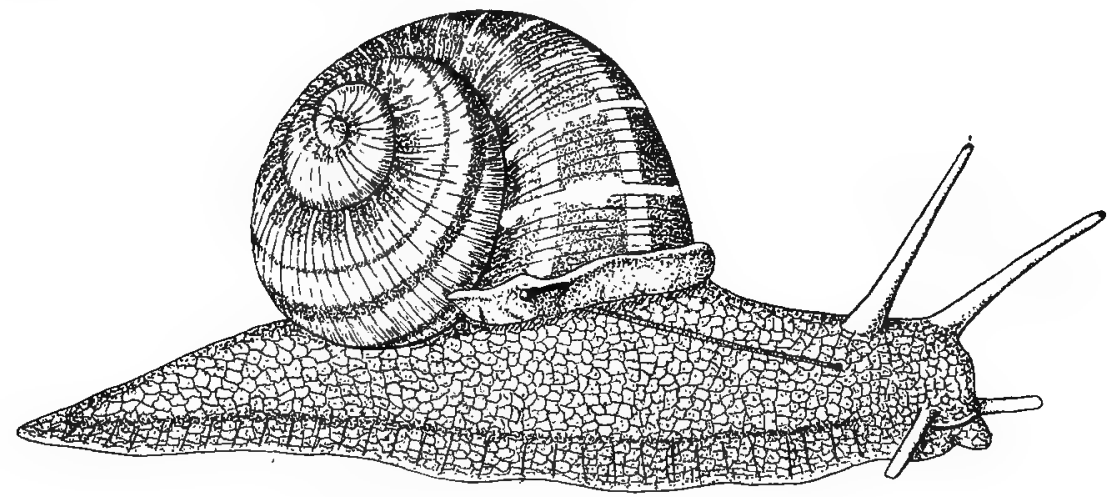

Frg. 35. -The Snail (Helix aspersa). $\times 1 \frac{1}{2}$.

(d) The opening of the slime or pedal gland, below the mouth.

(e) The genital aperture, situated at the end of a groove along the right side, just below and behind the right large tentacle.

$(f)$ The pulmonary or respiratory aperture, situated on the right side in the deep notch of the collar. The anus opens beside the pulmonary aperture.

2. Carefully break and detach the shell. Insert a seeker through the pulmonary aperture and determine the extent of the pulmonary chamber.

Fix the Snail down in water by pinning it through the edge of the foot. Make a dorsal-view sketch showing:

(a) The mantle, which forms the roof of the pulmonary. chamber and on the underside of which the pulmonary veins are spread out. The mantle secretes the shell.

(b) The collar, which is formed by the thickening of the edge of the mantle. 

(c) T'he heart, which may be seen from the outside through the mantle. It is situated in the pericardium at the back of the mantle, on the left side; and it has two chambers, an auricle and a ventricle. The main pulmonary vein leads into the auricle of the heart.

(a) The triangular-shaped kidney lying beside the heart.

(e) The spirally-coiled visceral region, mainly composed of the brown liver or bilobed digestive gland.

(f) The albumen gland, embedded in the liver on the right side.

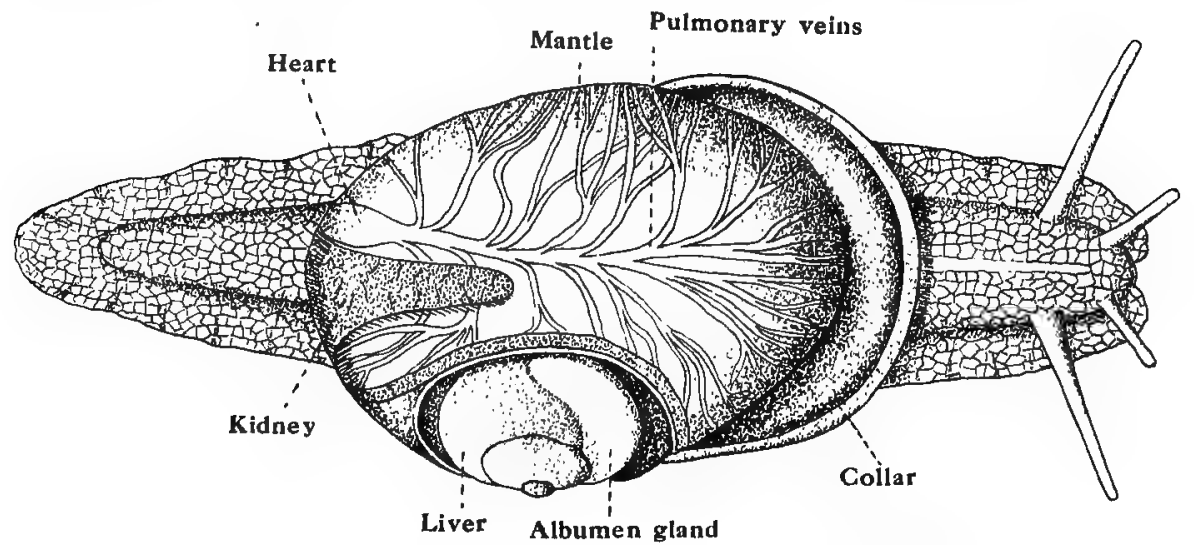

FI(i. 36. - The Snail (He/ix). Dorsal view after removal of the shell.

(g) The columellar muscle, along the inner side of the spiral. It is attached to the columella of the shell, and it enables the snail to withdraw inside the shell.

\section{Internal Structure.}

1. Insert the point of your scissors into the pulmonary aperture, and open the pulmonary cavity by cutting round under the base of the collar towards the left-hand side backwards as far as the heart, taking care not to cut through the floor of the mantle-cavity. Pin the mantle over towards the right-hand side.

Examine the mantle and note :

(a) The heart, consisting of a thin-walled auricle and a muscular pearshaped ventricle, enclosed in the pericardium.

(b) The pulmonary vein, branching over the mantle and leading into the auricle.

(c) The triangular-shaped kidney lying next to the heart.

(d) The ureter, passing from the kidney and extending along and above the rectum, which opens at the anus situated in the pulmonary aperture. The opening of the ureter is above the anus.

(e) The reno-pericardial canal or nephrostome, a narrow ciliated passage between the kidney and the pericardium. Its pericardial opening is opposite the ventricle.

2. Cut through the collar in the middle line and continue the incision backwards up the spiral and forwards to the region between the large tentacles. 

Pin out the collar on each side so as to expose the following internal organs :-

$A$. The Alimentary System.

The mouth leads into a swollen pharynx or buccal mass, the ventral floor of which bears the rasping organ or odontophore. (See page 124, Section D.) The pharynx is succeeded by a short gullet or œesophagus, which passes into a large thin-walled crop. On each side of the crop lies a large salivary gland

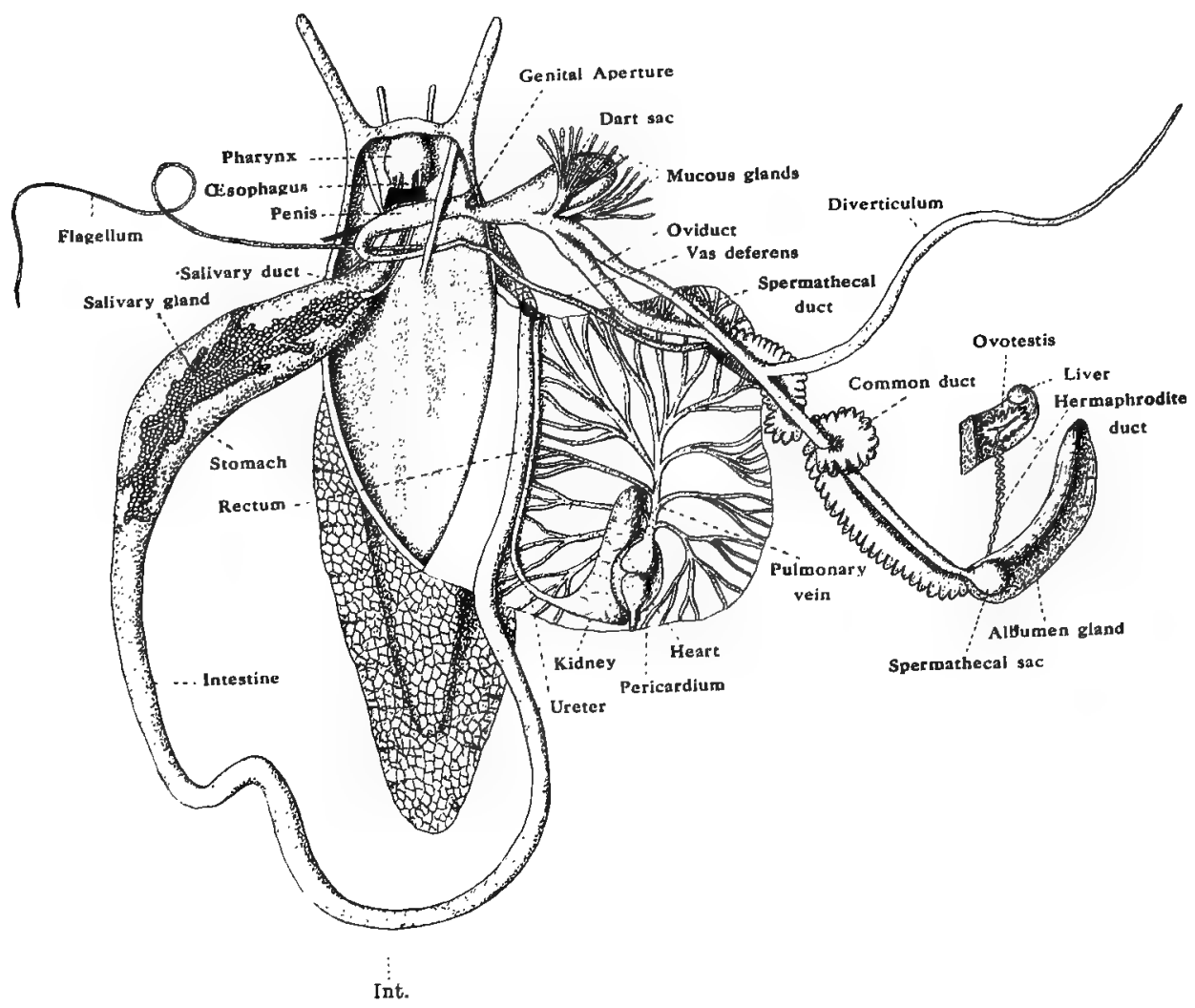

FIa. 37. -Dissection of the Snail (Helix), showing the alimentary and reproductive systems.

For "Stomach" read "Crop," and for "Intestine" read "Stomach." Int. indicates the Intestine.

which sends a duct to open into the pharynx. The salivary glands are joined together at their middle by means of a bridge of tissue. Following the crop is the stomach, a somewhat dilated loop into which the ducts from the liver or digestive gland open. Continuing from the stomach is the long intestine, which coils throughout the substance of the liver and passes forward as ithe rectum, opening to the outside at the anus, as already noted.

$B$. The Reproductive System.

Insert a pin into the large muscular dart sac, and pin it out on the right side of the animal. Put a pin through the loop of the vas deferens, and pin it out on the left side. Note the common duct, a much convoluted tube composed of a 

sacculated female or oviducal and a much narrower male or spermaducal channel. Passing long the top of the common duct is the finer spermathecal duct, which gives off a long coiled diverticulum and is continued on to the base of the albumen gland, where it ends in a swollen sac, the spermatheca or receptaculum seminis. Note the sinuous hermaphrodite duct from the hermaphrodite gland or ovotestis, a yellowish body which lies embedded in the second coil of the liver. The hermaphrodite duct leads into the base of the tongueshaped albumen gland, where the common duct arises. Trace the common duct forward and note that its male and female portions separate off as a vas deferens and an oviduct. The oviduct is short and thick; it leads into the muscular vagina, into which the spermathecal duct, the dart sac, and a pair of tufted mucous glands open. The vagina opens to the exterior, along with the penis, by the common genital aperture. Trace the vas deferens forward from its point of origin and note that it passes into a muscular penis provided with a long flagellum and a retractor muscle. The penis is protrusible and opens at the common genital aperture.

Make a drawing showing the alimentary and reproductive systems.

C. The Nervous System.

Cut through the oesophagus, just behind the buccal mass, and remove the alimentary tract. Pull the buccal mass forward and pin it down.

The supra-cesophageal or cerebral ganglia are incompletely fused and lie over the œsophagus. From each ganglion the following nerves pass off :-

(a) The buccal nerve, which enlarges to form a buccal ganglion situated on the posterior surface of the pharynx on each side of the osophagus. The buccal ganglia are connected by a transverse commissure passing under the oesophagus.

(b) The internal labial nerve.

(c) The external labial nerve.

(d) The facial nerve.

(e) A nerve running next to the facial and supplying the anterior body-wall.

(f) The optic nerve to the eye tentacle.

(g) A nerve passing to the otocyst which lies embedded in the pedal ganglion.

The right cerebral ganglion also gives off a nerve, the penial, supplying the penis.

Passing round the œsophagus and connecting the cerebral ganglia to the subœesophageal mass is a pair of commissures. The sub-œsophageal mass consists of the fused pleural, pedal, and visceral ganglia. The cerebro-pleural commissure connects the cerebral to the pleural ganglia, and the cerebro-pedal commissure connects the cerebral and pedal ganglia. The pedal ganglia give rise to pedal nerves supplying the foot. The visceral ganglia give rise to a left pallial nerve, a median pallial nerve, and a right pallial nerve (passing over the common duct) to supply the mantle, and a genital nerve supplying the common duct.

Make a drawing of the nervous system. 



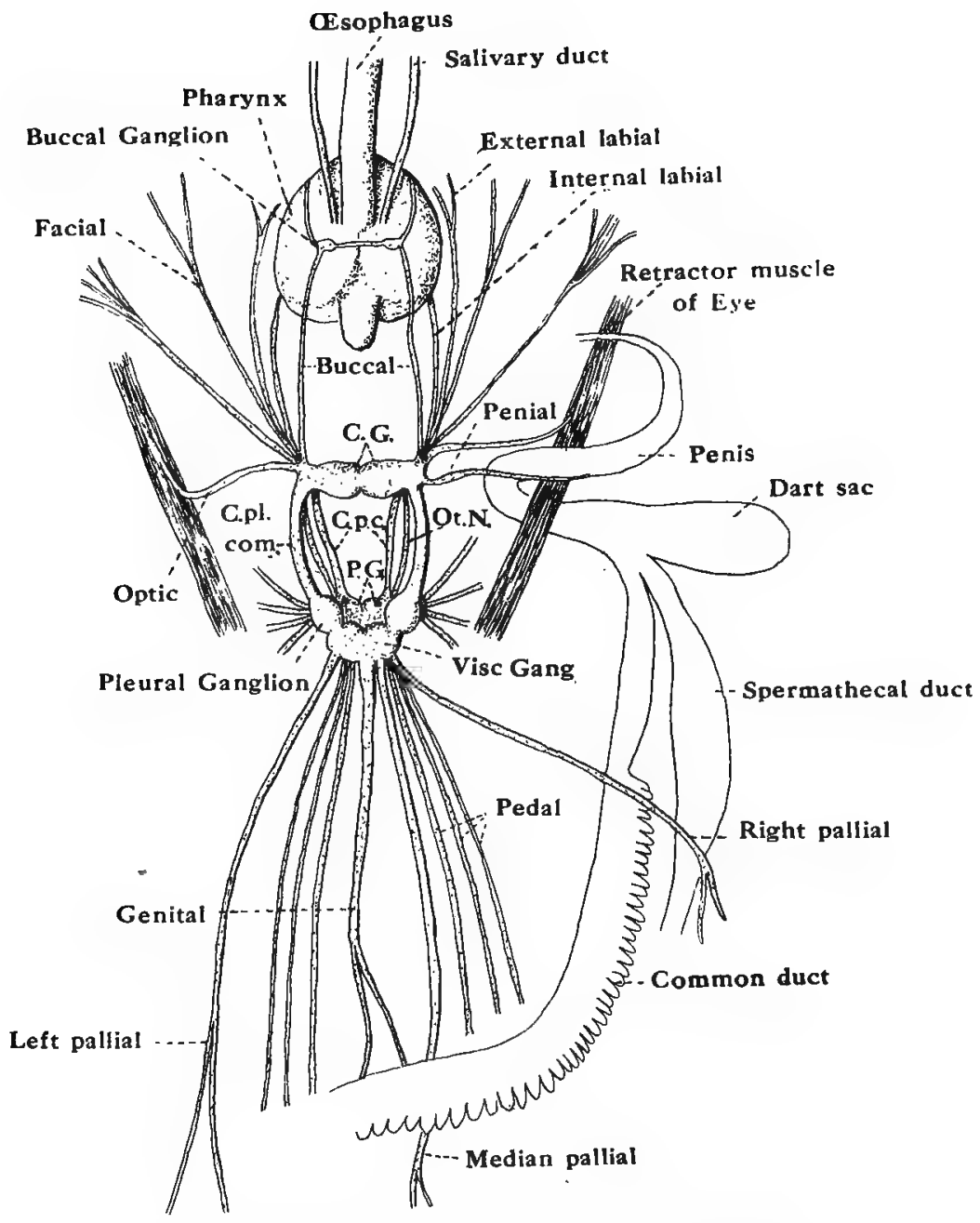

FIG. 38. -The Nervous System of the Snail (Helix aspersa).

C.G. Cerebral ganglia ; C.p.c. Cerebro-pedal commissure; C.pl.com. Cerebro-pleural commissure; Ot.N. Optic nerve; P.G. Pedal ganglia; Visc. Gang. Visceral ganglia. 

D. The Odontophore.

Make a median longitudinal section through the buccal mass so as to expose the odontophore. The posterior part of the floor of the pharynx is produced backwards into a hollow diverticulum, the radula sac. A chitinous band, the radula cr rasping ribbon, armed on its upper surface with a number of minute rasp-like teeth arranged in transverse rows, is secreted by the epithelial cells lining the ventral wall of the diverticulum. In front of the radula sac lies a cushion projecting into the cavity of the buccal mass or pharynx. The radula passes over this cushion. The odontophoral cartilage, .which can be moved by the intrinsic muscles, is firmly attached to the cushion. The radula works against the horny jaw situated in the mouth. The radula, the cushion and the muscles together constitute the odontophore.

Make a drawing showing the above parts.

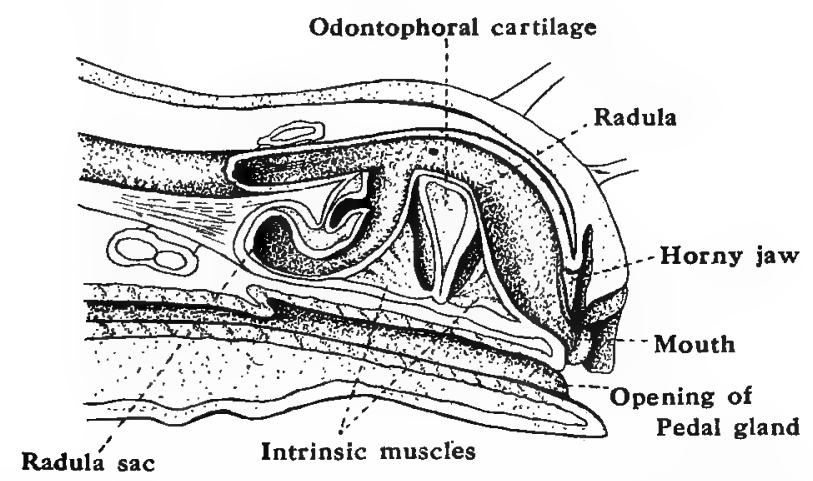

Frg, 39. - Inner view of the left half of the head region of the Snail (Helix), showing the odontophore and associated parts. $\times 2$. 



\section{THE FRESH-WATER MUSSEL (Anodonta cygnea) THE CÖMMON MARINE MUSSEL (Mytilus edulis)}

\section{External Features.}

Make a drawing of the Mussel, viewed from the left side, to show the following parts :-

(a) The umbo, representing the oldest part of the shell, close to the hingeline, and about a quarter of the length of the shell from the anterior end. The anterior end is more rounded than the posterior end. [In Mytilus the umbo is situated at the anterior end, the pointed end, of the shell.]

(b) The lines of growth, a number of concentric lines parallel to the free margin of the shell and having a common centre at the umbo.

(c) The hinge-ligament, occupying the greater part of the straight dorsal surface of the shell, and connecting the two valves of the shell together.

(d) The brownish-green periostracum, the thin outer horny layer of the shell.

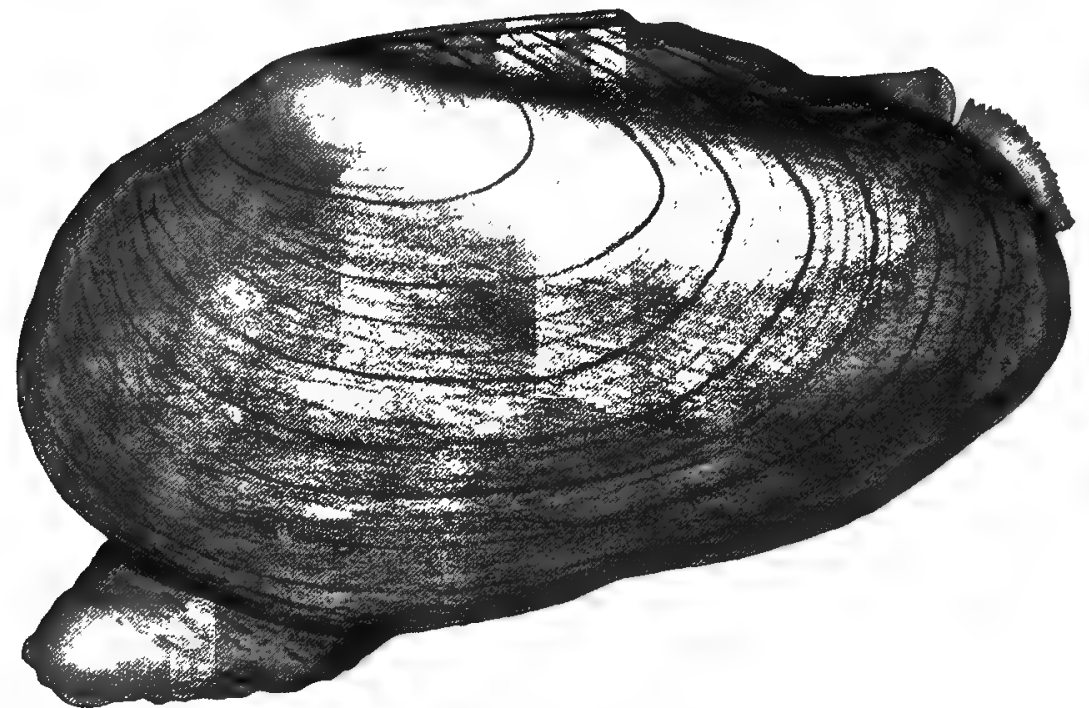

Frs: 40. - The Fresh-water Mussel (Anodonta cygnea). $\quad \times 1 \frac{1}{2}$.

(e) The "foot" (if protruded), semi-transparent, tongue-like, and projecting between the shells, near the antero-ventral end. [In Mytilus the foot is black and has a byssus attached to its posterior surface. The byssus is a long groveth of hairs, each tipped with a small flat disc, by rohich the animal attaches itself.]

(f) The ventral inhalent siphon (if protruded), formed by the projection of the mantle between the shells at the posterior end. The lips bear a fringe of small tentacles. 



\section{FRESH-WATER MUSSEL-COMMON MARINE MUSSEL}

(g) The dorsal exhalent siphon (if protruded), lying just above the inhalent siphon. The lips are smooth. [In Mytilus the inhalent and exhalent siphons do not protrude beyond the margin of the shell.]

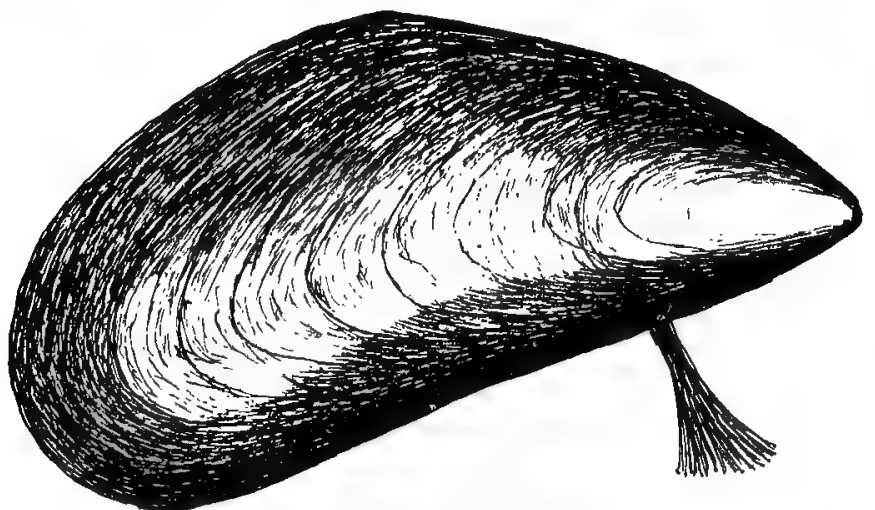

FI(t. 41.-The Common Marine Mussel (Mytilus edulin). $\times \mathrm{l}_{\frac{1}{2}}$.

\section{Internal Structure.}

1. Place the handle of a scalpel between the ventral edges of the valves of the shell and separate them. The muscles connecting the valves may then be seen. Cut through these as close as possible to their points of attachment to

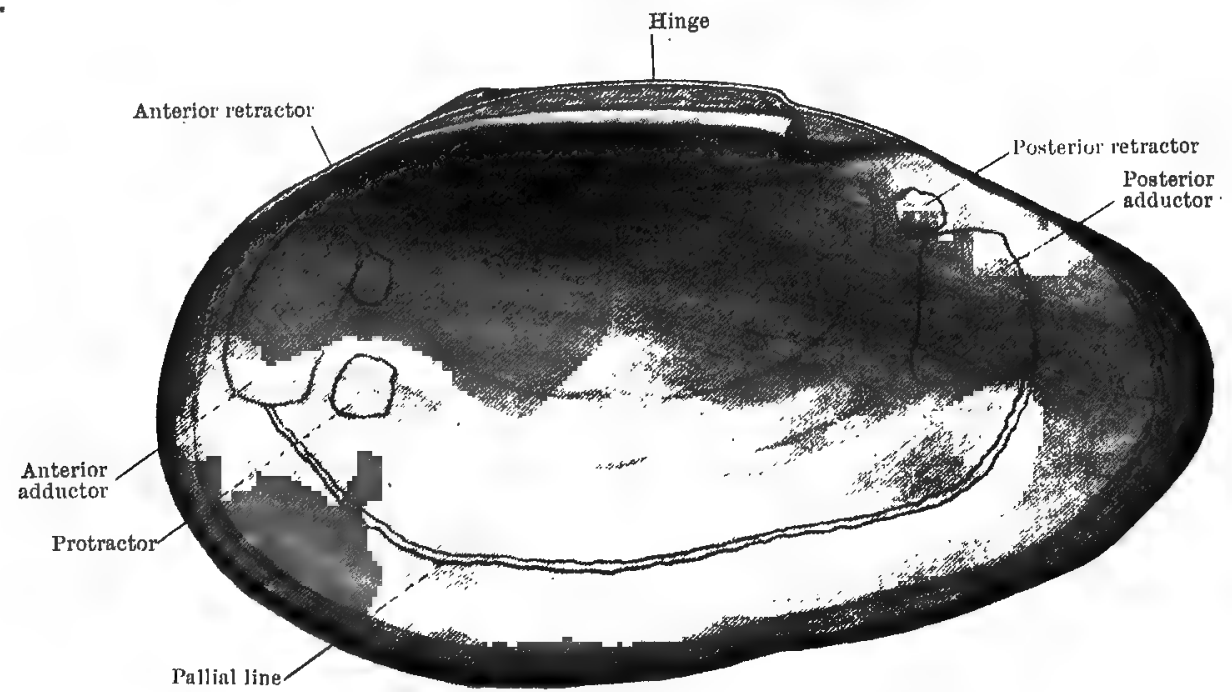

Fig. 42. - Inner side of the shell (right valve) of the Fresh-water Mussel (Anotlonta), showing the marks of the muscle insertions and the pallial line.

the left valve of the shell. Cut through the ligament along the hinge-line, and remove the left shell.

Make a sketch of the inside of this shell showing :-

(a) The marks of attachment of the following muscles:-

(i) The anterior adductor muscle, a large oval area, close to the 

anterior end of the shell. [In Mytilus there is no anterior. adductor muscle.]

(ii) The anterior retractor muscle, a small rounded area, contiguous with the posterior dorsal edge of the anterior adductor.

(iii) The protractor muscle, a rounded area behind the lower part of the anterior adductor muscle but quite separate from it. [In Mytilus there is no protractor muscle.]

(iv) The posterior adductor muscle, a large oval area, larger than the anterior adductor, near the posterior dorsal end of the shell.

(v) The posterior retractor muscle, a small rounded area, continuous with the antero-dorsal edge of the posterior adductor.

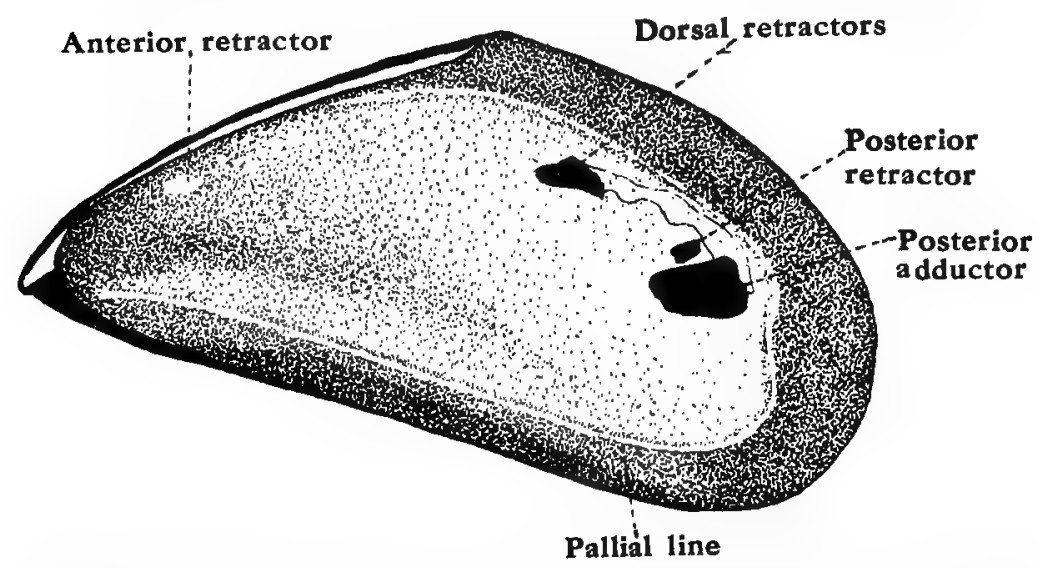

Fra. 43. - Inner side of the Shell (right valve) of the Marine Mussel (Mytilus), showing the marks of the muscle insertions and the pallial.line.

[(vi) In Mytilus there are three dorsal retractor muscles, the impressions of which lie along the mid-dorsal part of the shell.]

Note that the adductor muscles close the shell, and the other muscles work the "foot."

(b) The pallial line, a curved line marking the attachment of the mantle to the shell, and running parallel to the ventral border of the shell. It connects the posterior border of the posterior adductor area with the ventral border of the anterior adductor.

(c) The hinge, a smooth longitudinal ridge extending backwards from the umbo along the dorsal edge of the shell.

Notice the inner pearly or nacreous layer of the shell. This layer is made by the surface of the mantle which lines the shell. The median prismatic limy layer and the outer horny periostracum are formed by the thickened edges of the mantle.

2. Note the mantle closely lining the inside of the shell and covering the sides of the body. It is attached to the shell along the pallial line. Just behind the posterior adductor muscle the two lobes or flaps of the mantle fuse together, and this fused portion extends forward along the dorsal surface of the posterior 



\section{2}

FRESH-WATER MUSSEL -COMMON MARINE MUSSEL

adductor muscle a short distance. At the posterior end of the mussel the lobes of the mantle form the exhalent and inhalent siphons above described; and these are the openings of the two chambers into which-the mantle-cavity is divided by a partition at the bases of the gills.

3. Raise the mantle of the left side so as to expose the gills. Note that the gills are long and plate-like (Lamellibranchiata), and that there is a pair (an outer and an inner gill) on each side between the median "foot" and the mantle.

A
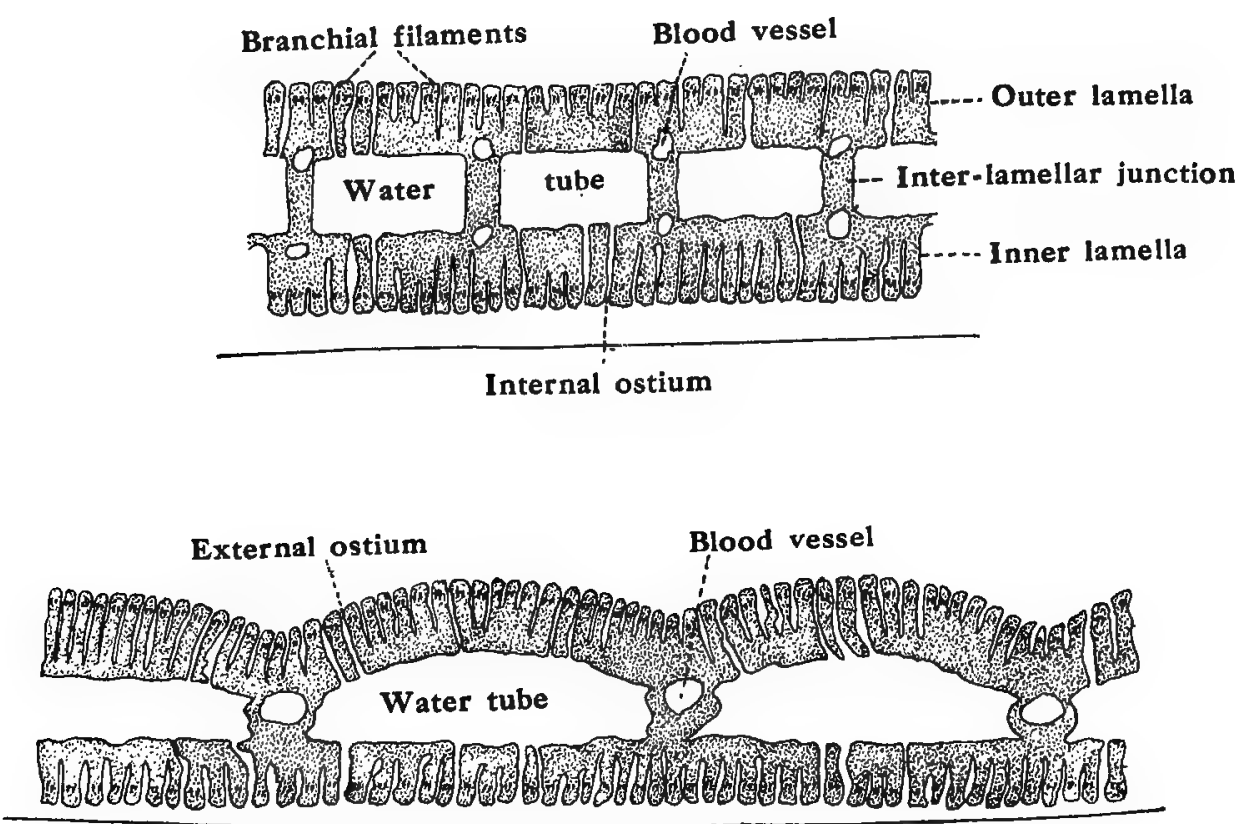

B

Fig. 44.-The Fresh-water Mussel (Anodonta). After Parker and Haswell.

A. Transverse Section of an outer gill; B. Transverse Section of an inner gill.

Each gill consists of two lamellæ, continuous along their anterior, ventral and posterior borders. The gill has thus the form of a long and extremely narrow bag open above. The cavity of the gill is subdivided by vertical strands of tissue, the interlamellar junctions, extending between the lamellæ and dividing the cavity into a series of water-tubes, which are closed ventrally but open along the dorsal edge of the gill. Each gill has a delicate striation, both horizontally and vertically. The vertical striation is due to the lamellæ being composed of a number of fine $V$-shaped gill-filaments, while the horizontal striation is due to the interfilamentar junctions, horizontal strands of tissue connecting the filaments. Between the filaments are minute apertures, the ostia, leading from the mantle-cavity into the water-tubes. The gill-filaments are richly ciliated, and the whole lamella is traversed by blood-vessels. [In Mytilus the gillfilaments are loosely connected by interlocking groups of cilia, the ciliary brushes. Therefore the junctions are ciliary junctions, not solid interfilamentar junctions.] 



\section{FRESH-WATER MUSSEL-COMMON MARINE MUSSEL}

4. Remove the mantle and gills from the left side. Note and draw the following parts:-

(a) The foot, a large muscular organ situated at the anterior end of the animal. The foot is axe-shaped (Pelecypoda). [In Mytilus there is a byssus inserted on the posterior surface of the base of the foot.]

(b) The pair of labial palps on each side of the mouth.

(c) The anterior adductor, anterior retractor, protractor, posterior retractor, and posterior adductor muscles. [In Mytilus the anterior adductor and protractor muscles are absent.]

(d) The gills of the right side.

(e) The mantle lobe of the right side, lining the shell.

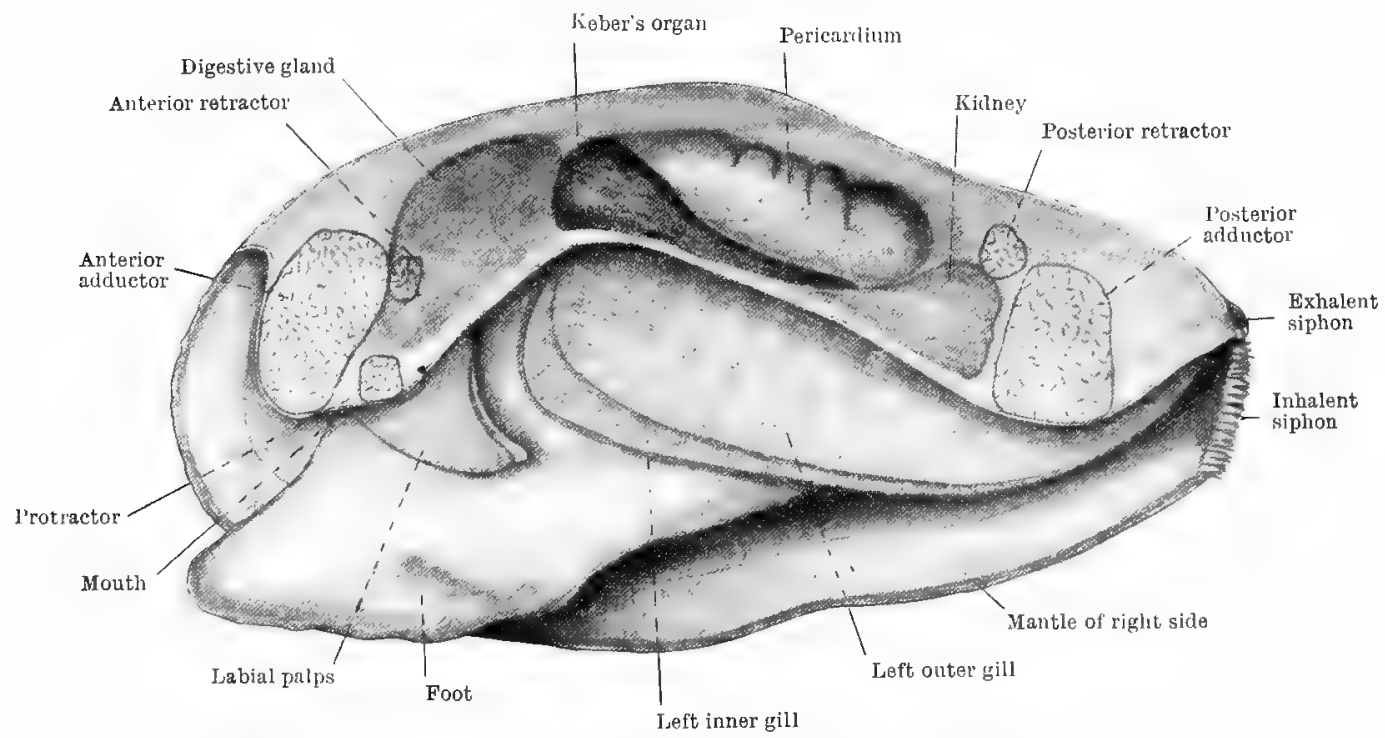

FIG. 45. -The Fresh-water Mussel (Anodonta). Shell removed. Part of the mantle of the left side has been taken away so as to expose the gills, foot, etc.

(f) The visceral mass forming the upper two-thirds of the large foot, a laterally compressed, oblong mass. The lower third is the muscular portion of the foot, or foot proper.

(g) The pericardium, lying along the dorsal surface, beneath the hingeligament. Within it is the heart, which consists of two auricles and a ventricle. The ventricle surrounds the rectum, which passes through the pericardium.

(h) The paired kidney or "organ of Bojanus," lying just beneath the pericardium, with which it communicates through two crescentic renopericardial openings (nephrostomes) at the anterior end. [In Mytilus the kidneys lie on the floor of the pericardium on either side of the heart.]

(i) Keber's organ or the pericardial gland, a glandular. reddish-brown mass, lying in the anterior region of the body just in front of the pericardium. [In Mytilus this gland does not occur.] 



\section{FRESH-WATER MUSSEL-COMMON MARINE MUSSEL}

( $j$ ) The digestive gland or liver, a large organ surrounding the stomach and the anterior end of the intestine.

5. Expose the heart by opening the pericardium. Note the heart, consisting of a single ventricle and a right and a left auricle. The ventricle is a thickwalled muscular organ surrounding the rectum. Each auricle is a thin-walled triangular sac. the base extending along the dorsal border of the gills, the apex opening into the ventricle. From the anterior end of the ventricle the anterior aorta arises, and runs forwards along the dorsal surface of the rectum to supply the visceral mass. From the posterior end of the ventricle the posterior aorta

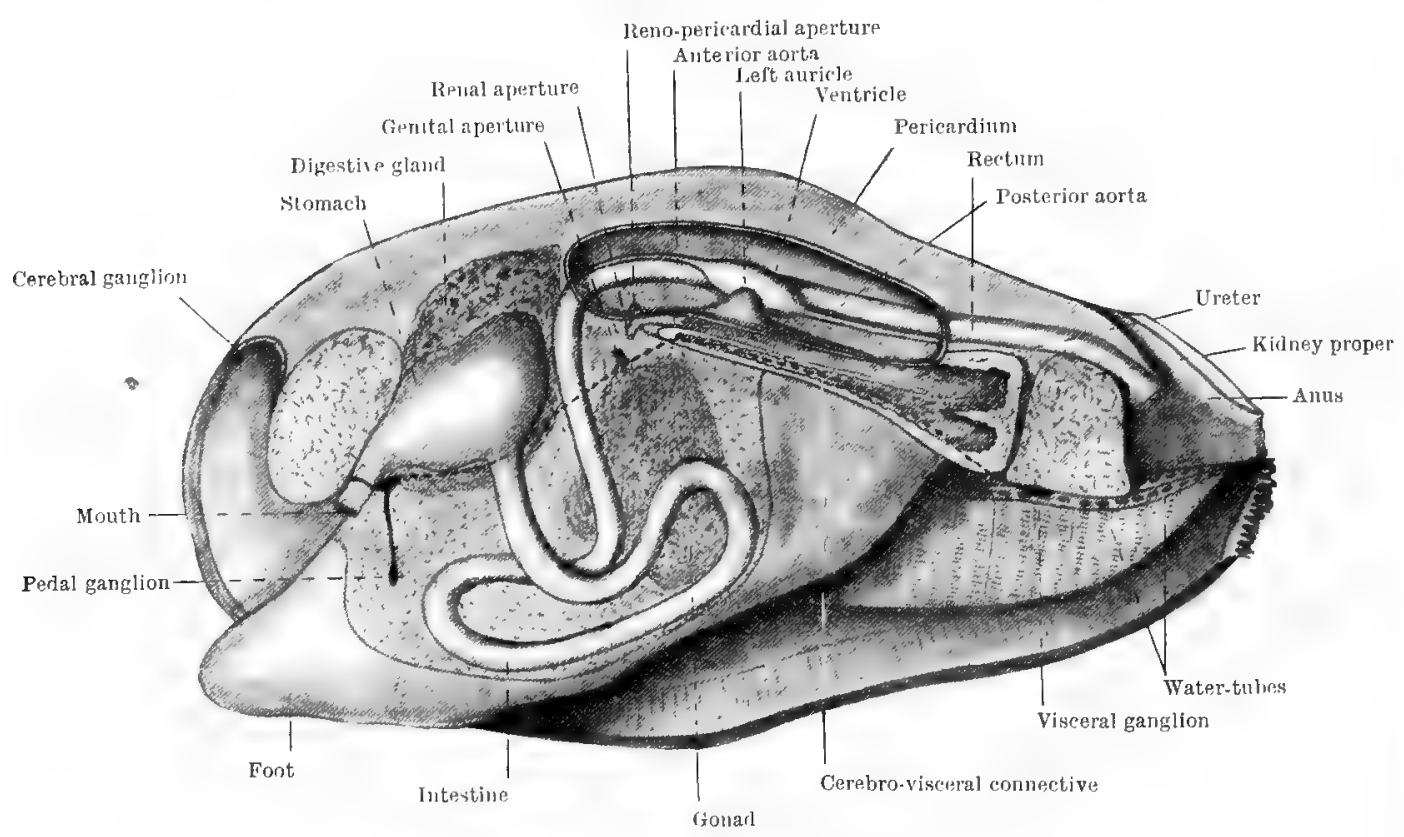

FIG. 46. - The Fresh-water Mussel (Anodonta) dissected from the left side to show the general structure. After Parker and Haswell.

arises, and passes backwards along the ventral surface of the rectum to supply the hinder part of the body. [In Mytilus the auricles are not so apparent, and the aorte are inconspicuous.]

6. Examine the kidney of the left side. It is a wide, thin-walled tube consisting of two parts, the one part doubled over on to the other so as to lie dorsally to it. The ventral part forms the kidney proper, while the dorsal forms the ureter or urinary bladder. The ureter opens to the exterior by a small aperture situated between the inner gill and the visceral mass. Just below this aperture may be seen the much smaller genital aperture. The kidney proper opens anteriorly into the pericardium by the crescentic reno-pericardial aperture or nephrostome. [In Mytilus the kidney has a simple structure, and from its posterior end the ureter passes backwards to unite with its fellow from the other kidney, the single duct thus formed opening on the dorsal surface of the posterior adductor muscle.] 



\section{FRESH-WATER MUSSEI-COMMON MARINE MUSSEL}

Open the ureter and the kidney proper, and note that they are in communication with each other at the posterior end.

Note that the vena cava, which carries impure blood to the gills, passes between the kidneys and through their walls.

The gonads (ovaries or testes), when ripe, form the greater part of the visceral mass.

\section{$A$. The Alimentary System.}

Carefully remove the digestive gland so as to expose the stomach. Expose the intestine by carefully cutting away as much of the visceral mass as is necessary.

The mouth lies behind the anterior adductor muscle and between the labial palps. It leads into a short and straight œesophagus which passes almost

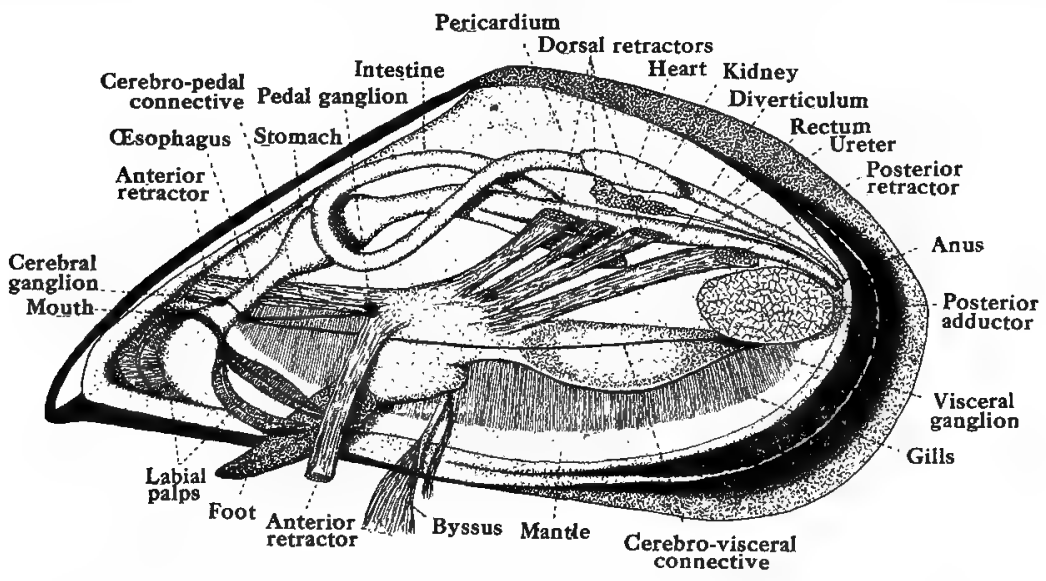

Fig. 47. - The Marine Mussel (Mytilus) dissected from the left side to show the general structure.

vertically into the stomach. The stomach may contain a crystalline style. The intestine arises from the lower wall of the stomach and passes backwards and down into the visceral mass, where it coils upon itself; it then ascends parallel to its first portion, turns sharply back and proceeds as the rectum through the pericardium, traversing the ventricle, and above the posterior adductor muscle, to end in the anus situated in the exhalent siphon (or cloaca). The ventral wall of the rectum is folded into a longitudinal ridge or typhlosole.

[In Mytilus the mouth lies between the labial palps. From it the oesophagus, which is flattened dorso-ventrally, leads into the stomach. From the stomach the intestine is continued backwards to the region between the dorsal retractors. There it bends sharply upon itself and coils forwards in the digestive gland, over the stomach, and thence passes backwards through the heart as the rectum, which opens at the anus situated above the posterior adductor muscle. At the posterior end of the digestive gland the intestine gives rise to a diverticulum, which passes backwards under the floor of the pericardium, to end blindly just under the anus. This diverticulum usually contains the crystalline style, a gelatinous rod of reserve food material.] 



\section{FRESH-WATFR MUSSEL-COMMON MARINE MUSSEL}

$B$. The Nervous System.

The ganglia are generally orange-yellow in colour. The visceral ganglia may be seen on the ventral surface of the posterior adductor muscle. They are closely joined together and supply nerves to the muscle, the gills, the posterior part of the mantle, the heart, and the alimentary canal. Trace the cerebrovisceral connective leading from each visceral ganglion along the inner surface of the kidney and through the visceral mass to the cerebral ganglion, which lies (close to the skin) on each side of the oesophagus. The two cerebral or cerebropleural ganglia are connected by a nerve passing over the dorsal surface of the osophagus. Carefully cut open the anterior part of the foot in the median plane, and separate the two halves so as to expose the pedal ganglia. They lie just within the visceral mass, close to the junction between the visceral mass and the muscular part of the foot. They are closely united and appear as a bilobed mass. Make out the cerebro-pedal connective, which passes from each cerebral ganglion downwards and backwards to the pedal ganglia.

Make a drawing showing as much as possible of the general anatomy of Anodonta.

[In Mytilus the visceral ganglia are separated from each other by a ridge, but a fine nerve of communication runs between them. The cerebro-visceral connective leads from each visceral ganglion along the base of the gill to the cerebral ganglion, which lies on either side of the cesophagus. By carefully removing that part of the digestive gland lying over the bases of the anterior and dorsal retractors, the pedal ganglia, a pair of incompletely fused ganglia in the angle between the anterior retractor muscles, are exposed. The cerebro-pedal connective passes through the substance of the anterior retractor muscle.]

Note.-The White Mussel (Donax serra) is readily obtained in South Africa, and may be used; but the nervous system and some other parts are not easily made out in this species. 



\section{THE LANCELET (Amphioxus, syn. Branchiostoma lanceolatus)}

Amphioxus is a small translucent animal, fairly abundant in the shallow coastal waters around the Mediterranean and other seas. A species, Amphioxus (Branchiostoma) capensis, is fairly common in South African waters, particularly in False Bay.

\section{External Features.}

The body is elongate, laterally compressed and pointed at both ends. Each side is marked by a series of <-shaped lines representing the connective tissue septa (myocommas) between the $\ll$-shaped lateral muscle segments or myotomes. Along the dorsal surface there is a median fold of skin forming the dorsal fin. This fold is extended round the tail region as the caudal fin, and is continued ventrally through the posterior third of the body as the ventral or anal fin.

Anteriorly the head region overhangs the oral hood, the edge of which bears

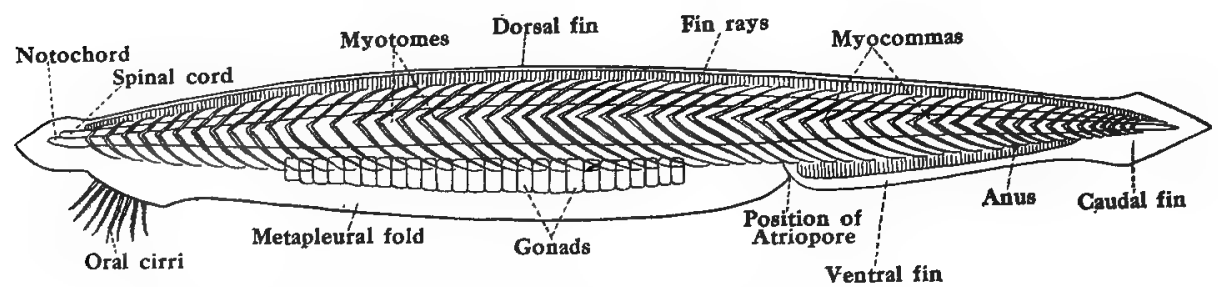

Fig. 48. - The Lancelet (Amphioxus lanceolatus) viewed from the left side. $\times 3$.

numerous ciliated processes, the buccal cirri. In the centre of the oral hood is the buccal opening. On the ventral surface of the anterior two-thirds of the body are the two lateral metapleural folds, extending from the oral hood to the anterior end of the ventral or anal fin.

The atrial aperture or atriopore is a median opening on the ventral surface at the junction of the ventral fin and the metapleural folds.

The anus is also on the ventral surface, about midway between the atrial aperture and the end of the body, slightly to the left of the middle line.

The gonads may be seen through the semi-transparent wall of the atrium.

Make drawings of the animal viewed $(a)$ from the left side and $(b)$ from beneath to show the above features.

\section{Internal Structure.}

Place under water a specimen that has been macerated in 20 per cent. nitric acid for about a day, and fix it down on its left side by two pins crossed over it at each end. Carefully remove the entire body-wall of the right side, stripping off the muscle segments from in front backwards, with a scalpel or a pair of 

forceps, so as to expose the alimentary canal, notochord, and other parts entirely. Note and draw the following structures :-

1. The Skeletal System.

(a) The notochord, a conspicuous flexible rod along the whole length of the body, between the dorsal spinal cord and the alimentary canal.

(b) The skeleton of the dorsal fin, a single series of fin-rays of connective tissue, extending along the dorsal surface.

(c) The skeleton of the ventral or anal fin, a double series of fin-rays of connective tissue, extending from the atrial aperture to the anus.

(d) The buccal cartilage, supporting the buccal cirri, around the oval margin of the oral hood.

(e) The skeleton of the gill-slit region of the pharynx (see the Alimentary System).

2. The Alimentary System.

The buccal cavity (stomodæum) is lined with cilia, a part of this ciliated lining having specially long cilia which form the "wheel-organ," which helps to drive water containing food particles into the pharynx. The buccal cavity leads into the pharynx, and separating them is a muscular diaphragm, the velum. The central opening of the velum, the mouth, has a fringe of twelve tentacles projecting into the pharynx. The pharynx is large ; it occupies most of the atrial chamber, and forms about half of the alimentary canal. The atrial cavity or atrium is a big space completely surrounding the anterior two-thirds of the alimentary canal, except dorsally. The side walls of the pharynx are perforated by a large number of gill-slits obliquely directed, downwards and backwards. Along the mid-ventral wall of the pharynx is a deep groove, the endostyle, lined with ciliated and glandular epithelium. Along the mid-dorsal wall there is a deep and ciliated epipharyngeal or epibranchial groove opening into the stomach. Following the pharynx is the equally long and straight intestine, which gradually narrows towards the posterior end, where it ends in the anus. The anterior part of the intestine is somewhat swollen and forms the "stomach." A pouch-like outgrowth from the floor of the "stomach" is the liver, which extends forwards on the right side.

Remove a small portion of the pharynx (the hind end), mount it in glycerine on a slide, examine under the microscope, and note :-

Between the successive oblique gill-slits are supporting skeletal structures known as the gill-arches, each strengthened by a chitinous axial rod, and each containing a cœlomic cavity. These rods are of two kinds and are arranged alternately :-

(a) The primary rods, split or forked at their ventral ends.

(b) The secondary rods or tongue-bars, unsplit, not forked. Each gill-slit, originally single, becomes double by the later development of these unsplit rods.

There are short horizontal bars connecting the successive pairs of primary rods together, while dorsally all the rods are connected by a horizontal rod. 

Notice the newly developed gill-slits at the extreme end of the pharynx.

3. The Circulatory System.

There is no heart, but the circulation of the blood is brought about by the contractile nature of the principal blood-vessels. A dorsal artery, the dorsal aorta, lies under the notochord and extends almost along the whole length of the alimentary canal. In the pharyngeal region it is paired, the two aortæ being formed by numerous efferent branchial vessels from the walls of the pharynx. A ventral aorta runs along the ventral wall of the pharynx. It is contractile and drives the blood forwards to the gill-slits, where the blood is purified. It gives off a series of afferent branchial vessels on each side, which

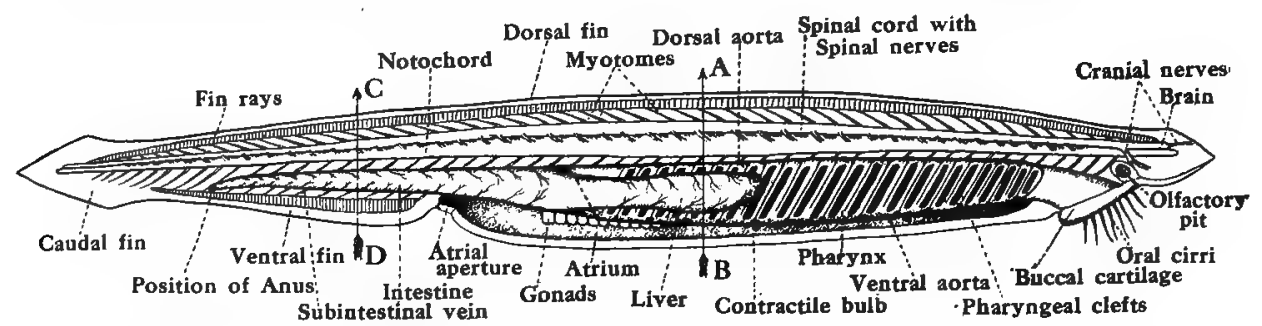

FI $\div$. 49.-Amphioxns dissected from the right side.

pass along the pharynx and communicate with the efferent branchial vessels by means of capillaries. The blood collects in the dorsal aorta and is sent to the posterior region of the body. The aorta supplies the intestine, and the smaller vessels there form the capillaries. The blood is collected from these in a median sub-intestinal vein running beneath the intestine to the liver, where it breaks into a series of capillaries. The blood is collected from the liver by hepatic veins which unite to form the ventral aorta. The bases of the afferent branchials are also contractile and form the contractile bulbs.

\section{The Muscular System.}

The lateral muscles of the body consist of sixty-two segments, the myotomes or myomeres, dovetailed into one another. The myotomes are separated by connective-tissue partitions. The myotomes of the right side alternate with those of the left side. Each is <-shaped and composed of numerous flat striated muscle-plates, arranged longitudinally.

A set of transverse muscles extends across the ventral surface of the anterior two-thirds of the body; these are situated in the floor of the atrial chamber, and are the ventral muscles of the body.

5. The Reproductive System.

The sexes are separate. The male and female reproductive organs are outwardly similar. The testis (or ovary) consists of twenty-six pairs of cube-shaped sacs lying along the inner wall of the atrium at the lower ends of the tenth to the thirty-fifth myotomes. There are no generative ducts.

Put the dissected specimen in water in a glass tube, and shake it thoroughly until the spinal cord is separated off. Stain the cord in picrocarmine, and mount it on a slide. 

6. The Nervous System.

This may be divided into the following two parts :--

(a) The central nervous system, consisting of a dorsal spinal cord lying above the notochord and almost as long as it. It is enclosed in a sheath of connective tissue. The central canal of the spinal cord expands anteriorly into a cerebral vesicle. From the anterior end of this vesicle arises a small diverticulum connected with an ectodermal olfactory pit.

(b) The peripheral nervous system, consisting of two series of nerves arising from the spinal cord, viz. :

(i) The dorsal sensory nerves, with a single root. The first two pairs may be regarded as cranial nerves. All these nerves supply the skin.

(ii) The ventral motor nerves, with multiple roots, supplying the myotomes.

Notice the pigment spots, one (the "eye") in the vesicle wall at the front end of the cord, and others at intervals along the cord.

\section{Transverse Sections through the Body.}

1. In a section taken through $A B$ (the posterior part of the pharynx) in Fig. 49 the following parts may be seen :-

(a) The section has, roughly, the shape of an isosceles triangle, the apex being formed by the dorsal fin and the base by the ventral surface, between the metapleural folds. The greater part of the interior is occupied by the atrial chamber.

(b) The body is covered by a single layer of epithelial cells, forming the epidermis. Underlying the epidermis is the dermis, formed mainly of soft connective tissue.

(c) The inyotomes of the lateral muscles, separated by partitions of connective tissue, the myocommas ; and the ventral or transverse muscles, extending across the ventral surface of the body in the floor of the atrial chamber.

(d) The fin ray of the dorsal fin.

(e) The spinal cord, situated above the notochord.

(f) The notochord, beneath the spinal cord.

(g) The pharynx, in the middle of the atrial chamber. Its side walls appear intermuted owing to the section cutting through a series of oblique gill-slits. The dorsal wall of the pharynx is folded to form the epipharyngeal groove; and the ventral wall is folded to form the endostyle.

(h) The liver, lying on the right side of the pharynx.

(i) The gonads attached to the lateral walls of the atrial chamber.

(j) The metapleural folds, with a canal or lymph space in each.

(k) The coelom, which is divided into :-

(i) A portion surrounding the liver.

(ii) The dorsal colomic canals, a pair of spaces at the sides of the epibranchial groove. 

(iii) The branchial cœlomic canals in the gill-arches.

(iv) The ventral or endostylar coelomic canal, in the ventral region of the pharynx.

(v) The gonad sacs.

(l) The right and the left dorsal aortæ, one at each side of the epibranchial groove.

(m) The ventral aorta lying beneath the endostyle.

$(n)$ The hepatic veins of the liver.

2. In a section taken through $\mathrm{CD}$ (the intestinal region) in Fig. 49, the following parts may be seen :-

(a) The section has the shape of an oval, the dorsal and ventral fins occupying the extremilies of the long diameter.

The atrial cavity is absent, the section passing through behind it.

The integument, muscles, notochord, and spinal cord are the same as in the first section, except for the absence of the ventral muscles.

(b) The intestine, lying just beneath the notochord, is a tube, oval in shape.

(c) The cœlome, surrounding the intestine except dorsally.

(d) The dorsal aorta between the notochord and the intestine.

(e) The sub-intestinal vein below the intestine.

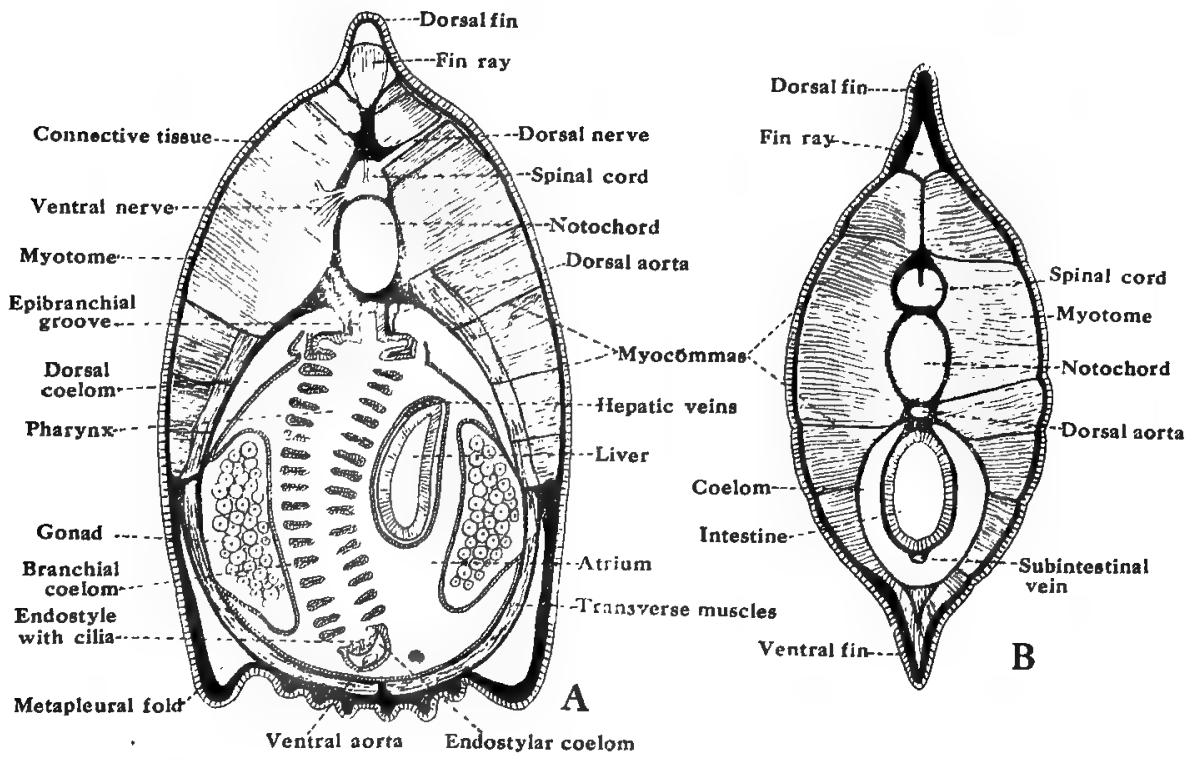

FIG. 50.-Amphioxus. A. Transverse Section through the pharyngeal region of the body; B. Transverse Section through the intestinal region. A., after Shipley and MacBride; B., after Wells and Davies. 

THE SPINY DOGFISH (Acanthias, syn. Squalus) oR

THE SPOTTED DOGFISH (Scyllium)

THE SKATE (Raia)

\author{
First Day
}

\title{
External Features.
}

Make a drawing of the Dogfish (Acanthias, or Scyllium) viewed from the side to show the following features :-

(a) The spindle-shaped body, ending in front in a bluntly pointed snout and tapering off behind into an upturned tail.

(b) The mouth, a large transverse crescentic-shaped opening on the ventral surface of the head. The integument covering the jaws bears numerous closely set rows of teeth (modified placoid scales).

(c) The nostrils, a pair of rounded openings situated ventrally in front of the mouth. Each nostril has a short narrow flap of skin produced from its anterior end over it. [In Scyllium the nostrils are connected with the mouth by naso-buccal grooves.]

(d) The eyes, situated one on each side of the head, above the mouth.

(e) The spiracles, modified gill-clefts through which the water enters the pharynx, a pair of small rounded openings, one just behind each eye. Each spiracle has a rudimentary gill, the pseudobranch.

(f) The five visceral or gill-clefts (II.-VI.), on either side of the head, some distance behind the mouth.

(g) The median and the paired fins. The median fins are: (i) the anterior and the posterior dorsal fin, along the middle of the back, each having a sharp spine in front of it; and (ii) the caudal fin, surrounding the end of the (heterocercal) tail. [In some dogfishes-e.g. Scyllium-there is a median analfin behind the anus. This fin is absent in Acanthias. The dorsal fins of Scyllium have no spines.] The paired fins are: (i) the pectoral fins, flat and triangular, attached to the sides of the ventral surface just behind the fifth gill-cleft; and (ii) the pelvic fins, smaller and narrower than the pectoral fins but of the same shape, attached on each side of the middle line on the ventral surface in front of the anus. In the male their inner edges are produced into a rod-like structure, the clasper, deeply grooved along its inner surface.

(h) The cloaca, situated between the pelvic fins; and on each side of it the abdominal pore, a minute opening leading into the body-cavity (abdominal or peritoneal cavity).

(i) The lateral line (of sense organs), a longitudinal groove extending along each side of the body from the spiracle to the tail region.

(j) The openings of the sensory jelly-tubes or ampullary canals, on the skin of the head (the snout especially). 

Note the placoid scales (dermal denticles or skin-teeth) covering the whole body, also two unroofed areas of the skull, the fontanelles, which can be felt through the integument of the head.

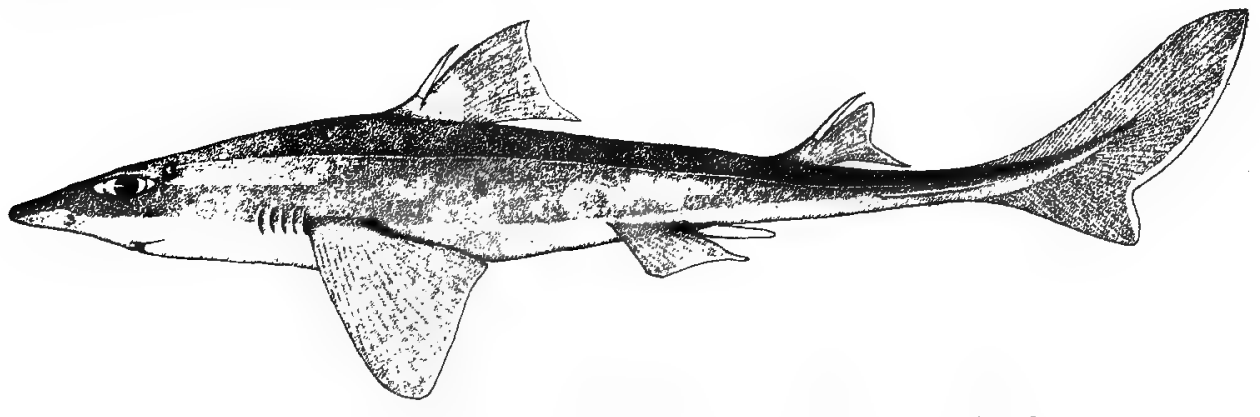

FIG. 51.-The Spiny Dogfish (Acanthias, syn. Squalus). Reduced.

[Make a drawing of the Skate (Raia) viewed from above to show the following features :-

(a) The rhomboidal-shaped body, flattened dorso-ventrally, ending in front in a pointed snout and produced posteriorly into a whip-like (heterocercal) tail.

(b) The eyes, situated near the anterior end.

(c) The spiracles, a pair of rounded apaertures situated just behind the' eyes, each containing a rudimentary gill (the pseudobranch).

(d) The large pectoral fins forming the sides of the body.

(e) The smaller pelvic fins behind the pectoral fins, one on each side of the base of the tail. In the male, claspers are present as in the Dog fish.

(f) The small unpaired fins and the spines on the tail.

(g) The small caudal fin surrounding the end of the tail.

Note the placoid scales on the skin (numerous in certain species of Skate), also the fontanelles, the unroofed areas of the skull.

Make a drawing of the Skate viewed from beloro to show the following fealures :-

(a) The mouth, a large transverse opening. The integument covering the jawes bears numerous closely sel rows of teeth.

(b) The nostrils, situated in front of the mouth, and connected each by a nasobuccal groove with the angles of the mouth.

(c) The five gill-clefts on each side of the body, behind the mouth.

(d) The cloaca situated betroeen the pelvic fins, and, on each side of it, the abdominal pore opening into the body-cavity.

(e) The sensory jelly-tubes of the skin.]

\section{Internal Structure.}

Remove a piece of the skin from the side of the body (towards the tail) to show the myotomes. Cut off the tail region of the body (behind the cloaca) and make a sketch of the cut surface to show the skin, muscles, centrum of vertebra with remains of the notochord, dorsal neural arch enclosing the spinal cord, and ventral hæmal arch enclosing the caudal artery (dorsal aorta) and the caudal vein (below the artery). 

Make a median incision on the ventral surface, cutting through the body-

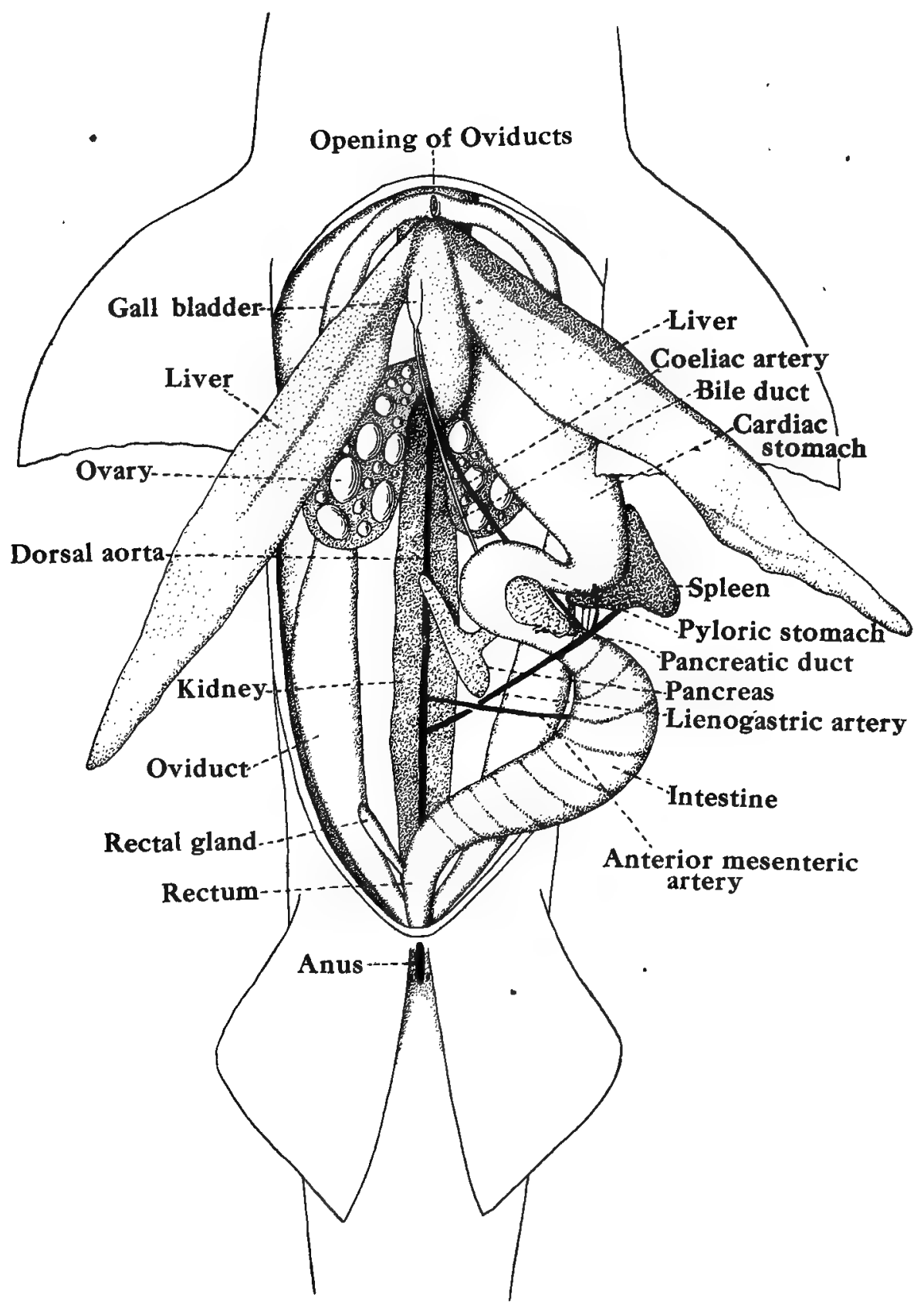

FI(; 52. - The Dogfish (Acanthias, syn. Squauls). Dissection showing the alimentary system, etc.

wall from between the pectoral fins to the cloaca, so as to expose the internal organs. 

$A$. The Alimentary System and Vascular System (part).

Make a drawing showing the following parts :-

(a) The liver, divided into two large lobes and a small intermediate lobe. It extends along the whole length of the abdomen. The gall-bladder is situated in the intermediate lobe, and from it the bile-duct passes backwards to open into the intestine some distance behind the pylorus. [In Scyllium the liver is bilobed, and the gall-bladder is lodged in the upper part of the left lobe. In the Skate the liver is trilobed, and the gall-bladder is situated between the right and median lobes.]

(b) The stomach, a large $\mathrm{J}$-shaped sac divided into a cardiac and a pyloric portion.

(c) The small intestine (duodenum), a short and narrow region following the pyloric part and receiving the bile-duct and the pancreatic duct.

(d) The large intestine, following the small intestine. It is a wide tube with an internal fold, the spiral valve.

(e) The rectum, the short terminal part of the large intestine, ending in the anus within the cloaca. Note the rectal gland attached to the dorsal surface of the rectum.

$(f)$ The pancreas, lying in the bend between the short distal limb of the stomach and the small intestine. It is long and narrow posteriorly, but anteriorly it is rounded, and from this lobe the pancreatic duct issues and at once enters the wall of the small intestine (at about an inch distance from the pylorus). [In the Skate the pancreatic duct. enters the intesine opposite lhe bile-duct.] Sometimes (in Acanthias) the pancreas is not visible, being only slightly developed in the intestine wall.

(g) The spleen, a dark red body, attached by mesentery to the bend of the stomach.

(h) The coeliac artery, running backwards in the same mesentery as the bileduct, supplying the stomach and liver and pancreas.

(i) The anterior mesenteric artery to the middle of the large intestine. [In the Skate the superior mesenteric artery supplies the intestine, pancreas, and spleen.]

(j) The lieno-gastric artery to the loop of the stomach and the spleen.

(k) The hepatic portal vein (from intestine and spleen), passing alongside the bile-duct and entering the liver about the median plane.

(l) The gonad and genital ducts. Notice the slit like common opening of the two oviducts (vestigial in the male) on the falciform ligament of the liver.

Note the peritoneum, and the way in which the spleen is attached to the stomach. The alimentary canal is attached to the dorsal wall of the abdominal cavity by mesentery-i.e., a double sheet of reflected peritoneum ; 

and the liver is attached to the front wall by the suspensory or falciform ligament.

Cut through the alimentary canal in front of the stomach and behind the
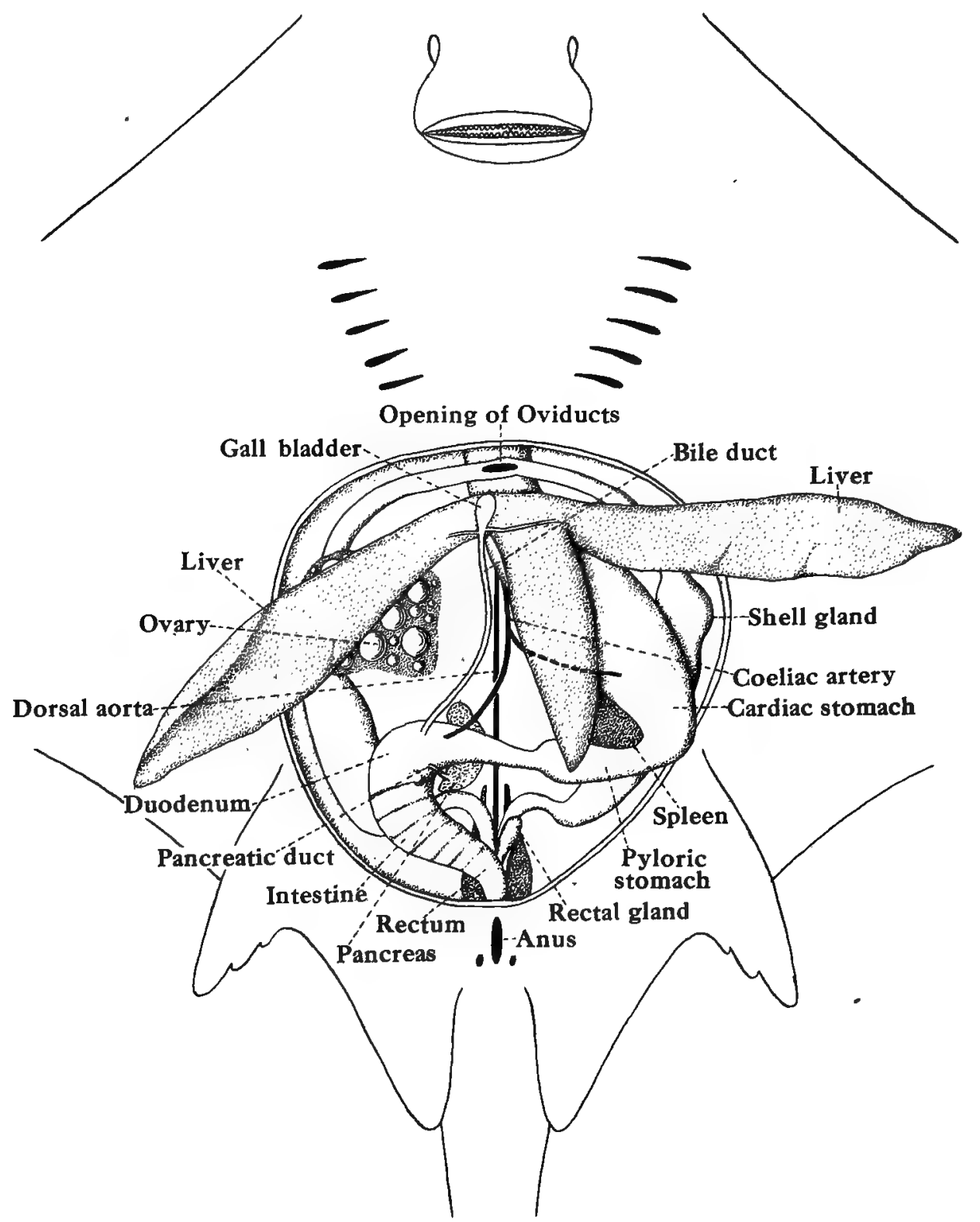

FIG. 53. - The Skate (Raia). Dissection showing the alimentary system, etc.

rectal gland. Remove it completely by carefully cutting through the mesenteric attachments.

Open the whole canal by making an incision along the right side, and wash out the contents. Examine the spiral valve. 



\section{Second Day}

B. The Urino-genital System.

1. The Female.

Remove the pelvic girdle from between the bases of the pelvic fins, taking care not to injure the structures lying beneath it. The mature ovary is a large lobulated organ, suspended by a fold of peritoneum from the dorsal wall of the body-cavity, and the eggs or ova form conspicuous prominences on its surface. It then appears paired as the eggs lie on each side of the vertebral column. The oviducts (Mirllerian ducts) are paired and extend along the whole length of the dorsal wall of the peritoneal cavity. Anteriorly they unite in front of the liver (on the suspensory ligament), and communicate with the peritoneal cavity by a common slit-like opening. In the anterior portion. of each oviduct a swelling appears; these are the oviducal or shell glands, which secrete the horny egg-capsules ("Mermaid's purse"). Posterior to this the oviduct becomes enlarged and may contain encapsuled eggs or developing embryos (Acanthias is viviparous, Scyllium is oviparous). The oviducts unite terminally and open into the cloaca by a common opening, behind the anus.

Cut open the cloaca and note the urinary papilla, situated in the middle of the anterior wall, and the opening of the oviducts behind the anus, the opening of the rectum.

Remove the peritoneum from the dorsal wall of the body-cavity and note the kidneys (opisthonephros), a pair of long narrow organs lying close to the vertebral column, one on either side of it. The ureters (metanephric ducts) are four to six fine tubes which issue from the posterior part (metanephros) of each kidney and open separately into the urinary sinus. The urinary sinus is formed by the union of the dilated ends of the Wolffian or mesonephric ducts, which are rudimentary and straight in the female. [In the Skate (Raia) there are two ovaries.]

Make a drawing of the female urino-genital system.

\section{The Male.}

Remove the pelvic girdle as in the female. Remove also the peritoneum from the dorsal wall of the body-cavity so as to expose the kidneys, etc.

The testes, when fully developed, are a pair of conspicuous elongate organs attached to the roof of the body-cavity by a fold of the peritoneum. The kidneys (opisthonephros) are larger than those of the female, and are differentiated into two parts : the anterior part or mesonephros (Wolffian body) is well developed and functions as the genital epididymis, and the posterior part or metanephros is the kidney proper. The ureters are formed each from the union of about five metanephric ducts, and open into the urino-genital sinus.

From the anterior end of each testis arise delicate efferent ducts which pass to the epididymis (mesonephros or Wolffian body) and are there connected with the sinuous Wolffian duct which acts as the vas deferens. Posteriorly each vas deferens expands to form an elongated and spindle-shaped vesicula seminalis, which opens into the urino-genital sinus (i.e., the united bases of two sperm sacs, which project forwards beneath the vesiculæ seminales).

The urino-genital sinus opens into the cloaca behind the anus or opening of the rectum. 

Note that only vestiges of the Muillerian ducts are present in the male. Notice the associated copulatory claspers of the pelvic fins.

Dissect away the sperm-sac to show the vesicula seminalis.

Make a drawing of the male urino-genital system.

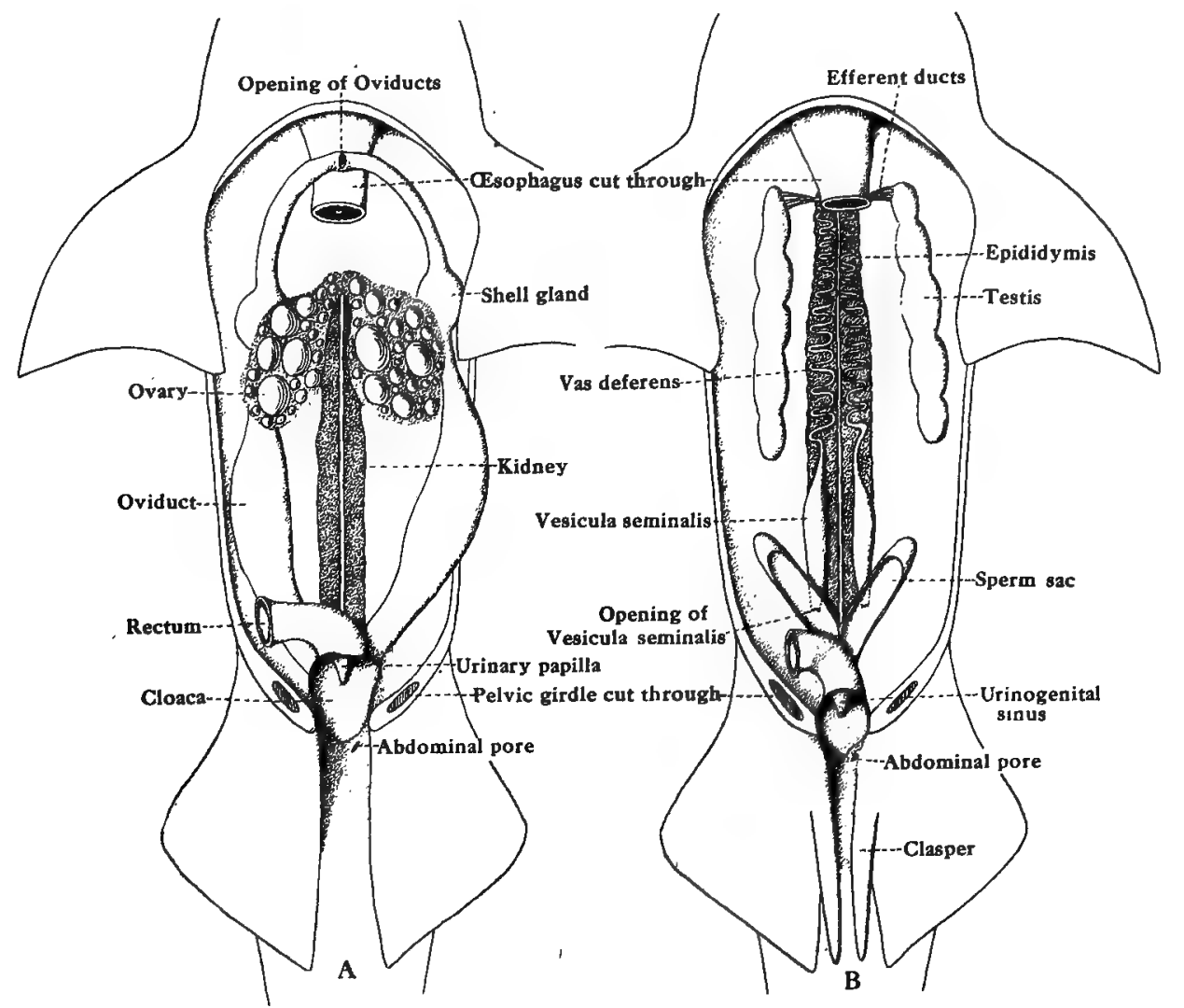

Fr(: 54.-The Dogfish (Acanthias, syn. Squalus). A. Urino-genital system of the female;

B. the male.

C. The Skeletal System (part).

Remove the skin and muscles from the region between the pectoral fins, and clean the base of a pectoral fin and the pectoral girdle to show the skeleton.

Make a drawing to show the following parts :-

1. The Pectoral Girdle.

This consists of a hoop of cartilage incomplete dorsally. Its thick ventral portion represents the coracoid, each side of which bears three articular (glenoid) facets for the three basal pieces of the pectoral fin. The incomplete dorsal portions of the girdle represent the scapula.

2. The Pectoral Fins.

Each fin articulates with the pectoral girdle by three basal pieces of cartilage-the very small propterygium, the mesopterygium, and the large metapterygium. The propterygium and the mesopterygium each bears a 

thick radial; the metapterygium bears several slender radials. These radials bear the horny fin-rays.

[In the Skate (Raia) the pectoral girdle is attached to the anterior vertebral plate, and there are three articular facets for the basal pieces of the fin, namely, a large propterygiurn, a small mesopterygium, and a large metapterygium.]

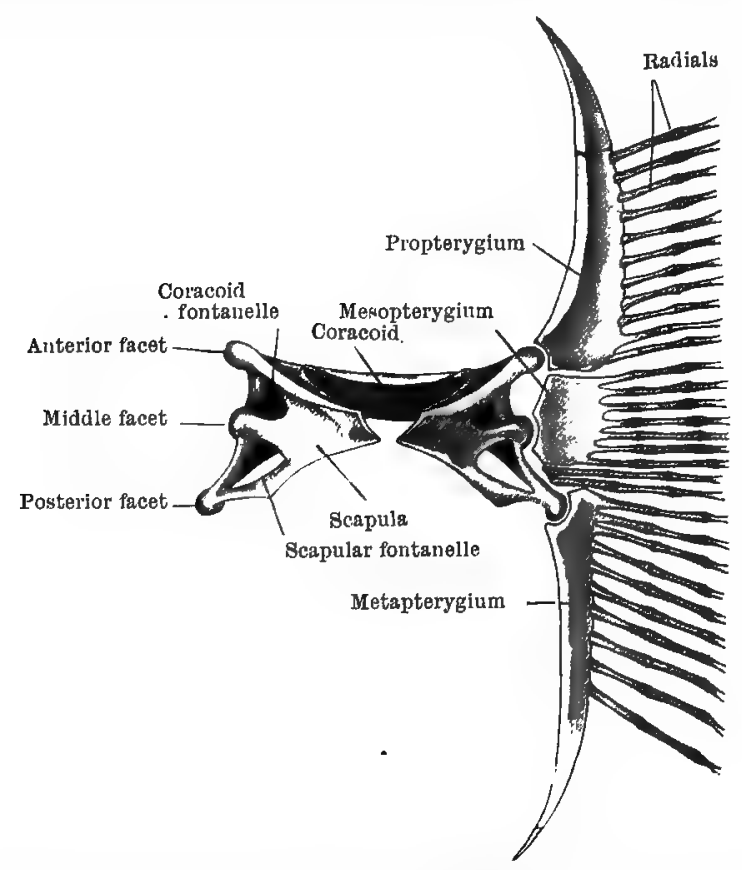

FI $\div$, 55.-Dorsal View of the Pectoral Girdle and Fin Skeleton of the Skate (Raia). From Masterman's Text-book of Zoology.

\section{The Vascular System.}

1. The Heart and the Afferent Branchial Vessels.

Carefully remove the middle portion of the pectoral girdle so as to expose the heart. Extend the opening by removing (in thin slices) the ventral wall of the pericardial cavity. Note that the heart, situated in the pericardial cavity, is composed of four parts. Posteriorly and dorsally is the small thin-walled sinus venosus, opening in front into a single large and thin-walled atrium or auricle. The auricle communicates with a thick-walled ventricle, from which is given off in front a tubular chamber with thick muscular walls, the conus arteriosus.

To see the sinus venosus properly, press the ventricle forwards.

Cut away or tear apart the covering muscles in front of the conus so as to expose the ventral aorta. This vessel is a continuation of the conus arteriosus, and passes forward between the gills. Trace the ventral aorta forward to near the middle of the lower jaw, and by carefully clearing away the tissue and muscles from its vicinity, expose the five afferent branchial vessels (on each side) from the aorta to the gills. Trace out these arteries, noting that the first or anterior branchial artery goes to the half-gill of the hyoid arch, and the other 

four branchial arteries go to the gills of the first four branchial arches. The fifth branchial arch is without a gill.

Notice the thyroid gland lying at the anterior end of the ventral aorta.

Note that each end of the sinus venosus passes into a short duct of Cuvier. The large posterior cardinal sinus, which extends forward dorsally from

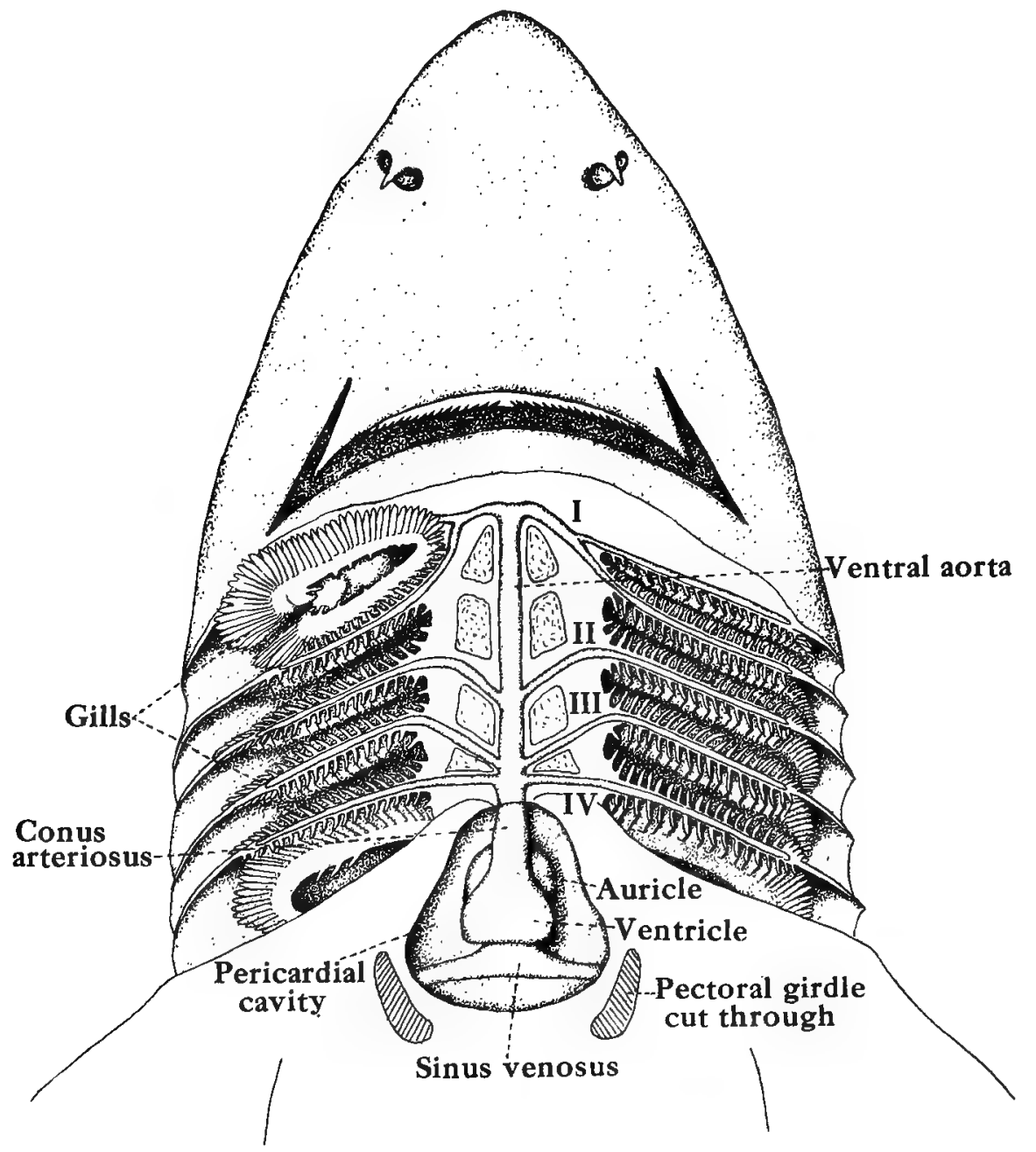

FIG. 56. -The Dogfish (Acanthias, syn. Squalus). Afferent Branchial or Ventral Arterial System.

between the kidneys, opens into the duct of Cuvier at each side. The anterior cardinal sinuses, which extend from around each eye and above the gill-arches, also open into the duct of Cuvier opposite the posterior cardinal sinus openings. The hepatic sinus of the liver opens (two openings) into the posterior wall of the sinus venosus. Slit open the sinus venosus, and pass a seeker into these sinus openings.

Note that the pericardium is a portion of the cœlome or body-cavity which has been separated off. It is, however, in communication with the main cavity 

(peritoneal or abdominal cavity) by the pericardio-peritoneal canal, which opens in front, in the middle line, above the sinus venosus. Find this opening, and pass a seeker along the canal (on the ventral surface of the cesophagus).

Make a complete sketch showing the heart, ventral aorta, and afferent branchial vessels.

[In the Skate the heart also consists of four parls-viz. the sinus venosus, auricle, ventricle, and conus arteriosus or pylangium. Connected with the anterior end of the pylangium is the synangium or bulbus arteriosus, which gives off the median ventral aorta. The ventral aorta passes forwards in the middle line and gives off the anterior and posterior innominate arteries. Each anterior innominate artery divides into tro afferent branchial vessels which convey blood

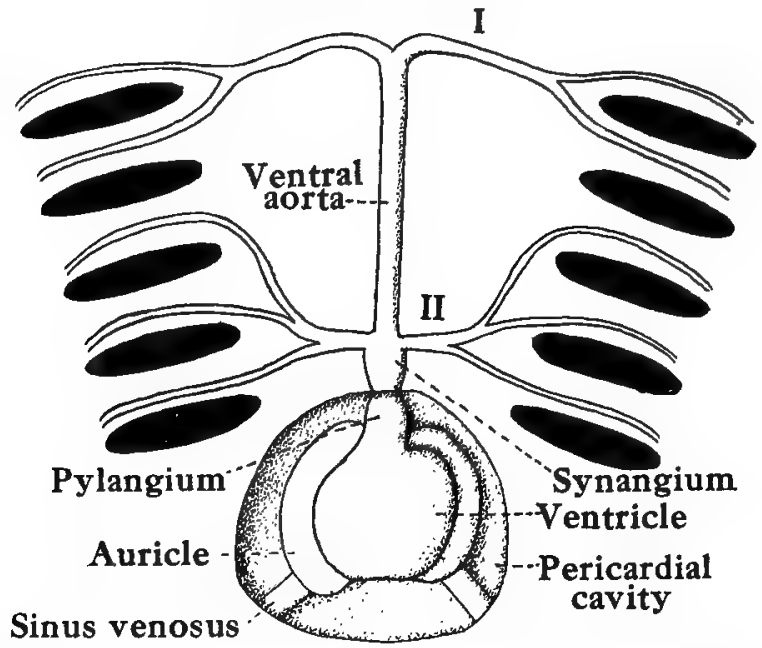

FI( . 57.-The Afferent Branchial or Ventral Artẹrial System of the Skate (Raia).

I. Anterior Innominate Artery; II. Posterior Innominate Artery.

to the half-gill of the hyoid arch and the gill of the first branchial arch. The posterior innominale arlery divides into three branches conveying blood to the gills of the second, third and fourth branchial arches.]

2. The Efferent Branchial Vessels and Dorsal Aorta.

Cut through the angle of the mouth on the right side and carry the incision backwards through the middle of the gill-clefts of that side. Turn the whole of the lower jaw over to the left side, and wash out the mouth. Carefully remove the mucous membrane from the roof of the mouth, working from the œsophagus forwards. The efferent branchial vessels will then be seen. There are four pairs, and these all join to form the median dorsal aorta, which passes backwards along the mid-dorsal line of the body. Trace each efferent vessel from the aorta to the gill. In Acanthias the first pair of efferents unite just between the fourth gill-clefts. From each a small artery is given off which soon disappears into the cartilage. This vessel probably corresponds to the vertebral artery of the Skate. Where the first efferent vessel forms a loop around the first branchial cleft. it gives off an artery corresponding to the common carotid of Raia and Scyllium. This common carotid runs along 

the inner side of the spiracle and upper jaw, joins its fellow of the other side in the middle line, then disappears in the cartilage of the skull. The second, third and fourth efferent branchial vessels from the gills all converge to join the dorsal aorta. Between the origin of the third and fourth pair of efferent vessels a

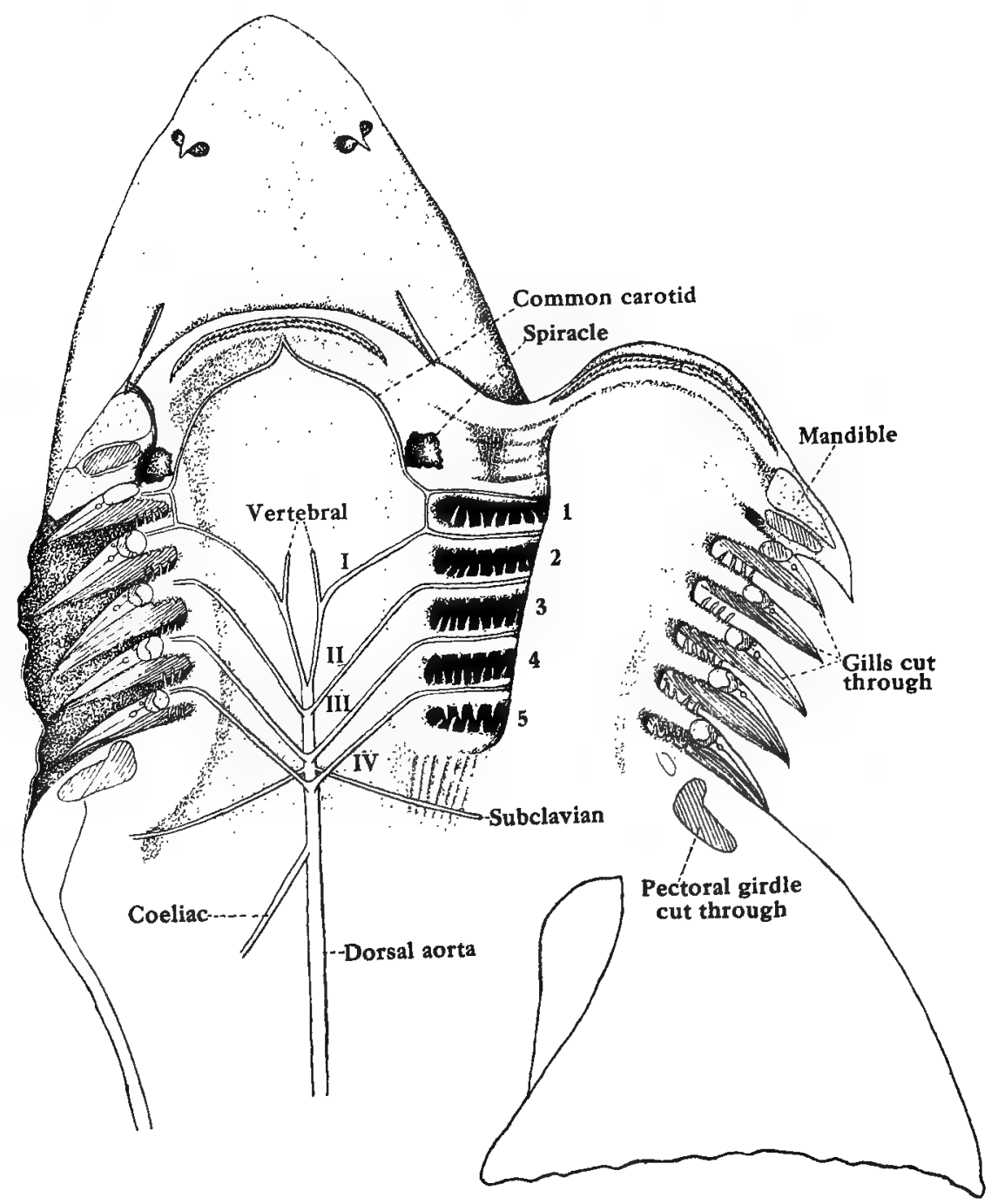

Fig. 58.-The Dogfish (Acanthias, syn. Squalus). Efferent Branchial or Dorsal Arterial System.

subclavian artery is given off on each side, passing backwards to the pectoral fin. Posterior to this the aorta gives off the cœliac artery already referred to. aorta.

Make a complete drawing of the efferent branchial vessels and the dorsal

[In Scyllium the first pair of efferent vessels unite to form the aorta between the first gill-clefts. At first each vessel forms a loop round the first gill-cleft. The 

remaining three pairs of efferent vessels are similar and form loops round the second, third and fourth gill-clefts. There is a half-loop or single vessel on the anterior side only of the fifth gill-cleft, as this cleft has no gill on its posterior side. This vessel is joined at its middle to the loop round the fourth gill-cleft. The loops are all connected with each other at about the middle of their lengths by short horizontal vessels passing across the gill-arches. From the inner anterior end of the first loop of each side a common carotid artery arises. These carotids curve forwards and inwards along the inner surface of the floor of the skull, each dividing into an external and an internal carotid artery. The former runs forwards to supply the upper jare and snout. The latter passes inwards to the mid-ventral line, where the two internal carotids cross each other, unite with the hyoidean artery, and supply the brain. The dorsal aorta is prolonged anieriorly in the middle line; and it bifurcates to form the pair of posterior carotid arteries, each of which joins a common carotid artery just where that vessel divides into external and internal carotids. From the middle of the anterior half of the first loop, and in line with the short horizontal vessels, the hyoidean artery arises; it runs forwards dorsal to the hyomandibular cartilage, passes to the spiracle to supply the pseudobranch, and enters the cranium by a small foramen in the inner wall of the orbit, and joins the internal carotid.]

[In the Skate (Raia) the efferent vessels form loops round the first four gill-clefts, just as in Scyllium. After leaving the clefts, the first and second efferent branchial vessels unite into one, and thus only ihree pairs of main efferent vessels join to form the dorsal aorta. The fifth gill-cleft has a small vessel on its anterior side, this vessel being connected by a short horizontal vessel with the loop round the fourth gill-cleft. The first efferent vessel gives off a vertebral artery, similar to that in Acanthias, passing to the brain and spinal cord. There is only a small hyoidean artery, which passes to the side of the hyomandibular curtilage and does not take a course as in Scyllium. The dorsal aorta is not produced anteriorly as in Scyllium, but resembles that of Acanthias. The common carotid artery resembles that of Acanthias and Scyllium. The dorsal aorta gives rise to a pair of subclavian arteries to the pectoral fins.]

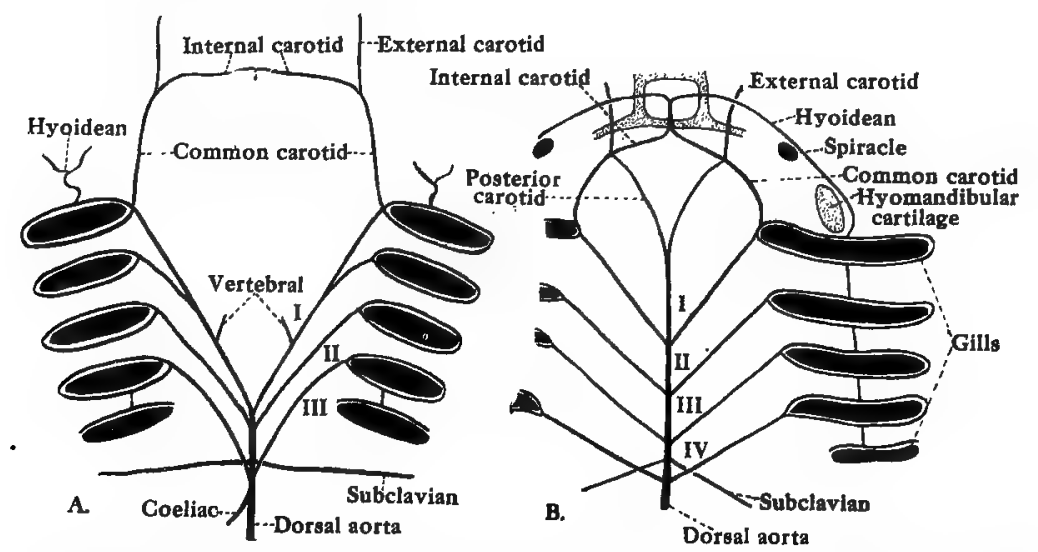

FI(: 59.-The Efferent Branchial or Dorsal Arterial System (A.) of the Skate (Raia); and (B.) of the Dogfish (Scyllium). 



\section{Third Day}

$E$. The Skeletal System (continued).

Remove the integument from the head and branchial region so as to expose the skull and the visceral arches. There are seven visceral arches, forming the supporting framework of the branchial region (pharynx). The first is the mandibular, represented by the upper and lower jaws, and the second is the hyoid, which is divided into an upper or hyomandibular portion, attached to the skull and serving (as the suspensorium) to connect the jaws with the cranium, and a lower portion, the hyoid proper or cerato-hyal. The other five are the branchial arches, and each is divided into four segments.

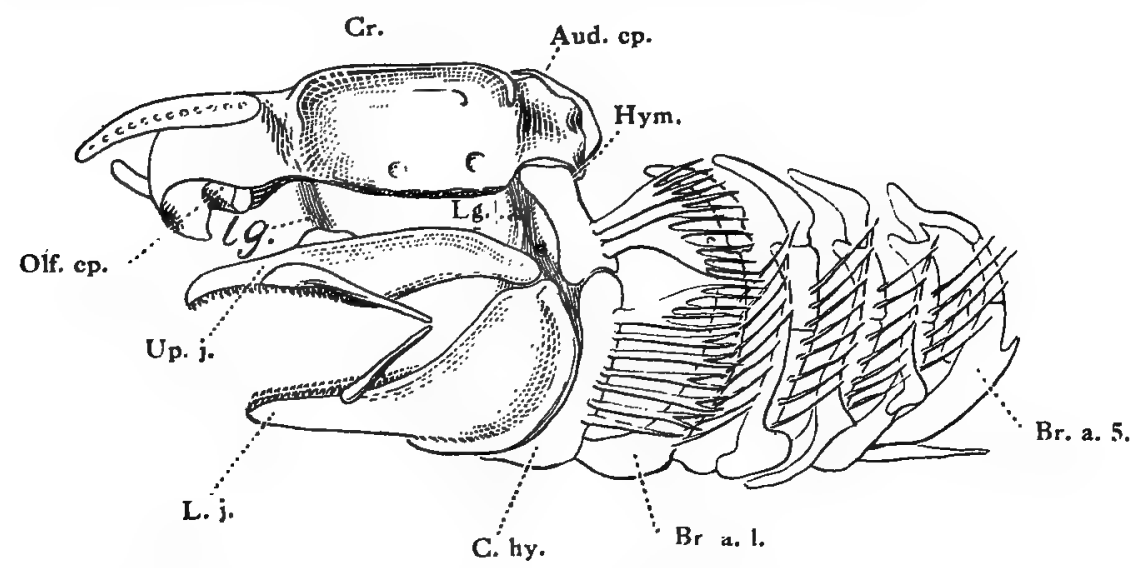

FI1: 60.-Skull and Visceral Arches of the Dogfish (Scyllium) as seen from the left side. After W. K. Parker.

Cr., Cranium; Olf. cp., Olfactory capsule; Aud. cp., Auditory capsule; Up. j., Upper jaw or palato-pterygoid cartilage; L. j., Lower jaw (Meckel's cartilage); Lg., Ligament; Hym., Hyomandibular; C. hy., Cerato. hysl or hyoid proper; Br. a. 1 to Br. a. 5, Branchial arches.

$F$. The Nervous System.

Slice away the cartilaginous cranium so as to expose the brain, taking care to leave the eye and the auditory organ (otocyst) of the left side uninjured. Note the olfactory capsules lying over each nostril.

1. The Brain.

(a) The olfactory lobes lie close to the olfactory capsules, and are connected to the cerebral hemispheres, each one by a long stalk.

(b) The cerebral hemispheres (prosencephalon) are fused together to form the anterior part of the brain.

(c) The thalamencephalon is the insunk part behind the cerebral hemispheres. It has a thin roof with a. choroid plexus of blood-vessels. Its narrow cavity is the third ventricle, and its thick side-walls are the optic thalami. From the posterior part of its roof a slender stalk-like outgrowth, the pineal organ or epiphysis, projects forward. An outgrowth from its floor is the infundibulum 

(with the inferior lobes and the saccus vasculosus). The pituitary body (hypophysis) is attached to the under-surface of the infundibulum.

(d) The optic lobes overlie the posterior part of the thalamencephalon, and represent the thick bulged-out roof of the mid-brain, the side-walls of which are the crura cerebri and its cavity is the iter.

(e) The large ovoid cerebellum partly covers the optic lobes in front and the medulla behind. It represents the thickened front part of the roof of the hind-brain.

$(f)$ The medulla oblongata, partly covered by the cerebellum, forms the posterior part of the brain. It is produced forwards along each side (restiform bodies), and is continuous behind with the spinal cord. Its cavity is the fourth ventricle.

Note that $(a),(b)$ and $(c)$ represent the cerebrum or fore-brain, $(d)$ represents the mesencephalon or mid-brain, and $(e)$ and $(f)$ represent the rhombencephalon or metencephalon or hind-brain.

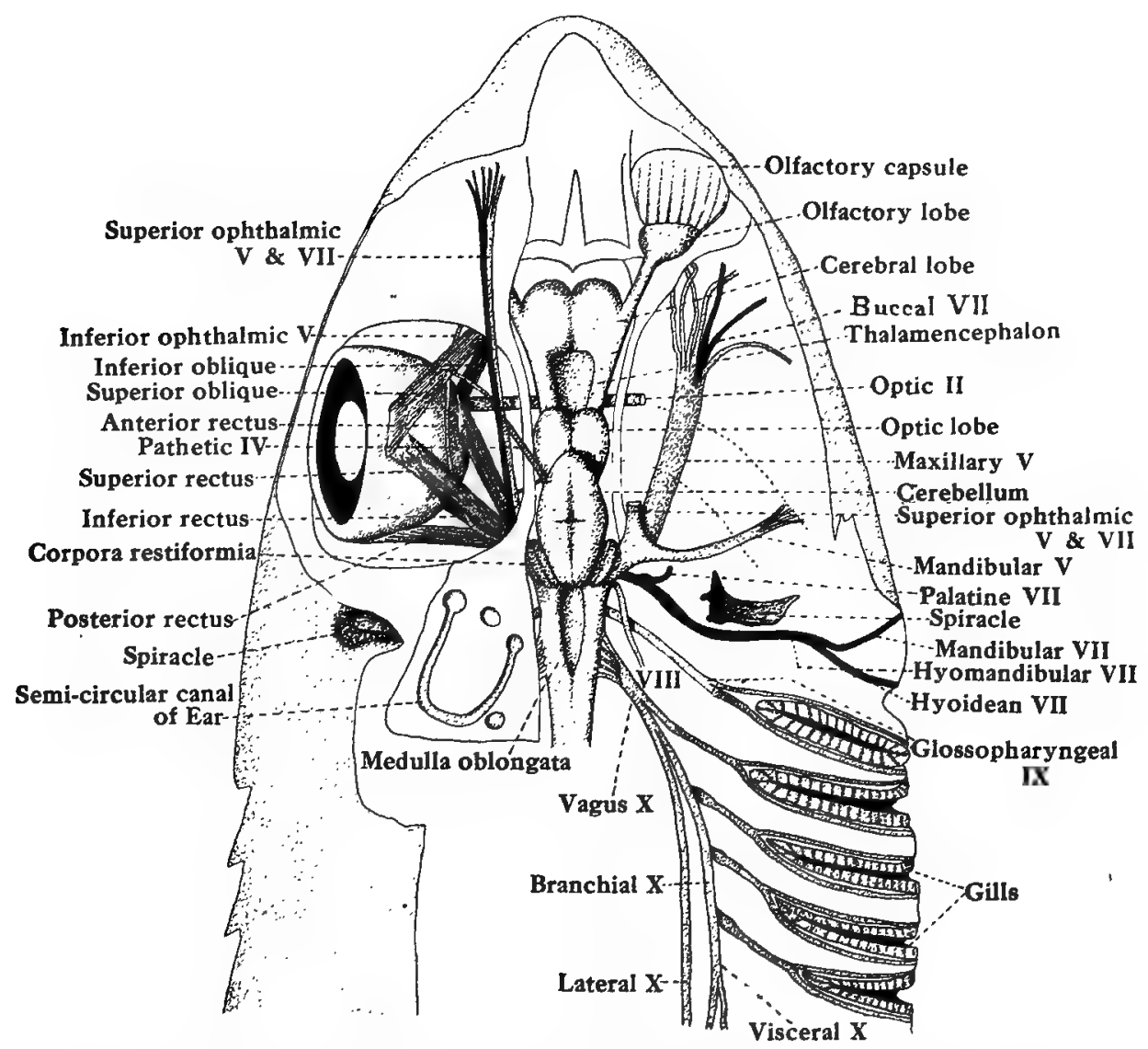

FIG. 61.-The Dogfish (Acanthias, syn. Squalus). Brain (dorsal view), Cranial Nerves, and Eye Muscles. 



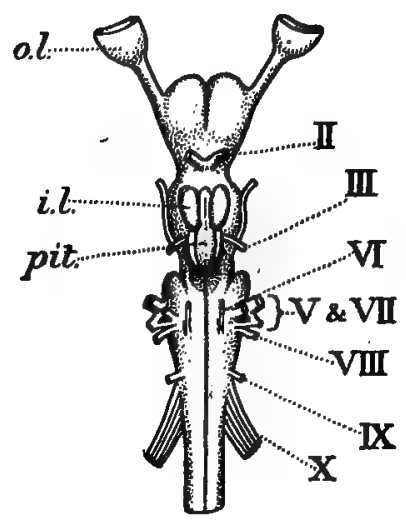

FIG. 62.-Ventral View of the Brain of the Dogfish (Acanthias). After Purser. With permission from J. Graham Kerr's Zoology for Medical Students.

$o_{0} l$. , olfactory bulb; $i . l$., inferior lobe; pite, pituitary body; II-X, Roots of Cranial Nerves.

\section{The Cranial Nerves.}

The following is a list of the cranial nerves and their chief branches :-

I. Olfactory.

II. Optic.

III. Oculomotor.

IV. Pathetic. Voiknew ns
V. Trigeminal $\left\{\begin{array}{l}(a) \text { Superior ophthalmic. } \\ (b) \text { Inferior ophthalmic. }\end{array}\right.$ (c) Maxillary.
(d) Mandibular.

VI. Abducent.

VIII. Auditory.
$\left\{\begin{array}{l}\text { (a) Superior ophthalmic. } \\ \text { (b) Buccal. }\end{array}\right.$
(c) Palatine.
(d) Hyomandibular.

VIl. Facial

IX. Glosso-pharyngeal.
X. Vagus $\begin{cases}(a) & \text { Branchial. } \\ (b) & \text { Visceral. } \\ (c) & \text { Lateral. }\end{cases}$

In dissecting out the cranial nerves and the eye muscles it is best to do so in the following order :-

(i) The olfactory nerve (I), represented by a number of fine branches arising from the anterior end of each olfactory lobe and passing at once into the olfactory capsule, where they become distributed to the epithelium of the olfactory organ.

(ii) The pathetic nerve (IV), arising from the dorsal surface of the brain, between the anterior part of the cerebellum and optic lobes, and passing 

into the cartilage of the skull. Cut away the cartilage above the eye until the superior ophthalmic branch of the trigeminal nerve (V) is exposed. This ophthalmic nerve represents the fused ophthalmic branches of the trigeminal nerve (V) and the facial nerve (VII). Trace this branch from its origin over the eye muscles to the snout. Follow the pathetic, which passes under the ophthalmic, to the superior oblique eye muscle.

(iii) Cut away the cartilage further down between the eye and the brain, and note the optic nerve (II) passing straight from the brain to the eye.

(iv) Note the upward cartilaginous projections of the upper jaw between the superior ophthalmic branch and the sides of the skull.

(v) Make out the following eye muscles :--

(a) The two oblique muscles, arising close together at the anterior part of the orbit and inserted widely apart on the anterior half of the eye, the superior oblique on the dorsal surface and the inferior oblique on the ventral surface.

(b) The four recti muscles, arising close together at the posterior part of the orbit and inserted mostly on the posterior half of the eye, the superior rectus on the dorsal surface, the inferior rectus on the ventral surface, the posterior rectus or rectus externus on the posterior surface, and the anterior rectus or rectus internus, which passes behind the eye and between the two oblique muscles, and which is inserted on the anterior surface of the eye.

(vi) The oculomotor nerve (III), arising from the under-surface of the midbrain, passing through the wall of the skull, and supplying the following eye muscles: the inferior oblique, the superior and the inferior and the anterior rectus.

(vii) The inferior ophthalmic or ophthalmicus profundus branch of the trigeminal nerve $(\mathbf{V})$, passing over the eye under the superior rectus and the superior oblique muscles, and going forwards to the snout. [This branch is absent in Scyllium.] Trace both the ophthalmic branches back to their origin. Raise the eye and note, passing along the floor of the orbit, the maxillary branch of the trigeminal nerve (along with the buccal branch of the facial nerve) to the upper jaw. Make out the mandibular branch of the trigeminal nerve, arising behind the maxillary and passing through the cartilage to the lower jaw.

(viii) Slice away the cartilage alongside the spiracle so as to expose the semicircular canals of the ear (otocyst), and make out the following nerves arising together with the trigeminal (V) from the side. of the medulla, anteriorly :-

(a) The hyomandibular branch of the facial nerve (VII), passing between the spiracle and the hyomandibular cartilage, and dividing into an external mandibular nerve to the lower jaw and a hyoidean nerve to the hyoid arch. 

(b) The palatine branch of the facial nerve (VII), passing forwards from the hyomandibular branch in front of the spiracle and going obliquely across the floor of the orbit to supply the roof of the mouth.

[In the Skate (Raia) the facial nerve (VII) gives off the following branches :-

(a) The superior ophthalmic, which is fused with the superior ophthalmic of the trigeminal and which supplies the snout (sensory ampulloe).

(b) The inner buccal, which runs under the eye and through the nasal capsule to the inner buccal ampulloe.

(c) The outer buccal, which runs under the eye, external to the olfactory capsule, and goes to the outer buccal ampulloe.

(d) The palatine, passing downre:ards in front of the spiracle, and supplying the roof of the mouth. It gives off a small prespiracular branch to the front of the spiracle.

(e) The hyomandibular, passing outwards behind the spiracle and the mandibular muscle, and giving off the folloring branches:-

(a) The recurrent facial, running external to the auditory capsule.

$(\beta)$ The internal mandibular or "chorda tympani," going under the spiracle to the inner side of the jare.

( $\gamma$ ) The facial proper, supplying the muscles of the hyoid arch.

$(\delta)$ The hyoidean or postspiracular, passing downroards to the muscles and ampulloe of the hyoid arch.

( $\epsilon)$ The exiernal mandibular ( $a$ branch from the hyoidean), passing behind and round the mandibular muscle to the mandibular ampulloe.]

(c) The auditory nerve (VIII), arising behind the facial nerve from the side of the medulla and passing directly into the auditory capsule, and in its course crossing the glosso-pharyngeal nerve (IX).

(ix) The glosso-pharyngeal nerve (IX), arising from about the middle of the medulla oblongata, and passing back across the floor of the auditory capsule to supply the first gill-cleft.

(x) The vagus or pneumogastric nerve (X), arising just behind the glossopharyngeal nerve, by several smaller roots which fuse together to form a conspicuous nerve. The vagus divides into a branchial nerve, which gives off four branches supplying the second to fifth gillclefts, and a lateral nerve running along the side of the body and supplying the lateral line. After giving off the branchial branches to the gill-clefts, the branchial nerve passes backwards as the visceral nerve to the heart and stomach and other viscera. Slit open the anterior cardinal sinus to show the branchial branches passing along its inner wall and across the floor.

(xi) The abducent nerve (VI), a small inconspicuous nerve completely concealed by the brain. It can be seen under the posterior rectus muscle, which it supplies; and it may be traced below the inferior ophthalmic 

to the under-surface of the medulla, where it arises between the roots of nerves $\mathrm{V}$ and VII and the mid-ventral line.

Make a complete drawing of the brain, cranial nerves, and eye muscles.

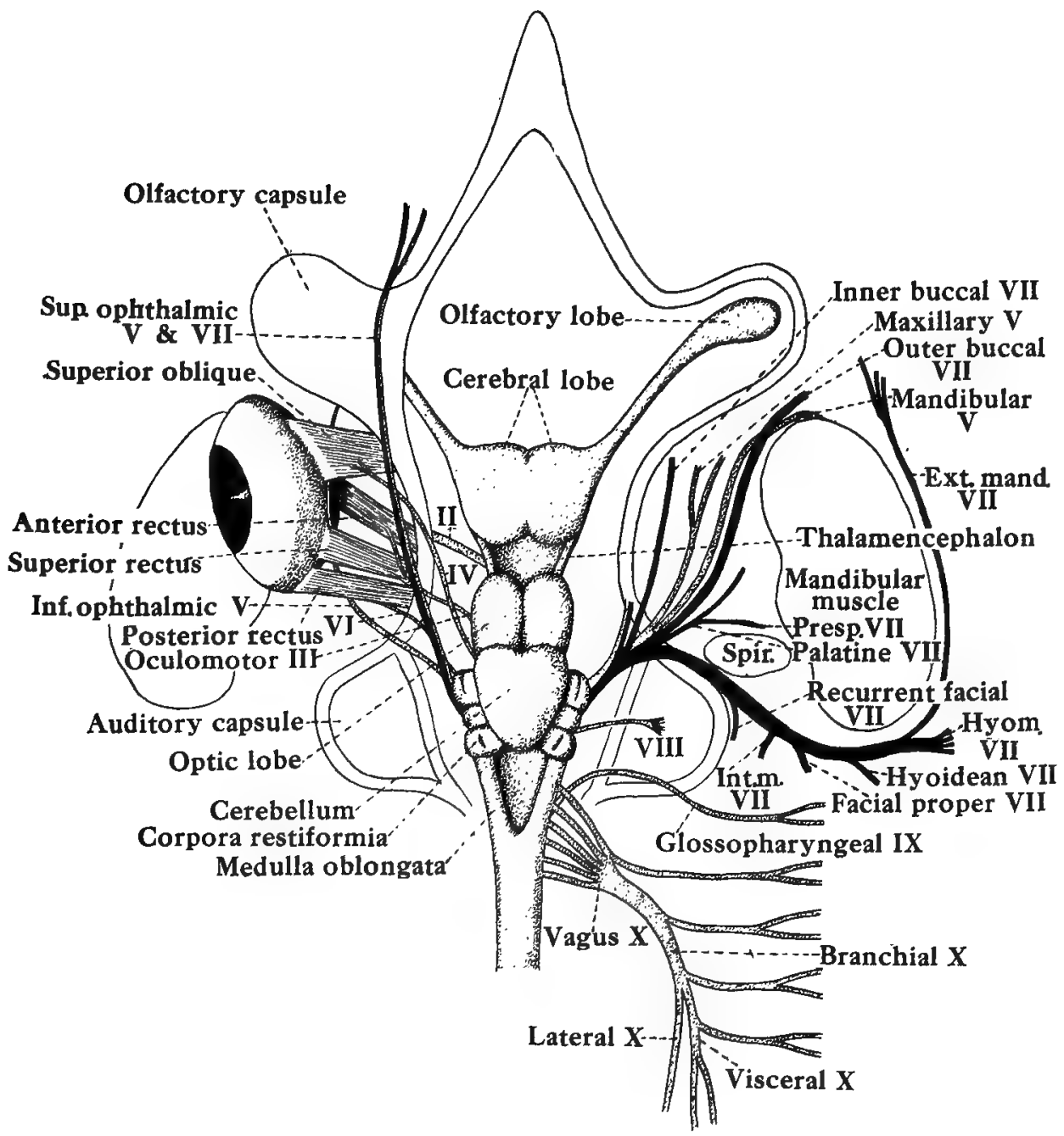

Fig. 63.-The Brain (dorgal view), Cranial Nerves, and Eye Muscles of the Skate (Raia). .

II. Optic nerve; IV. Pathetic nerve; VI. Abducent nerve; Lxt. mand. VII. External Mandibular branch of Facial nerve; Hyom. VII. Hyomandibular branch of Facial nerve; Int. m. VII. Internal Mandibular branch of Facial nerve; Presp. VII. Prespiracular branch of Facial nerve; VIII. Anditory nerve; Spir. Spiracle.

Examine one of the auditory organs or otocysts. Carefully remove the cartilage of the auditory capsule of the skull until the parts of the otocyst are exposed. It consists of three semicircular canals, an endolymphatic duct, otoliths (limy matter) in the lower part, and endolymph throughout the cavity and within the canals. Between the otocyst wall and the cartilaginous auditory capsule is the perilymph. 



\section{THE FROG (Rana) \\ THE PLATANA or CLAWED TOAD (Xenopus)}

\section{External Features.}

\section{First Day}

1. Make a drawing of the dorsal surface of the Frog (or the Toad), showing:

(a) The nostrils or external nares.

(b) The eyes, each with two eyelids. The upper eyelid is well developed, pigmented, and almost immovable; the lower one is a mere fold of skin, produced into a thin, transparent and freely movable nictitating membrane. [In the Platana there is also a short tentacle beneath the eye.]

(c) The circular tympanic membrane, situated just behind the eye. [This is absent in the Platana.]

(d) The opening of the cloaca, on the dorsal surface and between the legs. [In the female Platana there are three conspicuous folds of skin around the cloaca.]

(e) The limbs and their divisions.

$[(f)$ In the Platana the skin has tube-like lines round the body. These are the openings of the slime glands, with which the skin is richly supplied.]

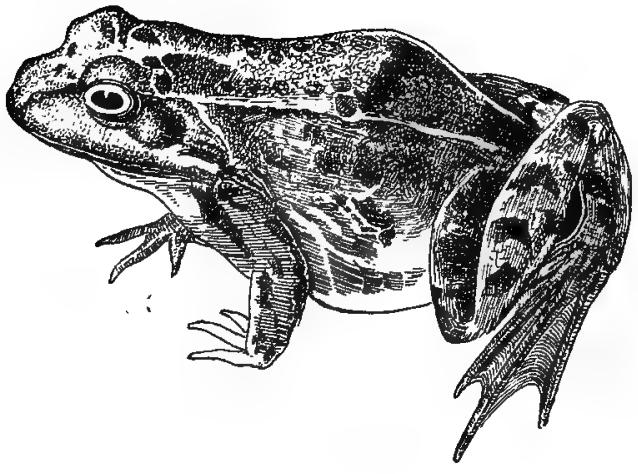

A

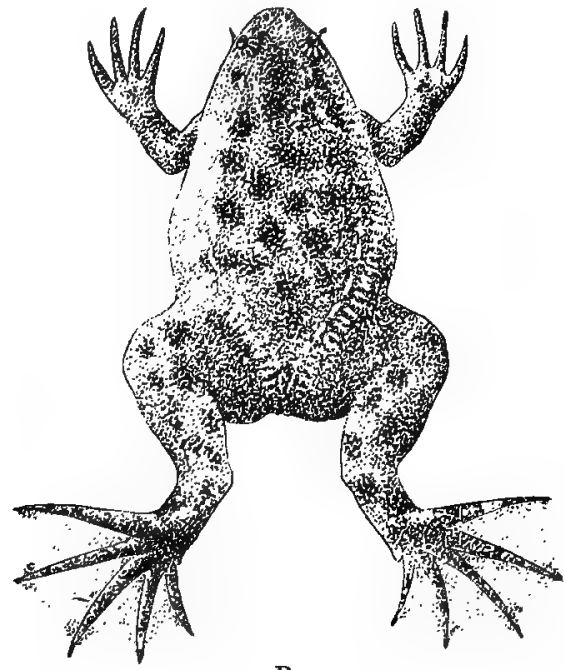

B

Fr(. 64.-A. The Frog (Rana), nat. size; B. The Platana or Clawed Toad (Xenopus), reduced.

2. Make an enlarged drawing, about twice the natural size, showing:

(a) The fore-limb, consisting of upper arm, fore-arm, and hand with four complete digits (the first digit, the pollex or thumb, being an inconspicuous rudiment). 

(b) The hind-limb, consisting of thigh, shank or leg, and foot with elongated ankle-region and five webbed digits, the shortest one being the hallux or "great toe." [In the Platana the inner three digits have clares.]

Name the parts of the limbs, and number the digits from within outwards.

\section{Mouth Cavity.}

Open the buccal or mouth cavity widely, and make a sketch showing :

(a) The teeth on the upper jaw.

(b) The teeth on the vomers. [There are no vomerine teeth in the Platana.]

(c) The internal nares or internal openings of the nostrils.

(d) The pair of Eustachian apertures, at the angles of the mouth. [In the Platana there is a single Eustachian aperture.]

(e) The tongue. [Absent in the Platana.]

$(f)$ The glottis, the slit-like opening of the larynx which leads from the lungs.

(g) The gullet.

Pass a seeker into the Eustachian aperture, along the Eustachian tube and through the tympanic membrane. [In the Platana, owing to the complexity of the Eustachian tubes and the bony form of the ear.cavity, it is not possible to do this.]

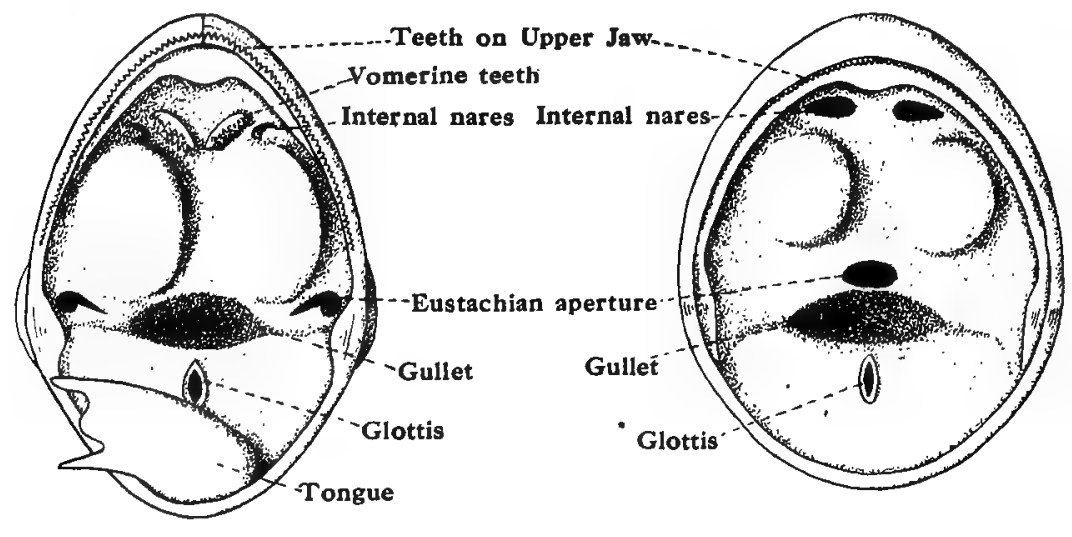

A

B

Fia. 65.-A. Buccal or Mouth Cavity of Rana ; and B. of Xenopus.

\section{Muscular System and Vascular System (part).}

1. Lay the Frog on its back under water in the dissecting-dish, and fix it firmly by pins through the limbs. Using scissors, cut through the skin along the middle line, the whole length of the body. Reflect the skin on each side and pin it down, noticing its loose attachment and the subcutaneous lymph spaces. Make a drawing showing:

(a) The muscles.

(i) Two pectoralis muscles, each consisting of two portions passing to the upper arm ; one portion arising from the sternum, the other from the outer side of the rectus abdominis muscle. 

Cut through the latter portion close to the arm, and fold it backwards to expose the underlying brachial vein.

(ii) Two recti abdomini muscles, one along each side of the midventral line of the body, and there separated by the white line (linea alba). Each rectus abdominis muscle is transversely divided into bellies.

(iii) The deltoid muscle to the arm.

(iv) The mylo-hyoid muscle, on the underside of the mouth region:

(v) The obliquus-externus muscles (which cover the sides of the body) underlying the recti abdomini and the abdominal portions of the pectoralis muscles.

(b) The musculo-cutaneous vein, lying under the pectoralis muscle. It joins with the brachial to form the subclavian vein; and it is formed by branches from the skin and muscles in the region of the arm. [In the Platana the muscular and cutaneous veins do not join to form one. There is a second cutaneous vein arising from the skin of the abdomen and joining the abdominal vein. Tro small cutaneous veins are seen on the skin of the leg, and another on the skin under the lower jarw.]

(c) The abdominal vein, visible through the body-wall as a dark longitudinal line between the recti abdomini muscles. Before it enters the liver, it receives the hepatic portal vein from the gut and spleen.

(d) The brachial vein of the arm. Near it is the white brachial nerve, which may often be seen. Try to trace the point of junction of the brachial and musculo-cutaneous veins, or the brachial, muscular, and cutaneous veins in the Platana, as shown in the figures.

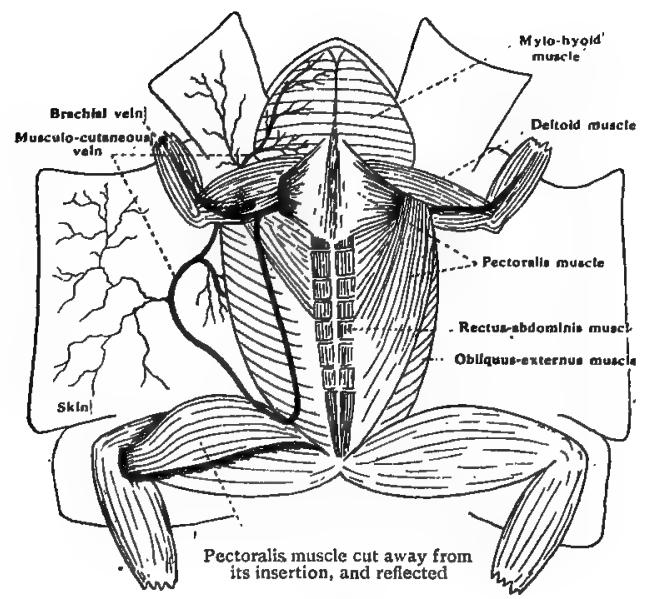

A

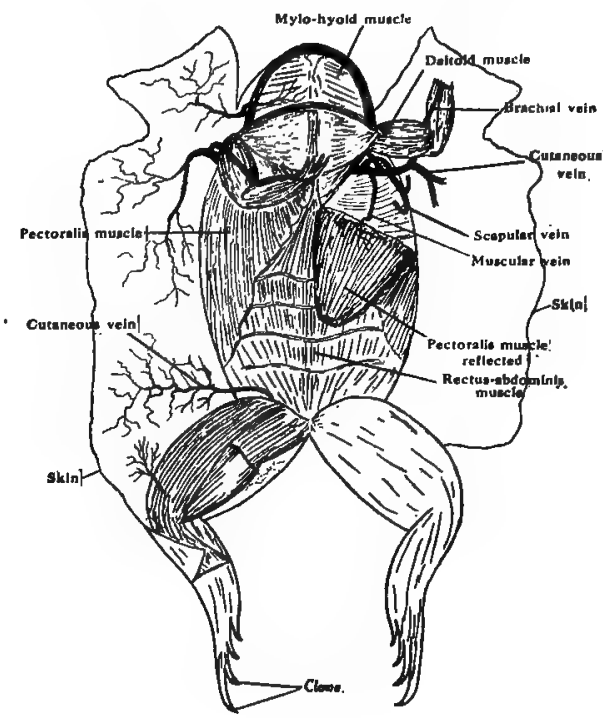

B

Frg. 66. -A. Muscular System and Vascular System (part) of Rana ; and B. of Xenopus. 

2. Make an incision in the body-wall, slightly to the right side of the abdominal vein, which may then be seen clearly on the inner side of the bodywall. Carefully detach this vein from the abdominal wall. Remove the skin from the legs.

\section{Second Day}

\section{Skeletal System (part).}

1. Remove the upper portions of the pectoralis muscles, covering the part of the body between the arms, to show the bones and cartilages of the central part of the shoulder girdle and sternum, viz. :

(a) The thick coracoids.

(b) The more slender clavicles anterior to the coracoids; and both extending, on each side, from the base of the arm towards the centre of the body.

(c) The sternum, consisting of a median row of cartilages which are believed to be derived from the shoulder girdle. It does not, therefore, correspond to, or is not homologous with, the sternum of the Pigeon or the Rabbit, which is derived from the ribs. The sternum consists of the following parts :-

(i) The omosternum, consisting of two parts-viz. an anterior cartilaginous part (sometimes called the episternum) and a posterior bony rod (the omosternum proper).

(ii) The two cartilaginous epicoracoids.

(iii) The metasternum, consisting of two parts-viz. an anterior bony part (sometimes called the mesosternum or sternum) and a posterior cartilaginous part (sometimes called the xiphisternum).

[In the Platana the sternum consists of the following parts :-

(i) The tro cartilaginous epicoracoids.

(ii) The metasternum, which is broad and consists of cartilage only.]

Make a sketch of the pectoral girdle. (See Fig. 76, A or B, page 218.)

2. Cut through the coracoids and clavicles on each side, close to the base of the arm, and carefully remove this part of the pectoral girdle and sternum so as to expose the heart lying beneath.

\section{Alimentary System.}

Make a sketch showing the heart, lungs, liver, gall-bladder, bile-duct (common duct of liver and pancreas) going to the duodenum, exposed parts of the stomach, duodenum, small intestine (or ileum), large intestine (or rectum), pancreas, spleen, and urinary or cloacal bladder. 



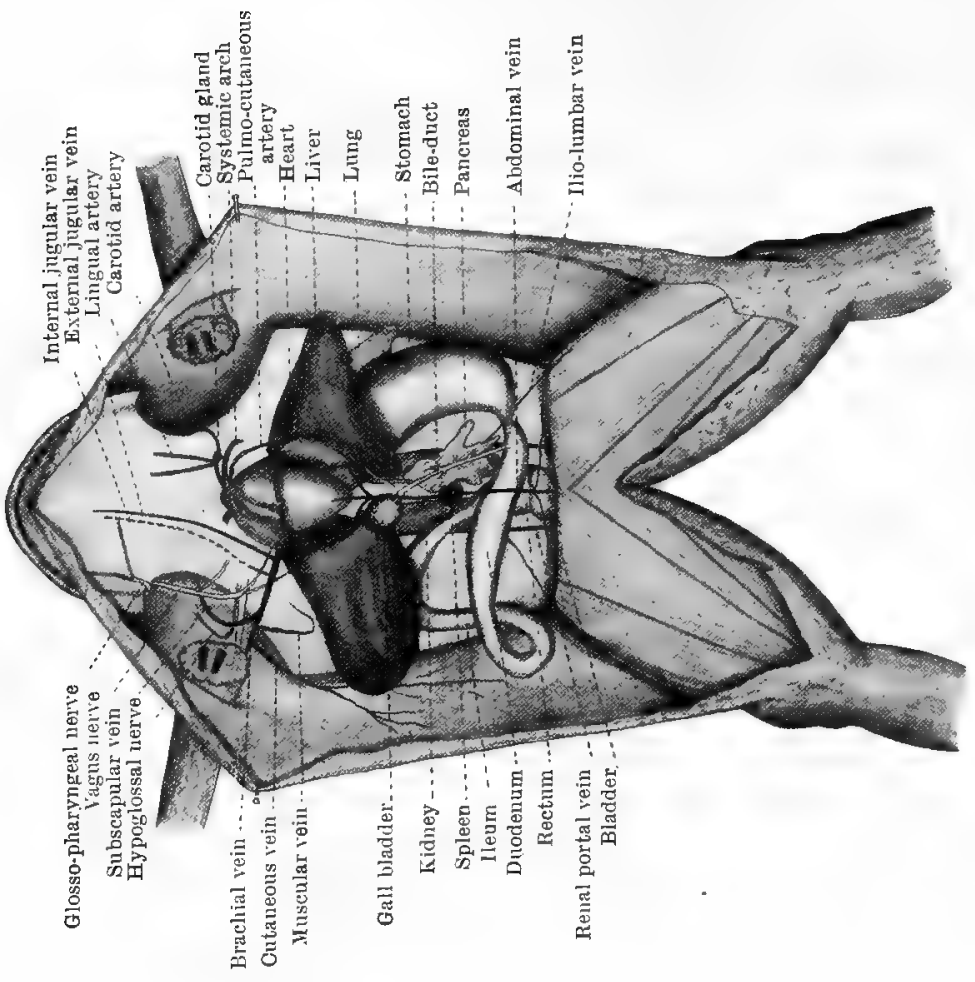

$\eta$

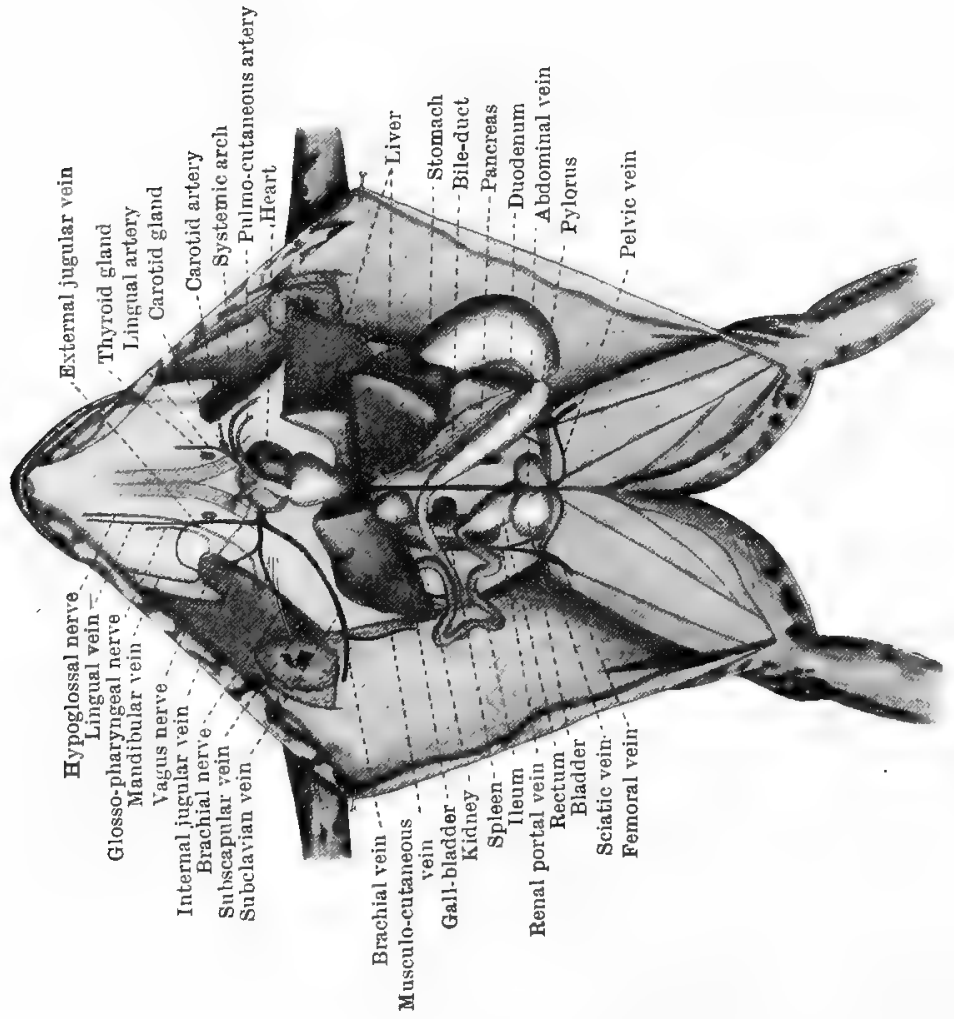

ป 



\section{Third Day}

\section{Muscular System and Vascular System (continued), and Nervous System (part)}

\section{A. Muscular System.}

In order to facilitate the location of the veins and arteries of the hind-limbs, it is necessary to make out the following muscles :-

1. Muscles of the Thigh (ventral surface) :

(a) The sartorius, a long flat muscle arising from the lower end of the ilium, and inserted into the inner side of the head of the tibia.

(b) The vastus internus, a large muscle arising from the ventral and anterior border of the acetabulum, and lying partly under the sartorius on the outside of the thigh.

(c) The rectus internus major, a large muscle arising from the ischium, occupying the inner side of the thigh and inserted into the head of the tibia. It is covered distally by the sartorius.

(d) The adductor magnus, a large muscle arising from the pubis and ischium. It lies between the sartorius and the rectus internus major, and is concealed by these muscles distally where it becomes inserted into the femur.

2. Muscles of the Shank (ventral surface) :

(a) The gastrocnemius, a large spindle-shaped muscle forming the calf of the leg. It arises mainly from the hinder side of the distal end of the femur; and it ends in the long and slender tendo Achillis, which passes under the ankle joint and into the sole of the foot.

A

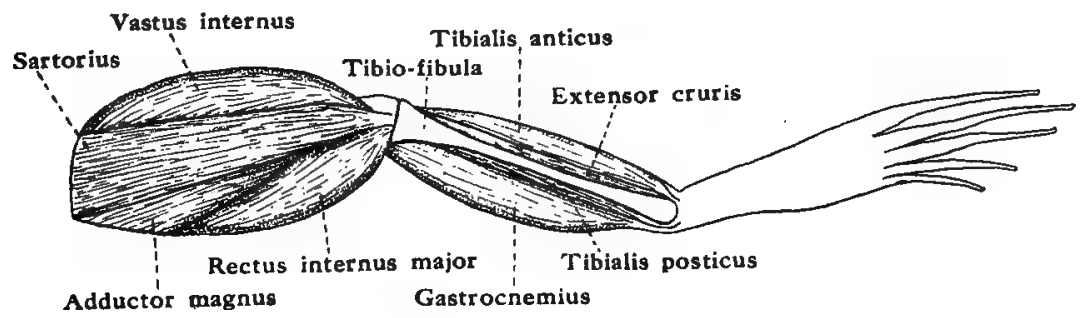

B

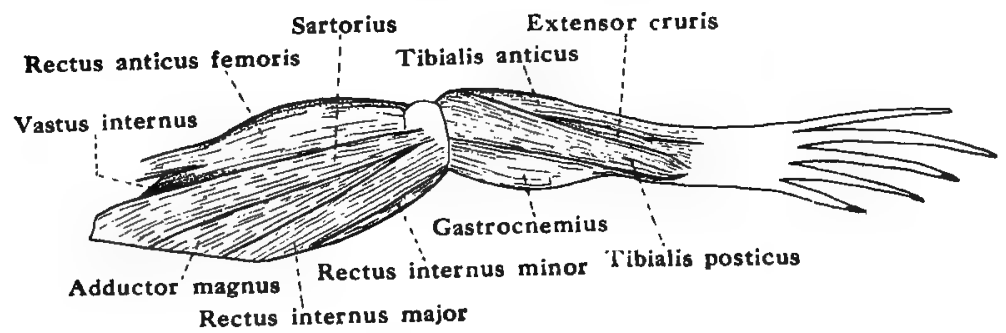

FiG. 68.-A. Muscles of the Left Hind-limb of Rana; and B. of Yenopus, from the ventral surface. 

(b) The tibialis posticus, lying between the gastrocnemius and the tibiofibula and running along the whole length of the tibio-fibula.

(c) The tibialis anticus, on the outer side of the leg.

(d) The extensor cruris, lying between the tibialis anticus and the tibiofibula.

3. Muscles of the Thigh (dorsal surface) :

(a) The rectus anticus femoris, occupying the outer dorsal surface of the thigh, arising from the ilium in front of the acetabulum and covering the vastus internus.

(b) The vastus externus, occupying the median dorsal part of the thigh and arising from the posterior dorsal edge of the ilium. These two muscles $(a)$ and $(b)$, along with the vastus internus of the ventral surface, join together to form the triceps extensor cruris, the great extensor muscle of the thigh, which is inserted into the tibia just below the head of that bone.

(c) The semimembranosus, a stout muscle occupying the inner surface of the thigh, and arising from the dorsal part of the ischium. It is inserted into the back of the head of the tibia.

(d) The biceps, a long slender muscle almost completely covered by the vastus externus and the semimembranosus.

4. Muscles of the Shank (dorsal surface) :

(a) The gastrocnemius.

(b) The peroneus, a stout muscle occupying the outside of the leg between the tibialis anticus and the gastrocnemius.

[The muscles of the hind-limbs of the Platana are very similar to thos: of the Frog, except that the rectus anticus femoris extends on to the ventro-lateral surface of the thigh so as to cover almost the rohole of the vastus internus. In the shank. the tibialis posticus is much enlarged and covers the tibio-fibula completely.]

$A$

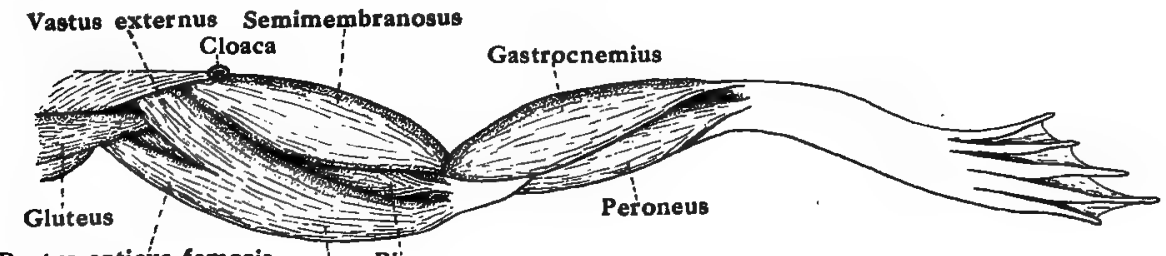

Rectus anticus femoris

Bíceps

Triceps extensor femoris

Semimemoranosus

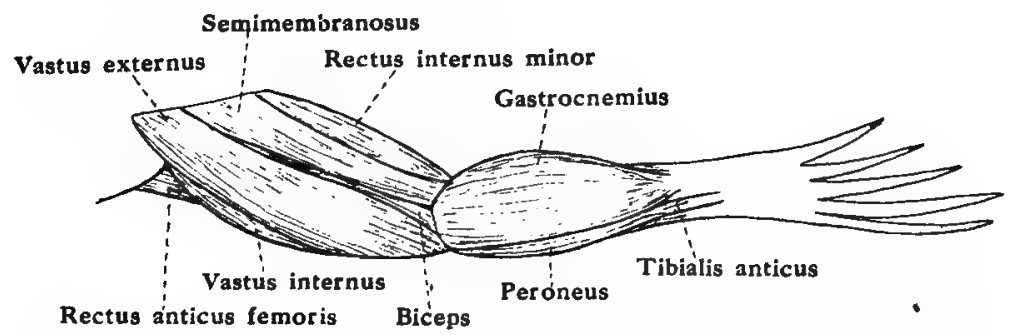

Fra. 69. A. Muscles of the Left Hind-limb of Rana ; and B. of Xenopus, from the dorsal surface. 

B. Venous System and Nervous System (part).

1. Note :-

(a) The heart within a thin pericardium, and consisting of the sinus venosus, the two auricles (divisions of the atrium), the single ventricle, and the conus arteriosus which is continued into the ventral aorta (the "truncus ") which divides into two branches.

Remove the pericardium from the heart and tilt the apex of the heart forwards, noting the dorsal and roughly triangular sinus venosus into which the right and the left superior venæ cavæ (or precavals) and the single inferior vena cava (or postcaval) open.

(b) The veins passing from each side of the sinus venosus. Each superior vena cava is formed by the union of the following branches :-

(i) The external jugular vein, formed by the union of the lingual vein from the tongue and the mandibular vein from the margin of the lower jaw.

(ii) The innominate vein, formed by the union of the internal jugular vein from the head and the subscapular vein from the back of the arm and shoulder.

(iii) The subclavian vein, formed by the union of the brachial vein from the fore-limb and the musculo-cutaneous vein from the muscles of the body and from the skin.

[In the Platana the superior vena cava is formed by the following vessels :-

(i) The external jugular vein, which passes under the mylo-hyoid muscle, from the region of the tongue and mandible.

(ii) The internal jugular vein, which runs on the under side of the floor of the mouth, parallel to the external jugular.

(iii) The thick subscapular vein from the shoulder. As the internal jugular and the subscapular veins join the precaษal vein separately, there is no innominate vein.

(iv) The subclavian vein, which is formed by the brachial vein from the arm, a cutaneous vein from the skin, and a muscular vein from the abdominal muscles. The muscular and the cutaneous veins are separate, consequently there is no musculo-cutaneous vein.]

(c) The hypoglossal (spinal nerve II) and the glosso-pharyngeal nerves, both running alongside the lingual vein. [In the Platana the glosso-pharyngeal nerve runs along the inner side of the lower jaw, while the first spinal nerve (corresponding to the hypoglossal of. the Frog) curves inwards to supply the mylo-hyoid muscle.]

(d) The vagus nerve, supplying the heart and lungs and stomach. It emerges just posterior to the glosso-pharyngeal, and closely follows the course of the internal jugular vein. [In the Platana it follors the course of the subscapular vein.]

Make an enlarged drawing showing the above parts. (See Fig. 67, A or B, page 196.) 

2. Note the inferior vena cava (postcaval vein) receiving the renal veins from the kidneys and the hepatic veins from the liver, and opening into the sinus venosus.

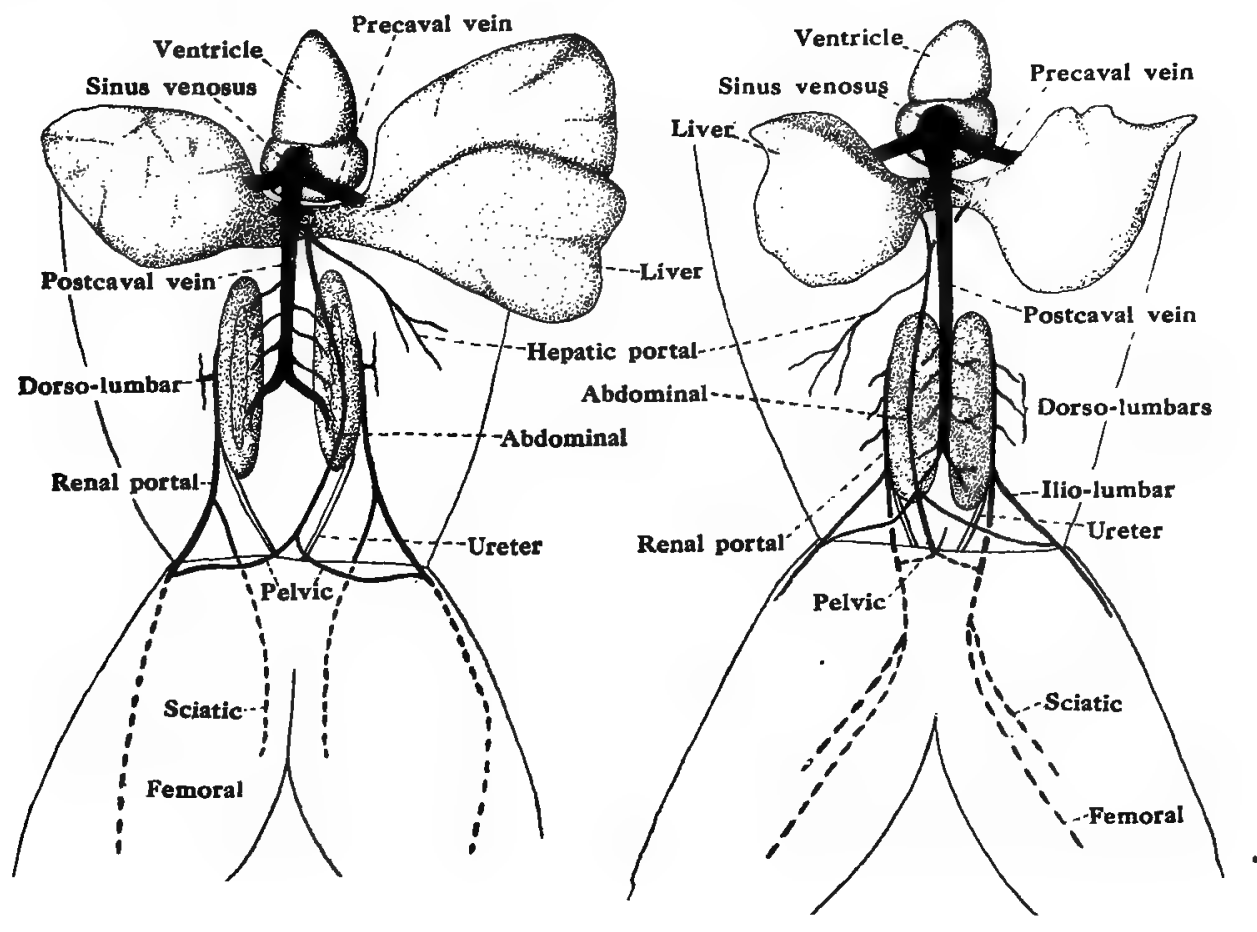

A

B

Fig. 70.-A. Venous System (posterior part) of Rana; and B. of Xenopus, from the ventral aspect. The ventricle of the heart is tilted forwards to show the sinus venosus. The veins of the legs, being on the dorsal side, are shown in broken lines.

3. In order to make out the femoral and sciatic veins, turn the Frog over so as to have the dorsal surface uppermost. Carefully separate the rectus anticus femoris muscle from the vastus externus muscle so as to expose the femoral vein; it lies between the vastus internus and the vastus externus, where it may be traced back a short distance, then gradually towards the inside of the thigh, under the vastus externus and biceps muscles. It follows the course of the biceps muscle, passing on to the ventral surface of the leg at the knee, just where the gastrocnemius muscle meets the semimembranosus.

Note the ramus communicans iliacus, a small vein on the anterior dorsal surface of the thigh just at the origin of the vastus externus muscle. It is a vessel communicating between the femoral and the sciatic veins.

Carefully separate the biceps muscle from the semimembranosus so as to expose the sciatic nerve. It divides into two branches at the anterior end of the biceps. The main branch, next the biceps muscle, divides just above the knee into the tibial and peroneal nerves supplying the leg and the foot respectively ; the other branch passes under the semimembranosus, and, as it supplies that muscle, it may be named the semimembranosus nerve. Following the 

dorsal surface of the main branch of the sciatic nerve, note the iliac artery, and also the sciatic vein alongside the semimembranosus nerve.

Now lay the Frog on its back, and trace the femoral and the sciatic veins forward. Note that these vessels join together a short distance behind the posterior end of the kidney to form the renal portal vein, which extends along the outer side of each kidney. Opposite the kidney the renal portal is joined by the dorso-lumbar vein, which drains the blood from the back and the lumbar region.

Just anterior to the point of insertion of the vastus internus muscle the femoral vein gives rise to the pelvic vein, which runs over the anterior end of the sartorius muscle and joins its fellow in the middle line to form the abdominal vein, already noted in the first day's work.

[In the Platana the femoral vein lies on the surface of the leg between the vastus externus and the semimembranosus muscles. Trace the femoral vein back along the leg. Carefully separate the biceps muscle from the semimembranosus, and expose the sciatic nerve. This nerve also branches into two, as in the Frog. Folloreing the dorsal surface of the main branch, note the iliac artery; and, on the ventral surface of this nerve, note the sciatic vein. The smaller branch of the sciatic nerve appears to run under the semimembranosus muscle to supply the rectus internus minor muscle. Just anterior to the origin of that nerve, the sciatic vein joins the femoral vein to form the renal portal vein which passes forwards to the kidney. A short distance anterior to its origin, the renal portal gives rise to a pelvic vein which

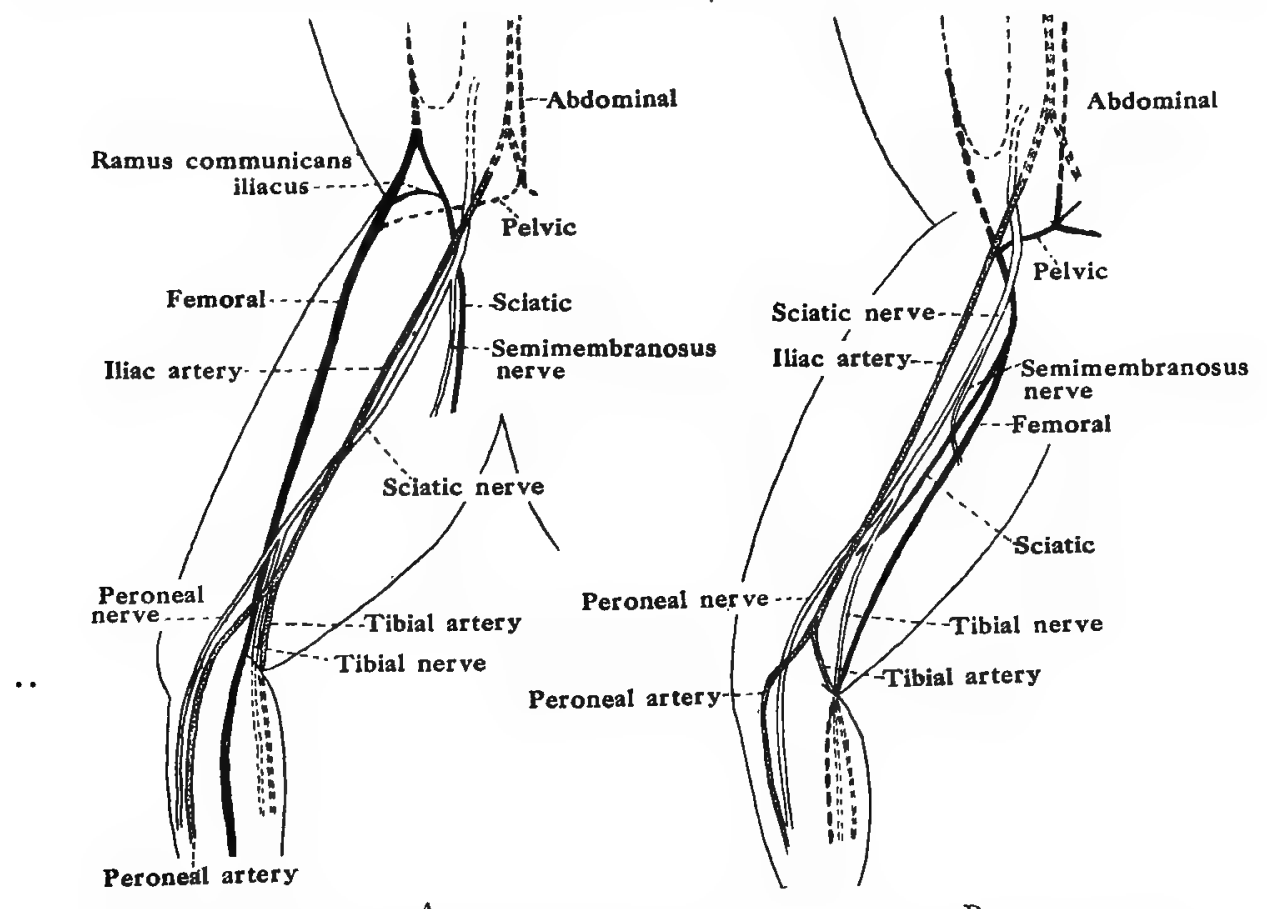

A

B

FIt. 71.-A. Dissection of the Leg of Rana; and B. of Xenopus, from the dorsal surface, showing the veins and arteries and the sciatic nerve. 

runs straight across to meet its fellow in the middle line to form the abdominal vein. At the origin of the abdominal vein a small rectal vein is given off to the rectum. In order to expose the pelvic vein clearly, cut through the pelvic girdle on one side and carefully sever the muscles of the leg from the vicinity of the pelvic girdle.]

\section{Arterial System (part).}

Distend the cesophagus with cotton-wool or a roll of paper in order to show the blood-vessels clearly, and follow out the anterior part of the arterial system. The two branches of the short ventral aorta or "truncus" at once divide into the following three arterial arches :-

(a) The carotid arch, which gives off the arteries to the head region.

(b) The systemic arch, which curves round the osophagus.

(c) The pulmo-cutaneous arch to the lungs and the skin.

\section{Fourth Day}

Arterial System (continued).

1. Trace the carotid arch, which gives off :-

(a) A lingual artery supplying the tongue.

(b) A carotid artery supplying the head. It goes round the side of the œsophagus. A slight swelling at its origin is the carotid gland.

2. Trace the systemic arches which curve round the œesophagus, one on each side, towards the dorsal surface of the body. Going backwards and inwards, the two systemics gradually.converge to meet in front of the kidneys, and there unite to form the dorsal aorta. Each systemic arch gives off :-

(a) A laryngeal artery to the larynx.

(b) An oesophageal artery to the dorsal wall of the cesophagus.

(c) An occipito-vertebral artery to the side of the head and the vertebral column.

(d) A subclavian artery to the shoulder and fore-limb.

At the point where the dorsal aorta is formed, note the large coliacomesenteric artery which arises there, and which sends branches to the stomach, liver, intestine, and spleen.

Trace the dorsal aorta backwards, and note that it passes between the kidneys, there gives off four or six renal arteries, and then divides posteriorly into two iliac arteries which supply the legs. The iliac artery is continued backwards as the sciatic artery in each leg, and divides above the knee into the peroneal and the tibial artery to leg and foot respectively.

3. Trace the pulmo-cutaneous arch, which gives off :-

(a) A pulmonary artery along the outer side of the whole length of the lung.

(b) A cutaneous artery, which passes forward close behind the ear, and then turns sharply backwards to supply the skin of the back and the sides of the head. 
[In the Platana-

1. The carotid arch gives off:

(a) Two arteries having a common point of origin near the carotid gland. One supplies the floor of the lower jaw, and may therefore be called the "lingual" artery; the other supplies the mylo-hyoid muscle.

(b) $A$ carotid artery passing to the head. It has, at its origin, a slight swelling, the carotid gland.

2. The systemic arches run backwards on each side of the body, meeting posteriorly to form the dorsal aorta. From each systemic arch an artery arises which has the following branches :-

(i) A scapular artery to the pectoral girdle.

(ii) $A$ cutaneous artery to the skin.

(iii) $\boldsymbol{A}$ brachial artery to the arm.

Trace the dorsal aorta backwards, and note that it gives off the coeliaco-mesenteric artery about midroay between its origin and the origin of the first pair of renal arteries. The dorsal aorta then passes between the kidneys, supplying four renal arteries to each kidney, and posteriorly it divides into two internal iliac arteries to the legs. Each internal iliac gives rise to a branch which divides into :

(i) An iliac artery to the muscles round the ilium.

(ii) A cutaneous artery to the skin of the body, just anterior to the leg.

(iii) $\boldsymbol{A}$ small artery to the dorsal surface of the leg.

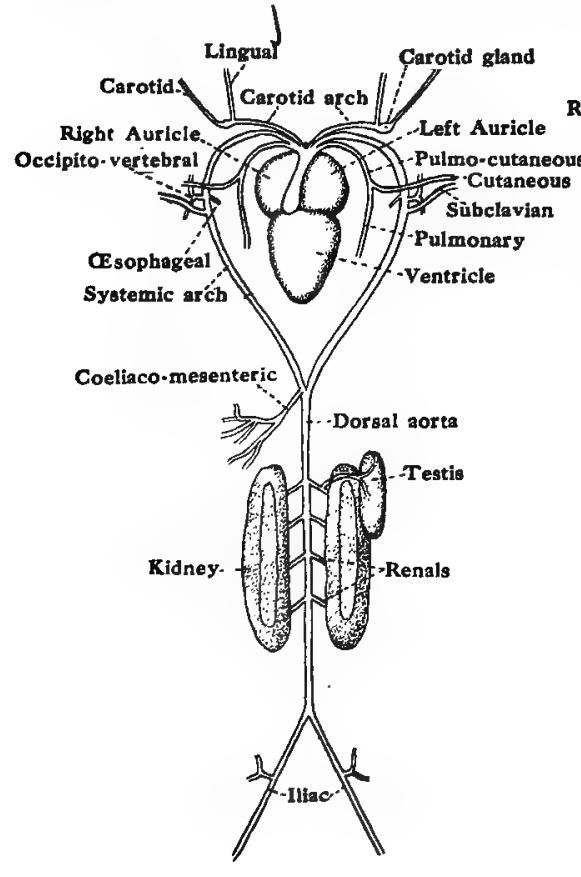

A

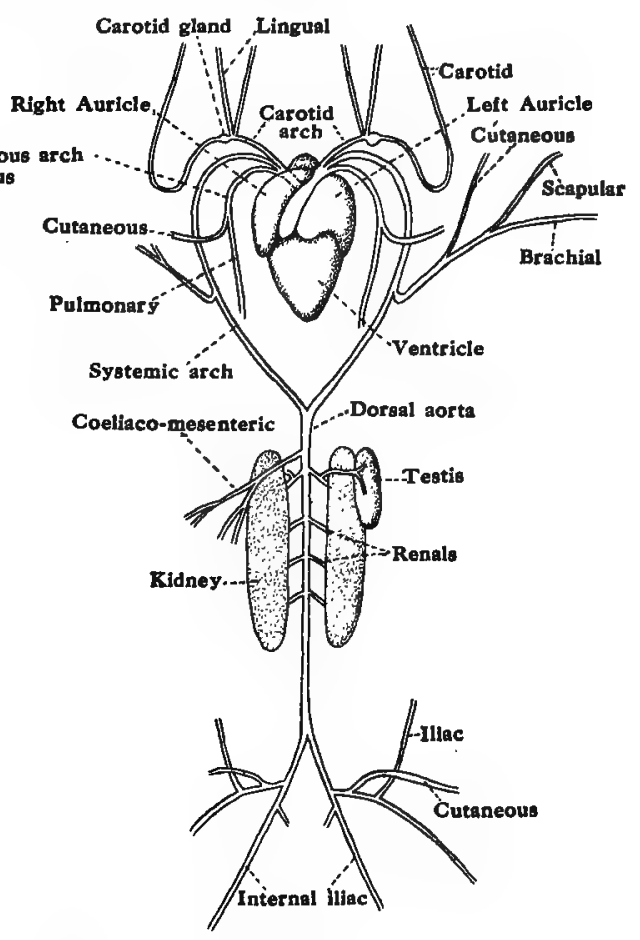

B

Fic. 72.-A. Arterial System of Rana ; and B. of Xenopus. 

3. The pulmo-cutaneous arch gives off:

(a) A pulmonary artery along the outer side of the whole length of the lung.

(b) A cutaneous artery, which at first goes forward to the base of the arm, and then spreads out on the skin of the back of the head.]

Make a complete sketch of the arterial system.

Remove the heart, taking care to leave attached to it as much as possible of the large vessels.

Note the sinus venosus, the conus, the ventral aorta or "truncus arteriosus," the two auricles, and the ventricle.

Slit open the conus, and notice the longitudinal spiral septum (spiral valve). The openings of the conus are guarded by pocket-valves, three at each end.

Remove the ventral wall of the two auricles and the ventricle, taking care not to cut away the conus which lies obliquely. across the right auricle. Having washed the blood out of the heart, observe the septum between the right and left auricles, the thick muscular walls and spongy cavity of the ventricle, also the wide auriculo-ventricular opening which is guarded by four valves. In the dorsal wall of the right auricle, near the septum, is the slit-like opening of the sinus venosus with two valves. Near this sinu-auricular aperture, but on the other side of the septum, in the dorsal wall of the left auricle, is the opening of the pulmonary vein from the lungs.

\section{Respiratory System and Alimentary System (continued).}

1. Remove the mylo-hyoid muscles to expose the hyoid apparatus. Pass a seeker through the glottis to one of the lungs, and slit it open with a pair of scissors. Examine the structure of the lung.

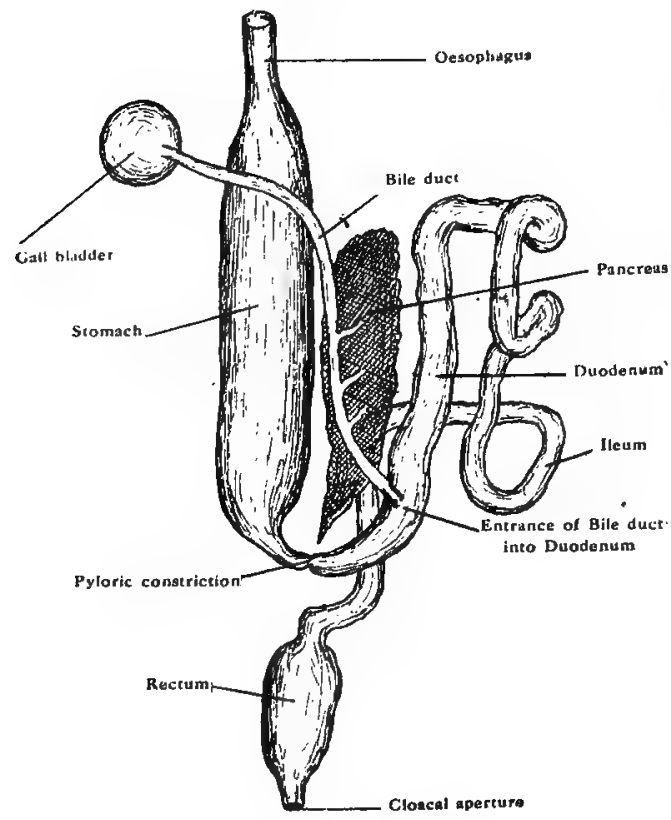

A

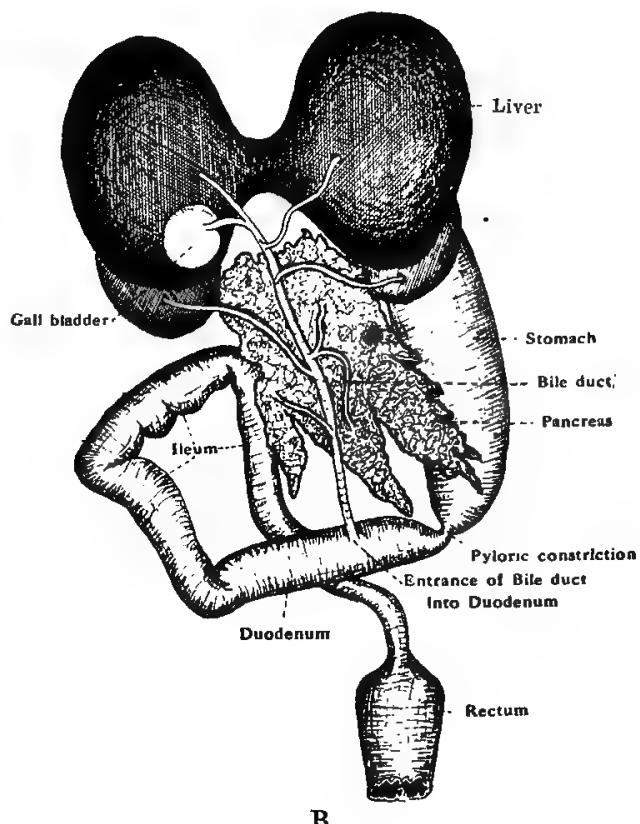

B

Fig. 73.-A. The Alimentary Canal of Rana; and B. of Xenopus. 

2. Remove the whole of the alimentary canal, with the liver, pancreas, and spleen, by cutting through the œsophagus and the large intestine (where it joins the cloaca), and detaching it from the roof of the body-cavity without injuring the kidneys and the reproductive organs.

Draw the complete alimentary canal.

\section{Urino-genital System.}

Note the kidneys, two elongated flattened dark-red organs lying one on each side of the vertebral column towards the posterior end of the abdominal cavity. From the outer edge of each kidney a duct, the ureter, passes backwards, and opens into the cloaca on the dorsal side, opposite the opening of the bladder. On the ventral sides of the kidneys the adrenal bodies appear as small yellow patches. [In the Platana these adrenal glands are apparently absent.]

In the male Frog note :

(a) The testes, a pair of ovoid pale yellow bodies attached to the dorsal wall of the body-cavity by a fold of peritoneum. They lie on the ventral sides of the kidneys and are connected to them by short efferent ducts (vasa efferentia) which pass into the kidneys.

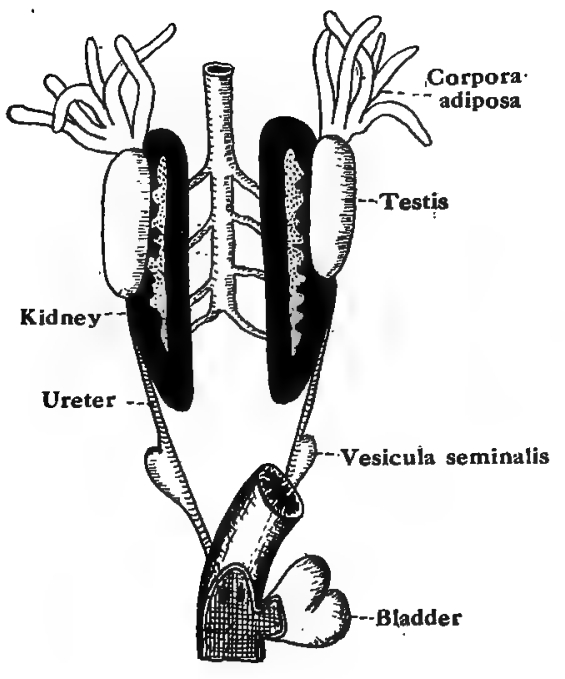

A

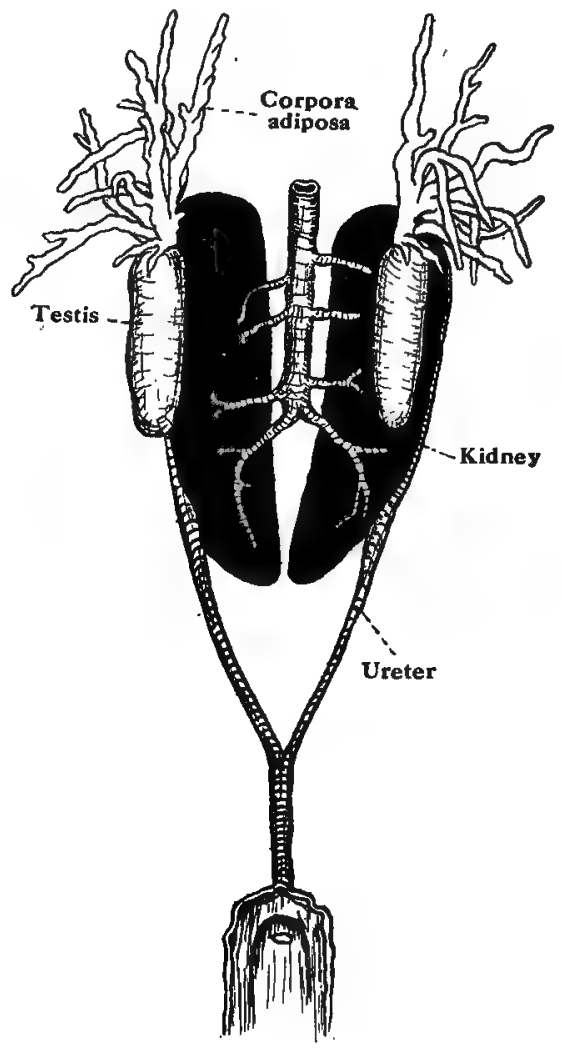

B

FIr: 74.-A. The Urino-genital System (male) of Rana; and B. of Xenopnz. 

(b) The corpora adiposa or fatty bodies lying in front of the kidneys.
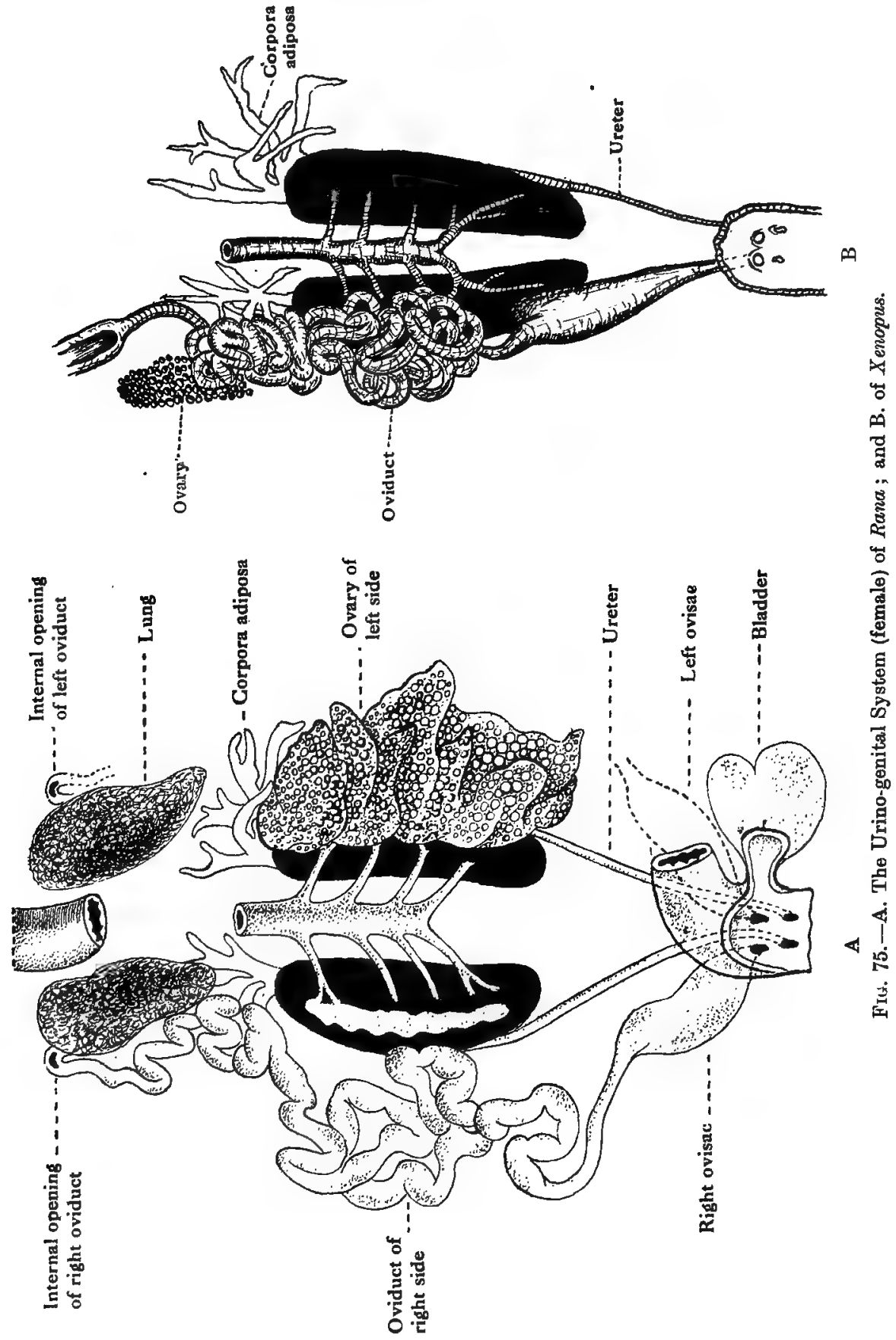

(c) The ureters, which function not only as urinary ducts, but also as vasa 

deferentia for the generative products. See ureter on page 214. Each ureter has a slight swelling, the vesicula seminalis, on its outer side.

[In the Platana the ureters unite posteriorly to form a single duct rohich opens into the cloaca.]

In the female Frog note:

(a) The ovaries, a pair of irregularly-lobed organs, usually consisting of rounded black and white bodies, the ova. The ovaries are attached to the dorsal wall of the body-cavity by a fold of the peritoneum.

(b) The corpora adiposa lying in front of the kidneys.

(c) The long convoluted oviducts opening in front into the body-cavity and behind into the cloaca. Their terminal portions are greatly dilated ovisacs in which the eggs are retained for a time.

[In the female Platana the ureters open separately into the cloaca.]

Make a drawing of the urino-genital system.

\section{Skeletal System (continued).}

\section{Fifth Day}

$A$. The Pectoral and Pelvic Girdles and the Limbs.

1. Detach a fore-limb with the remaining parts of the pectoral girdle. Make a preparation showing:

Supra-scapula, scapula, remainders of the clavicle and the coracoid, humerus, radio-ulna, carpal bones, and digits. Draw these parts.

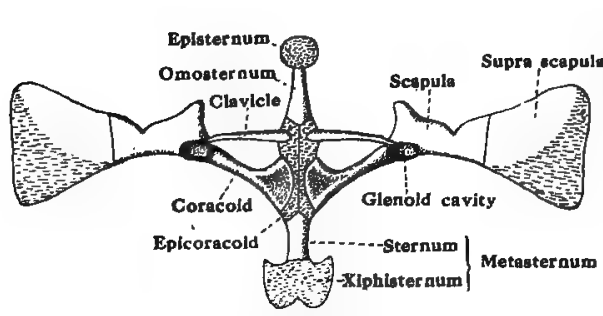

A

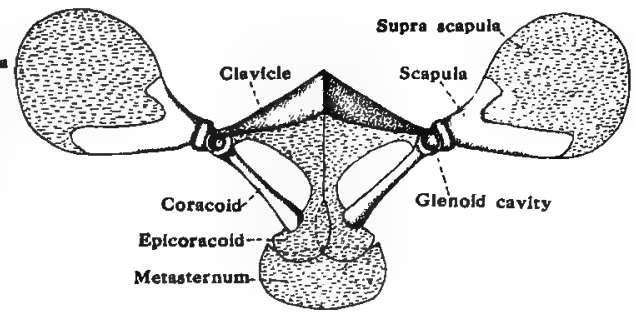

B

FIG. 76.-A. Pectoral Girdle of Rana; and B. of Xenopus. The dotted portions indicate cartilage.

2. Detach the pelvic girdle from the transverse processes of the 9th vertebra. Remove it along with the hind-limbs from the body. Detach the limb from one side of the pelvic girdle, and make a sketch showing the following parts of the pelvic girdle:-

Acetabulum or socket for head of femur, ilium, ischium, and pubis. (See Fig. 79.)

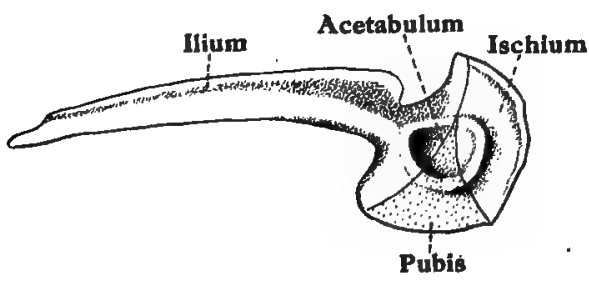

A

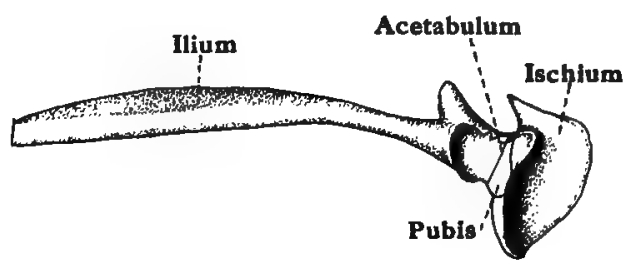

B

Fra. 77.-A. Pelvic Girdle of Rana ; and B. of Xenopus, side view. 

3. Make a preparation and a sketch of the hind-limb showing the femur, tibio-fibula, astragalus, calcaneum or os calcis, and the other bones of the tarsal region, five meta-tarsals, and digits. Number the digits from the inner side.

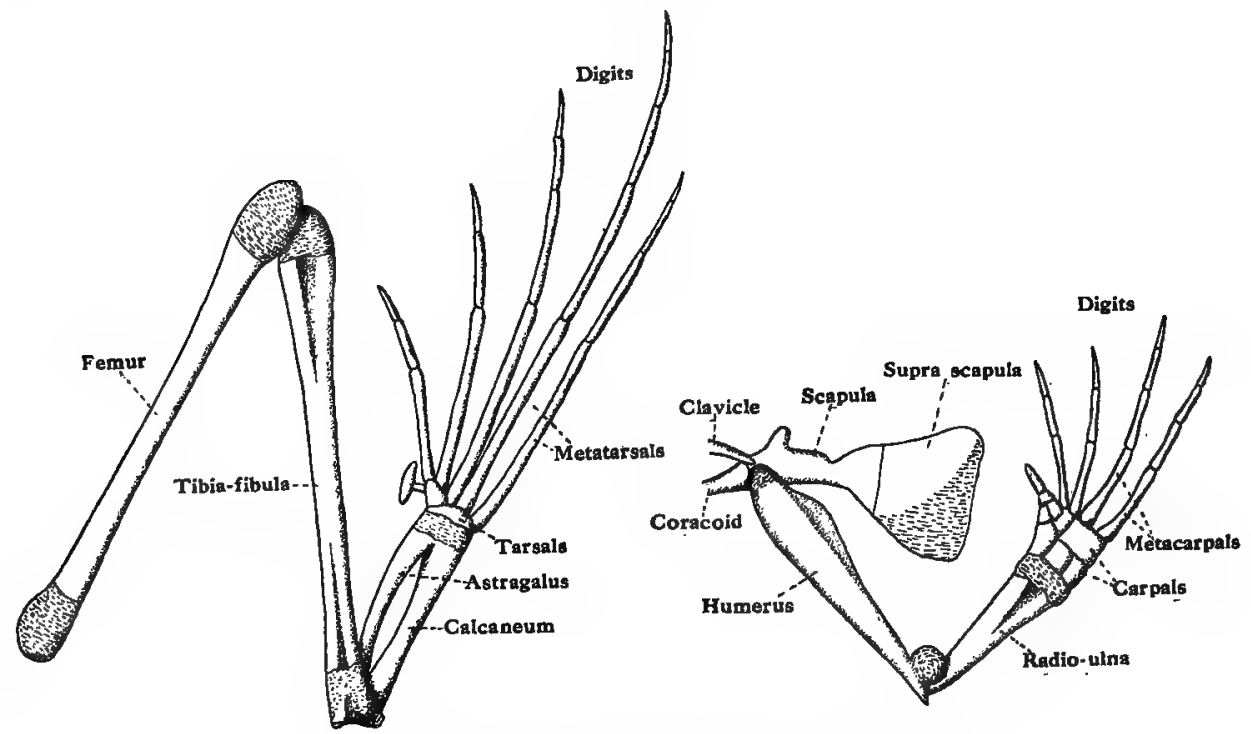

Fra. 78.-The Hind-limb and the Fore-limb of Xenopus.

$B$. The Vertebral Column.

1. Remove the skin and muscles from the dorsal surface of the back to show the nine vertebræ and the urostyle. Make a drawing showing the vertebræ with their transverse processes, and the urostyle attached to the posterior end of the 9 th vertebra.

The 2nd to the 9th vertebræ bear long transverse processes produced outwards. The urostyle is attached to the 9 th vertebra by two facets.

[In the Platuna the 2nd, 3rd, and 4th vertebrae bear long transverse processes curved backwards, those of the 3rd and 4th being tipped with small cartilaginous ribs. The transverse processes of the 5th, 6th, 7th, and 8th vertebrae are slender and project forwards and outwords. The 9th vertebra has long wing-like processes, attached to which are the ilia of the pelvic girdle. The urostyle is fused to the 9th vertebra.]

Note the intervertebral discs and the intervertebral foramina for the exit of the nerves from the spinal cord.

2. Remove, examine, and draw the 1st or atlas vertebra, noting its ringlike form, the absence of transverse processes, and the concave facets by which it articulates with the two occipital condyles of the skull.

3. Remove, examine, and draw the 3rd vertebra, noting the procolous ${ }^{1}$ centrum, neural arch and neural spine, anterior and posterior zygapophyses, and the transverse processes.

[The centrum is opisthocolous ${ }^{2}$ in the Platana, and each transverse process bears a cartilaginous rib.]

1 Proccelous means concave in front and convex behind.

2 Opisthocolous means convex in front and concave behind. 



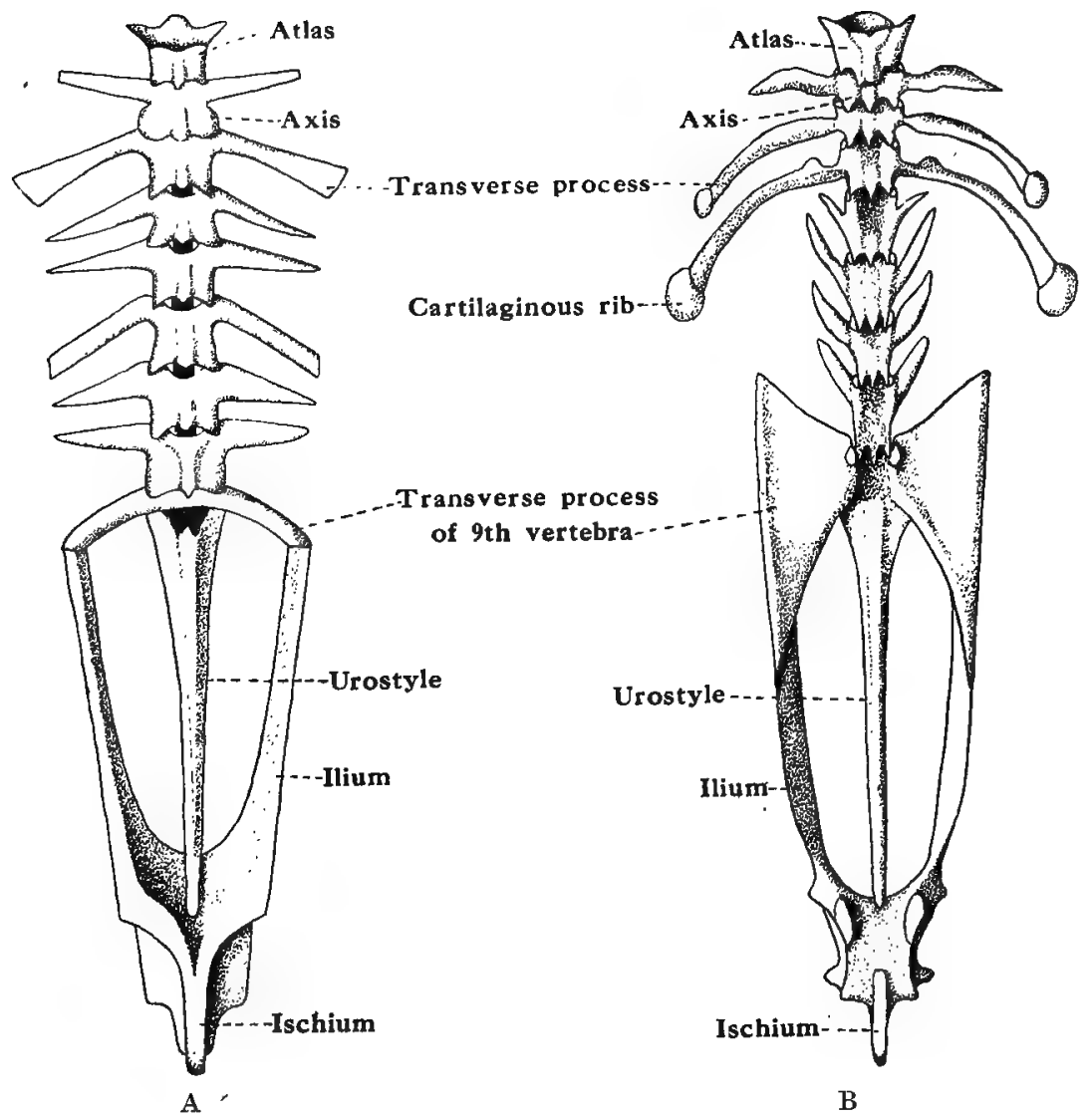

FIG. 79. -A. The Vertebral Column and Pelvic Girdle of Rana; and B. of Xenopius.

4. Remove and examine the 8th vertebra, and note that the centrum is amphicolous. ${ }^{1}$ Make a drawing of a section showing the centrum.

[The centrum is opisthoccelous in the Platana.]

5. Remove and examine the 9th vertebra or sacrum, and note that the centrum is slightly convex on its anterior surface. The urostyle articulates with the two convex facets on the posterior surface of the 9th vertebra. It is a rod-like bone gradually tapering to a point.

[In the Platana the urostyle is fused to the posterior surface of the 9th vertebra, and the transverse processes are long, flat, and wing-like.]

\section{Sixth Day}

Skeletal System (continued).

C. The Skull.

1. Remove the skin and other tissues from the top of the skull and observe the large fronto-parietals, sphenethmoid, nasals, premaxillæ, maxillæ,

1 Amphicolous means concave at both ends. 

squamosals, exoccipitals and pro-otics. The quadrato-jugals are well developed ; but the quadrate consists of a piece of cartilage at the posterior end of the quadrato-jugal, between the pterygoid and the squamosal. The lower jaw articulates with the quadrate cartilages. The columella is usually not well shown. Between the various bones of the skull there are considerable areas of unossified cartilage, persistent parts of the original chondrocranium.

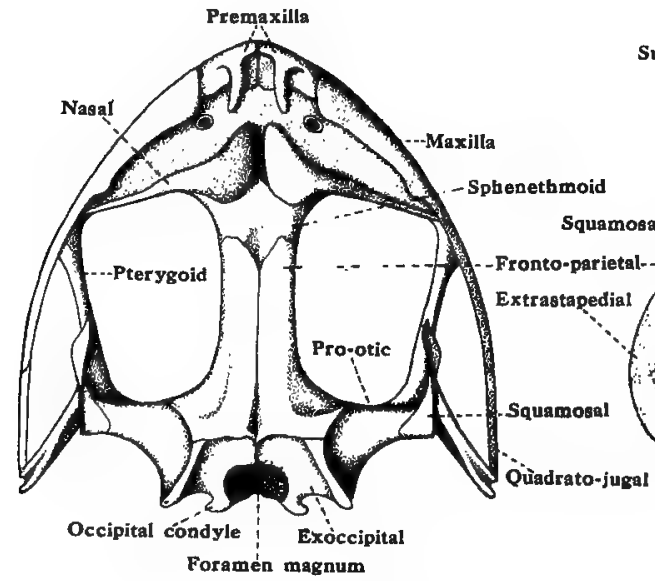

A

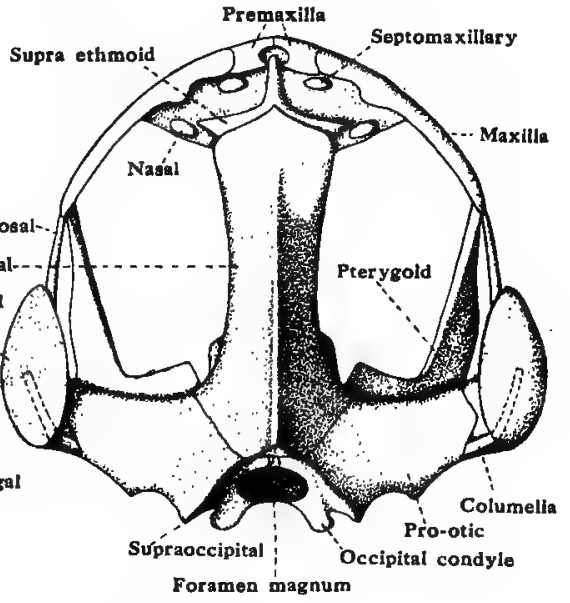

B

Fra. 80.-A. Dorsal Viow of the Skull of Rana ; and B. of Xenopus

[In the Platana the fronto-parietals, nasals, supra-ethmoid, premaxilloe, maxilloe, squamosals, exoccipitals, and pro-otics are well shown. The quadratojugals are very inconspicuous. An extrastapedial plate of cartilage is well developed, and the bony columella may be seen lying underneath it. . The sides of the skull consist of bones which represent the orbitosphenoids and alisphenoids of higher types. The supra-occipital is represented by a small cartilage.]

Make a drawing of the dorsal aspect of the skull.

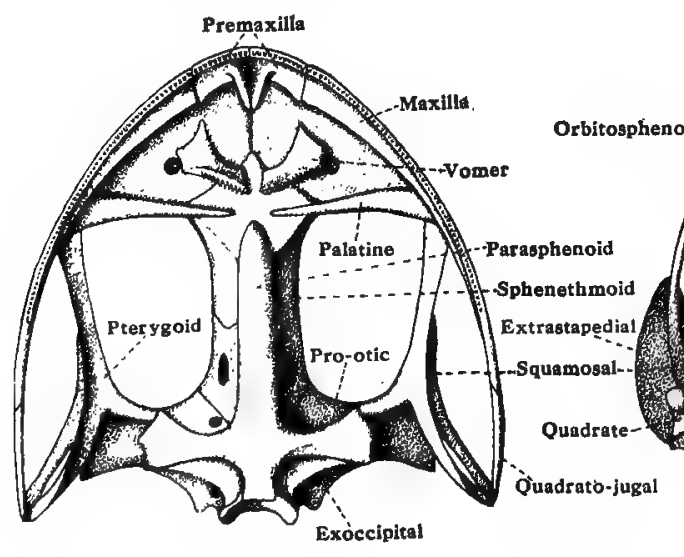

A

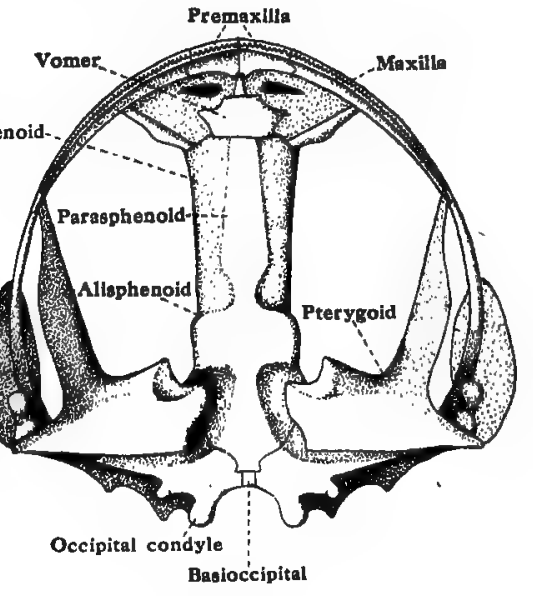

B

FrG. 81.-A. Ventral View of the Skull of Rana; and B. of Nenopus. 

2. Remove the skin from the roof of the mouth and note the parasphenoid, a large $\perp$-shaped bone occupying the ventral surface of the cranium, the paired vomers bearing the vomerine teeth, the premaxillæ, the maxillæ, the slender palatines, the triradiate pterygoids, the squamosals lying under the pterygoids, the quadrato-jugals, the pro-otics, and the exoccipitals. (See Fig. 81, page 224.)

[In the Platana there is only one vomer. The pterygoids are large and have leaflike processes, which are produced towards the middle line, and which cover the Eustachian passages. There are two rell-developed quadrates for the articulation of the lower jaw; and there is a basioccipital, composed of cartilage. The orbitosphenoid and the alisphenoid are roell marked. The palatines are absent.]

Make a drawing of the ventral aspect of the skull.

3. Make a drawing of the skull viewed from the side to show the premaxilla, maxilla, quadrato-jugal, nasal, sphenethmoid, fronto-parietal, pterygoid, squamosal, and pro-otic.

[In the Platana the supra-ethmoid, orbitosphenoid, alisphenoid, extrastapedial, and columella may be noted in addition.]

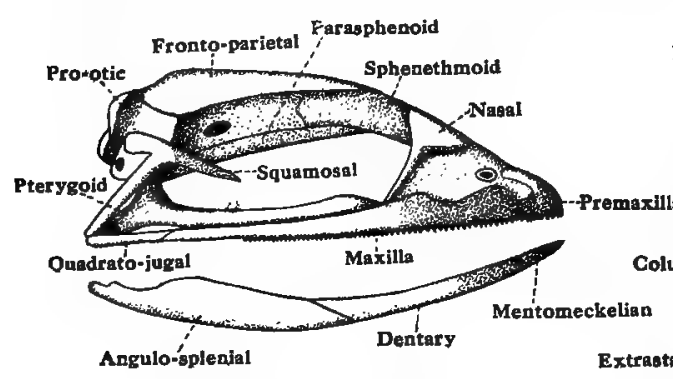

A

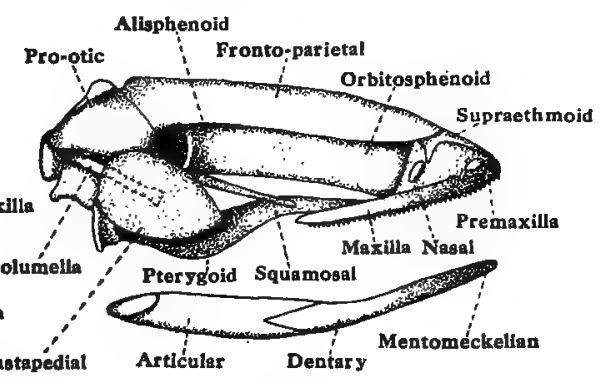

B

Fig. 82.-A. Side View of the Skull of Rana; and B. of Xenopus.

4. Remove the skin from the lower jaw, and make out the.bones replacing the original Meckel's cartilage, viz. the mento-meckelian, dentary, and angulosplenial.

[In the Platana the lower jare is composed of the mento-meckelian, dentary, and articular.]

Make a drawing of the lower jaw.

\section{Nervous System.}

$A$. The Central Nervous System.

The Brain.

Carefully remove the fronto-parietals so as to expose the brain and note the following parts :-

(a) The olfactory lobes, forming the most anterior portion of the brain, united together in the middle line. Anteriorly the olfactory nerves are given off.

(b) The cerebral hemispheres, a pair of smooth elongated bodies.

(c) The thalamencephalon, lying immediately behind the cerebral hemispheres. It is covered by the choroid plexus, a thick vascular 

membrane, and gives rise dorsally to the stalk of the pineal body. Its thickened sides are the optic thalami, and its cavity is the third ventricle.

(d) The optic lobes, a pair of ovoid bodies.

(e) The cerebellum, a narrow transverse band immediately behind the optic lobes.

(f) The medulla oblongata, behind the cerebellum. It gradually tapers towards its posterior end, where it is continuous with the spinal cord. On its roof the pia mater forms a very vascular choroid plexus. Its cavity is the fourth ventricle.

Make a sketch of the brain. (See Fig. 84, page 232.)

\section{Seventh Day. (Revision)}

With a second specimen revise the second, third, and fourth day's work, paying particular attention to the vascular system.

\section{Eighth Day}

Nervous System (continued).

$B$. The Peripheral Nervous System.

1. The Spinal Nerves.

Carefully remove the abdominal viscera so as to expose the spinal nerves. These appear as white cords on each side of the vertebral column and are as follows :-

(a) The first or hypoglossal nerve arising between the 1st and 2nd vertebræ. It runs forwards on the under surface of the head, beneath the mylo-hyoid muscle, and supplies the tongue. It was noted in the third day's work.

(b) The second and third nerves unite immediately after issuing from the spinal cord to form the brachial plexus, which supplies the muscles of the shoulder, and then extends along the arm.

(c) The fourth, fifth, and sixth nerves are small, and supply the muscles and the skin of the body-wall.

(d) The seventh, eighth, and ninth nerves unite to form the sciatic plexus which gives rise to the large sciatic nerve extending along the thigh and dividing above the knee into the peroneal and tibial nerves to the leg and the foot. The seventh nerve, before it joins the plexus, gives rise to an ileohypogastric nerve supplying the skin and muscles of the abdomen. Just beyond its union with the sciatic plexus it gives rise to the cruralis nerve to the skin and muscles of the outer surfaces of the thighs. The sciatic nerve also gives rise to the semimembranosus nerve (already noted in the third day's work) which supplies the semimembranosus muscle. 

(e) The tenth or coccygeal nerve, which passes through a small aperture in the side of the urostyle, and is distributed to the walls of the cloaca and urinary bladder. It is connected by a small branch with the sciatic nerve.

[In the Platana the seventh, eighth, and ninth nerves run obliquely backwards. The eighth and ninth unite to form the sciatic pleaus, which gives rise to a large sciatic nerve extending along the thigh and down the leg. The sciatic plexus also receives a branch from the seventh nerve. The seventh nerve gives rise to a cruralis nerve dividing into several smaller branches and supplying the skin and muscles of the outer surfaces of the thighs. The sciatic nerve gives off a smaller semimembranosus nerve to the semimembranosus muscle.

The coccygeal nerve is very variable in the Platana. It may be present on each side of the spinal cord, or only on one side, or it may be absent.]

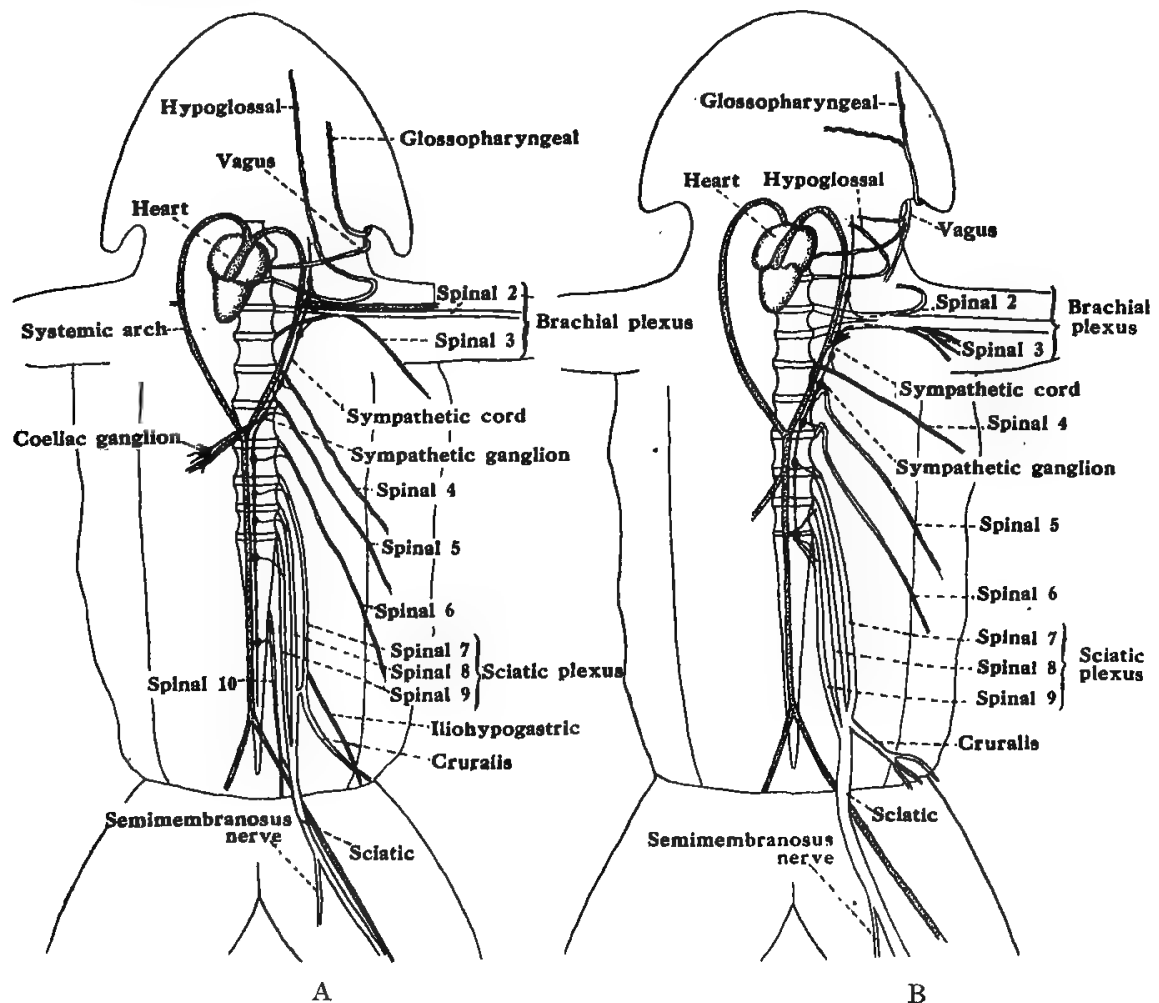

FIG. 83. -A. Spinal Nerves and Sympathetic Nervous System (left side only) of Rana; and B. of Xenopus.

2. The Sympathetic Nervous System.

This system is connected with the spinal and cranial nerves. It consists of a cord or chain of ganglia, on each side of the body, joined together by a longitudinal cord. Each ganglion is connected with a spinal nerve by a short branch (ramus communicans). Each cord extends alongside the vertebral column and the dorsal aorta. There are ten sympathetic ganglia altogether. The first 

ganglion lies over the hypoglossal nerve. The coccygeal nerve is joined to the last sympathetic ganglion by more than one branch. The sympathetic system gives rise to the solar plexus on the dorsal surface of the stomach; and the nerves forming that plexus are derived mainly from the third, fourth, and fifth ganglia. Anteriorly each sympathetic cord is connected with the Gasserian ganglion.

[In the Platana this system is similar and follows the same course. There are six ganglionic stellings on each cord; and there are connections (rami communicantes) between the ganglia and all the spinal nerves: Anteriorly each cord is joined to the vagus nerve, and ends posteriorly as a broad swelling on the ninth spinal nerve.]

Make a complete sketch showing the spinal nerves and the sympathetic nervous system. (See Fig. 83, A or B, page-230.)

3. The Cranial Nerves.

Expose the brain and note the following cranial nerves :--

(a) The olfactory nerve, arising from the anterior end of the olfactory lobes and supplying the olfactory capsule.

(b) The optic nerve, which arises from the ventral surface of the brain below the optic lobes and supplies the retina of the eye.

(c) The trigeminal nerve, arising just behind the optic nerve and giving off the following branches :-

(i) The ophthalmic nerve, which passes over the muscles of the eye and supplies the skin in the region of the olfactory capsule.

(ii) 'The maxillary nerve, which runs forward under the eyeball and supplies the skin covering the upper jaw.

(iii) The mandibular nerve, which is at first continuous with the maxillary, and then bends round the inner surface of the upper jaw to extend along the outer surface of the mandible. A large swelling on the trigeminal nerve is the Gasserian ganglion.

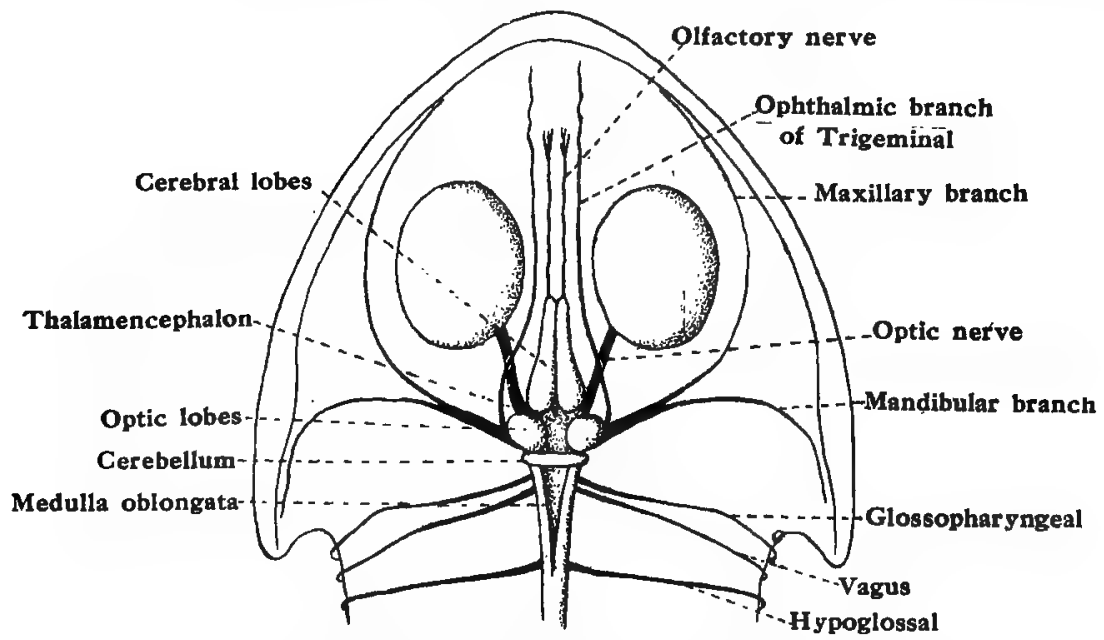

FIc. 84.-The Brain and the principal Cranial Nerves of the Frog (Rana). 

(d) The glosso-pharyngeal nerve and the vagus (or pneumogastric) nerve. These arise together and pass through a common aperture behind the auditory capsule. The glosso-pharyngeal passes in front of the hypoglossal nerve and extends along the base of the tongue. The vagus, after giving off branches to the dorsal muscles, reaches the walls of the pharynx and runs obliquely backwards to supply the pharynx, heart, lungs, and stomach.

Make a complete sketch showing the brain and the above-mentioned cranial nerves: (See Fig. 84, page 232.) 



\title{
THE PIGEON (Columba livia, var. domestica)
}

\author{
First Day
}

\section{External Features.}

1. Make a drawing of the Pigeon, viewed from the side, showing:

(a) The mouth, with the elongated upper and lower portions of the horny beak.

(b) The cere, a swollen area of soft skin at the base of the upper beak.

(c) The nostrils (external nares), between the upper part of the beak and the cere.

(d) The large eyes, each with an upper and a lower eyelid and a semitransparent nictitating membrane or third eyelid (at the inner angle of the eye).

(e) The external auditory apertures, situated a short distance behind the eyes and concealed by the feathers.

$(f)$ The fore-limbs, which are modified as wings, being provided with long flight-feathers and expansible membranes about the arm-pit.

(g) The hind-limbs or legs, the proximal part of each being covered by small feathers, while the distal portion and the foot has a covering of scales. The first of the four clawed toes is directed backwards.

(h) The various sets of feathers, viz. :-

(i) The remiges or wing feathers. Those attached to the bones of the hand or manus are the (eleven) primaries, and those attached to the ulna are the secondaries.

(ii) The ala spuria or bastard wing, a small tuft of feathers on the anterior border of the wing, attached to the phalanx of the first digit (thumb).

(iii) The rectrices or tail feathers.

(iv) 'The contour feathers covering the general surface of the body.

(v) The wing and tail coverts covering the bases of the quills.

2. Remove a wing-feather and make a drawing of it to show these parts :

(a) The calamus or quill, the transparent hollow proximal part of the longitudinal axis or stem of the feather, with the inferior umbilicus at its base and the superior umbilicus just below the vane.

(b) The rachis or shaft, the distal solid part of the axis, bearing the vane.

(c) The vane or vexillurn, attached on either side of the rachis and made up of barbs interlocked by barbules.

(d) The aftershaft or hyporachis, a small tuft of down situated in the neighbourhood of the superior umbilicus.

\section{The Mouth Cavity.}

Open the mouth widely and make a sketch showing the following parts :(a) The tongue, triangular and sharp-pointed. 

(b) The glottis, the opening of the trachea or windpipe, in the floor of the mouth and behind the tongue.

(c) The gullet or osophagus behind the glottis.

(d) The internal nares in the roof of the mouth.

(e) The single Eustachian aperture, a median opening behind the internal nares.

\section{Internal Structure.}

Remove all the feathers from the neck and trunk. Note the short tail or uropygium, with the oil or preen gland on its upper surface; and also the cloaca, a large transverse opening below the base of the tail. Make a median incision through the skin, along the keel of the breastbone. Reflect the skin off both sides, taking care not to injure the crop, which is under the neck and overlying the trachea. Notice the interclavicular air-sac, between the clavicles and round the lower part of the trachea. The exposed mass of muscle on each side of the keel is the pectoralis major of each side. Detach the pectoralis major of one side from the lower half of the keel and the whole length of the clavicle, and from the lateral part of the breastbone or sternum, by cutting close to these bones. Then reflect the muscle outwards so as to show its insertion on the humerus, by carefully separating it (with the blunt handle of the scalpel) from the deeper muscle of the breast, namely, the pectoralis minor or subclavian, which lies in the angle between the sternum and the keel, and which is completely covered by the large pectoralis major. Note the large pectoral vein and artery in the lower part of the pectoralis major, and take care not to damage these blood-vessels.

In a similar way reflect the pectoralis minor, which arises from the upper half of the keel and the inner portion of the sternum; and notice that its tendon. passes through the foramen triosseum (an archway formed by the ends of the coracoid, clavicle and scapula) which serves as a pulley; and so this muscle, when it contracts, raises the wing.

The pectoralis major, which depresses the wing, is the largest of the three muscles of flight; the smallest one is the coraco-brachialis, which arises chiefly from the outer side of the coracoid, and which helps to depress the wing.

Reflect outwards the corresponding muscles of the other side of the breast in the same way; and open the abdomen.

The Skeletal System (part).

Note the position of the clavicles, which are united at their lower ends to form the furcula or "merry-thought," and are situated just in front of the sternum. Remove the furcula by cutting through the clavicles as near as possible to their points of attachment. (See the third day's roork.)

Note the coracoids underlying the clavicles, articulating with deep facets on the anterior border of the sternum and directed upwards, forwards, and outwards. Raise the hind part of the sternum and cut (with scissors) through its attachment to the ribs (both sides). Cut through the coracoids as far away as possible from the •sternum. and remove the sternum entirely by lifting it up posteriorly and detaching it completely from the underlying tissue.

Make a sketch of the sternum or breastbone, viewed from the side, to show 

the body of the sternum, the manubrium, the keel or carina, the notched costal ridge to which the ribs are attached, the two xiphoid processes, the fontanelle, and the remains of the coracoid. (See Fig. 88, A.)

The Viscera in situ.

Continue the median incision through the skin along the mid-ventral line of the neck so as to expose fully the crop, trachea, and oesophagus.

Note the omentum, a fold of the peritoneum loaded with fat and covering

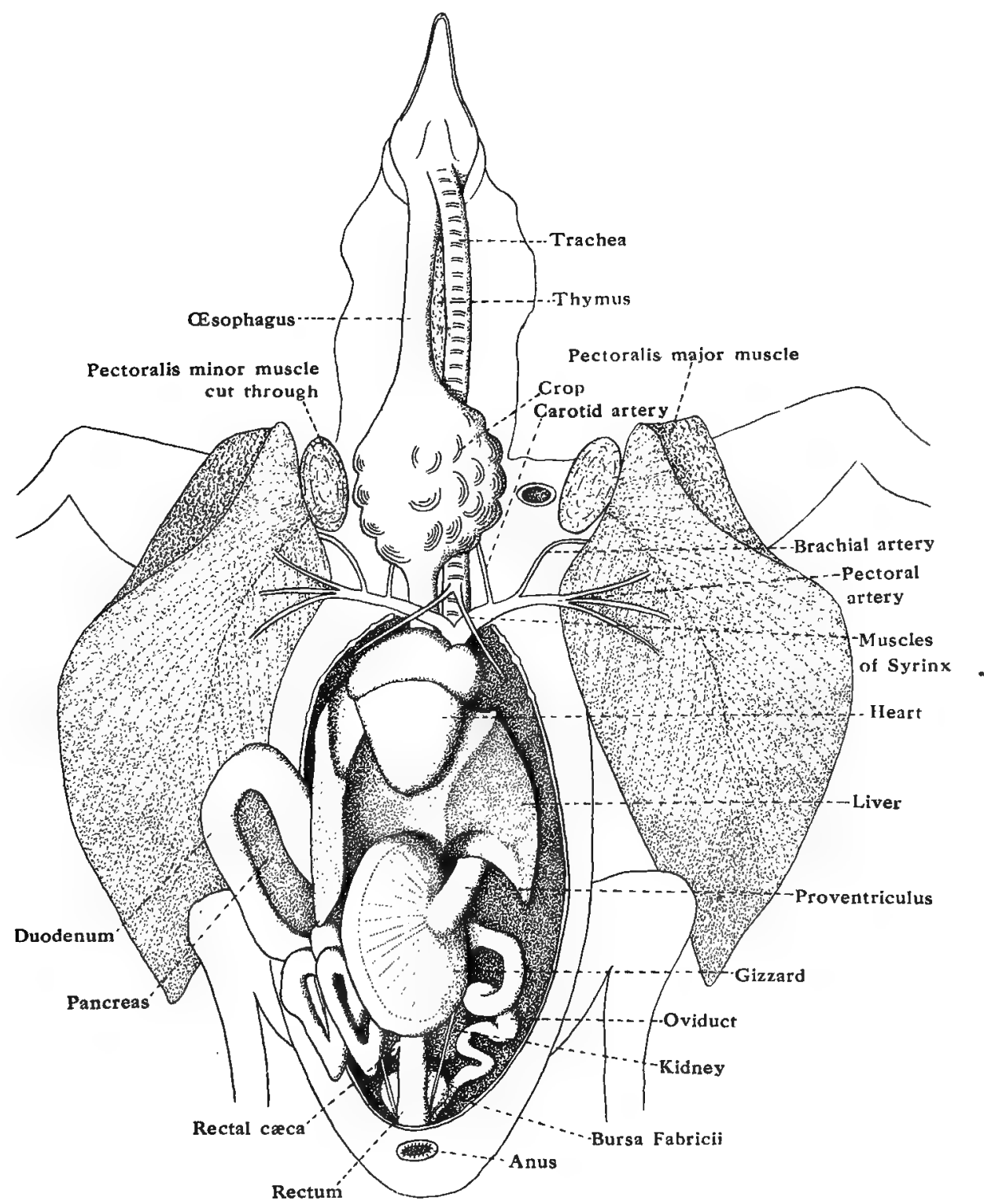

FIt. 85, -The Pigeon (Columba). Dissection showing the principal Viscera.

The dissection is that of a young bird; it shows the thymus gland and the bursa Fabricii, which are generally absent in the adult. 

the gizzard, intestine, and other viscera. From the omentum the epigastric vein may be seen passing between the two lobes of the liver and joining the left hepatic vein, just behind the heart. Notice the two anterior thoracic, the two posterior thoracic, and the two abdominal air-sacs, along the sides of the body under the ribs.

Make a drawing of the Pigeon, showing the following organs in situ as far as possible :- -

CEsophagus, crop, thymus gland, trachea, muscles of syrinx, heart, liver, gizzard, $\mathbf{U}$-shaped duodenum with the pancreas in its loop, pectoralis major and minor muscles and the position of the pectoral artery and vein and the brachial artery and vein, rectum with the pair of small rectal cæca, and on the dorsal surface of the cloaca, the bursa Fabricii. (See Fig. 85, p. 240.)

Raise the viscera from behind, and notice the following.:-

Ovary and oviduct, or testes and vasa deferentia; kidneys and ureters ; the caudal vein dividing into two "renal portal" veins, and at the point of division a coccygeo-mesenteric vein there arising and going forwards to join the hepatic portal vein which enters the liver; the "renal portals" receiving the internal iliac veins (from the pelvic wall) and entering the kidneys, and there joined by the sciatic and femoral veins of each side; the "renal portals" issuing from the kidneys as the common iliac veins, which unite to form the posterior vena cava or postcaval vein.

\section{Second Day}

The Alimentary System.

Carefully separate the alimentary canal, along its whole course, from the mesenteric attachments, leaving the duodenal loop intact. Notice particularly the various veins and arteries supplying the canal.

Make a complete sketch of the alimentary canal to show the following parts :-

(a) The gullet or oesophagus, dilating at the base of the neck to form the large thin-walled crop.

(b) The stomach or proventriculus, which secretes the digestive juice. A small red body, the spleen, is attached to the side of the proventriculus.

(c) The gizzard, with thick muscular walls. See reference to gizzard on page 246 .

(d) The duodenum or first part of the small intestine, a $\mathbf{U}$-shaped loop. Note the pancreas lying within the loop.

(e) The three pancreatic ducts, opening into the distal limb of the duodenum.

(f) The liver, without a gall-bladder, and consisting of a large right and a smaller left lobe.

(g) The two bile-ducts, one passing from the right lobe of the liver to the distal limb of the duodenum, the other from the left lobe to the proximal limb of the duodenum. 

(h) The small intestine, a long and much-coiled tube.

(i) The rectum, the short terminal portion of the alimentary canal, opening into the cloaca. At its commencement it gives off a pair of small rectal cæca.

Note the coccygeo-mesenteric vein running along the rectum, also the mesenteric veins which collect blood from the alimentary canal and combine to form the portal vein which enters the liver between the lobes.

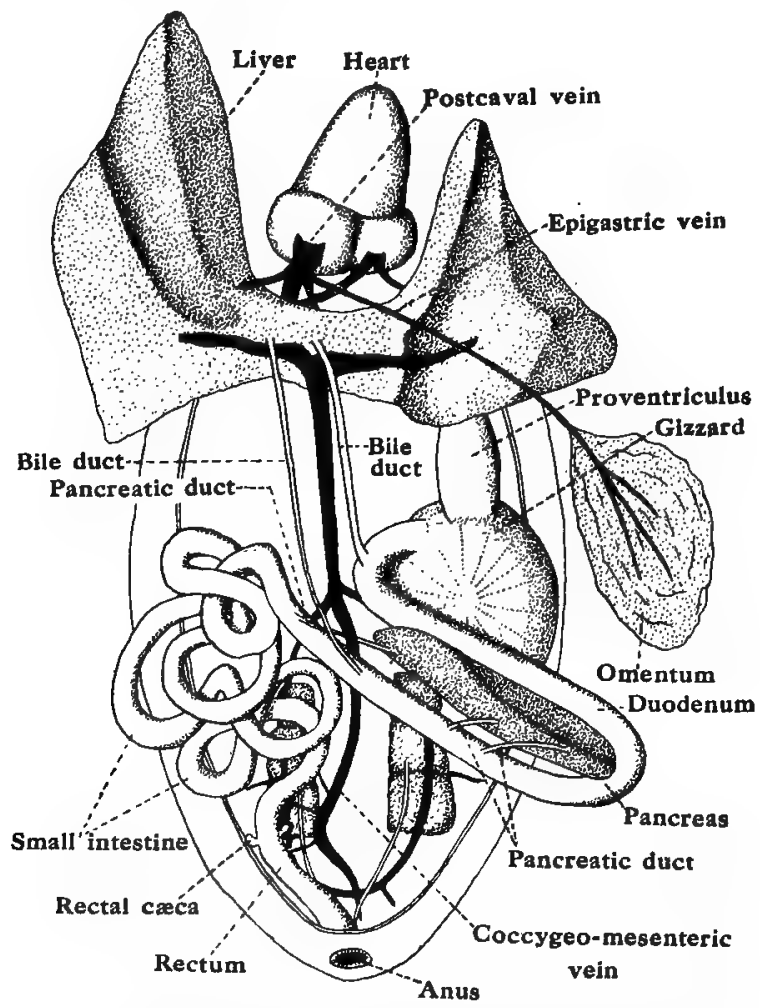

FI6. 86.-The Pigeon (Columba). Dissection showing the Alimentary Canal, the Bile ducts and Panereatic ducts, and the Posterior Vena Cava, Coccygeo-mesenteric, Hepatic portal, and Epigastric veins.

Follow the course of the trachea down to the lungs, which are spongy organs attached to the anterior dorsal wall of the thorax. The upper portion of the trachea is the larynx (without vocal cords); the terminal portion is dilated and forms the syrinx (the vocal organ), and there the trachea divides into two bronchi which enter the lungs. Note that the bronchi are in communication with the air-sacs, and that these are prolonged into several of the bones (e.g., pneumatic cavity in shaft of humerus. See page 252). Notice the thyroid gland, a paired body at the base of the neck.

Remove the alimentary canal from the body by cutting through the anterior end of the proventriculus and through the rectum, taking care to separate the coccygeo-mesenteric vein from the canal. 

Split open the gizzard and notice:

(a) The thickness of its muscular walls.

(b) The tough cuticular lining of the cavity and the small stones within it. The gizzard is therefore a mill for grinding the contained food.

(c) The openings of the proventriculus and duodenum which are situated dorsally and near together.

The Vascular System.

Examine the large conical four-chambered heart in the pericardium. Note the right and the left auricles which form the thin-walled dark-coloured anterior portion, and the right and left ventricles forming the posterior thick-walled paler portion. A line of fat on the outside indicates the division between the two auricles. The left ventricle is hidden from view, being partly encircled by the right ventricle; the former has a circular cavity and the latter a crescentic cavity in transverse section. There is no sinus venosus.

Make a section across the posterior portion of the heart so as to show the above arrangement of the ventricles.

$A$. The Venous System.

Notice that the right and the left anterior vena cava (precaval veins) and the single posterior vena cava (postcaval vein) open into the right auricle.

Each anterior vena cava or precaval vein is formed by the union of the following veins :-

(a) The external jugular vein running along the side of the neck close to the carotid artery and alongside the vertebral column. Anteriorly the jugulars meet in the region of the gullet.

(b) The brachial vein from the wing, underlying the brachial artery.

(c) The pectoral vein from the pectoral or breast muscles.

The posterior vena cava or postcaval vein is formed by the union of the two common iliac veins. It passes through the tissues of the liver forwards to the right auricle of the heart; and receives the hepatic veins as it issues from the liver. The caudal vein from the tail branches into two "renal portal" or hypogastric veins. Each receives a small internal iliac vein and passes on through the substance of the kidney, there receiving a sciatic and a femoral vein from the leg and then issuing from the kidney as the common iliac vein. The common iliacs receive small renal veins from the kidneys. At the origin of the " renal portal" veins there arises the coccygeo-mesenteric vein; it collects blood from the cloacal region and the large intestine and runs forward to join the hepatic portal vein, which is formed by the union of gastro-duodenal, anterior and posterior mesenteric veins and which enters the liver. The epigastric vein (from the omentum) joins the left hepatic vein. (See Fig. 86, p. 244.)

Note that the impure blood passes from the right auricle into the right ventricle. The pulmonary artery, which arises from the left side of the right ventricle anteriorly, conveys the blood to the lungs. The purified blood returns by the pulmonary veins, very short vessels which enter the left auricle dorsally. Thence the blood passes into the left ventricle, and is pumped to the body through the single aortic arch. 

B. The Arterial System.

The aortic arch arises from the right side of the left ventricle anteriorly and gives off a right and a left innominate artery. Each innominate divides into two branches :

(a) The common carotid artery, which gives off an internal carotid to the brain and an external carotid to various parts of the head.

(b) The subclavian artery, which gives off the brachial artery to the wing and the large pectoral artery to the pectoralis major muscle.

The aorta then arches round to the right and passes backwards as the dorsal aorta, giving off the following arteries in its course :-

(a) A median coliac artery, passing to the mesentery and supplying the stomach, gizzard, and anterior portion of the intestine.

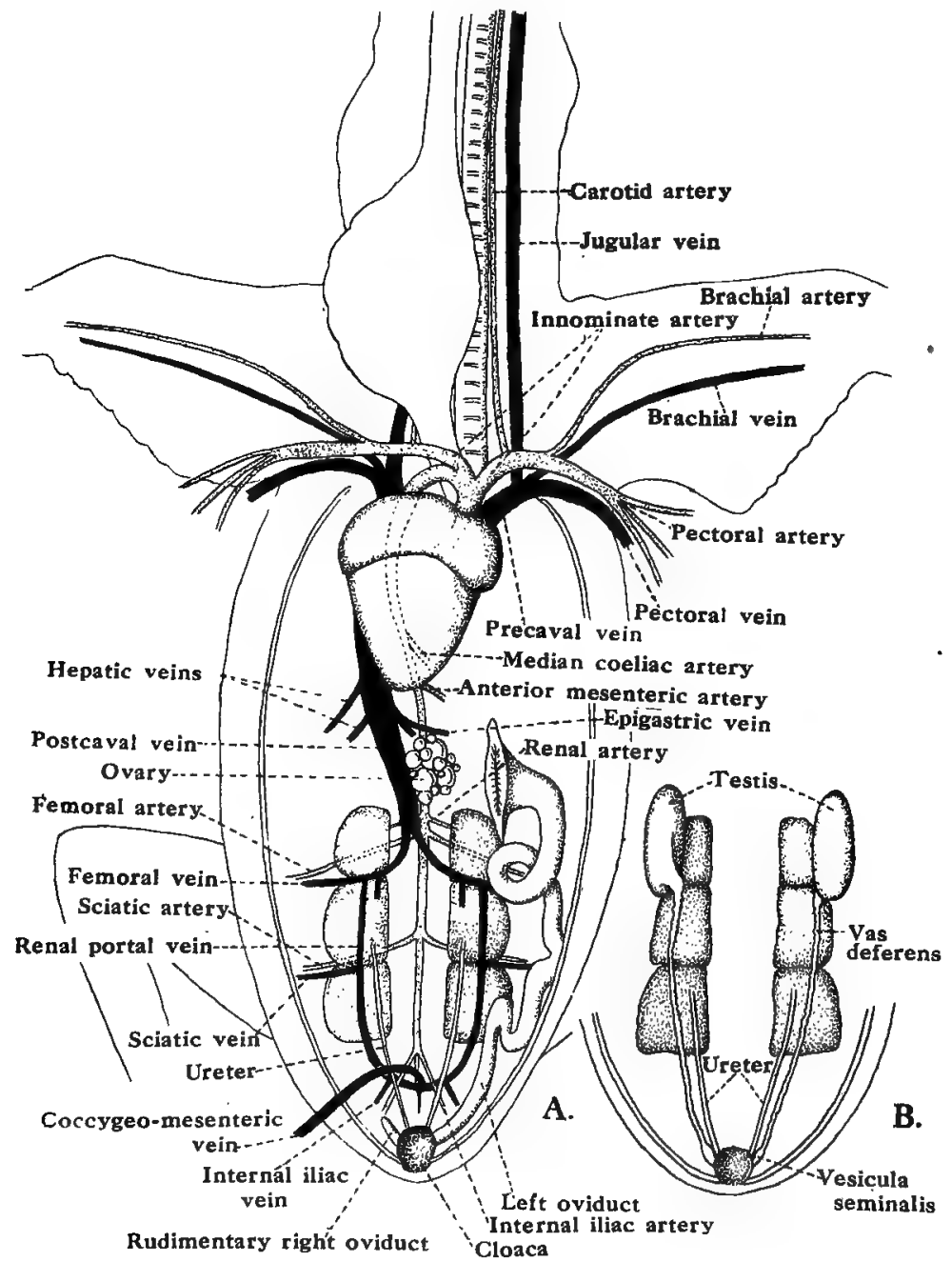

FIc. 87.-The Pigeon (Columba'). A. the Vascular System, and the Renal and Reproductive Systems of the Female; B. the Renal and Reproductive Systems of the Male. (See also Fig. 86.) 

(b) An anterior mesenteric artery, supplying the main portion of the intestine.

(c) A pair of small anterior renal arteries to the anterior lobes of the kidneys.

(d) A pair of femoral arteries to the thighs.

(e) A pair of sciatic arteries, which give off small renal arteries to the median and posterior lobes of the kidneys and then pass to the legs.

(f) A pair of internal iliac arteries to the pelvis.

(g) A posterior mesenteric artery to the rectum and the cloaca.

(h) A caudal artery to the tail region.

Notice that the pulmonary artery (referred to on page 246) crosses the aorta ventrally and then divides into two.

Make a complete sketch of the vascular system. (See Fig. 87, p. 248.)

The Renal System.

The kidneys (metanephros) are a pair of three-lobed solid organs lodged in hollows of the pelvis. A small ureter passes from the ventral face of each kidney backwards to open into the cloaca. At the front ends of the kidneys are the small yellow. adrenal or supra-renal bodies.

The Reproductive System.

(i) The Male.

The testes are a pair of oval white bodies attached by peritoneum to the front lobes of the kidneys. Each gives off a narrow and twisted duct, the vas deferens, which, before opening into the cloaca, widens out into a small vesicula seminalis.

(ii) The Female.

Only the left ovary persists, and it is situated between the front lobes of the kidneys. It is attached to the dorsal body-wall, and usually contains eggs at various stages of development. The left oviduct is a large coiled tube which opens internally (cœlomic funnel) near the ovary. Posteriorly it opens into the cloaca. The right ovary atrophies during development, and only a vestige of the right oviduct remains.

Make a complete sketch of the renal and reproductive systems. (See Fig. 87, $A$ and $B$.)

\section{Third Day}

The Skeletal System (continued).

Remove the skin and muscles from the head, neck, trunk and limbs so as to expose as much as possible of the skeletal system ; or. alternatively, examine a prepared skeleton of the Pigeon or the Fowl.

Characteristic features of the Bird's skeleton are the lightness of the bones (mostly marrowless and containing air cavities), the extensive fusion, and the absence of epiphyses.

A. The Appendicular Skeleton (the Girdles and Limbs).

1. The Pectoral or Shoulder Girdle.

(a) The clavicles, already noted in the first day's work, are fused together at their lower ends to form the furcula or "merry-thought" bone. 

At the point of union of the clavicles the furcula is laterally compressed to form the episternum. The upper end of each clavicle is attached by ligaments to the acromion process of the scapula and to the acrocoracoid process of the coracoid.

(b) The large coracoids, already noted, articulate with the sternum at their broad bases, which connect the shoulder-girdle firmly with the sternum. The other end of each coracoid has an articular surface and is produced into an acro-coracoid process.

(c) The scapula is a thin blade-like bone situated above the ribs and parallel to the backbone. It is connected with the coracoid at its anterior end, which has a shallow articular cavity and is produced into a small process. Note the foramen triosseum, formed by the conjoined upper ends of the coracoid, clavicle and scapula. The articular surfaces of the coracoid and scapula form the glenoid cavity.

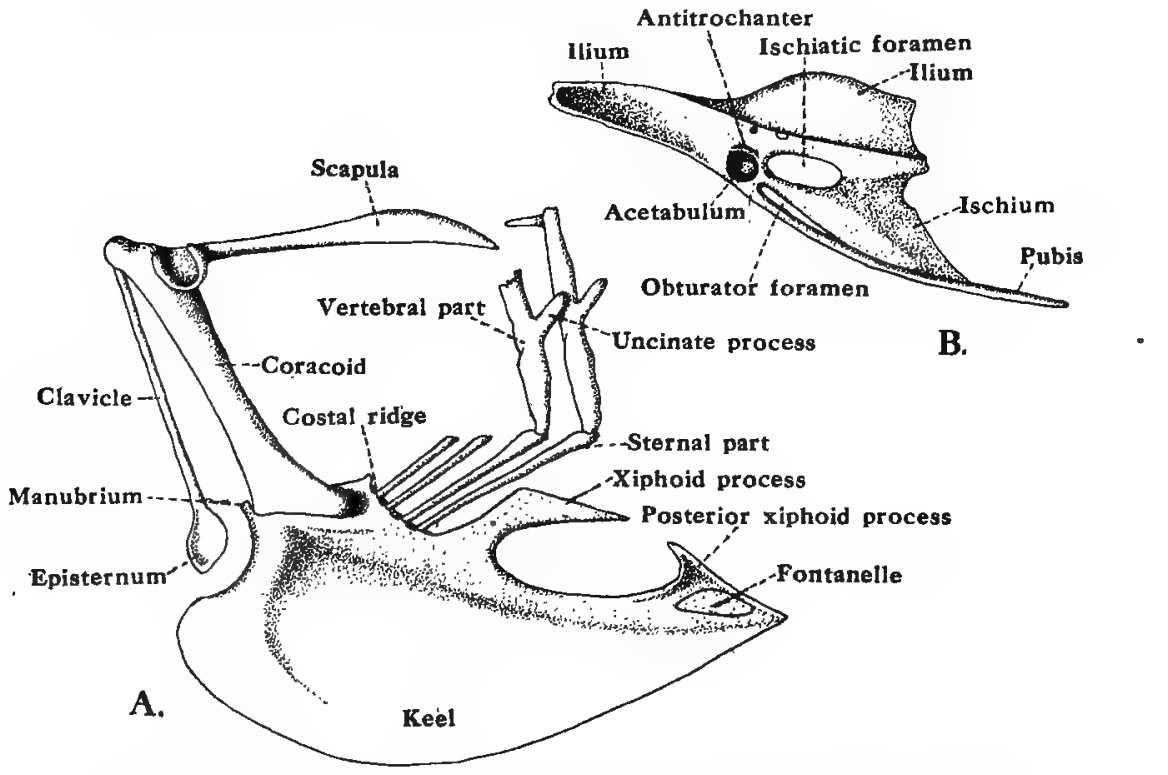

Fic. 88. -A. The Pectoral Girdle, Sternum and Ribs; and B. the Pelvic Girdle of the Pigeon (Columba).

2. The Fore-limb.

Detach a fore-limb (wing) and note the following bones :-

(a) The humerus, enlarged at its proximal end to form the prominent head, which articulates with the glenoid cavity. Note the deltoid ridge, on which the pectoral and deltoid muscles are inserted, and the pneumatic foramen, a deep depression opening into a pneumatic cavity in the shaft of the humerus.

(b) The radius, a slender and almost straight bone.

(c) The ulna, lying parallel to the radius, a larger and curved bone prolonged proximally as the olecranon process. The shaft of the ulna bears the marks of the secondary feathers. 



\section{THE PIGEON}

(d) The radiale and ulnare, the two proximal carpal bones of the wrist.

(e) The carpo-metacarpus, a compound bone formed by the fusion of the three distal carpals and the three metacarpals. It bears the first digit with a single phalanx, the second digit with two phalanges, and the third digit with one small phalanx.

Draw the complete fore-limb and as much as possible of the pectoral girdle.

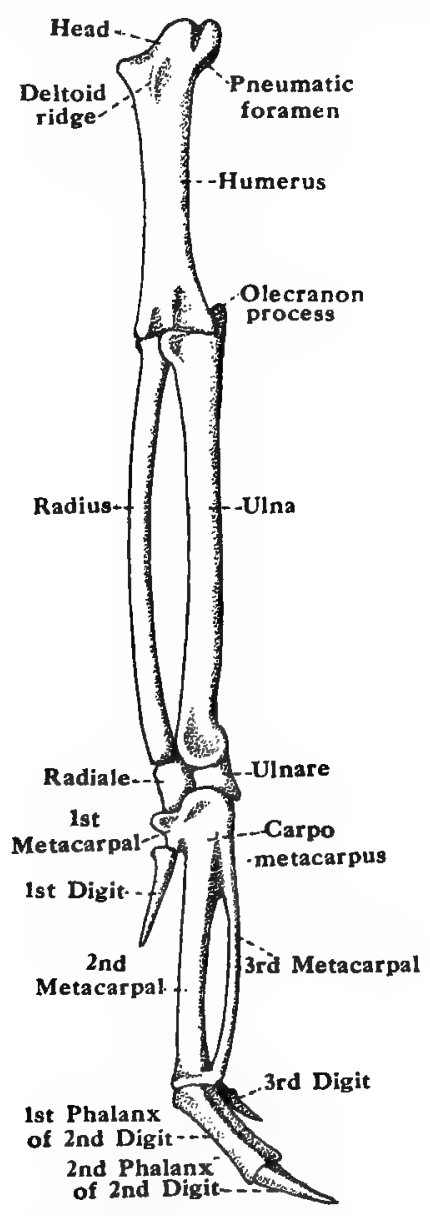

FIG. 89. -The Fore-limb of the Pigeon (Columba).

\section{The Pelvic or Hip Girdle.}

Each side of the pelvic girdle consists of the following parts :-

(a) The ilium, a very large bone, fused along its inner border with the whole of the sacrum. It is divisible into pre-acetabular and post-acetabular portions of nearly equal size. It provides the dorsal portion of the acetabulum, and on the posterior edge of that socket it is produced into a process, the antitrochanter, an articular facet for the great trochanter, a process of the femur.

(b) The ischium, which is posterior to the ilium, and triangular in shape. 



forms the vertebra-arterial canal, through which a vertebral artery runs. The centra of these vertebræ have saddle-shaped surfaces, the anterior face being

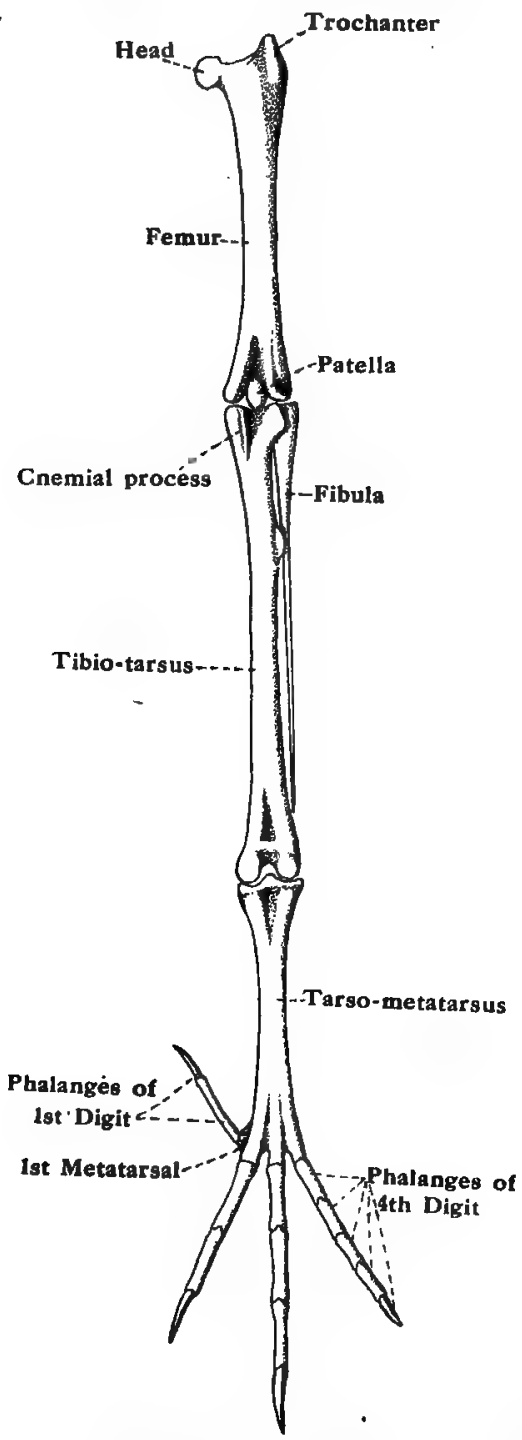

FIG. 90. - The Hind-limb of the Pigeon (Oolumba).

concave from side to side and convex from above downwards, the posterior face convex from side to side and concave from above downwards. This type of vertebra is termed heterocolous. The ribs of the last two cervical vertebræ are not rudimentary, and the heads are not fused with the vertebræ.

(a) The Atlas is the first cervical vertebra. It has no distinct centrum; it is ring-like. On its anterior surface ventrally it bears a smooth articular facet for the single occipital condyle of the skull. 

(b) The Axis is the second cervical vertebra. It has a short odontoid process projecting from the centrum. This process is part of the centrum of the atlas.

Draw a typical cervical vertebra, e.g., the sixth.

2. The Thoracic Region.

This region consists of five vertebræ. The fourth is free, the others are fused. Each bears a pair of well-developed ribs; and each rib consists of a vertebral portion articulating with the vertebra by a double head (the capitulum and the tubercle), and a sternal portion articulating with the sternum. An uncinate process arises from the posterior edge of the vertebral portion and projects backwards.

3. The Syn-sacrum.

Following the fourth thoracic vertebra are thirteen vertebræ all fused together, forming the composite sacral region, the syn-sacrum, and supporting the pelvic girdle. The first of these bears a pair of free ribs and is therefore the fifth thoracic vertebra. The next five have no free ribs and may be regarded as the lumbar vertebræ. These are followed by the two sacral vertebræ. The remaining vertebræ of the fused sacral region are the first five caudals.

\section{The Caudal Region.}

The syn-sacrum is followed by six free caudal vertebræ, and the posterior end of the vertebral column is an upturned and compressed ploughshare bone, the pygostyle, formed by the fusion of the last four caudal vertebra.

The following formula shows the composition of the vertebral column of the Pigeon :--

Cervical, 14. Thoracic, $4+\overbrace{\text { 1. Lumbar, 5. Sacral, 2. Caudal, } 5}^{\text {Syn-sacrum }}+6+$ Pygostyle, 4.

Note that the centra of the vertebræ are without epiphyses, i.e., later terminal ossifications.

The Skull.

Make a sketch of the skull viewed from $(a)$ the dorsal surface, $(b)$ the ventral surface, and $(c)$ the side, showing the various bones.

The skull of the Bird compared with that of the Rabbit shows certain important differences, indicated below by italics.

Notice that the skull is high and rounded. Many of the bones are ankylosed, the sutures between them being obliterated.

The cranium (the brain-case) extends forwards; forming the long facial region, which is movable. The large orbits are almost in front of the cranium, and each has a lachrymal bone anteriorly. Between the orbits there is only a thin bony vertical interorbital septum, mainly composed of the mesethmoid and the presphenoid. The cranial cavity does not extend between the orbits into the interorbital septum. The lower border of the interorbital septum is covered by the thin rostrum, a forward prolongation of the basi-sphenoid. The basisphenoid is covered by the basi-temporal (which probably represents the posterior portion of the parasphenoid of the Frog; the anterior portion being 

represented by the rostrum). The basi-sphenoid (basi-temporal) and rostrum form the base of the cranium.

Behind the basi-temporal is the basi-occipital, which bears the single condyle for the articulation of the skull with the atlas vertebra. The basi-occipital, the two ex-occipitals, and the supra-occipital surround the foramen magnum (through which the spinal cord passes), and together form the back of the cranium.

The roof of the cranium is formed by the paired parietals and frontals ; and at its sides are the tympanic cavities, with the squamosals above and the basitemporal below. Each squamosal has a projecting zygomatic process which meets the descending post-orbital process of the frontal.

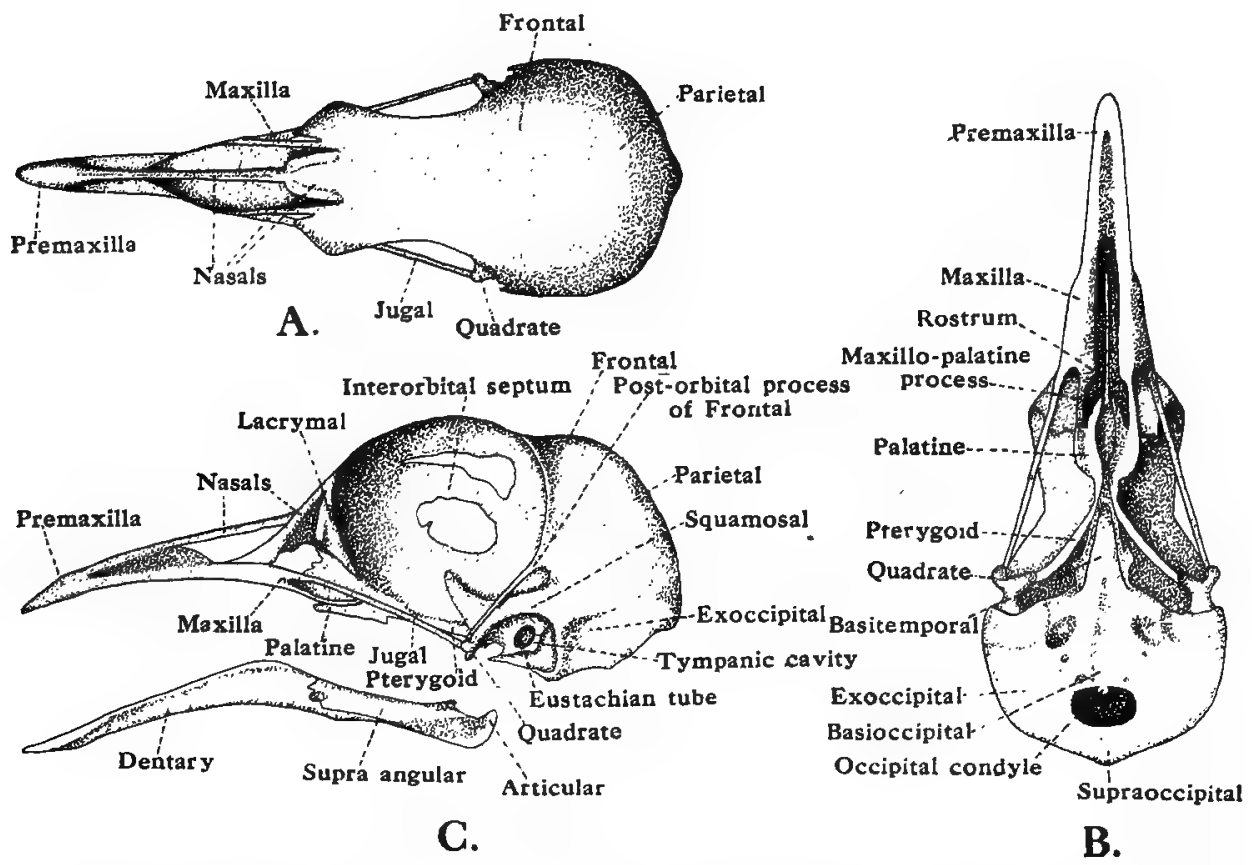

FIG. 91.-The Skull of the Pigeon (Columba). A. Dorsal view ; B. Ventral view ; C. Lateral view.

The facial region of the skull comprises the small nasals, the long triradiate premaxillæ (which together form the greater part of the upper beak), and the bones of the upper jaw and the bony palate or roof of the mouth. The nasals are forked bones; the two processes of each meet the ascending and outer processes of the premaxillax and enclose the external nares. Each side of the upper jaw consists of premaxilla, small maxilla, and quadrato-jugal, with a jugal overlapping parts of the latter two bones. Note that as the jugal has no ascending process meeting the zygomatic (of the squamosal), the orbit is therefore confluent with the temporal fossa behind. The roof of the mouth is formed by the palatines, connected in front with the inner parts of the maxillæ (maxillopalatine processes) and premaxillæ and behind with the rostrum of the basisphenoid and the rod-like pterygoids. two obliquely-directed bones which articulate behind with the quadrate. W'hen the mouth is opened and the upper 

jaw raised, the quadrates swing round and the pterygoids and palatines slide forward along the basi-sphenoidal rostrum.

The quadrate (the suspensorium) bears the articular surface for the lower jaw ; it is a stout triradiate and movable bone, and it is articulated with the squamosal, the quadrato-jugal, and the pterygoid.

Each ramus of the lower jaw is composed of five bones, namely, the articular, angular, supra-angular, splenial (along the inner side of the middle portion of the ramus), and dentary. The dentary forms the distal half of the ramus ; and the two dentaries are fused in front at the symphysis.

The upper and lower jaws are without teeth, but have horny sheaths. There is only one auditory ossicle, the columella. In the floor of the mouth is the hyoid, which is partly ossified and partly cartilaginous. (See Fig. 91, p. 262.)

The Nervous System.

The Brain.

Remove the roof of the cranium (frontals and parietals) by carefully paring off the bone, and take away the sides, piece by piece, so as to expose the brain. Notice the spongy nature of the bone.

Note and draw the following parts :- -

The large cerebral hemispheres overlie the thalamencephalon and reach the cerebellum, hence the large optic lobes are displaced and lateral in position. The olfactory lobes are very small, poorly developed. The large cerebellum is grooved transversely, and is divided into a median lobe and two small lateral lobes (flocculi). The medulla oblongata is largely overlapped and hidden by the cerebellum, and descends almost vertically from it. 



\title{
THE RABBIT (Lepus cuniculus)
}

\author{
First Day
}

\section{External Features.}

The body is thickly covered with hair. The head is connected with the trunk by a short neck. The tail is very short. Note the following features :-

(i) The Head. Notice the general form; the rounded cranial region, the elongated facial region, and the cheeks (zygomatic arches). Note the following parts :--

(a) The mouth, on the under surface at the front of the head, bounded by the soft upper and lower lips. The upper lip is cleft in the middle. This "hare-lip" cleft connects the mouth with the nostrils.

(b) The nostrils, two oblique slits at the end of the snout.

(c) The eyes, at the sides of the head, are protected by an upper and a lower eyelid, and by a nictitating membrane or third eyelid.

(d) The vibrissæ, long stout tactile hairs on the sides of the snout, and about the eyes.

(e) The large external ears or pinnæ.

Open the lips and note the diastema, a gap between the front incisors and the back teeth on each side. The hairy lip extends over the gap into the mouth cavity.

(ii) The Trunk. It consists of two portions, the anterior part or thorax, and the posterior part or abdomen. Note the following :-

(a) The anus, under the tail.

(b) The openings of the perineal glands, bare patches at the sides of the anus. The characteristic smell of the rabbit is due to the secretion of these glands.

(c) The urino-genital opening, in front of the anus. In the male it is small and is situated at the end of the penis, which is retractile within a loose sheath of skin (the prepuce). In the female it is a large and slit-like vulva.

(d) The scrotal sacs of the adult male, two pouches situated one on either side of the penis and containing the testes.

(e) The teats of the female, four or five pairs along the ventral surface of the abdomen and thorax. The ducts of the mammary or milk glands open through the teats.

(iii) The Limbs.

(a) The fore-limbs are short. Each limb is composed of an upperarm, a fore-arm, and a manus or hand. The manus has five clawed digits, the innermost of which, the pollex, does not reach the ground. 

(b) The hind-limbs are much longer than the fore-limbs. Each limb is composed of a thigh, a leg, and a pes or foot. The foot has four clawed digits.

\section{The Thoracic and Abdominal Viscera.}

Lay the rabbit on its back, and fasten it firmly to the dissecting-board by putting large pins through the limbs. Make an incision through the skin, beginning at the pelvis and continuing forwards along the mid-ventral line of the body and neck to the region of the lower jaw. Carefully free the skin from the underlying muscles. Note that a very thin sheet of muscle, the panniculus carnosus, lies immediately beneath the skin, and between it and the underlying muscles is the panniculus adiposus, a layer of fat. In the female the mammary glands may be seen, yellowish branching fat-like masses.

Open the abdomen by making a median incision from the pelvic region to the posterior end of the sternum, taking care not to injure the viscera. Cut outwards, behind the ribs, and then pin out the flaps of muscle at each side. Remove the ventral wall of the thorax (i.e., the sternum and lower portions of the ribs) by cutting through the ribs (except the first pair) along each side. Note the following organs in their position, and make a sketch of them :--

(i) Thoracic Viscera.

(a) The four-chambered heart, enveloped in the thin two-layered pericardium, and lying in the middle of the thorax, in the mediastinal space between the pleural sacs.

(b) The thymus gland, in front of the heart, lying over the arterial arches at their origin from the heart.

(c) The lungs, two spongy organs occupying the sides of the thorax, and separated by the mediastinal space. The lungs are attached at their roots only and are enclosed in pleural sacs.

(d) The lower portion of the trachea, which divides into the right and left bronchi which enter the lungs.

(e) The diaphragm, separating the thorax from the abdomen. It is dome-shaped, and its margin is muscular.

(f) The oesophagus, lying underneath the trachea and extending backwards through the thorax, under the backbone ; it passes through the diaphragm to open into the stomach.

(ii) Abdominal Viscera.

(a) The liver, a large red solid organ attached to the diaphragm by the suspensory ligament, a median vertical fold of peritoneum. Its anterior surface is applied to the diaphragm and is convex; its posterior surface is concave and rests against the stomach. The liver is divided into five lobes, viz. :-

(1) The left centra! lobe, lying against the left half of the diaphragm.

(2) The left lateral lobe, largest in size and partially 

subdivided, lying between the left central lobe and the cardiac end of the stomach.

(3) The right central lobe, almost as large as the left lateral lobe, lying against the right half of the diaphragm. It is grooved on its posterior surface, and the gallbladder lies in this groove.

(4) The caudate lobe, closely applied to the pyloric end of the stomach and to the right kidney.

(5) The Spigelian lobe, smallest in size, and situated posteriorly to the left lateral lobe. It is closely applied to the anterior surface of the stomach.

Note the gall-bladder lying in the groove of the right central lobe. From its posterior end arises the cystic duct, which passes backwards and joins the smaller hepatic ducts from the lobes of the liver to form the bile-duct. The common bile-duct passes beside the portal vein and opens into the duodenum about a quarter of an inch behind the pyloric constriction.

(b) The stomach, lying behind the liver and partly covered by it.

(c) The duodenum, arising from the posterior end of the stomach.

(d) The ileum, the main portion of the small intestine, much-coiled and long and narrow.

(e) The wide cæcum, ending in the vermiform appendix.

(f) The colon, with sacculated walls.

(g) The rectum.

(h) The urinary bladder, at the end of the abdomen, in front of the pubic symphysis.

Turn the alimentary canal towards the right side so as to expose the following parts :-

(a) The spleen, a dark red body behind the stomach and attached to its anterior end.

(b) The kidneys, embedded in fat on the dorsal wall of the abdomen, the right one being the more anterior in position.

(c) The supra-renal or adrenal bodies, small rounded yellowish organs, one near the hilum or inner margin of each kidney.

(d) The mesentery supporting the alimentary canal. It is a double fold of the glistening peritoneum, which lines the abdominal cavity.

(e) The great omentum, a fat-laden fold of peritoneum connected with the stomach.

(f) The veins of the hepatic portal system, namely, the lieno-gastric (from stomach and spleen), the duodenal, the mesenterics (from the intestines). These veins pass between the folds of the mesentery and join to form the main portal vein, which is alongside the posterior vena cava. 



\section{Second Day}

\section{The Alimentary System and Vascular System (part).}

Free the alimentary system from the abdominal cavity, by severing as much as possible of the mesenteric attachment without damaging the veins and arteries supplying the canal. Leave the duodenal loop intact. Make out the following parts :-

(a) The liver, composed of five lobes, with the gall-bladder embedded in the right central lobe.

(b) The stomach, following the gullet or œesophagus and partly covered by the liver. The dilated anterior or left end of the stomach is the cardiac end, the narrower posterior or right end is the pyloric end.

(c) The spleen, a dark red body behind the stomach and attached to the cardiac end.

(d) The duodenum, the first portion of the small intestine, extending from the pyloric end of the stomach along the right side of the abdomen, and forming a $\mathbf{U}$-shaped loop.

(e) 'The pancreas, a diffuse gland, consisting of a number of lobules like masses of fat, and spread out in the mesentery which connects the two limbs of the duodenum. The pancreatic duct, receiving smaller ducts, and opening into the distal limb of the duodenum (inner side) about two inches from the bend.

(f) The ileum (main portion of small intestine), following the duodenum. It is much-coiled and very long (about seven feet).

(g) The sacculus rotundus, the dilated end of the ileum.

(h) The cæcum, the first portion of the large intestine, into which the sacculus rotundus opens. The cæcum is a wide tube marked by a winding spiral constriction. It ends blindly in a finger-shaped process, the vermiform appendix, and proximally it is continuous with the colon.

(i) The sacculated colon, which is a continuation of the cæcum.

(j) The long and narrow rectum, which follows the colon and terminates in the anus. The fæcal pellets within the rectum give it a moniliform appearance.

(k) The bladder, opening to the exterior by the urino-genital opening.

N.B.-The mesentery is often infested with small semi-transparent sac-like bodies; these are "bladder-worms" of the common dog tapeworm (Táenia serrata). They may also be seen in the liver.

Note the following veins and arteries in connection with the alimentary canal :--

(i) The portal vein (see page 2\%0), which conveys the blood from the alimentary canal and associated organs to the liver (hepatic portal system), is formed by the union of the following veins :--

(a) The posterior mesenteric, which collects the blood from the posterior part of the rectum. 

(b) The anterior mesenteric, formed by veins.from the ileum and large intestine.

(c) The duodenal, from the duodenum and pancreas. This vein lies under the pancreas in the mesentery which joins the two limbs of the duodenum.

(d) The lieno-gastric, formed by the union of smaller veins from the stomach and spleen.

(ii) The canal is supplied by the following arteries arising from the dorsal aorta :-

(a) The coeliac, branching into an hepatic to the liver and a lienogastric to the stomach and spleen.

(b) The anterior mesenteric, supplying the duodenum and pancreas, the ileum, the crecum, and the colon.

(c) The posterior mesenteric, to the posterior portion of the rectum.

Make a complete sketch showing the alimentary canal with the blood-vessels supplying it. (See Fig. 92, p. 276.)

\section{The Structures of the Neck.}

Make a careful dissection of the neck region so as to expose the following parts :-

$A$. The Trachea or windpipe, extending along the middle line of the neck and concealing most of the osophagus. It has rings of cartilage in its walls and they are incomplete dorsally. (See Trachea, page 268.)

$B$. The Larynx, the organ of voice, is the anterior part of the trachea. Externally may be noted the large anterior thyroid cartilage and the smaller posterior ring-like cricoid cartilage, which form the outer wall of the larynx.

C. The Thyroid, a two-lobed body, one lobe lying on either side of the cricoid cartilage of the larynx. The lobes are connected by a ventral isthmus.

D. The Nerves.

(a) The cervical sympathetic cords, arising in the head and passing backwards, one on either side of the trachea between the vagus and depressor nerves. Anteriorly in the neck region each has two ganglia, the superior cervical sympathetic and the inferior cervical sympathetic ganglion. In the thorax each cord has twelve ganglia, and in the abdomen there are also twelve.

(b) The vagus or pneumogastric nerves are the tenth cranial nerves, and each emerges just at the posterior end of the mandible. Here it gives rise to the vagus ganglion and then branches to form :

(i) The vagus nerve, a stout cord running parallel to the trachea, along the outer side of the carotid artery, and supplying the heart, lungs, œsophagus and stomach.

(ii) The superior laryngeal nerve, which runs from the ganglion straight across the trachea to the thyroid cartilage. 



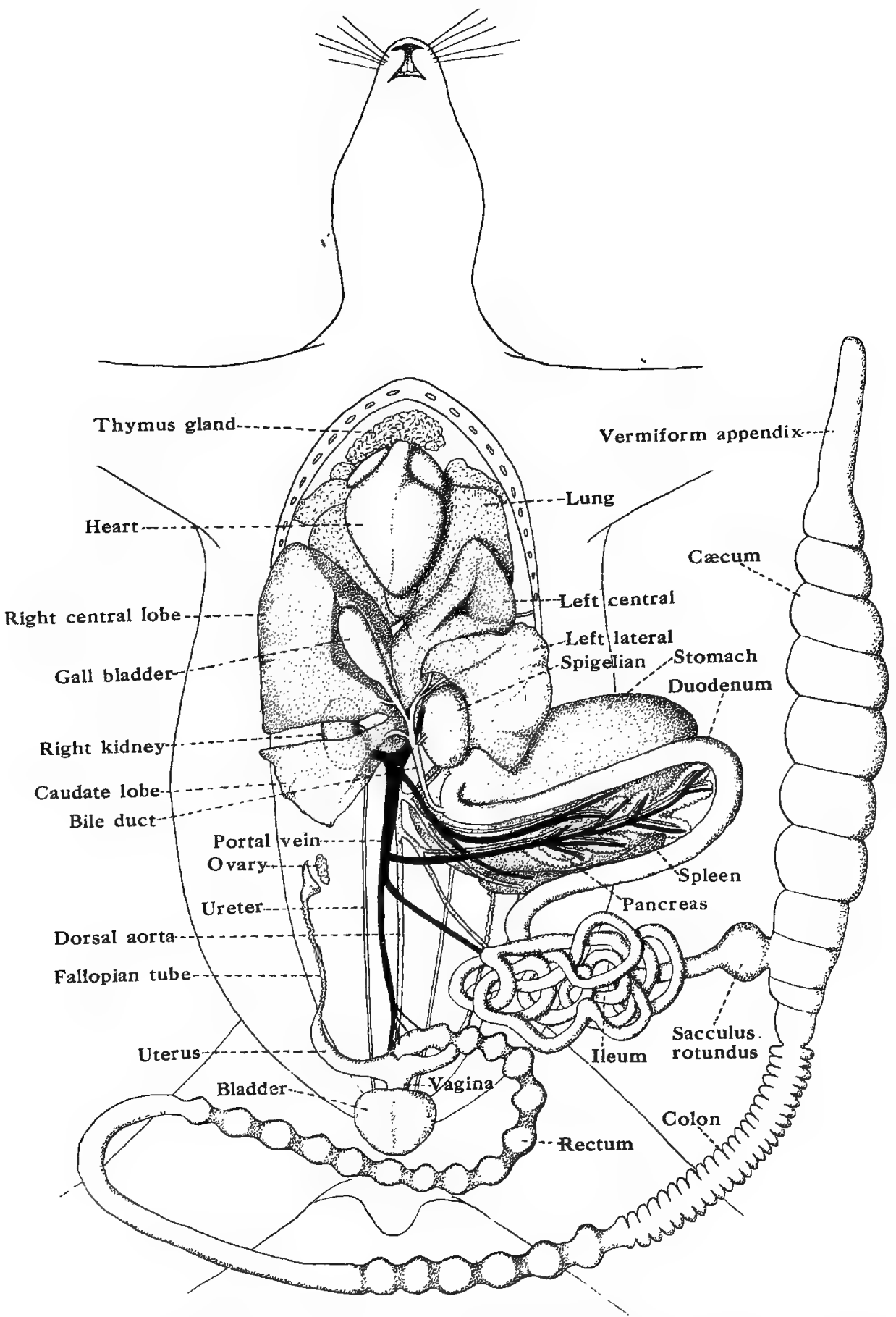

FIG. 92.-The Rabbit (Lepus cuniculus), Dissection showing the Alimentary System, the principal Blood-vessels of the Alimentary Canal, the Reproductive System (female), etc. The dorsal aorta gives off the coeliac artery (branching into the hepatic and lieno-gastric) and the anterior mesenteric artery. The portal vein is formed by the lieno-gastric, duodenal, anterior and posterior mesenteric veins. 

(iii) The depressor nerve to the heart, passing. backwards over the cervical sympathetic cord and continuing close to it and alongside the common carotid artery.

(iv) The inferior or recurrent laryngeal. At the posterior end of the neck the right vagus gives off the inferior or recurrent laryngeal nerve just where it passes over the right subclavian artery. This recurrent laryngeal then passes under the subclavian artery and proceeds along the side of the trachea to the larynx. The vagus of the left side also gives off a recurrent laryngeal, but it arises where the ductus arteriosus joins the aorta, and it passes under the ductus arteriosus, then along the side of the trachea to the larynx.

(c) The spinal accessory or eleventh cranial nerves, beside the hypoglossals.

(d) The hypoglossal or twelfth cranial nerves, each curving forwards round the angle of the jaw.

(e) The spinal nerves (arising from the spinal cord), of which the third pair give rise each to a great auricular branch to the ear, and the fourth and fifth pairs give off branches which join to form the phrenic nerves. Each phrenic nerve passes backwards under the precaval vein and over the subclavian artery of each side, and supplies the diaphragm. In the thorax the phrenic nerves may be followed out between the heart and the lungs.

$E$. The Sub-maxillary Salivary Glands.

There is a pair of these glands situated one at either end of the lower jaw, and in front of the larynx. Each is a compact reddish ovoid body, and its duct (Wharton's duct) passes forward along the inner side of the jaw to open into the floor of the mouth a short distance behind the lower incisors.

$F$. The Blood-vessels.

On either side of the trachea are the following vessels :-

(a) The common carotid artery, along the outer side of the trachea. It divides into an internal carotid artery, just posterior to the larynx, and an external carotid, which continues alongside the trachea to the side of the head.

(b) The internal jugular vein from the brain. It runs alongside the vagus nerve, and joins the external jugular near the union of that vein with the subclavian.

(c) The external jugular vein, along the side of the neck. It is formed by the union of the anterior and the posterior facial veins.

Makc a complete sketch showing the above parts, A-F. (See Fig. 93, page 280.)

\section{The Solar Plexus.}

Turn the stomach over to the right side and note the following parts :-

Arising from the last thoracic ganglion of either side is the splanchnic nerve. Each splanchnic nerve passes backwards next to the aorta. Just over the origin of the anterior mesenteric artery these nerves unite into a group of cœliac 



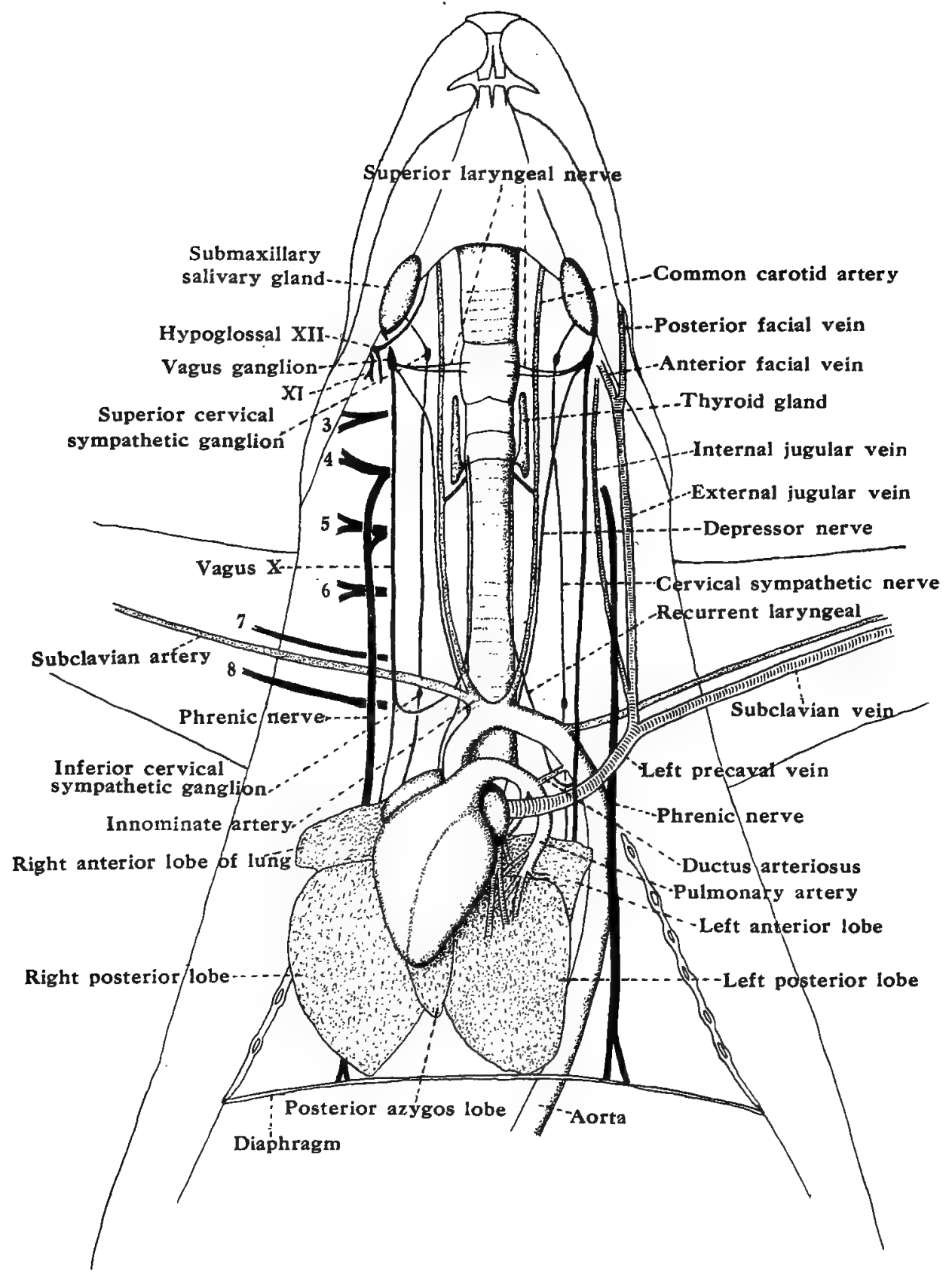

Frg. 93.-The Rabbit (Lepous cuniculus). Dissection of the Neck and Thorax showing the lungs, heart, aorta, etc., and the nerves and blood-vessels and other parts of the Neck.

$\mathrm{XI}$ indicates the eleventh cranial nerve, the spinal accessory. 

ganglia. "These ganglia, giving rise to nerves which supply the stomach and neighbouring parts, constitute the large coliac or solar plexus.

Make a drawing showing the solar plexus and neighbouring parts.

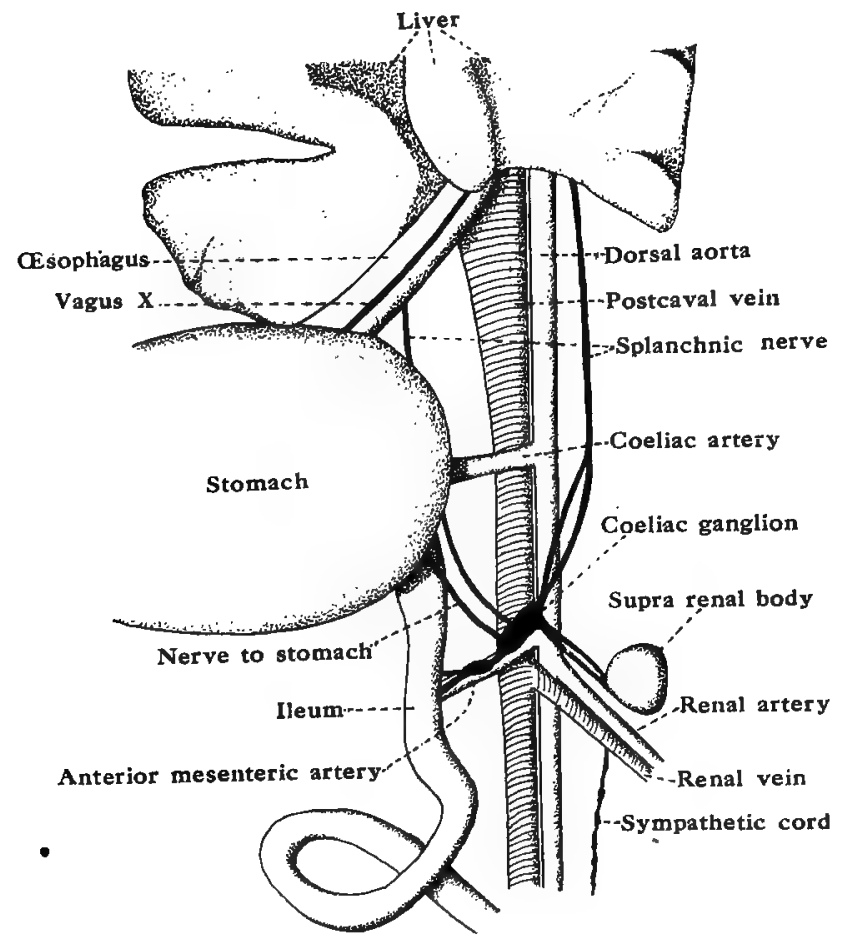

FIc. 94.-The Solar Plexus, and neighbouring structures, of the Rabbit.

\section{Third Day}

The Vascular System (continued).

Carefully remove the thymus gland so as to expose the origins of the bloodvessels from the heart. Remove the pericardium. Note that the heart is four-chambered and conical in shape. (See Heart, page 268.)

The two ventricles occupy nearly the whole of the ventral aspect of the heart. A groove-line, which is directed obliquely from the base and which does not quite reach the apex (see Fig. 93), indicates the division of the ventricles; that one on the right of the line, and not reaching the apex of the heart, is the right ventricle. Only portions of the two auricles are seen on the ventral surface (above the ventricles).

The following vessels open into the right auricle of the heart :-

(a) The right superior vena cava or precaval, on the dorsal wall of the right auricle.

(b) The left superior vena cava or precaval, on the left side of the right auricle. 

(c) The inferior vena cava or postcaval, which returns blood from the abdominal region, passes through the diaphragm and opens into the posterior end of the right auricle.

From the right ventricle the pulmonary artery arises. It conveys the venous blood from heart to lungs. It arches over to the dorsal surface of the left auricle, and there divides into the right and the left pulmonary arteries. It is connected with the aorta by the ductus arteriosus.

The pulmonary veins, which return the blood from the lungs to the heart, open into the left auricle on its dorsal surface.

The aorta, which conveys the purified blood from the heart to the body, arises anteriorly from the left ventricle. It goes forwards, then bends over to the left (aortic arch) and passes backwards, along the vertebral column, as the dorsal aorta. Note the ductus arteriosus, which arises just before the bifurcation of the pulmonary arch and connects that arch with the aorta.

$A$. The Venous System.

The right precaval (right anterior or superior vena cava) is formed? by the following veins :-

(a) The right subclavian vein, from the fore-limb and shoulder.

(b) The right external jugular vein, along the side of the neck, formed by the union of the anterior and posterior facial veins in the anterior region of the neck. It joins the subclavian vein at the base of the arm. (See page 278.)

(c) The right internal jugular vein, running close to the trachea, and joining the external jugular. (See page 278.)

(d) The azygos vein, passing forwards along the vertebral column on the right-hand side only, and joining the right precaval vein near the right auricle. It receives seven or eight pairs of intercostal veins from the spaces between the ribs.

The left precaval (left anterior or superior vena cava) is formed by similar veins on the left-side, and then passes over the anterior surface of the lungs to open into the right auricle. It does not receive an azygos vein, there being only one.

The postcaval (posterior or inferior vena cava), running forwards through the dorsal part of the liver, receives the following veins in its course :-

(a) The posterior phrenic veins from the diaphragm.

(b) The hepatic veins from the liver.

(c) The pair of renal veins from the kidneys.

(d) The pair of spermatic veins from the testes, or the pair of ovarian veins from the ovaries. In the male each spermatic vein and spermatic artery together with some connective tissue form a spermatic cord, which passes from the abdomen to the testis.

(e) The pair of ilio-lumbar veins from the hinder part of the abdominal walls.

(f) The pair of external iliac veins, which are continuations of the femoral veins from the thighs. 

(g) The pair of internal iliac veins from the sciatic region of the legs and the pelvic cavity. The postcaval vein arises or is formed from the union of these two vessels at the posterior end of the body.

$B$. The Arterial System.

The aorta on leaving the heart bends over to the left, and from the aortic arch thus formed the following arteries arise :-

(a) The innominate artery, arising at the beginning of the aortic arch, and dividing into a right subclavian artery to the shoulder and a right common carotid artery to the head. Just posterior to the larynx the carotid divides into an internal carotid artery to the brain and an external carotid artery to the right side of the head and face. The subclavian is continued as the brachial artery into the fore-limb.

(b) The left common carotid, arising from the arch at or near the base of the innominate. Its course and branches are the same as those of the right common carotid artery.

(c) The left subclavian artery, to the left shoulder and fore-limb.

The aortic trunk then passes backwards as the dorsal aorta along the ventral surface of the vertebral column. The dorsal aorta gives rise to the following arteries:-

(a) The coliac artery, arising about half an inch beyond the diaphragm, and branching into an hepatic to the liver, and a lieno-gastric to the stomach and spleen.

(b) The anterior mesenteric artery, about an inch behind the coeliac, and supplying the duodenum and pancreas, the ileum, cæcum, and colon.

(c) The pair of renal arteries to the kidneys.

(d) The pair of spermatic arteries to the testes, or the pair of ovarian arteries to the ovaries.

(e) The posterior mesenteric artery to the rectum.

(f) The pair of common iliac arteries, formed (in front of the pubic symphysis) by the division of the aorta, and running to the hind-limbs and there continued as the femoral arteries. Each common iliac gives rise (in the abdomen) to an ilio-lumbar artery to the body-wall, and an internal iliac artery to the anal region.

(g) The small caudal or median sacral artery, arising from the dorsal aorta just in front of the origin of the common iliacs.

Make a sketch, showing the complete vascular system. (See Fig. 95, page 288.)

\section{The Urino-genital System.}

\section{$A$. The Renal or Urinary System.}

Examine the kidneys (metanephros), noting their ovoid shape and the notch on the inner side (the hilus) where the blood-vessels and ureters enter and leave. Trace the ureters from the kidneys to the bladder. Note the form and the thin wall of the bladder. Note also the supra-renal gland or adrenal body in front of each kidney. 

The urinary system is the same in both sexes, except that in the female the ureters open into the bladder near its front end.

$\boldsymbol{B}$. The Reproductive System.

(a) The Male.

The scrotal sacs, two pouches of the abdominal wall, communicate with the abdomen through the narrow inguinal canal (the neck of the scrotal sac).

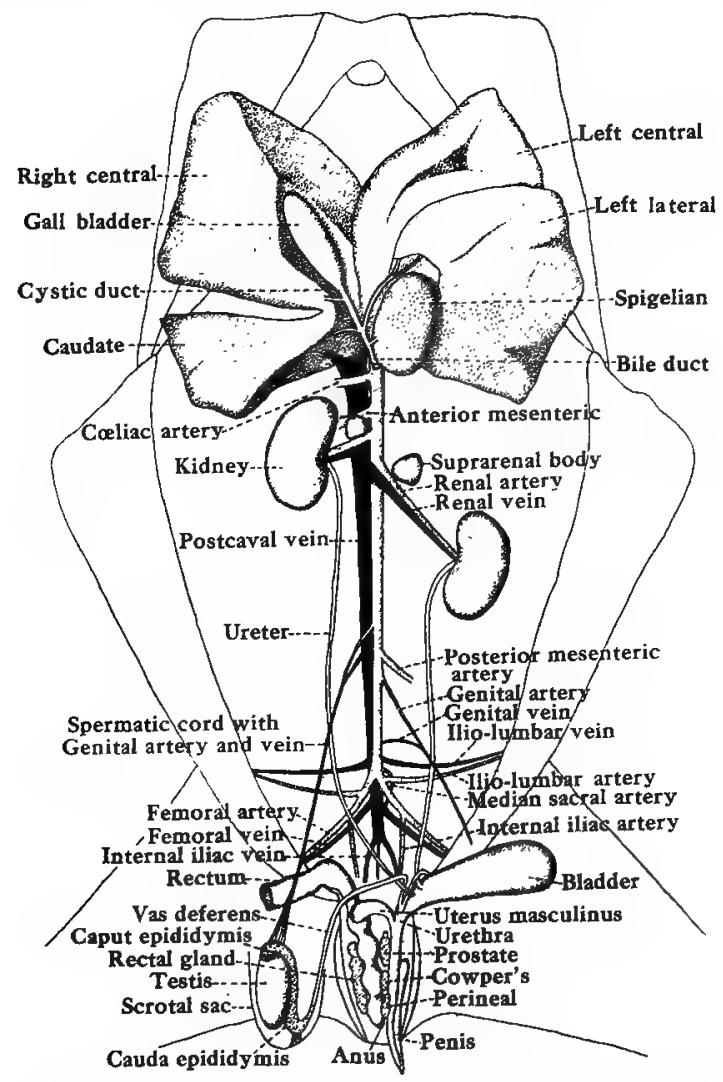

FIG. 95.-The Rabbit (Lepus cuniculus). The veins and arteries of the Abdominal Region, and the Urinogenital System of the Male. (See also Fig. 93.)

Open a scrotal sac along its ventral surface and note:

(1) The testis, with the spermatic cord (containing the artery, the vein, and connective tissue), entering the anterior end.

(2) The epididymis (mesonephros or Wolffian body), a mass of convoluted tubules lying along the inner border of the testis, and divided into

- a caput epididymis at the front end and a cauda epididymis at the hind end.

(3) The vas deferens (Wolffian duct), extending from the cauda epididymis into the abdominal cavity and there looping over the ureter where that duct opens into the bladder. 

Carefully remove the pelvic symphysis by cutting through the bones on either side of the middle line, and note the following :--

(1) The urino-genital canal or urethra, which is a continuation backwards of the neck of the urinary bladder. It is situated below the rectum and above the pelvic symphysis, behind which it traverses the penis.

(2) The penis, which is traversed by the terminal portion of the urethra.

(3) The uterus masculinus, a sac lying about half-way along and above the bladder and opening into the urethra.

(4) The terminal portions of the vasa deferentia, which together pass backwards above the neck of the bladder, between it and the uterus masculinus, and open separately into the ventral wall of the uterus masculinus, just before its opening into the dorsal wall of the urethra.

(5) The prostate gland, which is on the walls of the uterus masculinus, at the commencement of the urethra and the ends of the vasa deferentia.

(6) Cowper's glands, a pair of small ovoid glands, lying just behind the prostate, close to the side of the urethra.

(7) The rectal glands, a pair of brown bodies about one inch in length, situated on either side of the last two inches of the rectum.

(8) The perineal glands, a pair of glands which are situated on either side of the penis. Their ducts open on the perineal patches at the sides of the anus.

Slit open the urethra, also the urinary bladder, and note :

(1) The openings of the ureters on the dorsal wall of the bladder.

(2) The opening of the uterus masculinus on the dorsal wall of the urethra.

(3) The openings of the prostate ducts (usually four in number) into the urethra.

Make a sketch of the male urino-genital system. (See Fig. 95.)

(b) The Female.

Remove the pelvic symphysis, as in the male, and note :

(1) The ovaries a pair of ovoid bodies on the dorsal wall of the abdomen and behind the kidneys.

(2) The two oviducts (Müllerian ducts). Each consists of three distinct portions, namely, (3), (4) and (5) undernoted.

(3) The narrow Fallopian tubes, continuous with the uteri. Their wide funnel-like openings are close to the ovaries.

(4) The uteri opening separately into the vagina.

(5) The vagina a wide median tube formed by the union of the vaginal portions of the oviducts. It unites with the neck of the bladder at the beginning of the vestibule.

(6) The vestibule or urino-genital canal, which opens externally at the vulva.

(7) The clitoris, corresponding to the penis of the male and situated in the vestibule just inside its outer opening.

(8) Cowper's glands (reduced, sometimes absent), on the dorsal wall of the vestibule.

(9) The perineal and rectal glands, as in the male.

Make a sketch of the female urino-genital system. (See Fig. 92.) 



\section{Fourth Day}

\section{The Skeletal System.}

Remove the muscles from the head, neck, trunk and limbs so as to expose as much as possible of the skeletal system; or, alternatively, examine a prepared skeleton of the Rabbit.

I. The Axial Skeleton.

A. The Skull.

The original cartilaginous skull (the chondrocranium) is almost entirely replaced by bones. The skull therefore consists of these substitution or replacement bones (also called cartilage bones) and of additional membrane bones, i.e., bones of dermal origin which cover or invest the original cartilage. The membrane bones are here marked *.

The skull is composed of the cranium proper (the brain-case), the olfactory and auditory capsules, the mandible or lower jaw, and the hyoid bone in the floor of the mouth between the rami of the mandible.

The cranium consists of segments (groups of bones) which come apart more or less readily.

Detach the skull from the atlas vertebra of the neck and note the following parts : -

(a) The occipital segment, or back of the skull :-

(i) The basi-occipital, forming the floor of the hinder end of the cranium and bounding the foramen magnum ventrally or in front.

(ii) The ex-occipitals, bounding the foramen magnum at the sides and forming the greater part of the two condyles. Note the par-occipital processes, directed backwards and closely applied to the tympanic bulla.

(iii) The supra-occipital, bounding the foramen magnum posteriorly or above.

(b) The parietal segment, which is connected with the occipital segment above and below, and separated from it at the sides by the auditory capsules and squamosals :--

(i) The basi-sphenoid, in front of the basi-occipital.

(ii) The ali-sphenoids, fused to the sides of the basi-sphenoid and forming part of the floor of the cranium. From the side of each the external pterygoid process projects downwards, and is connected along its inner edge with the palatine bone.

(iii) The parietals, meeting together mid-dorsally (sagittal suture) and forming the roof of the cranium.

(iv) The small median interparietal,* between the parietals and the supra-occipital.

(c) The frontal segment:-

(i) The pre-sphenoid, a small laterally compressed bone in front of the basi-sphenoid. 

(ii) The orbito-sphenoid, around the optic foramen, a pair of platelike bones, fused with the pre-sphenoid, forming part of the wall of the cranium and of the orbits. They unite behind with the frontals, squamosals, and ali-sphenoids.

(iii) The frontals, ${ }^{*}$ forming the roof and sides of the anterior part of the cranium and the upper part of the wall of the orbit ; each bearing a prominent supra-orbital process, and articulating with each other in the middle line.

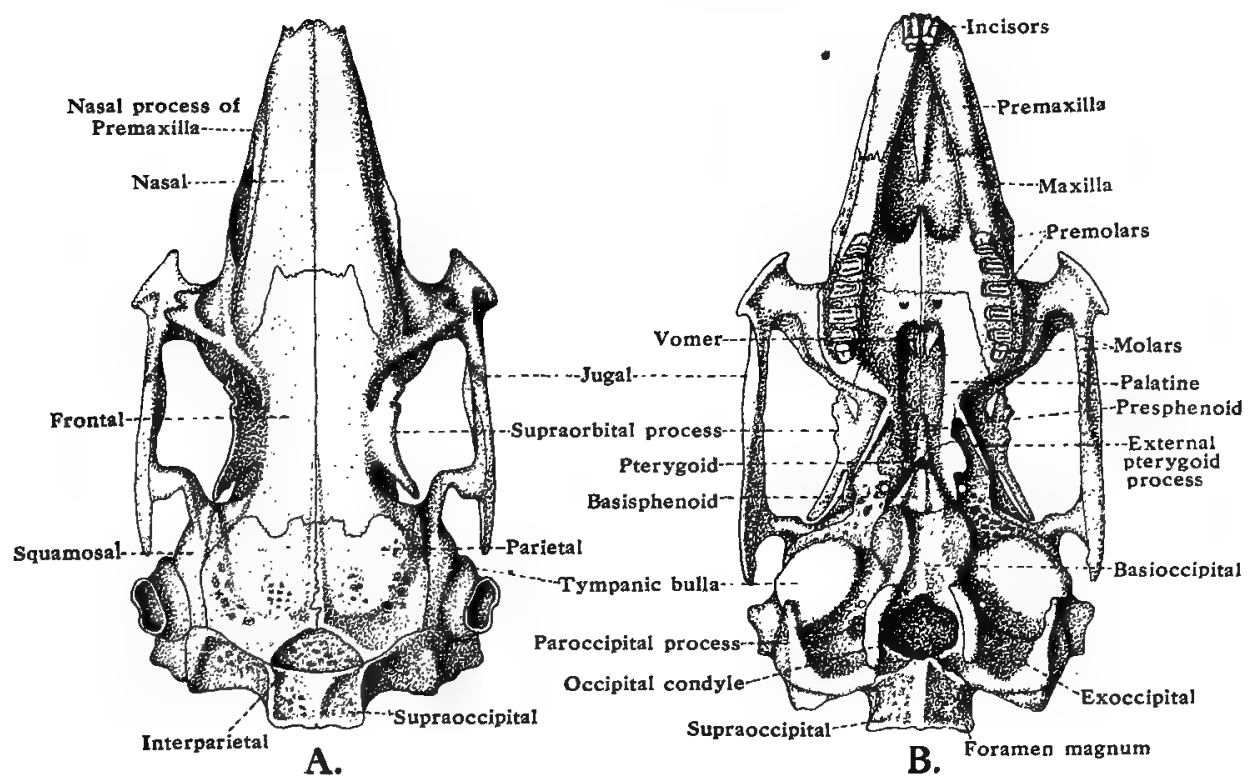

Frr. 96.-The Skull of the Rabbit (Leyus cuniculus). A. Dorsal view ; B. Ventral view.

(d) The nasal region :-

(i) The nasals, * a pair of elongate bones forming the roof of the nasal cavities.

(ii) The vomers, * a pair of slender bones fused along their ventral margins, forming the base of the nasal cavities.

(iii) The mesethmoid cartilage, which forms the vertical internasal septum separating the olfactory or nasal capsules. Along its lower edge are the slender vomers. It is expanded behind to form the sieve-like cribriform plate, through which the olfactory nerves pass to the nose.

(iv) The turbinals, intricate folds of very thin bone within the nasal cavities.

The large olfactory capsules occupy a great part of the facial region of the skull.

Note the following bones composing the sides of the skull :-

(i) The lachrymals, * a pair of small plate-like bones forming part of the front walls of the orbits and articulating with the frontals and the maxilla. 

(ii) The periotics (around the internal ear), between the occipital segment and the squamosals. Each periotic has an outer dense petrous portion and an inner porous mastoid portion.

(iii) The tympanics,* on the outer sides of the periotics. Each consists of an upper funnel-like part (the bony wall of the external auditory meatus), and a bulbous base, the tympanic bulla, which encloses the tympanic cavity containing the three ear ossicles.

(iv) The squamosals, * connected with the auditory capsules, a pair of bony plates situated in front of the periotics below the parietals and articulating with the parietals, frontals, orbito-sphenoids, and ali-sphenoids. Each sends forwards and outwards a stout zygomatic process, which has ventrally the articular surface for the lower jaw and which articulates with the jugal bone to form the zygomatic arch.

The upper jaw consists of the following bones :-

(i) The premaxillæ,* a pair of bones forming the anterior part of the upper jaw, articulating with each other in front and with the maxillæ behind and sending a long, slender nasal process backwards between the nasal bone and the maxilla. The palatal processes of the premaxillæe on the roof of the mouth form the incomplete anterior portion of the hard palate.

(ii) The maxillæ,* a pair of large irregular bones. From each a zygomatic process is given off; it is prolonged upwards as the orbital process, and outwards it fuses with the jugal, forming the boundary of the orbit anteriorly. The zygomatic process of the squamosal, fused to the other end of the jugal, completes the zygomatic arch. The body or alveolar portion of each maxilla is produced inwards ; and these parts meeting together in the middle line of the roof of the mouth, thus form a part of the posterior portion of the hard palate.

(iii) The pterygoids, * a pair of thin vertical plates of bone attached to the skull at the junction of the ali-sphenoids with the basi-sphenoid.

(iv) The palatines, * a larger pair of plates, each consisting of a vertical portion attached above to the ventral side of the presphenoid and behind to the pterygoid, and a horizontal portion which meets its fellow in the middle line in the roof of the mouth, thus forming a part of the posterior portion of the hard palate.

(v) The jugals or malars, ${ }^{*}$ a pair of flattened bar-like bones. Each one is connected with the zygomatic processes of the maxilla and squamosal, and forms the median and longest portion of the zygomatic arch.

Note the two incisor teeth on each premaxilla, and the three premolars and three molars on each maxilla.

The lower jaw or mandible has the following parts :--

A pair of bones, the rami of the mandible, united in front. Each ramus represents a single bone, the dentary, and is made up of a stout horizontal portion bearing a single incisor, two premolar and three molar teeth, and a thinner posterior portion with a dorsal or coronoid process and a ventral posterior part or angular process. The ascending portion of the ramus ends in 

the elongated condyle, which articulates with the under surface of the zygomatic process of the squamosal.

Make three drawings showing dorsal, ventral, and lateral views of the skull.

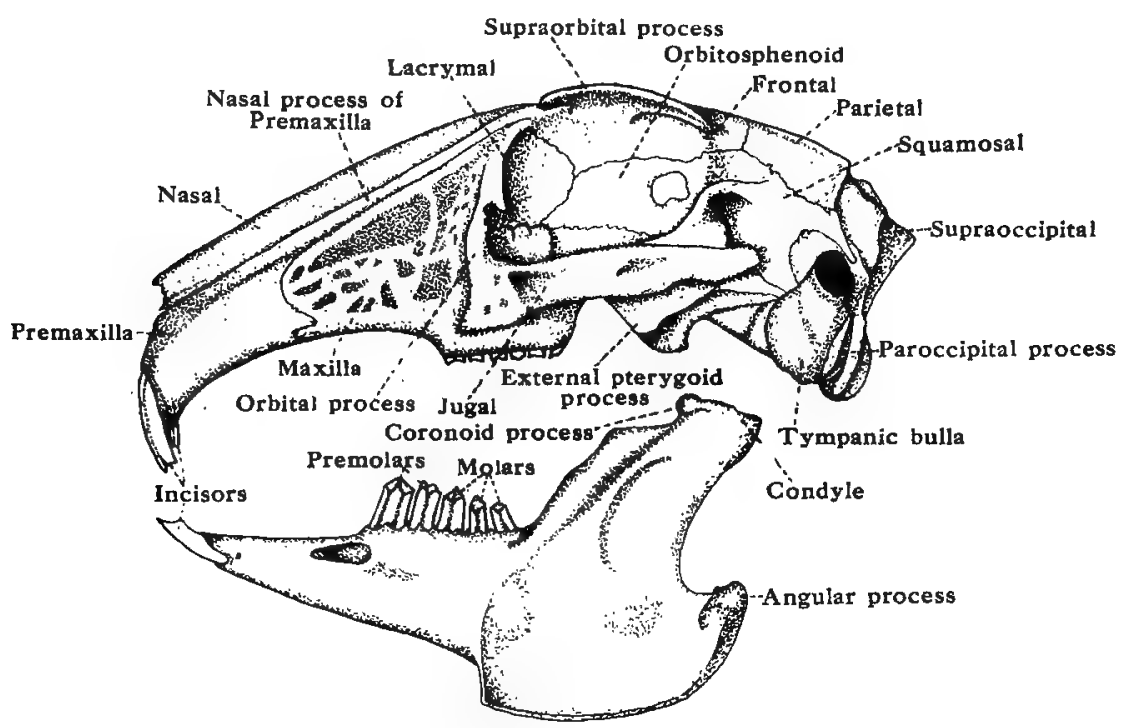

FI: 97.-.The Skull of the Rabbit (Lepus cuniculus). Lateral view.

B. The Vertebral Column.

The vertebral column or backbone is divided into five regions, namely, the cervical, thoracic, lumbar, sacral, and caudal. The centra of the vertebræ have thin epiphyses at their ends; and between the centra there are cartilaginous intervertebral discs.

1. The Cervical or Neck Region.

There are seven cervical vertebræ. Typically they have short centra and small spines. They may be readily recognised by the character of each transverse process, which consists of a rib fused with the vertebra and is pierced by a foramen through which the vertebral artery passes, so that a continuous vertebra-arterial canal is thus formed.

(a) The Atlas.

This is the first cervical vertebra. It is ring-shaped, and its lower portion is

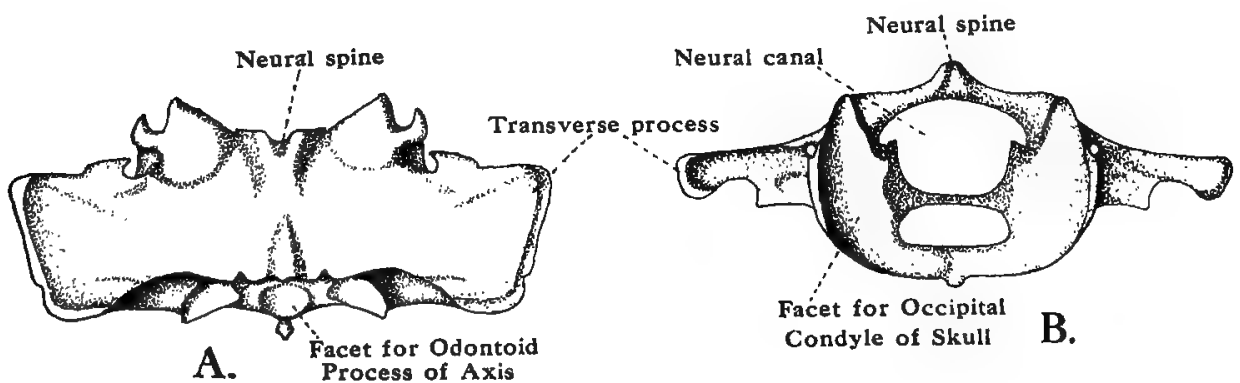

F'IC. 98. -A. Dorsal view ; and B. Anterior view of the Atlas Vertebra of the Rabbit. 

narrow owing to the absence of a distinct centrum. The neural canal is large ; and it is divided by a ligament into an upper part through which the spinal cord passes, and a lower part into which fits the odontoid process of the axis. The transverse processes are very broad. Anteriorly there are two large concavities, the articular surfaces for the occipital condyles of the skull.

Draw the atlas vertebra from above and from in front. (See Fig. 98, page 298.)

(b) The Axis.

This is the second cervical vertebra. It has a large crest-like neural spine ; and its centrum bears the odontoid process, which represents a fusion of the centra of the atlas and the axis. The transverse processes are small, and each is perforated by the vertebra-arterial foramen. The zygapophyses occur only on the posterior surface of the arch.

Draw the axis vertebra as viewed from the left side and from in front.

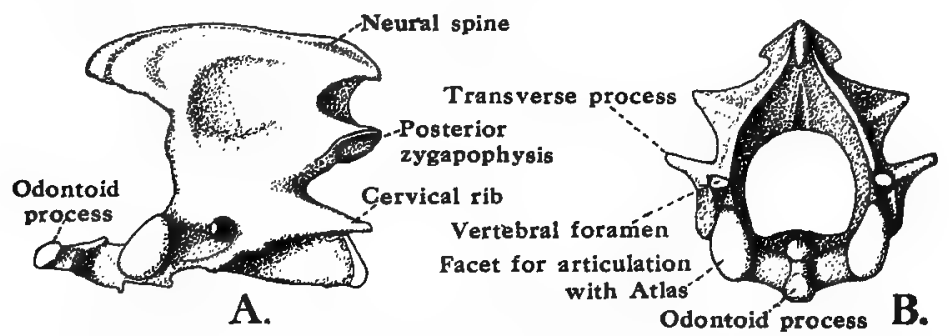

FIt. 99.-A. Left-side view ; and B. Anterior view of the Axis Vertebra of the Rabbit.

(c) The Sixth Cervical Vertebra.

This vertebra has a centrum bearing a cervical rib fused with the transverse process on each side. The transverse processes are perforated by the vertebra-arterial foramina. The neural spine is short. Both anterior and posterior zygapophyses occur on the neural arch.

Draw this vertebra from the left side and from in front.

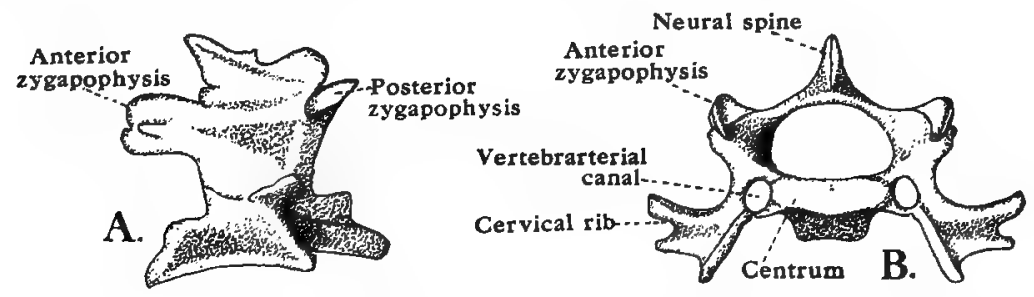

FIG. 100.-A. Left-side view ; and B. Anterior view of the Sixth Cervical Vertebra of the Rabbit.

2. The Thoracic Region.

This region consists of twelve or thirteen vertebræ which bear movably articulated ribs. The neural spines are long. The transverse processes are short and stout; and each, in the first nine vertebræ, is provided on the underside with a facet for the articulation with the tuberculum of the rib. The short and thick centrum bears on each side a facet for the head (capitulum) of the rib. 

Examine the fifth thoracic vertebra and note the rounded centrum with the neural arch dorsal to it, the long neural spine, the anterior and the posterior zygapophyses, the transverse processes with the tubercular facet on the under side of each, and, at the base of the neural arch, the facet for the head or capitulum of the rib.

Draw this vertebra viewed from the side and from in front.

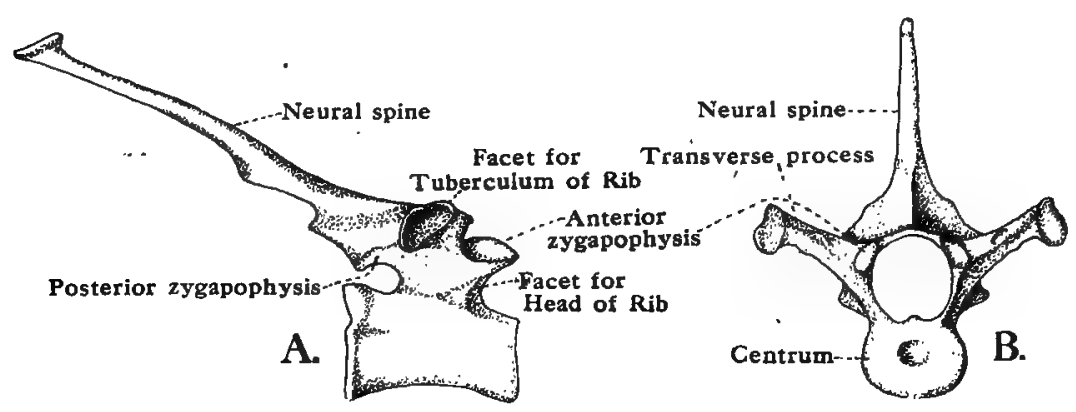

FI': 101.-A. Right-side view; and B. Anterior view of the Fifth Thoracic Vertebra of the Rabbit.

3. The Lumbar Region.

The lumbar vertebræ, usually seven in number, are characterised by their large size and the great development of their processes. The pre-zygapophyses are borne on the inner sides of large metapophyses, while posteriorly the small anapophyses overhang the intervertebral notches. In the first two lumbars the centrum has a median ventral hypapophysis. They do not bear ribs.

Examine and draw the second lumbar vertebra. Note the large transverse processes, and the other parts as indicated above.

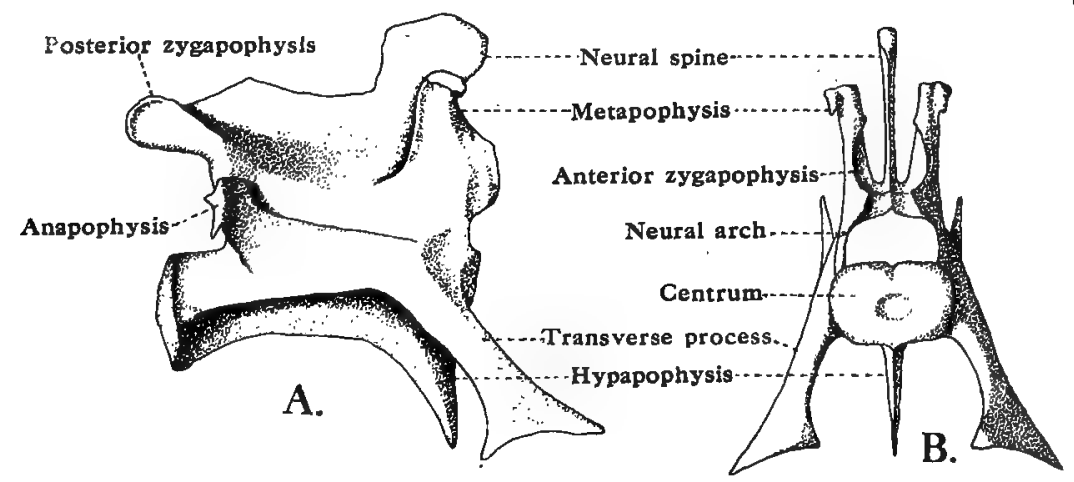

Frs. 102.-A. Right-side view; and B. Anterior view of the Second Lumbar Vertebra of the Rabbit.

\section{The Sacral Region.}

This region consists of three or four vertebræ fused together to support the pelvis. Usually they are large and bear at the sides a pair of wing-like expansions, which support the pelvic girdle. A certain number of caudal vertebræ are fused with the true sacral vertebræ (one or two) to form the composite sacrum. 

5. The Caudal Region.

The caudal vertebræ, from fifteen to eighteen in number, are gradually reduced in size and lose their processes towards the end of the tail. The first two or three are fused with the sacral vertebræ.

\section{The Ribs and Sternum.}

The ribs (along with the thoracic vertebræ) form the supporting framework of the walls of the thorax. There are twelve or thirteen pairs of ribs, each having the form of a curved rod articulating with the thoracic vertebræ, and consisting (typically) of an upper bony vertebral portion and a lower cartilaginous sternal portion. The first seven pairs of ribs are connected with the sternum or breast-bone by their cartilaginous sternal portions. The sternal portions of the eighth and ninth pairs of ribs are connected with the ribs in front of them. The last three pairs have no sternal portions. The ends of the ribs which articulate with the vertebral column have each a knob known as the head or capitulum. The first nine pairs have an additional facet, the tubercle, for articulation with the transverse process of the vertebra.

The sternum or breast-bone is transversely segmented. The first segment, the manubrium, is keeled ; the last or seventh segment, the xiphisternum, ends in a flattened cartilage.

II. The Appendicular Skeleton.

1. The Pectoral or Shoulder Girdle.

Remove the pectoral girdle and fore-limb. The girdle is attached, outside the ribs, by muscles and ligaments only. Note the following parts :-

(a) The scapula or shoulder-blade, a flattened triangular bone, with its apex directed downwards and forwards and enlarged and hollowed out ventrally to form the glenoid cavity for the articulation of the head of the humerus.

(b) The cartilaginous suprascapula, on the short upper border of the scapula.

(c) The prominent ridge or spine, along the outer surface of the scapula, ending in the acromion process, which is prolonged backwards as the long metacromion process.

(d) The short and hook-like coracoid process, at the apex of the glenoid cavity.

(e) The clavicle, a small and slender, curved bone, lying in the ligament between the acromium and the sternum.

Make a sketch of the scapula.

2. The Fore-limb.

Carefully clean the left fore-limb, and note the following parts :-

(a) The humerus (upper arm), a long bone. Its head articulates in the glenoid cavity of the scapula. In front of the head is the bicipital groove for the tendon of the biceps muscle; this groove is bounded by two roughened projections, the lesser tuberosity on the inner side, and the greater tuberosity on the outer side. At the lower end is a pulleylike trochlea, which articulates with the radius and ulna to form the elbow-joint. Above the trochlea are two supra-trochlear fosse, the 

coronoid fossa in front and the olecranon fossa behind; the two communicating by a supra-trochlear foramen.

(b) The radius, a long and slightly curved bone. Its head is provided with a double surface for articulation with the trochlea of the humerus; its distal extremity has a pair of slight concavities for articulation with the carpal bones, the scaphoid or radiale and the semilunar or intermedium.

(c) The ulna, a long bone articulating at the elbow with the humerus and at the wrist or carpus with the cuneiform. Behind the elbow-joint it is produced into the olecranon process, which fits into the olecranon fossa. The radius and ulna constitute the fore-arm.

(d) The carpus or wrist, consisting of two rows of carpal bones :-

(i) The proximal row is composed of the scaphoid or radiale (on the inner side and articulating with the radius), the semilunar or intermedium (articulating with the radius), and the outer cuneiform or ulnare (articulating with the ulna).

(ii) The distal row is composed of the trapezium (on the inner side and articulating with the scaphoid, and forming the support for the first metacarpal), the trapezoid (also articulating with
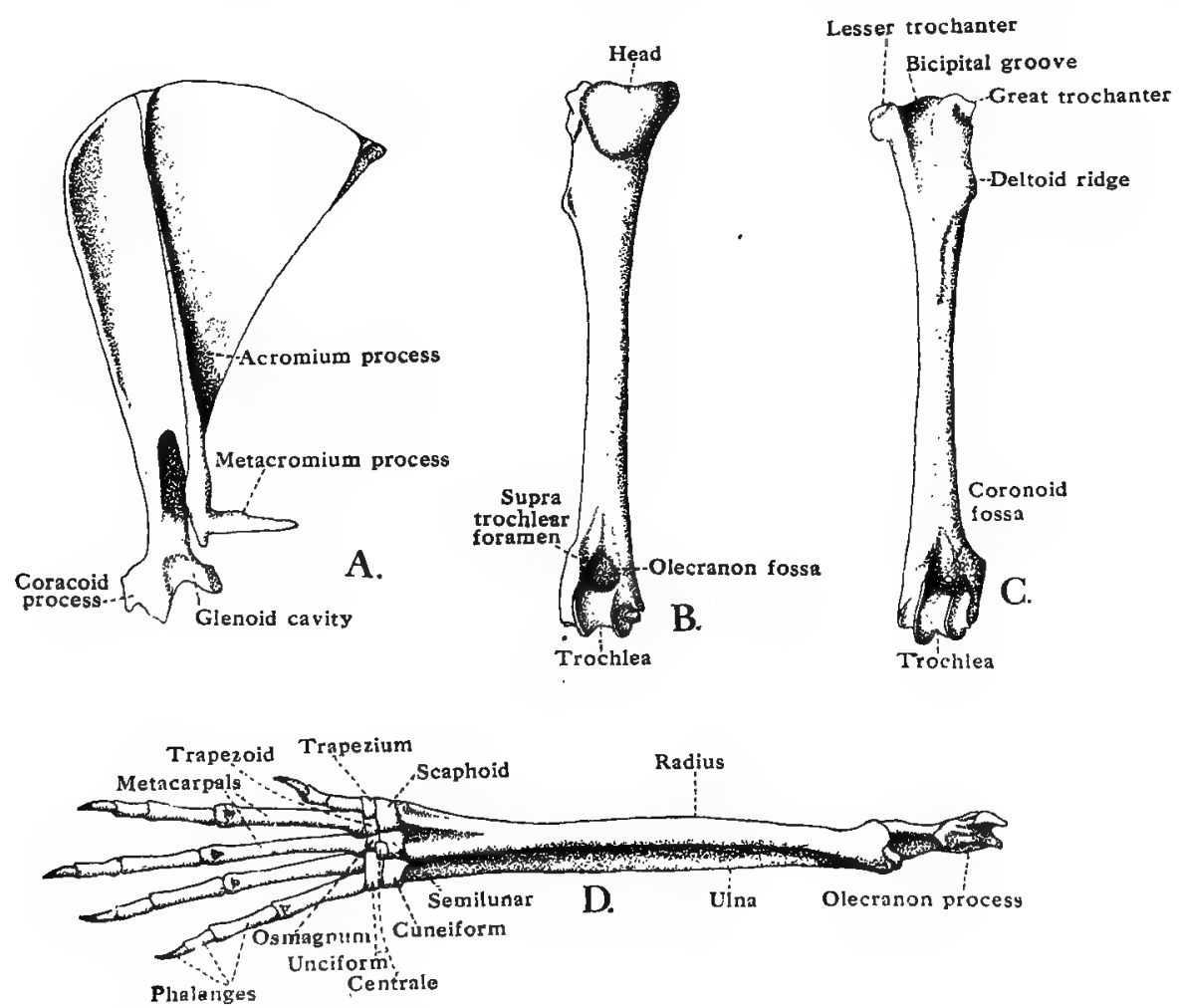

FIr. 103.-The Rabbit (Lepus cuniculus). A. Left Scapula or Shoulder-blade; B. Left Humerus (from behind); C. Left Humerus (from in front); D. Skeleton of Fore-arm, Wrist (carpus) and Hand (manus). 

the scaphoid, and forming the support for the second metacarpal), the os magnum (articulating with the semilunar, and supporting the third metacarpal), and the outer unciform (composed of the fused fourth and fifth distal carpals, articulating with the cuneiform, and supporting the fourth and fifth metacarpals). A small bone, the pisiform, articulates with the cuneiform and the ulna. Between the proximal and distal rows of carpal bones lies the os centrale, between the semilunar and the os magnum.

(e) The manus or hand, consisting of five metacarpals bearing five clawed digits. Fach digit has three phalanges, except the preaxial pollex (thumb), which has only two.

Make a sketch of the fore-limb. (See Fig. 103, page 306.)

3. The Pelvic or Hip Girdle.

Note that the pelvic girdle articulates with the sacrum. Free the girdle from the sacrum, and note the following parts :---

The pelvis consists of two lateral halves, the innominate bones, the long axis of which is almost parallel with that of the vertebral column. Anteriorly and internally they unite with the fused transverse processes of the sacrum by a rough surface; ventrally they are connected together by cartilage at the pelvic symphysis. On the outer surface of each innominate bone, at about the middle of its length, is a deeply concave cup, the acetabulum (completely ossified). Each innominate bone consists of :--

(a) The ilium, which articulates with the sacrum, a flattened bone forming

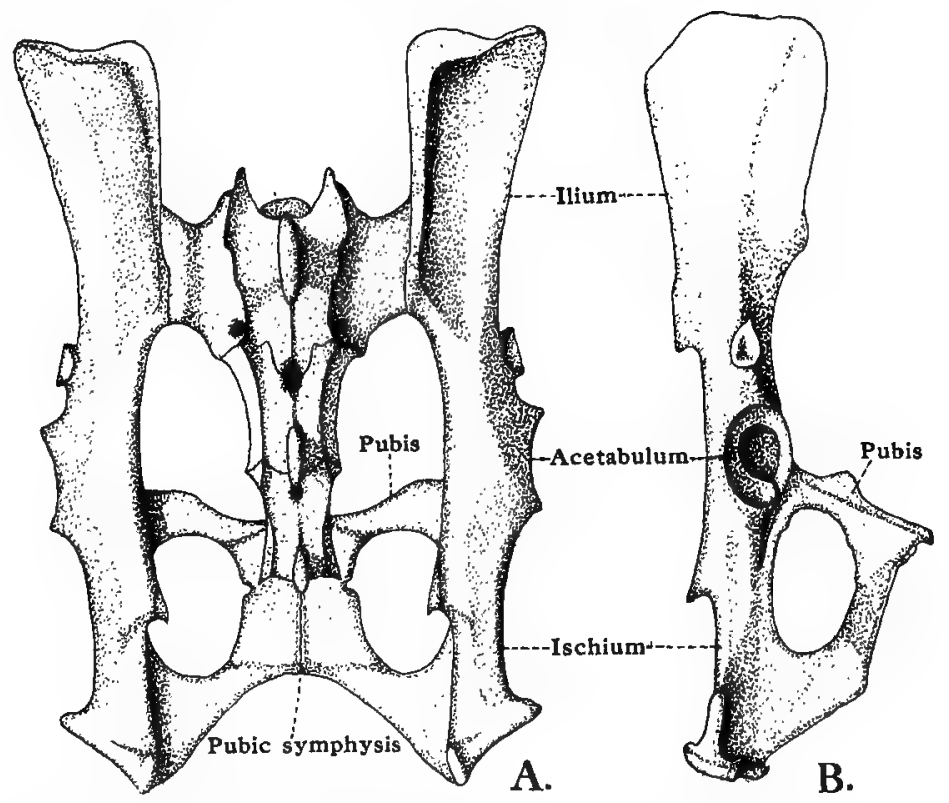

FIG. 104.-The Rabbit (Lepus cuniculns). A. The Sacrum and the Pelvic Girdle (Dorsal view); B. The Right Innominate Bone (Lateral view). 

the anterior dorsal portion of the os innominatum and the anterior and greater portion (about half) of the acetabulum.

(b) The ischium, forming the posterior dorsal portion of the os innominatum and the posterior third of the acetabulum. The two ischia unite ventrally, forming the posterior part of the pelvic symphysis, the anterior and greater part being pubic.

(c) The pubis, the ventral portion of the os innominatum. The pubes unite ventrally in the middle line to form the pubic symphysis, and join the ischia to form the obturator foramen of each side. The pubis completes the acetabulum below.

Make a sketch of the pelvic girdle. (See Fig. 104, page 308.)

4. The Hind-limb.

Carefully clean the left hind-limb, and note the following parts :-

(a) The femur or thigh bone, a long bone with a cylindrical shaft and enlarged extremities. The prominent head articulating with the acetabulum forms the hip-joint. External to the head, and forming the anterior extremity of the shaft, is a large process, the great trochanter. Below the head and on the inner side of the shaft is the lesser trochanter ; and opposite it, on the outer side, is the third trochanter. The trochanters serve for the attachment of the muscles of the leg. The lower extremity has two large condyles (with a groove between) for articulation with the tibia.

(b) The small knee-pan or patella, opposite the knee-joint, situated in the front groove on the lower end of the femur. It is a sesamoid. bone in the extensor muscle tendon.

(c) The tibia, a stout and straight long bone, articulating at its upper and triangular end with the femur, by two facets, and at its lower end with the astragalus.

(d) The fibula, a slender bone, articulating at its upper end with the outer surface of the head of the tibia. Its distal portion is fused with the tibia and articulates (at the end) with the calcaneum. The inner tibia and outer fibula constitute the leg, lower leg or shank.

(e) The tarsus or ankle, consisting of two rows of tarsal bones :-

(i) The proximal row is composed of the astragalus on the inner side, and the calcaneum (os calcis or fibulare) on the outer side. The calcaneum is produced into the large calcaneal process which forms the heel, and on which the tendo Achillis is inserted. These two tarsals articulate with the tibia-fibula.

(ii) The distal row is composed of three bones, viz. the inner mesocuneiform supporting the second metatarsal, the median ecto-cuneiform supporting the third metatarsal, and the outer cuboid articulating with the calcaneum and supporting the fourth and fifth metatarsals. Corresponding to the centrale of the carpus there is a navicular, between the two rows and in front of the astragalus, and articulating with the mesocuneiform and ecto-cuneiform. 

(f) The pes or foot, consisting of four long metatarsals and four digits or toes. The first or preaxial digit is vestigial or absent. Each digit has three phalanges, and the last phalanx is modified to support a claw.

Make a sketch of the hind-limb.

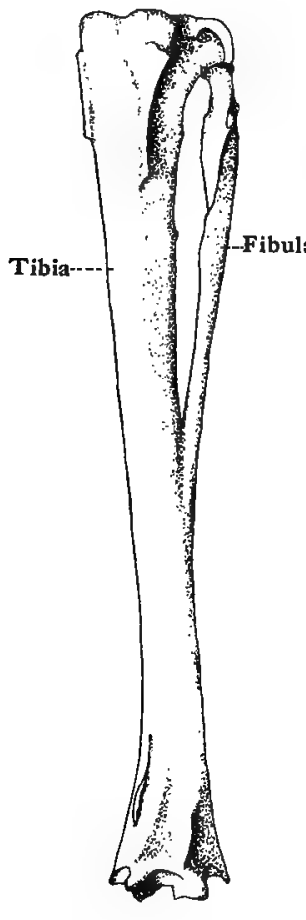

B.

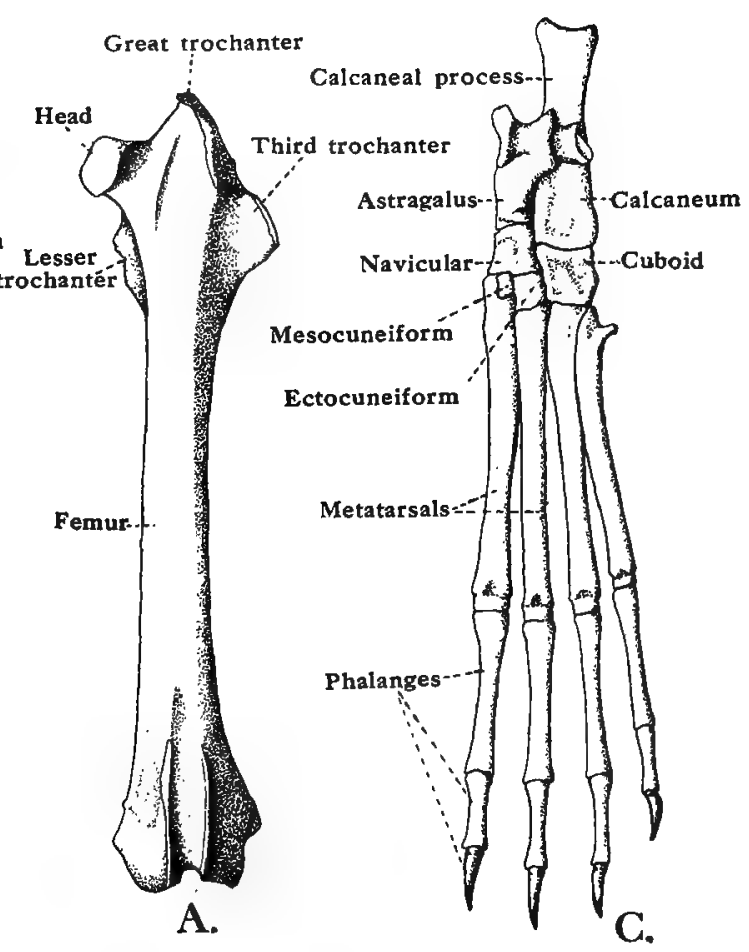

FIG. 105. - The Rabbit (Lepus cuniculus). A. Left Femur or Thigh-bone; B. Left Tibia-fibula; C. Left Tarsus (ankle) and Pes (foot).

Compared with the Bird skeleton that of the Mammal shows the following important differences :-

The sutures between the bones of the skull are generally persistent.

The cranial cavity extends between the orbits into the interorbital septum.

The internasal septum is produced in front of the nasal bones, and forms the cartilaginous support of a flexible nose or muzzle.

There is a tympanic bone around the outer ear.

The otic bones (auditory capsule), are united to form a periotic, which is fused with the squamosal.

There are three ear ossicles (malleus, incus, stapes).

The skull has two (ex-occipital) condyles.

The lower jaw articulates on the squamosal. The quadrate is absent.

Each ramus of the lower jaw consists of a single bone (the dentary).

The jaws have teeth; and the teeth are specialised, are typically heterodont, i.e., different in form and in function.

The vertebral centra, and also the long bones, usually have epiphyses. 

There are (typically) seven cervical vertebræ.

The sternum is segmented.

The coracoid is a small hook-like process of the scapula.

The pubes and ischia unite ventrally, forming a pelvic symphysis. (In the Ratitae or Running Birds a symphysis is present.)

The acetabulum is, as a rule, completely ossified. 

010

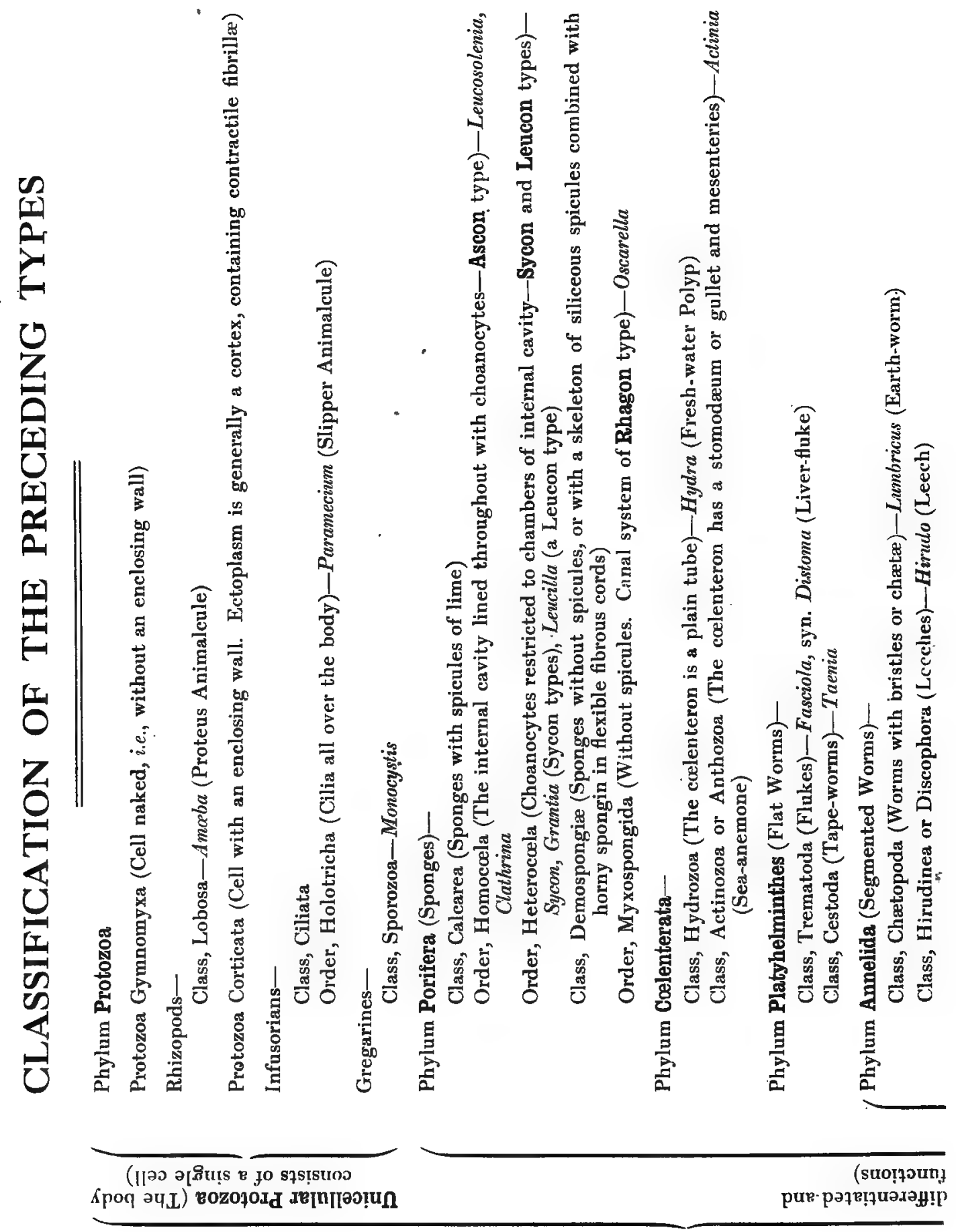

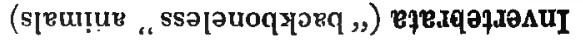




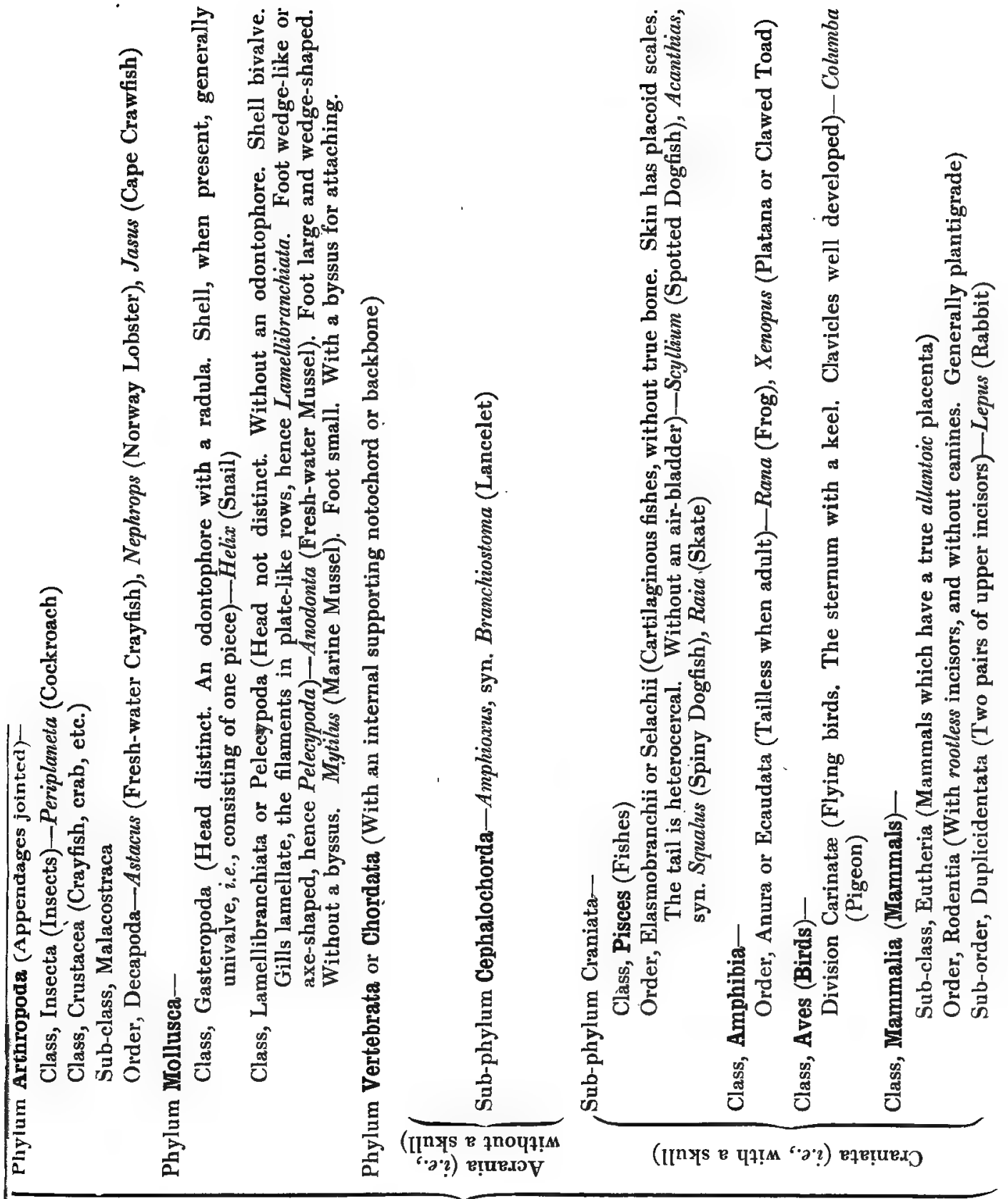

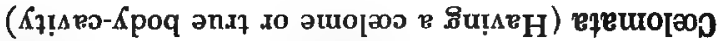

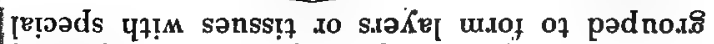

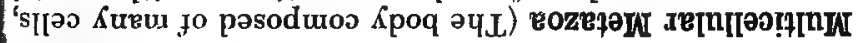





\section{INDEX}

\section{(Page Numbers in thick type indicate Illustrations.)}

A

ABDOMEN, 74, 266

Abdominal or peritoneal cavity, 152, 170

Abdominal viscera, 268

Acanthias, syn. Squalus (Spiny dogfish), 152-186, 316. See Dogfish

Acetabulum, 218,.254, 256, 308, 310, 314

Acontia, 38

Acrania, 316

Acro-coracoid, 252

Acromion, 252, 304

Actinia, 34-38, 316. See Sea-anemone

Actinozoa or Anthozoa, 316

Adrenal body : Frog, 214 ; pigeon, 250 ; rabbit, 270,286

Afferent branchial system. See Afferent branchial artery

Aftershaft or hyporachis, 236

Air-bladder, 316

Air-sacs, 238, 242, 244

Air-tubes. See Tracheæ

Ala spuria or bastard wing, 236

Albumen gland. See Gland

Alimentary system, Alimentary canal : Liverfluke, 40 ; earth-worm, 56,58 ; leech, 66,68 ; cockroach, 82, 84; crayfish, 104, 108; crawfish, 104, 110; snail, 118 ; fresh-water mussel, 136, 138; marine mussel, 138 ; Amphioxus, 144, 146; dogfish, 156, 158 ; skate, 158,160 ; frog, 194, 196, 212 ; Xenopus, $194,196,212$; pigeon, 242, 244; rabbit, 272,276

Alisphenoid, 224, 226, 292

Amoba (Proteus Animaleule), 2-4; form and general structure, $2 ; 316$

Amcebocytes, 16, 34

Amphibia, 316

Amphicolous. See Vertebra

Amphioxus, syn. Branchiostoma (Lancelet), 142. 150 ; external features, 142 ; skeletal and alimentary systems, 144, 146; circulatory, muscular and reproductive systems, 146; nervous system, 148; transverse sections, 148,$150 ; 316$

Ampullary canals, 152

Anapophysis, 302

Angular bone, 264; process, 296

Angulo-splenial, 226

Ankle. See Tarsus

Ankle-joint, 256

Annelida (Segmented Worms), 316

Annuli, 54, 64

Anodonta, 126-140, 316. See Fresh-water mussel

Antenna : Cockroach, 74, 80 ; crayfish, 88, 96, 102 ; crawfish, 88, 100, 102

Antennule: Crayfish, 88,96, 102 ; crawfish, 88, 100,102

Anti-trochanter, 254
Anura or Ecaudata, 316

Anus: Paramecium, 8; earth-worm, 56; leech, 64, 66 ; cockroach, 74, 84; crayfish,. 94, 104; snail, 114, 118; mussel, 138; Amphioxus, 142, 144; dogfish, 158; rabbit, 266

Aorta, 136 (mussel) ; dorsal, 146, 154, 170, 174 , $208,210,248,276,284,286$; ventral, 146 , $166,170,202,208,212$

Aortic arch, 246, 248, 284, 286

Aperture, atrial (atriopore), 142; auditory, 236 ; auriculo-ventricular, 212 ; buccal, 142 ; cloacal. See Cloaca; Eustachian, I90, 238 ; exeretory, 40, 56 (nephridiopore) ; genital, 40, $50,60,64,70,92,106,114,120,136$; of oviducts, $56,58,158,162,250$; of prostate ducts, 290 ; of seminal ducts, 60 ; of spermathecæ, 56 ; of ureter, $116,136,290$; of uterus masculinus, 290 ; of vasa deferentia, 56 ; pulmonary or respiratory, 114 ; reno-pericardial, Helix, 116, Anodonta, 134, 136 ; respiratory (stigmata), 76 ; sinu-auricular, 212 ; urinogenital, 266

Apopyles, 20, 22, 24

Appendages, abdominal, 94 ; head, 78, 100 ; of cockroach, 78, 80, 82; of crawfish, 8. 102, 100 ; of crayfish, 88-102, 96 ; thoracic, 98

Appendicular skeleton. See Skeleton

Arm. See Fore-limb

Arterial system : Dogfish, 158, 166, 168, 172, 174 ; skate, 158, 166, 170, 174 ; frog, 208, 210 ; Xenopus, 210 ; pigeon, 248; rabbit, $276,278,280,286,288$

Arterial systems, dorsal and ventral. See Efferent and afferent branchial arteries.

Artery, abdominal, 104, 110; antennary, 104 ; brachial, $210,246,248$; afferent branchial, $146,166,168,170$; efferent branchial, 146 , 170 , 172, 174; carotid arch, 208, 210; common carotid, 170, 174, 208, 210, 248, 278, 286 ; external and internal carotid, 174 , $248,278,286$; posterior carotic, 174 ; caudal, $154,250,286$; coliac, $158,172,248,274$, 276, 286 ; coeliaco-mesenteric, 208, 210 ; cutaneous, $208,210,212$; femoral, 250, 286 ; hepatic, 104, 276, 286 ; hyoidean, 194 ; iliac, $206,208,210,250,286$; ilio-lumbar, 286 ; innominate, $170,248,286$; laryngeal, 208 ; lieno-gastric, 158, 276, 286 ; lingual, 208, 210 ; mesenteric, $158,250,274,276,286$; anterior mesenteric, 274, 276, 286 ; posterior mesenteric, 274,286 ; occipito-vertebral, 208 ; œsophageal, 208 ; ophthalmic, 104 ; ovarian, 286 ; pectoral, 238,248 ; peroneal, 208 ; pulmo-cutaneous arch, 208,212 ; pulmonary, 208, 212, 246, 250, 284 ; renal, $208,210,250,286$; scapular, 210 ; sciatic, 208,250 ; spermatic, 286 ; sternal, 104, 110; subclavian, 172, 208, 248, 286; systemic arch, 208, 210 ; thoracic, 110 ; tibial, 208; vertebral, $170,174,258$ 
Arthrobranch gill, 94

Arthropoda, 316

Articular bone, 264 (pigeon); facets, 164, 220, $222,238,254,258,300,302,304,310$

Ascon sponge, 14, 18 ; transverse section, 20 ; 316

Astacus, 88-112, 316. See Crayfish.

Astragalus, 220, 256, 310

Atlas vertebra : Frog, 220 ; pigeon, 258 ; rabbit, 298

Atrial aperture (atriopore) of Amphioxus, 142

Atrial cavity (atrium) of Amphioxus, 142, 144, 148

Atrium. See Auricle

Auditory aperture. See Aperture

Auditory capsule: Dogfish, 186 ; rabbit, 292, 312 ; meatus, external, 296 ; organ, 88, 182, 186,266 ; ossicle, 264, 312

Auricle of heart, 116, 134, 136, 166, 170, 202, $212,246,282$

Aves (Birds), 316

Axial skeleton. See Skeleton

Axis vertebra : Pigeon, 260; rabbit, 300

\section{B}

Backione. See Vertebral column

Baler. See Scaphognathite

Barbs, 30, 236

Barbules, 236

Basi-occipital, 226, 262, 292

Básipodite, 98, 100

Basi-sphenoid, 260, 262, 292

Basi-sphenoidal rostrum, 264

Basi-temporal, 260, 262

Bastard wing. See Ala spuria

Beak, 236, 262

Beef Tape-worm, 46

Bicipital groove, 304

Bile-duct, 158, 194, 242, 244

Birds. See Aves

Bivalves. See Lamellibranchiata or Pelecypoda

Bladder, 214, 272

Bladder-worms, 272

Blood capillaries, $62,66,72,146$

Blood sinus, cardinal, 168,184 ; dorsal, 66,72 ; hepatic, 168 ; lateral, 72 ; of Cuvier. See Duct; venosus, 166, 170, 202, 212; ventral, 66, 72

Blood system : Earth-worm, 56, 58; leech, 66 ; crayfish, 104, 110; Amphioxus, 146; dogfish, 158, 166 ; frog, 190, 192 ; Xenopus, 192 ; pigeon, 246,248 ; rabbit, 272,282

Blood vessel, afferent and efferent, 94 ; dorsal, $54,56,62,66$; lateral, 66,72 ; sub-intestinal or ventral, 56,62 ; sub-neural, 62

Body : Tape-worm, 48; earth-worm, 54, 60, 62 ; leech, 64, 70 (transverse section); Amphioxus, 148, 150 (transverse sections); skate, 154; rabbit, 266

Body-cavity. See Colome

Bojanus, organ of, 134 ( Anodonta)

Bone, cartilage (substitution or replacement), 292 ; membrane or investment, 292 ; sesamoid, 256,310

Botryoidal tissue of Hirudo, 70, 72

Brain: Earth-worm, 58; cockroach, 84; dog. fish, 176, 178, 180 ; skate, 186; frog, 226, 232 ; pigeon, 264

Branchiæ. See Gills

Branchial arches, 176

Branchial clefts. See Gill-slits
Branchial vessels. See Afferent and efferent branchial arteries

Branchio-cardiac groove, 88

Branchiostegite or gill-cover, 88

Branchiostoma. See Amphioxus

Breast-bone. See Sternum

Bronchi, 244, 268

Buccal or mouth cavity, 56, 82, 144, 190, 236

Buccal cartilage, 144 ; cirri, 142,144 ; mass, 118 (snail); skeleton, 144

Budding or gemmation, 14

Buds, daughter, 28

Bulbus arteriosus, 170

Bulla, tympanic, 296

Bursa Fabricii, 240

Byssus, 126, 134, 316

\section{$\mathrm{C}$}

CArCA, 40, 44

Cæcum : Crayfish, 104 ; rabbit, 270,272

Calamus or quill, 236

Calcaneum (os calcis or fibulare), 220, 256, 310

Calcarea, 18, 20, 22, 316

Calciferous glands or œsophageal pouches, 56

Canal, ampullary, 152 ; colomic, 148, 150 ; collecting, 8 ; excretory, 50, 52 ; incurrent or inhalent, 14, 16, 18, 20 ; neural, 300. See Vertebra; pericardio-peritoneal, 170 ; radial, $14,16,18,20,22$; reno-pericardial, 116 ; semicircular, 182, 186; urino-genital, 290; vertebra-arterial, 258,298

Canal system of Sponges, .14, 16; types of, 18, 316

Capillary tubules, 40

Capitulum of rib, 260, 300, 302, 304

Carapace or cephalo-thoracic shield, 88

Cardiac chamber of stomach, 104, 158, 272

Cardo, 80, 82 (cockroach)

Carina or keel, 240,316

Carinatæ (Flying Birds), 316

Carpal bones, 218, 254, 306

Carpo-metacarpus, 254

Carpopodite, 98

Carpus or wrist, 218, 254, 306

Cartilage, 144, 224

Cartilage bones, 292; buccal, 144; odontophoral, 124

Caudal region of vertebral column, 260, 298, 304

Centrum, 154, 220. See Vertebra.

Cephalic cone or head lobe, 40

Cephalochorda, 316

Cephalo-thoracic shield. See Carapace

Ceratohyal, 176

Cerci, 76 (cockroach)

Cere, 236

Cerebellum, 178, 228, 264

Cerebral hemispheres, $176,226,264$; vesicle, 148

Cerebrum. See Fore-brain

Cervical groove, 88

Cervical region of vertebral column, 256, 298

Cervical rib, 300

Cestoda (Tape-worms), 316

Chætæ or setæ, 54, 54, 56, 60, 62, 80, 82

Chrtopoda (Bristle-worms), 316

Chela, 98

Cheliped, 88, 98

Chilota (South African Earth-worm), 62

Chitin, 76, 80

Choanocytes (collar-cells), 16, 18, 20, 316

Chondrocranium, 224, 292 
Chordata. See Vertebrata

Choroid plexus, $176,226,228$

Cilia, 8, 36, 132, 144, 316

Ciliary brushes, 132 ; junctions, 132

Ciliata, 316

Ciliated cells, 34 ; groove, 36

Cinclis, 38

Circulatory system. See Blood system

Cirri, buccal, 142, 144.

Cirrus or penis, 42

Cirrus sac, 42

Clasper, 152, 154, 164

Olathrina, 18, 316

Clavicle, 194, 218, 238, 250, 304, 316

Claws, 82, 256

Clitellum, 54

Clitoris, 290

Cloaca, 138, 152, 154, 158, 162, 188, 214, 238 , 244,250

Clypeus, 78

Cnemial crest, 256

Cnidoblast (stinging cell), 30

Cnidocil, 30

Cockroach (Periplaneta), 74-86; external fea. tures, 74; head, 78 ; appendages, 80 ; mouth parts, 80 ; walking leg, 80, 82; alimentary system, etc., 82,84 ; nervous system, $84 ; 316$

Colenterata, 316

Ccelenteron, 28, 30, 316

Ccelomata, 316

Colome or body-cavity, 56, 60, 62, 66, 72, 148 , $150,152,168,316$

Cœlomic canal, dorsal, 148; branchial, 150 ; ventral or endostylar, 150; cavity, 144; epithelium, 56,60

Collar of snail, 114,116

Collar-cells. See Choanocytes

Collecting canals of Paramecium, 8

Colon, 82, 270, 272

Columba, 236-264, 316. See Pigeon

Columella (ossicle), 224, 226, 264; of shell, 116

Column of sea-anemone, 34

Commensal, 32

Commissures. See Nerve commissures

Condyle of skull, 262, 292, 298, 312; of femur, 310

Conjugation of gametes, 12

Connective tissue, 60, 142, 144, 146, 148, 288

Contractile bulbs, 146

Conus arteriosus, $166,170,202,212$

Coracoid, 164, 194, 218, 238, 252, 314; process, 304

Coronoid fossa, 306 ; process, 296

Corpora adiposa or fatty bodies, 216,218

Cortex, 6, 10, 316

Corticata, 316

Coverts. See Feathers

Coxa, 82 (cockroach)

Coxopodite, 98, 100

Craniata, 316

Cranium, 176, 226, 260, 292

Crawfish (Jasus), 88-112; external features, 88,92 ; appendages, $88,94,100$; respiratory system (gills), 94 ; alimentary system, 104, 110 ; vascular system, 104,110 ; reproductive system, 106 ; skeletal system, 106; nervous system, 106, 110 ; larva, $110 ; 316$

Crayfish (Astacus), 88-112; external features, 88,90 ; appendages, $88,94,96$; respiratory system (gills), 94; alimentary system, 104, 108 ; vascular system, 104, 110 ; reproductive system, 106 ; skeletal system, 106 ; nervous system, 106, $108: 316$
Cribriform plate, 294

Cricoid cartilage, 274

Crop, 56, 66, 72, 82, 118, 238, 242

Crura cerebri, 178

Crustacea, 316

Crystalline style, 138

Ctenidia. See Gills

Cuboid, 310

Cuneiform or ulnare, 306

Cuticle, 44, 50, 60, 70, 74, 78, 82

Cyst, 10, 12

D

DACTYLOPODITE, 98

Dart sac of snail, 118

Decapoda, 316

Deltoid ridge, 252

Demospongiæ, 24, 316

Dentary bone, 226, 264, 296, 312

Dermal denticles or skin teeth. See Placoid scales. Dermal epithelium, 16 ; layer, 16

Derrnis, 60, 72, 148

Diaphragm, 268

Diastema, 266

Diastole, 8

Digits, 188, 190, 218, 220, 254, 256, 266, 268, 308,312

Dipylidium (Tape-worm of dog), 46

Directive mesenteries, 34, 36

Disc, 36, 220 (intervertebral)

Discophora. See Hirudinea

Distoma (Liver-fluke). See Fasciola

Dogfish (Acanthias and Scyllium), 152-186; external features, 152, 154; alimentary and vascular systems, 156, 166, 168, 172, 174; urino-genital system, 162, 164; skeletal system, 164, 176; nervous system (brain), 176, 178, 180; cranial nerves, 178, 180; өye muscles, 178 ; otocyst, 186 ; 316

Donax (White mussel), 140

Duct, bile, 194, 270; common, 70, 118, 194 ; of Cuvier, 168 ; cystic, 270 ; endolymphatic, 186 ; excretory, 44; genital, 158 ; hepatic, 104, 270 ; hermaphrodite, 120 ; mesonephric. See Wolffian; metanephric, 162 ; Müllerian, 162 , 164, 290 ; pancreatic, 158, 194, 242, 244, 272 ; seminal, 60 ; spermathecal, 120

Duct, vitellarian or yolk, 40, 44; Wharton's, 278 ; Wolffim, 162

Ductus arteriosus, 284

Ductus ejaculatorius, 42,70

Duodenum, 158, 194, 242, 270, 272

Duplicidentata, 316

E

EAR. See Auditory organ

Earth-worm (Lumbricus), 54-62 ; external features, 54; alimentary and vascular systems, 56,58 ; nervous and reproductive systems, 58 ; transverse section, 60,62 ; nephridium, $62 ; 316$

Ecaudata. See Anura

Ecto-cuneiform, 310

Ectoderm, 14, 16, 28, 30, 34; cells, 28, 30 (of Hydra), 50

Ectoparasite, 32

Ectoplasm, 2, 6, 10, 316

Ectosare, 2, 6 
Efferent branchial system. See Efferent branchial artery

Egg. See Ova

Egg capsule ("Mermaid's purse"), 162

Elasmobranchii or Selachii, 316

Elbow-joint, 304

Elytra or tegmina or wing-covers, 74

Embryo, 48, 52

Endoderm, 14, 16, 28, 30, 34; cells, 30, 34

Endolymph, 186

Endolymphatic duct, See Duct

Endophragmal -skeleton, 102

Endoplasm, 2, 8, 10

Endopodite, 98, 102

Endosare, 2, 8

Endostyle, 144, 148

Enteric or digestive cavity of Hydra, 28

Epibranchial groove, 144, 148

Epicoracoids, 194

Epicranium of cockroach, 78

Epidermis, 60, 70, 148

Epididymis, 70, 162 ; caput and cauda, 288

Epimeron, 92

Epipharyngeal or epibranchial groove, 144, 148

Epiphysis of vertebra, 260, 298, 312

Epiphysis. See Pineal body

Epipodite, 94, 98, 102

Episternum, 194, 252

Epithelial cells, 148

Epithelium, 16, 18, 56, 60, 144

"Euglenoid" movement, 12

Eustachian apertures, 190, 238

Eutheria, 316

Excretory canal, 50, 52 ; cell, 40 ; pore, 40

Excretory system : Liver-fluke, 40; tape-worm, 50 ; earth-worm, 62 ; leech, 68 ; cockroach, 82 ; mussel, 134. See also Urino-genital systern

Exhalent openings or oscula, 14, 18, 20 ; siphon, $128,134,138$

Ex-occipital, 224, 226, 262, 292

Exopodite, 96, 98, 102

Exoskeleton, 106

Extrastapedial plate or cartilage, 224, 226

Eye muscles. See Muscles

Eyelid, 188, 236

Eyes, 64, 74, 78, 88, 114, 148, 152, 154, 188, 236, 266

\section{$\mathbf{F}$}

Fallopian tube, 290

Fasciola, syn. Distoma, 40-44, 316, See Liverfluke

Fatty body, 82. See also Corpora adiposa

Feathers: Aftershaft, 236 ; ala spuria, 236 ; contour, 236; coverts, 236; primary, 236; secondary, 236,252 ; tail, 236 ; wing, 236

Femur or thigh bone, $82,220,256,310,312$

Fenestræ, 80

Fibrillæ, contractile, 316

Fibula, 256, 310

Fin, caudal, 142, 152, 154 ; dorsal, 142, 144, 148,152 ; pectoral, 152, 154, 164 ; pelvic, 152, 154; ventral or anal, 142, 144, 152; radials, 166 ; rays, $144,148,166$; skeleton, 166

Fishes (Pisces), 316

Flagella, 30

Flagellate cells, 34

Flagellates, symbiotic, 32

Flagellum, 16, 120

Flame cell, 40

Flor'uli, 264
Flukes. See Trematoda

Fontanelles, 154, 240

"Foot": Hydra, 28 ; snail, 114; mussel, 126, 134; 316

Foot. See Pes

Foramen, ilio-sciatic, 256 ; inter-vertebral, 220 ; ischiatic, 256; magnum, 262, 292; obturator, 256,310 ; occipital, 78 ; optic, 294: pneumatic, 252; supra-trochlear, 306 ; triosseum, 238, 252 ; vertebra-arterial, 300

Fore-arm. See Fore-limb

Fore-brain (Cerebrum or prosencephalon), 176, 178

Fore-gut or stomodæum, 36, 82, 104, 144, 316

Fore-limb, 188, 218, 220, 236, 252, 254, 266, 304, 306

Fresh-water Polyp. See Hydra

Frog (Rana), 188-234; external features, 188 ; mouth cavity, 190; muscular system, 190, 198, 200; skeletal system, 194 ; girdles and limbs, 218, 220 ; vertebral column, 220, 222 ; skull, 222, 224, 226 ; alimentary system, 194, 196, 212 ; venous system, 192, 202, 204, 206 ; arterial system, 208, 210; heart, 212 ; nervous system, 202; brain, 226, 232; spinal nerves, 228, 230 ; sympathetic, 230 ; cranial nerves, 232 ; respiratory system, 212 ; urinogenital system, 214, 216 ; 316

Frontal bone, 262, 294 ; segment, 292

Fronto-parietal, 222, 224, 226

Furcula or " merry-thought," 238,250

\section{G}

GaLEA of cockroach, 80, 82

Gall-bladder, 158, 194, 242, 270, 272

Gamete, 10, 12

Gametocyte, 10, 12

Ganglia. See Nerve ganglia

Ganglion, 68

Gasserian ganglion, 232

Gasteropoda, 316

Gastral cavity, 16, 18, 20, 22 ; layer, 16

Gastric mill. See Gizzard

Gemmation. See Budding

Genæ or cheeks of cockroach, 78

Genital aperture, $40,50,60,64,70,92,106,114$, 120,136 ; atrium, 50 ; cells, 16 ; outlet, 42 ; organs, 38, 38, 68; papilla, 50; sinus, 162

Gill-arches, 144

Gill-cover, See Branchiostegite

Gill-filaments, 132

Gill-slits (Branchial or visceral clefts), 144, 146 , $148,152,154$

Gills (Branchiæ or ctenidia): Crayfish and crawfish, 94 ; mussel, 132, 134; dogfish, 152, $154 ; 316$

Gizzard, 56, 82, 102, 104, 106, 242, 246

Gland, albumen, 70, 116, 120 ; calciferous, 56 ; capsulogenous or spermaducal, 54, 56 ; carotid, 208,210 ; cells of Hydra, 30 ; of sea-anemone, 34, 36 ; Cowper's, 290 ; digestive, 104, 116 , $118,134,136,138$; green (nephridium), 90, 102 ; hermaphrodite, 120 ; mammary, 266, 268 ; mucous, 120 ; oviducal, 162 ; pedal or slime, 114; pericardial (Keber's organ), 134; perineal, 266, 290 ; preen or oil, 238 ; prostate, 290 ; rectal, 158,290 ; salivary, 118, 278 ; shell, 162; slime, 188; spermaducal, 54, 56 ; sub-maxillary, 278; thymus, 240, 268; thyroid, 168, 244, 274; unicellular, 66; vitelline or yolk, 44,50 
Glenoid cavity, 252, 304

Glossa, 82

Glottis, 190, 238

Gonads. See Reproductive organs

Grantia, 14, 316

Green gland, 90, 102 (crayfish)

Gregarines (Sporozoa), 316

Gullet, See Esophagus

Gut, 82 (fore-gut), 84, 104 (hind-gut)

Gymnomyxa, 316

\section{$\mathbf{H}$}

H再MAL arch, 154

Hallux or great toe, 190, 256

Hand. See Manus

"Hare-lip," 266

Head, 46, 48, 74, 78, 114, 124, 266

Head lobe or cephalic cone, 40

Heart: Cockroach, 82; crayfish, 104, 108 . snail, 116; mussel, 134, 136 ; dogfish, 166, 168 ; skate, 170 ; frog, $194,196,202,212$; pigeon, 244, 246 ; rabbit, $268,276,280,282$

"Hearts," 56

Helix, 114-124, 316. See Snail

Hepatic cæca, 82 ; sinus, 168

Hepatic-portal system, 270, 272

Hermaphrodite, 28, 40, 48, 58

Hermaphrodite duct, 120

Hermaphrodite gland, 120

Heterocercal tail, 152, 154, 316

Heteroccela, 20, 22, 316

Heterocclous. See Vertebra

Heterodont teeth, 312

Hilus, 286

Hind-brain (metencephalon or rhombencephalon), 178

Hind-gut or proctodæum, 84, 104

Hind-limb, 190, 220, 236, 256, 258, 268, 310

Hinge of shell, 126, 130

Hip-joint, 310

Hirudinea or Discophora (Leeches), 316

Hirudo, 64-72, 316. See Leech

Holotricha, 316

Homoccla, 18, 316

Hooks, 48, 52

Humerus, 218, 252, 304, 306

Hydra (Fresh-water Polyp), 26-32; form and external features, 26 ; structure, 28-32; longitudinal and transverse sections, 26, 28, $30 ; 316$

Hydrozoa, 316

Hyoid, 176, 292

Hyomandibular, 176

Hypapophysis, 302

Hypopharynx, 82

Hypophysis, 178

Hyporachis or aftershaft, 236

Hypostome or oral cone, 28

I

ILEUM (small intestine), 82, 194, 270, 272

Ilium, 218, 254, 308

Incisor teeth, 296, 316

Incus, 312

Infundibulum, 176

Infusoria, 6, 32, 316

Inguinal canal, 288

Inhalent canals, 14, 16, 18, 20 ; pores, 14, 16 ; siphon, 126, 134
Innominate bone, 256, 308

Insecta (Insects), 316

Integument or skin, 152, 154, 188

Interfilamentar junctions, 132

Interlamellar junctions, 132

Internasal septum, 312

Interorbital septum, 312

Interparietal, 292

Interseptal cavity, 36

Interstitial cells, 28

Intervertebral disc, 220 ; notches, 302

Intestine: Liver-fluke, 40, 44 ; earth-worm, 56, 60 ; leech, 66 ; crayfish, 104 ; snail, 118 ; mussel, 138; Amphioxus, 144, 150. See Alimentary system

Intestine, large, 82, 158, 194; small, 82, 158, $194,270,272$

Intraseptal cavity, 36

Invertebrata, 316

Investment or membrane bones, 292

Ischiopodite, 98

Ischium, 218, 254, 310, 314

Jasus, 88-112, 316. See Crawfish

Jaws, 64, 66, 78, 124, 152, 154 ; upper and lower, $176,224,262,264,292,296,312$

Jugal, 262, 296

$\mathbf{K}$

KEBER's organ, 134

Keel. See Carina

Kerona, 32

Kidney, 116, 134, 136, 162, 214, 242, 250, 270 , 286

Knee-pan. See Patella

$\mathbf{L}$

LABIAL palp, 82, 134

Labium or lower lip of cockroach, 80, 82

Labrum or upper lip, 78, 80 (cockroach), 104 (crayfish)

Lachrymal bone, 260, 294

Lacinia, 80, 82 (cockroach)

Lamella, Supporting. See Mesoglcea

Lamellæ, 132

Lamellibranchiata or Pelecypoda (Bivalves), 132,316

Lancelet. See Amphioxus

Larva of Cape Crawfish (Jasus), 110, 112

Larynx, 190, 244, 274

Lateral line, 152, 184

Laurer's canal, 42

Leech (Hirudo), 64-72; external features, 64, 68; alimentary and vascular systems, 66, 68; nervous and reproductive systems, 68 ; transverse section, $70 ;$ nephridium, $68,70,72 ; 316$

Leg, 82, 88, 98, 190, 268, 310

Lepus, 266-314, 316. See Rabbit

Leucilla, 22, 316

Leucon sponge, 20 ; transverse section, 22 ; 316

Leucosolenia, 14, 18, 316

Ligament, falciform, 158, 160 ; suspensory, 160, 162

Ligula, 82 (cockroach)

Limb. See Appendages, fore-limb (arm), hindlimb (leg) 
Linea alba, 192

Lingua or hypopharynx (tongue), 82

Lips, 266

Liver, 104, 116, 118, 136, 144, 148, 158, 194, 242, 268,272

Liver-fluke (Fasciola, syn. Distoma), 40-44; external features, 40 ; alimentary, excretory and reproductive systems, 40,42 ; nervous system, 42 ; transverse section, 44 ; 316

"Liver-rot," cause of, 40

Lobi inferiores (inferior lobes), 178

Lobopod, 2

Lobosa, 316

Lumbar region of vertebral column, 298, 302

Inumbricus, 54-62, 316. See Earth-worm

Lungs, 194, 244, 268

Lymph space, 148, 190

Macronucleus, 8

Malacostraca, 316

Malleus, 312

MaIpighian tubules, 82 (cockroach)

Mammæ or teats, 266

Mammals (Mammalia), 316

Mandible, 78, 80, 102, 104, 292. See also Lower jaw

Mandibular arch, 176

Mantle, 114, 116, 130, 134

Manubrium, 240, 304

Manus or hand, $188,266,308$

Mastoid portion of periotic bone, 296

Maxilla, first, 80, 100 ; second, 80, 82, 100

Maxilla bone, 222, 224, 226, 262, 296

Maxillary palp, 80

Maxillipeds, 98

Maxillo-palatine processes, 262

Meckel's cartilage, 226

Mediastinum, 268

Medulla, 8, 10

Medulla oblongata, 178, 228, 264

Meganucleus, 8

Membrane bones. See Investment bones

Mento-meckelian, 226

Mentum of cockroach, 82

"Mermaid's purse." See Egg capsule

Meropodite, 98

"Merry-thought" or furcula, 238, 250

Mesencephalon. See Mid-brain

Mesenchyme, 34

Mesenterial filaments, 36

Mesenteric filament, 34

Mesenteries, 34, 36, 56, 316

Mesenteron. See Mid-gut

Mesentery, 158, 270, 272

Mesethmoid, 260, 294

Meso-cuneiform, 310

Mesoderm, 34

Mesogl œa (Supporting lamella), 14, 16, 28, 30, 32 , 34

Mesonephros (Wolffian body), 162, 288

Mesonephric (Wolffian) duct, 162

Mesonotum, 74

Meso-pterygium, 164

Mesosternum, 194

Mesothorax, 74

Metacarpals, 254, 306, 308

Metacromion, 304

Metanephric duct, 162

Metanephros, 162, 250, 286

Metanotum, 74

Metapleural folds, 142, 148, 150 (Amphioxus)

Metapophysis, 302

Meta-pterygium, 164

-Metasternum, 194

Metatarsals, 220, 256, 310, 312

Metatarsus, 220

Metathorax, 74

Metazoa, 16, 316

Metencephalon. See Hind-brain

Micronucleus, 8

Mid-brain or mesencephalon, 178

Mid-gut or mesenteron, 82, 104

Molar teeth, 296

Mollusca, 316

Monoeystis, 10-12; form and structure of Monocystis magna, 10; structure and life-history stages of Monocystis agilis, 10, 12; 316

Motor nerves, 148

Mouth : Paramecium, 8; Hydra, 28; seaanemone, 34 ; liver-fluke, 40 ; earth-worm, 54, 56 ; leech, 64, 66; cockroach, 78, 82; crayfish, 104 ; snail, 114, 118 ; mussel, 138 ; Amphioxus, 144; dogfish, 152; skate, 154 ; frog, 190 ; pigeon, 236 ; rabbit, 266

Mouth-parts of cockroach, 80

Muillerian duct, $162,164,290$

Muscle, 6, 154 ; adductor, 102, 128, 130, 134, 198 (magnus); biceps, 200, 304; cells, 28, 30, 34 ; circular, 44, 50, 60, 72; columellar, 116 ; coraco-brachialis, 238 ; deltoid, 192 ; dorsoventral, 72 ; extensor, 102 ; extensor cruris, 200 ; flexor, 102; gastrocnemius, 198, 200; insertions, 128 (Anodonta), 130 (Mytilus); intrinsic, 124 ; lateral, 142, 146, 148: longitudinal, $34,36,38,44,50,60,62$, 72 : mandibular, 184 ; mylo-hyoid, 192, 228 ; oblique, 72 , 182 ; obliquus externus, 192 ; of eye, 178, 182 (dogfish), 186 (skate); of leg of Rana and Xeñopus, 198, 200 ; panniculus carnosus, 268 ; parietal, 38 ; pectoralis, 190 ; pectoralis major, 238 ; pectoralis minor or subolavian, 238; peroneus, 200 ; protractor, 130,134 ; radiating, 56, 66 ; rectus, 182,192 (abdominis), 198 (internus major), 200 (anticus femoris); retractor, $36,38,120,130,134$; sartorius, 198 ; semi-membranosus, 200, 228, 230 ; sphincter, 38 ; tibialis anticus and posticus, 200 ; triceps extensor cruris, 200 ; vastus internus, 198 ; externus, 200 ; ventral, 146,148

Muscular fibres, 34 ; processes of Hydra, 28, 30

Muscular system : Hydra, 28; sea-anemone, 38 ; earth-worm, 60, 62; leech, 70, .72; crayfish, 102; mussel, 130 ; Amphioxus, 146 ; frog, $190,192,198 ;$ Xenopus, 192 ; pigeon, 238

Mussel, Fresh-water (Anodonta), 126-140 : external features, 126; shell, 126, 128 ; internal structure, 128, 134, 136 ; alimentary system, 138 ; nervous system, $140 ; 316$

Mussel, Marine (Mytilus), 126-140; external features, 126 ; shell, 126, 128, 130; internal structure, 130, 138; alimentary system, 138 ; nervous systern, $140 ; 316$

Myocommas, 142,148

Myo-epithelial cell, 28, 30

Myomeres, 146 . See Myotomes

Myoneme threads, 6

Myophan striations, 6

Myotomes or myomeres, 142, 146, 148, 154

Mytilus, 126-140, 316. See Marine Mussel

Myxospongida, 24, 316 
NaCREOUS or pearly layer of shell, 130

Nares, external, 188, 236, 262 ; internal, 190, 238

Nasal bone, 222, 224, 226, 262, 294, 312 ; capsule. See Olfactory capsule; process, 296 ; region of skull, 294

Naso-buccal grooves, 152, 154

Navicular, 310

Neck, 74, 78, 266, 274, 278, 280

Nematocyst, 28, 30; stinging cells of seaanemone, 34,38

Nematode worms, parasitic, 62

Nephridiopore, 56, 64, 66

Nephridium, 56, 62, 66, 68, 70, 72, 90, 102 ; eiliated funnel of, 62 ; bladder of, 62,66 ; testis-lobe of, 66, 72

Nephrops (Norway lobster, or "crayfish" ), 94 (gills), 316

Nephrostome, 62, 66, 70, 116, 134, 136

Nerve cell, 30

Nerve commissures, cerebro-pedal and cerebropleural, 120 ; circum-œsophageal, 84, 106, 108 ; circum-pharyngeal, 58,68 ; postcesophageal, 108

Nerve connectives, cerebro-pedal, 140 ; cerebrovisceral, 140

Nerve cord, sympathetic, 230, 274 ; ventral, 58, $62,66,68,86,106,108$

Nerve cords, 50, 52. See Nervous system

Nerve ganglia, $42,58,68,106,140$; buccal, 120 ; cerebral, 84, 140; cerebro-pleural, 140 ; cervical sympathetic, superior and inferior, 274 ; cœliac, 278; Gasserian ganglion, 232 ; parieto-splanchnic. See Visceral ; pedal, 120, 140 ; pletural, 120 ; sub-cesophageal, 84, 106 ; sub-pharyngeal, 58, 68 ; supra-cesophageal, 84 , 106,120 ; supra-pharyngeal, 58,68 ; sympathetic, 230, 232 ; thoracic, 86, 108, 278; vagus ganglion, 274 ; visceral, 120,140

Nerves, 42, 58 ; abducent, 180,184 ; antennary, 84 ; auditory; 180,184 ; auricular, great, 278 ; brachial, 192, 228; branchial, 180, 184 ; buccal, 120, 180, 182, 184 (inner and outer); chorda tympani, 184; coccygeal, 230, 232 ; cranial, $178,180,186,232,278$; cruralis, 228, 230 ; depressor, 278 ; facial, $120,180,182184$; recurrent facial, 184 ; genital, 120 ; glossopharyngeal, 180, 184, 202, 234; hyoidean, 182, 184 ; hyo-mandibular, 180, 182, 184 ; hypoglossal, 202, 228, 232, 278; ileo-hypogastric, 228 ; labial, 120 ; laryngeal, inferior or recurrent, 278 ; superior, 274 ; lateral, 42, 44, 180, 184 ; mandibular, $180,182,232$; external mandibular, 182, 184 ; internal mandibular, 184 ; maxillary, 180, 182, 232 ; oculomotor, 180 , 182 ; of neck (rabbit), 274, 278, 280 ; olfactory, $180,184,226,232$; ophthalmic, superior and inferior, $180,182,232$; optic, 84,120 , $180,182,232$; palatine, 180,184 ; pallial, 120 ; pathetic, 180,182 ; pedal, 120 ; peripheral, 148, 228; peroneal, 204, 228 ; phrenic, 278; pneumogastric. See Vagus; post-spiracular, 184 ; pre-spiracular, 184 ; recurrent laryngeal, 278 ; sciatic, $204,206,228$; semimembranosus, $204,228,230$; sensory and motor, 148 ; spinal, $228,230,278$; spinal accessory, 278 ; splanchnic, 278; sympathetic, 230, 274 ; tibial, 204, 228 ; trigeminal, $180,182,232$; vagus or pneumogastric, $180,184,202,234,274$; visceral, $108,180,184$
Nervous system : Liver-fluke, 42 ; tape-worm, 50 ; earth-worm, 58; leech, 68 ; cockroach, 84; crayfish, 106; snail, I20, 122 ; mussel, 140; Amphioxus, 148 ; dogfish, 176 ; frog, 202, 206, 226-234; X' Xnopus, 202, 206, 226-234; pigeon, 264; rabbit, 274, 278, 280, 282

Nervous system, peripheral, 148, 228*; sympathetic, 230, 232, 274

Neural arch, 154, 220, 302. See Vertebra

Neural canal, 300 . See Vertebra

Neural spine, 220, 300, 302. See Vertebra

Nictitating membrane, $188,236,266$

Nose. See Olfactory organ

Nostrils, 152, 154, 188, 236, 266

Notochord, 144, 146, 148, 154, 316

Nucleus, 2, 8 (macro- and micro-nucleus), 12, 16, 28,30

\section{O}

Occipital condyle. See Condyle. Occipital segment, 292

Odontoid process, 260,300

Odontophore, $118,124,316$

Esophageal pouches or calciferous glands, 56

Esophagus or gullet, 8, 34, 36, 40, 56, 66, 82, $104,118,138,190,238,242,268,316$

Oil or preen gland, 238

Olecranon process, 252,306 ; fossa, 306

Olfactory capsules, $176,292,294$

Olfactory lobes, $176,226,264$; nerves. See Nerves ; organ, 180 ; pit, 148

Omentum, 240, 270

Omosternum, 194

Opisthocclous. See Vertebra

Opisthonephros, 162

Optic lobes, $178,228,264$; nerve. See Nerves ; thalami, 176,228

Oral groove (peristome), 8 ; cone (hypostome), 28 ; hood, 142, 144

Orbit, 260, 262, 312

Orbital process, 296

Orbito-sphenoid, 224, 226, 294

Organ of Bojanus, 134

Oscarella, 24, 316

Os centrale, 308

Osculum, 14, 18, 20

Os innominatum, 256, 308

Os magnum, 308

Ossicles, 106 ; auditory, 296

Ostia, 20, 24, 104, 132

Ostium, 36, 38

Otocyst. See Auditory organ

Otoliths, 186

Ova or eggs, 48, 52, 62, 162, 218, 250

Ovary: Hydra, 28 ; liver-fluke, 40, 44 ; tape. worm, 48, 52; earth-worm, 58, 62 ; leech, 68 ; crayfish, 104, 106; mussel, 138 ; Amphioxus, 146 : dogfish, 162; frog, 216, 218 ; Xenopus, 216, 218 ; pigeon, 242, 248, 250 ; rabbit, 290

Oviduct, $40,48,52,58,68,104,106,120,162$, $218,242,290$

Ovisacs, 218

Ovo-testis or hermaphrodite gland, 120

$\mathrm{P}$

PADDLE, swimming, 98

Palatal process, 296

Palate, 262, 296

Palatine bone, 226, 262, 296 
Pallial line, 128, 130

Palp, 102 ; labial, 82, 134 ; maxillary, 80

Pancreas, 158, 194, 242, 272

Panniculus adiposus, 268 ; carnosus, 268

Papilla, 50 (genital), 162 (urinary)

Paragastric cavity, 16, 20, 22

Paraglossa, 82

Paragnatha, 104

Paramecium (Slipper Animalcule), 6-8; form and general structure, $6 ; 316$

Parasite, 10, 32, 40, 46, 62

Para-sphenoid, 226

Parenchyma, 44, 52

Parietal bone, 262, 292 ; segment, 292

Par-occipital processes, 292

Patella or knee-pan, 256, 310

Pectoral fin. See Fin

Pectoral girdle, 164, 166, 194, 218, 250, 252, 304

Pelecypoda. See Lamellibranchiata

Pellicle, 6, 10

Pelvic fin. See Fin

Pelvic or hip girdle, 218, 222, 252, 254, 308

Pelvic symphysis, 308, 314

Pelvis, 308

Penis, 42, 70, 120, 266, 290

Pereiopods or walking legs, 98

Pericardio-peritoneal canal, 170

Pericardium, 104, 116, 134, 136, 166, 168, 202, $246,268,282$

Perilymph, 186

Perineal glands, 266, 290

Periostracum, 126, 130

Periotic, 296, 312

Peripheral nervous system, 148, 228

Periplaneta, 74-86, 316. See Cockroach

Peristome, 8, 34

Peritoneal cavity, 162

Peritoneum, 158, 214, 218, 240, 268, 270

Pes or foot, $190,268,312$

Petrous portion of periotic bone, 296

Phalanges, 254, 256, 308, 312

Pharynx : Liver-fluke, 40 ; earth-worm, 56 ; leech, 66 ; snail, 118 ; Amphioxus, 144, 148 ; dogfish, 176

Phyllosoma larva of Cape Crawfish (Jasus), 110, 112

Pia mater, 228

Pigeon (Columba), 236-264; external features, 236 ; feathers, 236 ; mouth cavity, 236; pectoral muscles, 238 ; skeletal system, girdles and limbs, 238, 250, 252, 254, 256, 258; vertebral column, etc., 256-260; skull, 260 , 262,264 ; air-sacs, 238, 242, 244, 252 ; viscera in situ, 240 ; alimentary system, 242, 244; respiratory organs, 244 ; vascular system, 244, 246,248 ; renal and reproductive systems, 248,250 ; nervous system (brain), $264 ; 316$

Pigment spots, 148

Pineal body or epiphysis, 176, 228

Pinne (ears), 266

Pisces (Fishes), 316

Pisiform, 308

Pituitary body, 178

Placenta, allantoic, 316

Placoid scales, 152, 154, 316

Platana. See Xenopus

Platyhelminthes (Flat worms), 316

Pleopods, 98

Pleura, 88

Pleural sacs, 268

Pleurobranch gill, 94
Plexus, brachial and sciatic, 228; solar, 232, 278,282

Ploughshare bone or pygostyle, 260

Podical plates, 74

Podobranch gill, 94, 98

Pollex (thumb), 188, 266, 308

Polyp, Fresh-water. See Hydra

Pore, abdominal, 152, 154 ; dorsal, 54; excretory, 40 ; inhalent, $14,18,20$; tentacle, 34

Porifera (Sponges), 14-24; form and general structure, 14; spicules, 16, 18; types of canal system, 18-24; 316

Porocyte, 16, 20

Portal vein. See Vein

Post-orbital process, 262

Pre-axial digit, 308, 312

Preen or oil gland, 238

Premaxilla, 222, 224, 226, 262, 296

Premolar teeth, 296

Prepuce, 266

Pre-sphenoid, 260, 292

Prestomium, 54

Pre-zygapophyses, 302

Primary feathers, 236 ; rods, 144

Prismatic or limy layer of shell, 130

Proccelous. See Vertebra

Proctodæum. See Hind-gut

Proglottides, 48

Proglottis, 46, 48, 50 (transverse section), 52

Pronotum, 74

Pro-otic, 224, 226

Propodite, 98

Pro-pterygium, 164

Prosencephalon. See Fore-brain

Prosopyle, 14, 20, 22, 24

Prostate, 290

Proteus Animalcule. See Amœba

Prothorax, 74

Protoplasm, 2, 12 (residual)

Protopodite, 96, 98, 100, 102

Protozoa, 316

Proventriculus, 82, 242

Pseudobranch (rudimentary gill), 152, 154

Pseudonavicella (spore), 10, 12

Pseudopodia, 2, 30

Pterygoid bone, 224, 226, 262, 296

Pterygoid process, 292

Pubic symphysis, 310

Pubis, 218, 256, 310, 314

Pulmonary or respiratory aperture, 114 ; chamber, 114

Pulvillus, 82

Pygostyle, 260

Pylangium, 170

Pyloric chamber of stomach, 104, 106, 158, 272

Pylorus or pyloric constriction, 158, 196, 212, 270

\section{Q}

QUadrate, 224, 226, 264

Quadrato-jugal, 224, 226, 262

Quill. See Calamus

\section{$\mathrm{R}$}

Rabbit (Lepus), 266-314; external features, 266 ; thoracic and abdominal viscera, 268 ; alimentary and vascular systems, 272, 276, 282 ; structures of the neck, 274,280 ; solar 
Rabbit-continued

plexus, 278,282 ; renal system, 286 ; reproductive system, 276, 288; skeletal system, skull, 292, 294, 298; teeth, 296; vertebral column, 298, 300, 302; girdles and limbs, 304, $306,308,312 ; 316$

Rachis or shaft, 236

Radial canals (Radiating chambers), 14, 16, 18 , 20,22

Radiale, 254

Radio-ulna, 218

Radius, 252, 306

Radula or rasping ribbon, 124, 316 ; sac, 124

Raia, 152-186, 316. See Skate

Ramus communicans, 230,232

Ramus of lower jaw or mandible, 264, 292, 296

Rana, 188-234, 316. See Frog:

Rasping organ. See Odontophore

Ratitæ or Running Birds, 314

Receptacula seminis. See Spermathecæ

Rectal cæca, 244 ; gland, 158

Rectrices or tail feathers, 236

Rectum, 66, 82, 118, 134, 138, 158, 194, 244, 270, 272

Remiges or wing feathers, 236

Renal system: Pigeon, 248, 250 ; rabbit, 286, 288. See Urino-genital system

Reno-pericardial canal (nephrostome), 116

Reproductive system: Hydra, 28; sea-anemone, 36,38 ; liver-fluke, 40,42 ; tape-worm, 48,50 ; earth-worm, 58,60 ; leech, 68,70 ; crayfish, 106, 108 ; crawfish, 106, 110 ; snail, 118, 120; mussel, 136, 138 ; Amphioxus, 146,148 ; dogfish, 162 , 164; skate, 160, 162 ; frog and Xenopus, 214, 216, 218; pigeon, 248,250 ; rabbit, $276,288,290$

Respiratory system : Cockroach, 76, 82 ; crayfish and crawfish, 94, 102; snail, 114, I16; mussel, 132 ; dogfish, 168, 172; frog, 190, 212 ; pigeon, 244 ; rabbit, $268,274,276$

Restiform bodies, 178

Retina, 232

Rhagon sponge, 22 ; transverse section, 24; 316

Rhizopods, 316

Rhombencephalon. See Hind-brain

Rib, 220, 238, 240, 252, 256, 258, 260, 298, 300, 304

Rodentia, 316

Rostellum, 48

Rostrum, 88, 260, 262

SACCULUS rotundus, 272

Saccus vasculosus, 178

Sacral region of vertebral column, 260, 298, 302

Sacrum, 222, 302,308

Sagittal suture, 292

Salivary glands, 82 ; reservoir, 82

Scaphognathite or baler, 102

Scaphoid or radiale, 306

Scapula, 164, 218, 238, 252, 304, 314

Sciatic nerve. See Nerves

Sclerite, 74,80

Scleroblast, 16,20

Scolex, 46, 48

Scrotal sac, 266, 288

Scyllium, 152-186, 316. See Dogfish

Sea-anemone (Actinia), 34-38; external features, 34 ; general structure, $34,36,38$; transverse section, 34; longitudinal section, 36,$38 ; 316$
Secondary feathers, 236,252 ; rods, 144

Segmented worms. See Annelida

Segments, 48, 54, 64, 74, 88, 292

Selachii or Elasmobranchii, 316

Semicircular canal, 182,186

Semilunar or intermedium, 306

Seminal duct, 60 ; vesicle. See Vesicula semi. nalis

Sense organs, 152, 154, 184

Sensory cells, 34 ; jelly-tubes, 152, 154 ; nerves, 148; papilla, 64

Septa, 56, 62, 142

Septum, internasal, 312 ; interorbital, 312

Sesamoid bone, 256, 310

Setæ. See Chæetæ

Setigerous sacs, 60 ; pads, 82

Shaft or rachis, 236

Shank. See Leg

Shell, 114, 126, 128, 130, 316

Shell-gland, 42, 50

Shoulder girdle. See Pectoral girdle

Sinus, peri-nephrostomial, 72 ; urinary, 162 ; urino-genital, 162. See also Blood sinus

Siphon, exhalent, 128, 134, 138 ; inhalent, 126. 134

Siphonoglyph, 34, 36

Skate ( Raia ), 152-186 ; external features, 154 ; alimentary and vascular systems, 158, 160, 170, 174; urino-genital system, 162 ; skeletal system, 166; nervous system (brain), 176, 186 ; cranial nerves, 180,186 ; eye muscles, 186 ; otocyst, $186 ; 316$

Skeletal system: Sponge, 16 ; crayfish and crawfish, 106 ; Amphioxus, 144, 146 ; dogfish, 164, 176; skate, 166 ; frog, 194, 218, 220, 222, 224, 226 ; Xenopus, 194, 218, 220, 222, 224,226 ; pigeon, 238, 250, 252, 254, 258, 262 ; rabbit, $292-312$

Skeleton, appendicular (girdles and limbs), 218, $220,250,252,254,256,304,306,308,312$; axial (skull, vertebral column, etc.), 222-226, 256 , 262, 292, 294, 298, 300, 302 ; branchial, 144,176 ; buccal, 144 ; endophragmal, 106 ; exoskeleton, 106 ; of bird and mammal compared, 312 ; of fins, 144, 146, 164, 166 ; visceral (gill-slit region), 144,176

Skin. See Integument

Skull : Dogfish, 176; frog and Xenopus, 222, 224, 226 ; pigeon, 260, 262 ; rabbit, 292, 294; $296,298,312$

Skull of bird and mammal (rabbit) compared, 260

Slipper Animalcule. See Paramecium

Snail (Helix), 114-124; external features, 114 ; alimentary and reproductive systems, 118; nervous system, 120,122; odontophore, 124; 316

Snout, 152, 154, 184

Solar plexus, 232, 278, 282

Somites, 54

Sperm morula, 10, 12 ; reservoir, 60 ; sac, 60 , 162

Spermathecæ or receptacula seminis, $56,60,62$, 120

Spermatic cord, 284, 288

Spermatozoa, 12, 62

Sphenethmoid, 222, 226

Spicules, Sponge, 14, 16 ; types of, 18 ; 316

Spinal cord, 148, 154, 178, 228

Spinal nerves, 228, 230, 278

Spines, 40, 152, I54

Spinous process. See Vertebra 
Spinules, 44

Spiracle, 152, 154

Spiral valve, 158

Spleen, 158, 194, 242, 270, 272

Splenial, 264

Sponges. See Porifera

Spongin, 316

Spongy layer of Paramecium, 8

Spore, 10, 12

Sporozoa, 10, 316

Sporozoite, 10, 12

Squalus. See Acanthias

Squame, 102

Squamosal, 224, 226, 262, 296, 312

Stapes, 312

Sternum, 74, 88, 194, 238, 240, 252, 304, 314, 316

Stigmata or respiratory openings, 76

Stinging cells. See Nematocyst.

Stipes, 80, 82

Stomach, 66, 82, 102, 104, 106, 118, 138, 144, $158,194,242,270,272$

Stomodæum. See Fore-gut

Storing pockets (crop), 66, 72

Strobila, 48

Styles, anal, 76 (cockroach)

Submentum, 82

Substitution or replacement bones, 292

Sucker, 40, 48, 64

Supra-angular, 264

Supra-ethmoid, 224, 226

Supra-occipital, 224, 262, 292

Supra-orbital, 294

Supra-renal body. See Adrenal

Supra-scapula, 218, 304

Supra-trochlear fossæ, 304

Suspensorium, 176, 264

Suspensory ligament, 268

Suture, 78 (epicranial), 260, 292 (sagittal), 312

Sycon sponge, 18, 20 ; transverse section, 14, 22 ; 316

Symbiotic flagellates, 32

Sympathetic nervous system, 230, 232, 274

Symphysis, 264, 308, 310, 314

Synangium, 170

Syncytium, 16

Syn-sacrum, 260

Syrinx, 244

Systole, 8

\section{$\mathrm{T}$}

Taenia. Siee Tape-worm

Tail, 90, 152, 154, 238, 266, 316

Tape-worm (Taenia), 46-52; form and general structure, 46 ; proglottis, 48 , 52 ; reproductive system, 48 ; nervous and excretory systems, 50; transverse section (proglottis), $50 ; 316$

Tape-worms. See Cestoda

Tarso-metatarsus, 256

Tarsal bones, 220, 256, 310

Tarsus or ankle, $82,190,220,310,312$

Teats. See Mammæ

Teeth, 66, 82, 106, 152, 154, 190, 226 (vomerine), 296, 312 (heterodont), 316. See also Placoid scales

Telson, 88, 90, 98

Temporal fossa, 262

Tendo Achillis, 198, 310
Tentacle, 28, 34, 114, 126, 144

Tergum, 74, 88

Testis : Hydra, 26, 28 ; liver-fluke, 42 ; tapeworm, 50, 52 ; earth-worm, 58, 60 ; leech, 68, 70 ; crayfish, 104, 106, 108 ; crawfish, 106, 110; mussel, 138 ; Amphioxus, 146 ; dogfish, 162, 164; frog, 214; Xenopus, 214; pigeon, $242,248,250$; rabbit, 266,288

Thalamencephalon, 176, 226, 264

Thigh, 190, 268

Thigh bone. See Femur

Thoracic region of vertebral column, 260, 298, 300 ; viscera, 268

Thorax, 266, 280

Thread-cell. See Nematocyst

Thumb. See Pollex

Thymus, 240

Thyroid gland, 168, 274 ; cartilage, 274

Tibia, 82, 256, 310

Tibio-fibula, 220, 312

Tibio-tarsus, 256

Toad, Clawed. See Xenopus

Toes. See Digits and hallux

Tongue, 190, 236. See also Hypopharynx

Tongue-bars, 144

Trachea (windpipe), 238, 244, 268, 274

Tracheæ (air-tubes), 82

Transverse processes, 220, 298, 300, 302, 308

Trapezium, 306

Trapezoid, 306

Trematoda (Flukes), 316

Trichocysts, 6

Trichodina, 32

Trochanter, 82; great, 254, 256, 310 ; lesser and third, 310

Trochlea, 304

Trophozoite, 10, 12

Truncus arteriosus, 202, 208, 212

Tuberculum or tubercle of rib, 260, 300, 304

Tuberosity, greater and lesser, 304

Turbinal bones, 294

Tympanic bone, 296, 312 ; bulla, 296 ; cavity, 262, 296 ; membrane, 188

Typhlosole, 60, 62, 138

\section{U}

ULNA, 252, 306

Ulnare, 254

Umbilicus, superior and inferior, 236

Umbo, 126

Unciform, 308

Uncinate process of rib, 260

Undulating membrane, 8

Unicellular Protozoa, 316

Upper arm, 188, 304

Ureter, 116, 136, 162, 214, 242, 250, 286, 288

Urethra, 290

Urinary bladder, 136, 194, 270, 286, 290 ; papilla, 162 ; sinus, 162

Urino-genital canal (urethra or vestibule), 290 ; sinus, 162

Urino-genital system : Dogfish, 162, 164; frog, 214, 216; Xenopus, 214, 216; pigeon, 248; rabbit, 286, 288

Uropods, 90, 96, 98

Uropygium or tail, 238

Urostyle, 220, 222

Uterus, 42, 44, 48, 52, 290

Uterus masculinus, 290 


\section{V}

VACUOLE, contractile, 4, 8 ; food, 4, 8; noncontractile, 28,30

Vagina, 50, 52, 70, 120, 290

Valves of heart, 212 ; pocket, 212

Vane or vexillum, 236

Vascular system. See Blood system

Vas deferens, $42,44,50,60,70,72,104,106$, $118,120,162,216,218,242,250,288,290$

Vas efferens, 50, 214

Vein, abdominal, 192, 206, 208 ; azygos, 284 ; brachial, 192, 202, 246 ; caudal, 154, 242, 246 ; coccygeo-mesenteric, $242,244,246$; cutaneous, 192, 202 ; dorso-lumbar, 206 ; duodenal, $270,274,276$; epigastric, $242,244,246$; facial, anterior and posterior, 278, 284; femoral, 204, 242, 246 ; gastro-duodenal, 246 ; hepatic, 146, 150, 204,242, 246, 284; hepatic portal, 158, 192, 242, 244, 246; hypogastric. See Renal-portal ; iliac, 242, 246, 284, 286 ; ilio-lumbar, 284; innominate, 202 ; intercostal, 284 ; jugular, 202, 246, 278, 284 ; lieno-gastric, 270, 274, 276 ; lingual, 202 ; mandibular, 202; mesenteric, 244, 246, 270, $272,274,276$; muscular, 192, 202 ; musculocutaneous, 192, 202 ; ovarian, 284 ; pectoral, 238,246 ; pelvic, 206 ; phrenic, 284 ; portal, $158,244,270,272,276$; postcaval (inferior vena cava), 202, 204, 242, 244, 246, 270, 284, 286 ; precaval (superior vena cava), 202, 246, $270,282,284$; pulmonary, 114, 116, 212, 246, 284; ramus communicans iliacus, 204; rectal, 208; renal, 204, 284 ; renal-portal, 206, 242,246 ; sciatic, 204, 206, 242, 246 ; spermatic, 284 ; subclavian, 192, 202, 284 ; subintestinal, 146, 150 ; subscapular, 202 ; vena cava, inferior. See Postcaval; superior. See Precaval

Velum, 144

Vena cava, 138. See also Vein

Venous system : Dogfish, 158, 166, 168 ; skate, $158,166,170$; frog and Xenopus, 192, 202, 204, 206; pigeon, 246,248 ; rabbit, 272, 274, $276,278,280,282,284,288$

Ventricle of brain, third, 176, 228 ; fourth, 178 , 228

Ventricle of heart, 116, 134, 136, 166, 170, 202, $212,246,282$

Vermiform appendix, 270, 272

Vertebra, amphicœlous, 222 ; heterocœlous, 258 ; opisthocolous, 220 ; proccelous, 220

Vertebræ, caudal, 260, 302, 304 ; cervical, $256,258,298,300,314$; lumbar, 260, 302 ; sacral, 260,302 ; thoracic, $260,300,302$

Vertebral column, 220, 222, 256, 260, 298 ; plate, 166

Vertebra-arterial canal, 258, 298

Vertebrata or chordata, 316
Vesicula seminalis, $12,42,50,60,62,70,162$, 218,250

Vessel. See Blood-vessel, artery and vein

Vestibule or urino-genital canaI, 290

Vexillum or vane, 236

Vibrissæ, 266

Viscera, thoracic and abdominal, 268

Visceral arches, 176; clefts. See Gill-slits ; hump, 114 ; mass, 134 ; skeleton, 144, 176

Vitellarian or yolk-duct, 40,44

Vitelline or yolk-gland, 44, 50

Vomer, 226, 294

Vulva, 266, 290

\section{W}

WATER-TUBES, 132

Wharton's duct, 278

Wheel organ, 144

Wing, 74

Wing covers or tegmina. See Elytra

Wolffian body. See Mesonephros

Wolffian or mesonephric duct, 162

Worms, 316

Wrist. See Carpus

\section{$\mathrm{X}$}

Xenopus (Platana or Clawed Toad), 188-234; external features, 188; mouth cavity, 190 ; muscular system, 190, 192, 198, 200 ; skeletal system, 194; girdles and limbs, 218, 220 ; vertebral column, 220,222 ; skull, 222, 224, 226 ; alimentary system, 194, 196, 212; venous system, 192, 202, 204, 206; arterial system, 210 ; heart, 212; nervous system, 202 ; brain, 226 ; spinal nerves, 228, 230 ; sympathetic, 230, 232 ; cranial nerves, 232 ; respiratory system, 212 ; urino-genital system; 214, 216 ; 316

Xiphisternum, 194, 304

Xiphoid processes, 240

YELLOW cells, 56, 60, 62

Yolk or vitellarian duct, 40, 50

Yolk or vitelline gland, 44, 50

\section{Z}

ZYGAPOPHYSIS, 220, 300, 302

Zygomatic arch, 266, 296

Zygomatic process, 262, 296

7ygote, 10, 12 




